BRUNO VIEIRA BERTONCINI

\title{
UMA PROPOSTA DE ESTIMAÇÃO DA MATRIZ OD A PARTIR DOS FLUXOS DE TRÁFEGO OBSERVADOS NAS INTERSEÇÕES DA REDE DE TRANSPORTES
}

Tese apresentada à Escola de Engenharia de São Carlos da Universidade de São Paulo, como parte dos requisitos para obtenção do título de Doutor em Ciências, Programa de Pós-Graduação em Engenharia de Transportes, Área: Planejamento e Operação de Sistemas de Transportes.

Orientador: Prof. Titular Eiji Kawamoto 
AUTORIZO A REPRODUÇÃO E DIVULGAÇÃO TOTAL OU PARCIAL DESTE TRABALHO, POR QUALQUER MEIO CONVENCIONAL OU ELETRÓNICO, PARA FINS DE ESTUDO E PESQUISA, DESDE QUE CITADA A FONTE.

Ficha catalográfica preparada pela Seção de Tratamento da Informação do Serviço de Biblioteca - EESC/USP

Bertoncini, Bruno Vieira

B547p Uma proposta de estimação da matriz OD a partir dos fluxos de tráfego observados nas interseçōes da rede de transportes / Bruno Vieira Bertoncini ; orientador Eiji Kawamoto. -- São Carlos, 2010.

Tese (Doutorado - Programa de Pós-Graduação em Engenharia de Transportes e Área de Concentração em Planejamento e Operação de Sistemas de Transportes) -Escola de Engenharia de São Carlos da Universidade de São paulo, 2010.

1. Planejamento de transportes. 2. Matriz sintética. 3. Matriz OD. 4. Estimação de matriz. 5. Médias sucessivas. 6. QUEENSOD. 7. TransCAD. 8. MEMS. I. Titulo. 
Candidato(a): Engenheiro BRUNO VIEIRA BERTONCINI.

Tese defendida e julgada em 19/11/2010 perante a Comissão Julgadora:

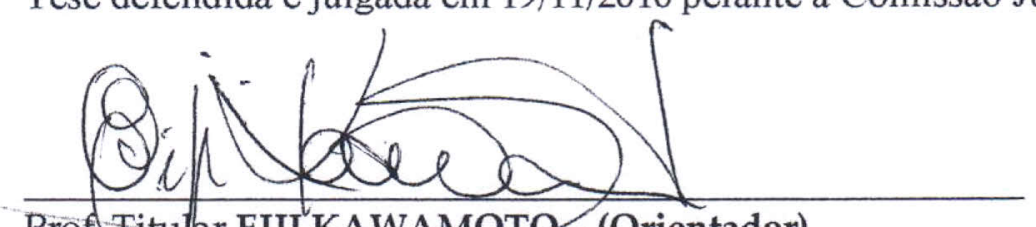

Prof. Titufar.EIJI KAWAMOTO - (Orientador)

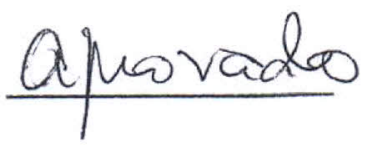

(Escola de Engenharia de São Carlos/USP)

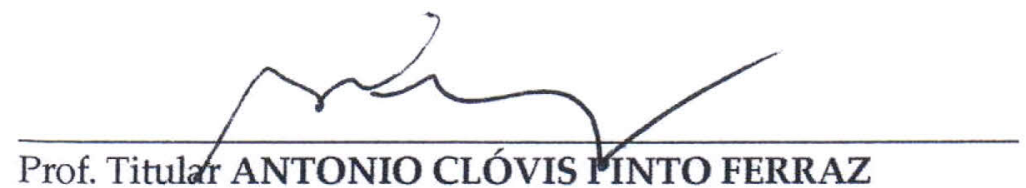

$$
\text { APRivaros }
$$

(Escola de Engenharia de São Carlos/USP)

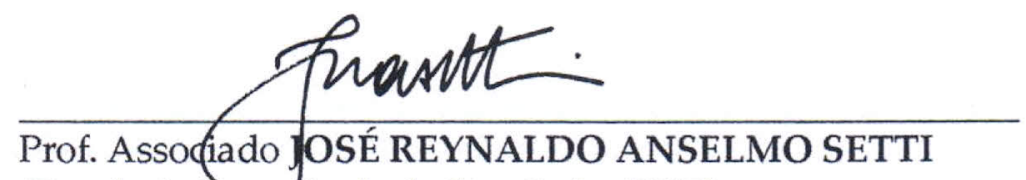

\section{APROVAMO}

(Escola de Engentharia de São Carlos/USP)

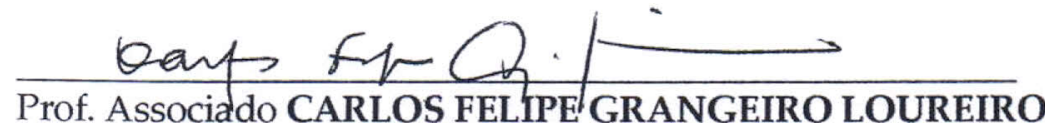

ARCOMADO

Prof. Associado CARLOS FELIPE GRANGEIRO LOUREIRO

(Universidade Federal do Ceará/UFC)

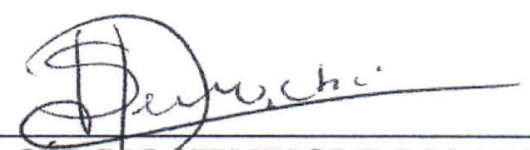

Dr. SERGIO HENRIQUE DEMARCHI

(Logit Engenharia Consultiva)

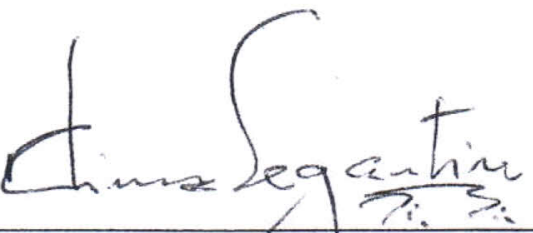

Prof. Associado PAULO CESAR LIMA SEGANTINE

Coordenador do Programa de Pós-Graduação em

Engenharia de Transportes e Suplente do Presidente da

Comissão de Pós-Graduação em Exercício 
"Não tenhamos pressa, mas não percamos tempo"

(José Saramago 1922-2010)

"Se eu vi mais longe, foi porque estava sobre ombros de gigantes"

(Isaac Newton 1643-1727) 
Aos meus pais e minha irmã que me deram apoio e incentivo ao longo desses anos.

A Manu, pelo companheirismo dedicado.

Ao Professor Eiji Kawamoto, por ter dado a oportunidade e ter contribuido para meu aprendizado. 


\section{AGRADECIMENTOS}

A Deus, por ter me proporcionado este caminho.

À Nossa Senhora das Graças pela proteção.

Aos meus pais Ademir e Cláudia por terem me ajudado e contribuído para fortalecer minha fé, dando incentivo diário para que desse continuidade neste trabalho.

Ao Professor Eiji, que nesses anos foi muito mais que um orientador, mas um grande amigo. Obrigado pela paciência, atenção e ensinamentos, através de seus sábios conselhos. Posso dizer que sinto muito orgulho por ter trabalhado junto a ele.

À Fundação de Amparo à Pesquisa do Estado de São Paulo - FAPESP, pela concessão de bolsa de estudo que possibilitou o desenvolvimento deste trabalho. Agradeço, também, ao Conselho Nacional de Pesquisa - CNPq, pela bolsa de pesquisa concedida nos meses iniciais.

Ao assessor científico deste trabalho junto à FAPESP, por ter acreditado no potencial desta pesquisa, recomendando a sua aprovação junto à agência e por ter expressado em seus pareceres idéias que serviram para incrementar esta tese.

Aos Professores do Departamento de Engenharia de Transportes da EESC/USP meu muito obrigado por terem contribuído para minha formação profissional. Em especial os Professores José Reynaldo Setti, Antonio Clóvis Pinto Ferraz (“Coca”) e Antônio Nelson Rodrigues da Silva, por contribuírem para o desenvolvimento deste trabalho. Também aos Professores Adalberto Faxina, Ana Furlan, José Leomar Fernandes Junior e Glauco Túlio Pessa Fabri.

Gostaria de agradecer o Professor Sergio Henrique Demarchi, que deu início a minha atividade científica durante a graduação, sem isso não teria atingido esta etapa. Agradeço pelas sugestões dadas no exame de qualificação.

Ao Professor Carlos Felipe Grangeiro Loureiro com quem tive a oportunidade de dialogar sobre estimação de matrizes e que durante o período em que esteve em Nebraska - EUA enviou diversos trabalhos interessantes sobre o tema, que contribuíram bastante 
para o desenvolvimento desta pesquisa. Quero agradecer, ainda,as sugestões feitas no exame de qualificação e a oportunidade de integrar o grupo de estudos do projeto do MCT.

À Professora Ruth de Gouvêa Duarte, que foi muito mais do que uma professora, nesses anos tem sido uma grande amiga, sempre disposta a ajudar. Suas recomendações sempre são muito preciosas, bem como seus conselhos. Obrigado pela oportunidade de poder fazer parte do seu convívio.

Aos companheiros Mateus Araújo e Silva, André Cunha, Professor Pablo Brilhante, Professora Cira Souza Pitombo e Professor Marcus Seraphico. Vocês contribuíram muito para o desenvolvimento deste trabalho, nele há participação de vocês. Obrigado pelo convívio diário, pela ajuda e pela solidariedade. Mateus, a dedicação que você teve quando fiquei internado não será esquecida, muito obrigado. Aos demais amigos de departamento.

Aos funcionários do departamento, em especial Heloísa, Beth, Dona Magali, Vicente e Toco.

Aos amigos Paulo Toyama, Gigante, João, Jesner, Alex, Luis Miguel, Vivian, Sergio, Vitor, Elievam, Diego, Dinato que sempre estiveram presentes nesses últimos anos e a Jorge Chueire (in memoriam), grande amigo.

A meu amigo Ed Pinheiro Lima, com quem pude discutir idéias e me auxiliou no desenvolvimento da pesquisa.

A todos aqueles que contribuíram, de alguma forma, para o desenvolvimento e conclusão deste trabalho e que por um lapso tenha esquecido de referir os nomes. 
BERTONCINI, B.V. (2010) Uma proposta de estimação da matriz OD a partir dos fluxos de tráfego observados nas interseções da rede de transportes. Tese (Doutorado) - Escola de Engenharia de São Carlos, Universidade de São Paulo. São Carlos - SP.

A meta do trabalho é propor e testar a hipótese que a contagem de tráfego nas interseções da rede de transportes, ao invés de contagem de tráfego nos arcos, reduz o grau de indeterminação e torna mais precisa a matriz OD estimada pelo modelo sintético. Ademais, é proposto e detalhado um método de estimação da matriz OD através de médias sucessivas (MEMS). É apresentada a descrição matemática das propostas e o detalhamento dos experimentos elaborados para testá-las. Três métodos de estimação, QUEENSOD, TransCAD e MEMS, foram utilizados na verificação da hipótese. A inserção de "arcos virtuais" na rede de transportes constituiu um artifício que permitiu aos programas QUEENSOD e TransCAD realizarem a estimação utilizando fluxos observados nas interseções. A utilização de contagens de fluxo nas interseções propiciou à matriz OD estimada, melhorias que acarretaram sua aproximação com a matriz OD "real". O experimento mostrou que a matriz OD estimada ao considerar contagens de tráfego nas interseções apresenta melhor desempenho em comparação a matriz estimada ao considerar contagens nos arcos da rede de transportes. A matriz estimada gradativamente aproximou-se da "real" à medida que foi aumentada a quantidade de informação de fluxo e sua distribuição na rede. Assim, a hipótese formulada para este trabalho não pôde ser refutada.

Palavras-chave: matriz sintética. Matriz OD. Estimação de matriz. Fluxo de tráfego. Médias Sucessivas. QUEENSOD. TransCAD. MEMS. 


\section{ABSTRACT}

BERTONCINI, B.V. (2010) A proposal for OD matrix estimation from traffic flow observed at transportation network intersections. PhD. Thesis - Engineering School of Sao Carlos, University of Sao Paulo, Sao Carlos - SP.

The aim of this work is to propose and test the hypothesis that traffic counts collected at network intersections, instead of traffic counts collected at links, reduce indeterminacy and make more accurate the OD matrix estimated by the synthetic model. Furthermore, a method is proposed and described in detail to estimate the OD matrix based on successive averages (MEMS). The model formulation of the proposals and a description of the experiments are presented. Three estimation methods, QUEENSOD, TransCAD, and MEMS were used in the hypothesis verification. The use of "virtual links" in the network consists of an artifice that enable the QUEENSOD and TransCAD to estimate the OD matrix based on traffic counts at intersection. By using flow counts conducted at intersections, improvements could be made to the estimated OD matrix bringing it closer to "real situations". The experiments results show that the OD matrix estimation based on traffic counts collected on network intersection has a better performance in contrast to the estimation based on traffic counts collected on network links. The estimated matrix gradually becomes closer to "real situations" while the quantity of information flow and its distribution to the network is increased. Therefore, the formulated hypothesis for this work cannot be refuted.

Keywords: synthetic matrix. OD matrix. Matrix estimation. Traffic flow. Successive Averages. QUEENSOD. TransCAD. MEMS. 
1.1 Contextualização do Tema

1.2 Questões da Pesquisa

1.3 Meta e Objetivos do Trabalho

1.4 Descrição do Trabalho

1.4.1 Linha de Pesquisa

1.4.2 Método Elaborado para Realização do Trabalho

1.5 Justificativa para o Estudo

1.6 Estrutura do Trabalho

Capítulo 2 - Revisão Teórica

2.1 Estimação das Viagens a partir das Contagens de Tráfego

2.2 Métodos de Estimação

2.2.1 Modelos de Gravidade

2.2.2 Inferência Estatística

2.2.2.1 Matriz OD Dinâmica

2.4 Estimação da Matriz OD a partir dos Fluxos de Tráfego Utilizando Maximização da Entropia 
2.5.1.1 Funcionamento do Método

3.2.1 Descrição matemática da proposta de consideração dos fluxos de tráfego observados nas interseções para estimação da matriz OD sintética

3.2.2 Descrição matemática do método de estimação da matriz OD por médias sucessivas

3.3 Segunda Etapa: Procedimento Adotado para Verificar o Desempenho da Proposta

3.3.1 Adoção de uma rede viária e de uma matriz OD que a demanda, hipotéticas

3.3.2 Alocação da matriz OD à rede viária

3.3.3 Contagem hipotética de tráfego

3.3.3.1 Contagem hipotética de tráfego nas interseções 80

3.3.4 Estimação da matriz OD em função das contagens de tráfego 82

(1) Parte A - Estimação considerando contagens nas interseções 88

(2) Parte B - Estimação considerando contagens nos arcos 88

3.3.5 Comparação entre matrizes e análises dos resultados 88 
4.1.1 Adoção de uma rede viária e de uma matriz OD que a demanda, hipotéticas

4.1.2 Alocação da matriz OD à rede viária e contagem hipotética de tráfego 93

4.1.2.1 Contagem hipotética de tráfego nas interseções 95

4.1.3 Estimação da matriz OD em função das contagens de tráfego 98

4.1.3.1 Parte A - Estimação considerando contagens de tráfego realizadas nas interseções

Teste $1(\mathrm{~T} 1) \quad 98$

Teste 2 (T2) 102

$\begin{array}{ll}\text { Teste } 3(\text { T3) } & 105\end{array}$

$\begin{array}{ll}\text { Teste } 4(\mathrm{~T} 4) & 108\end{array}$

Teste 5 (T5) 111

$\begin{array}{ll}\text { Teste } 6(\mathrm{~T} 6) & 114\end{array}$

$\begin{array}{ll}\text { Teste } 7 \text { (T7) } & 117\end{array}$

4.1.3.2 Parte B - Estimação considerando contagens de tráfego realizadas nos $\operatorname{arcos}$

Teste 8 (T8) 124

$\begin{array}{ll}\text { Teste } 9(\mathrm{~T} 9) & 128\end{array}$

Capítulo 5 - Análises dos Resultados 133

5.1 Considerações 133

5.2 Análises dos Resultados Estimados $\quad 134$

5.3 Análise dos Resultados quanto a Qualidade da Matriz Semente 155

5.4 Discussões dos Resultados 172

Capítulo 6 - Considerações Finais 175 
6.1.2.1 Formulação matemática da proposta de considerar os fluxos de tráfego observados nas interseções

6.1.2.2 Formulação matemática do método de estimação por médias sucessivas (MEMS) 


\section{CAPÍTULO 1 INTRODUÇÃO}

O capitulo inicial desta tese responde às indagações básicas para o desenvolvimento da pesquisa: Escolha do tema e como ele é tratado; Quais objetivos do trabalho?; Como atingir estes objetivos?; Por que eles são importantes?; e, por fim, Quais questões motivaram a pesquisa?

\subsection{CONTEXTUALIZAÇÃO DO TEMA}

O conhecimento da matriz de viagens (matriz OD) tem grande importância na análise de sistemas de transportes e para definir o padrão de deslocamento da população, por conter informações acerca do número de viagens entre diferentes zonas de tráfego e consistir em elemento fundamental para o planejamento e tomada de decisão em transportes (ORTUZAR; WILLUMSEN, 1994).

Todavia, a obtenção de uma matriz OD constitui processo moroso e que despende significativa quantidade de recursos financeiros (WILLUMSEN, 1981). Além do mais, por questões práticas e econômicas, raramente é possível obter matrizes para períodos fragmentados de tempo, o que constitui dado importante para a tomada de decisão em engenharia de tráfego, bem como para aplicação das técnicas de simulação de tráfego (RAKHA et al, 1998).

Uma alternativa a tais óbices poderia ser a obtenção de matrizes OD a partir de contagens de fluxo. Em função dessa idéia - menos onerosa e mais direta - têm sido 
desenvolvidos modelos - denominados sintéticos, por sintetizarem a quantidade de informação (WILLUMSEN, 1981) - que possibilitam a estimação da matriz de viagens. De modo geral, esses modelos trabalham com fluxos veiculares, mas nada impede que outros fluxos (por exemplo: de pedestres, de passageiros do transporte público etc.) sejam considerados, desde que respeitada as características de cada um deles (ABRAHAMSSON, 1998).

A idéia consiste basicamente em uma técnica inversa ao processo de alocação do fluxo de tráfego à rede de transportes. Ou seja, quando uma matriz OD conhecida é alocada à rede viária, são obtidos os fluxos em cada arco constituinte, portanto, a técnica inversa seria obter a matriz OD que corresponda ao conjunto de fluxo observado em cada arco, de acordo com o método de estimação empregado. No entanto, assim como a alocação de matrizes distintas pode retornar iguais conjuntos de fluxo, um mesmo conjunto de fluxo poderá gerar diferentes combinações para a matriz OD (WILLUMSEN, 1981). Este seria o principal foco dos estudos que tiveram início na segunda metade da década de 1970: propor um modelo capaz de estimar a matriz OD mais provável que corresponda às contagens de tráfego.

O modelo sintético pode ser dividido em: (i) Estático; (ii) Dinâmico. O primeiro não leva em consideração a variação temporal da demanda. Por sua vez, o segundo é capaz de representar as viagens em função da variação temporal da demanda ao longo do dia. Por ser mais fácil a sua modelagem e permitir a transição para um modelo dinâmico, os processos estáticos são mais estudados.

A vantagem do modelo sintético é que os fluxos de tráfego podem ser obtidos de maneira relativamente simples e com baixo custo. As contagens de tráfego que já são realizadas para diversos propósitos, como análise de capacidade viária, na avaliação das causas de congestionamento, no dimensionamento do pavimento, nos projetos de 
canalização do tráfego, programação do ciclo semafórico e outras melhorias (DNIT, 2007), podem ser aproveitadas para a estimação da matriz OD.

Um dos pontos negativos do modelo está no fato de não ser aplicável à estimação de demandas em cenários ainda inexistentes, bem como por não possibilitar uma relação entre demanda e condições socioeconômicas dos usuários. Além disso, os métodos atualmente utilizados encontram dificuldades em estimar viagens em redes de transporte congestionadas (BELL et al, 1993). A incorporação de informações adicionais contidas em uma matriz OD previamente conhecida (matriz OD semente) torna-se um problema por deixar o resultado dependente da qualidade dessa matriz. Outros problemas que constituem as dificuldades práticas do modelo, conforme listados por Rakha et al (1998), são a não continuidade do fluxo de tráfego e o desconhecimento das rotas de viagem. 0 desconhecimento da base teórica e as dificuldades práticas no processo de estimativa da demanda fazem com que este método não seja amplamente difundido e utilizado (VAN AERDE et al, 2003).

\subsection{QUESTÕES DA PESQUISA}

Este estudo, de caráter exploratório, objetiva proporcionar melhores resultados ao utilizar o modelo sintético, bem como compreender alguns pontos referentes a ele. Esta análise passa pelas seguintes questões:

a) Aumento da quantidade e melhor distribuição da informação de fluxo traz benefícios significativos à qualidade da matriz OD estimada?

b) Qual influência o uso da matriz semente exerce na qualidade dos resultados estimados?

c) Qual a eficiência das implementações computacionais do modelo sintético?

d) Qual diferença conceitual na formulação do problema e nos algoritmos de solução dos programas de estimação disponíveis no Departamento de Engenharia de 
Transportes da Escola de Engenharia de São Carlos da Universidade de São Paulo (EESC/USP)?

e) Qual efeito ocasionado ao resultado desses programas devido ao aumento da quantidade de informação? E quanto à qualidade da matriz OD semente?

f) Os programas de estimação disponíveis terão capacidade de considerar dados das interseções?

g) Um novo algoritmo de estimação da matriz OD baseado na maximização da entropia que não necessite de matriz OD semente trará contribuição?

h) A idéia da maximização da entropia é uma boa simplificação para estimar a matriz de viagens?

i) Quais benefícios para o meio acadêmico e futuramente para aplicações práticas este estudo trará?

\subsection{META E OBJETIVOS DO TRABALHO}

A meta deste trabalho é propor e testar a idéia que a contagem de tráfego nas interseções da rede de transportes, ao invés de contagem de tráfego nos arcos, faz com que a matriz estimada pelo modelo sintético seja mais precisa.

Para isso, foram propostos os seguintes objetivos:

(i) Verificar a eficiência da proposta através de experimentos, considerando uma rede viária e uma matriz OD hipotéticas que reflitam uma situação de congestionamento;

(ii) Utilizar os programas de estimação da matriz OD (QUEENSOD e TransCAD) ambos licenciados para uso em pesquisas do Departamento de Engenharia de Transportes da EESC/USP;

(iii) Verificar a sensibilidade dos métodos implementados nos dois programas utilizados quanto ao uso de matriz semente; 
(iv) Propor um método para estimação da matriz OD, baseado no conceito de média sucessiva;

(v) Comparar os resultados gerados pelos programas (QUEENSOD e TransCAD) com os obtidos pelo método proposto, através de análises entre a matriz OD estimada e a matriz OD "real".

Foi estabelecida a premissa que a matriz não sofre influência da variação temporal das contagens (matriz OD estática), evitando, com isso, impor dificuldade adicional ao processo, e foi estimada conforme os princípios da maximização da entropia.

\subsection{DESCRIÇÃO DO TRABALHO}

\subsubsection{Linha de pesquisa}

O presente trabalho é continuidade de estudos realizados no Departamento de Engenharia de Transportes da Escola de Engenharia de São Carlos, da Universidade de São Paulo (EESC/USP), sob orientação do Professor Titular Eiji Kawamoto a partir de 2005. Esta será a primeira tese de doutorado desenvolvida sobre o assunto na EESC/USP.

A motivação por esta linha de pesquisa deve-se a uma série de questões a citar: é um método de estimação que possibilita obtenção da matriz OD de forma mais direta, em comparação aos métodos tradicionais; o tema ficou estagnado durante décadas e foi retomado nos últimos anos; a possibilidade de propor novas idéias, capazes de trazer melhores resultados; e, ajudar a difundir esse assunto no Brasil.

Os trabalhos desenvolvidos na EESC/USP sobre estimação de matrizes OD a partir de contagens de tráfego são investigativos e exploratórios, devido às dificuldades e desafios do tema.

O primeiro trabalho objetivou propor um método de carregamento incremental do fluxo de tráfego para estimação da matriz OD sintética, realizado por Bertoncini e Kawamoto 
(2006). Posteriormente, Bertoncini (2007) apresentou uma dissertação de mestrado sobre carregamento incremental do fluxo para estimação da matriz sintética. Depois, Bertoncini e Kawamoto (2008a) publicaram outro artigo sobre este tema.

Porém, foi constatado que o carregamento incremental pode não ser eficiente quando a diferença entre os custos para percorrer rotas alternativas for muito elevada. Isso poderia fazer com que um carregamento excessivo fosse imposto ao caminho mínimo inicial e, desta forma, não seria corrigido futuramente, acarretando erros na matriz OD estimada.

As atenções se voltaram para solucionar este problema e Bertoncini e Kawamoto (2008b) apresentaram um método de estimação em que a escolha dos caminhos seria feita através do modelo Logit.

Depois dessa publicação, os esforços se concentraram na proposição de um método mais simples, que não demandasse a calibração de parâmetros como proposto por Bertoncini e Kawamoto (2008b).

Um dos objetivos desta linha de pesquisa é propor métodos de estimação que não demandem muitos recursos, procurando adaptar tais idéias de modo que elas possam ser utilizadas por programas de estimação da matriz OD atualmente em uso.

\subsubsection{Método elaborado para realização do trabalho}

A hipótese da presente pesquisa é que ao considerar os fluxos observados nas interseções, será possível aumentar a quantidade de informações, o que poderá reduzir a indeterminação e os erros, além de contribuir para o processo de estimação da matriz OD. Alterando o paradigma que a matriz OD seria estimada a partir de contagens de fluxos nos trechos de via, como afirmou Willumsen (1981), passando também a considerar os fluxos conforme movimento de conversão. 
A seqüência de procedimentos adotada a fim de verificar a hipótese principal do trabalho consiste no método. De acordo com Abbagnano (1970), o método científico pode ser definido como um procedimento de investigação ordenado, repetível e auto-corrigível, que garanta a obtenção de resultados válidos. As etapas adotadas para conclusão deste trabalho são apresentadas na Figura 1.1.

A primeira etapa consistiu na proposição dos objetivos. Na seqüência foi realizada a revisão teórica, que teve como função fornecer subsídios para responder as questões de pesquisa. Neste trabalho a ênfase maior foi dada ao modelo de maximização da entropia para estimação de matrizes OD estáticas, pois este é o modelo utilizado na pesquisa. Também, foram descritos os programas utilizados nesta tese e feita explanação sobre as técnicas que consideram os movimentos de conversão para estimação de fluxo.

Posteriormente, foi descrita a formulação matemática da proposta de estimação considerando os fluxos observados nas interseções (meta do trabalho), bem como a formulação do método de estimação por médias sucessivas (um dos objetivos específicos). Essas duas formulações, mais a descrição do experimento elaborado para verificação da proposta, compõem o capítulo do detalhamento da proposta do trabalho.

O experimento foi realizado considerando uma rede viária hipotética, bem como a matriz OD "real" que a demanda. A rede viária refletiu as condições de congestionamento, problema de difícil solução ao considerar o modelo sintético (BELL et al, 1993). Foram formulados testes de verificação para estimar a matriz OD através dos dois programas de estimação e do método de médias sucessivas. A estimação foi dividida em duas partes: a Parte A considerou contagens realizadas nas interseções; e na Parte B contagens foram realizadas apenas nos arcos. Isso permitiu verificar o desempenho da proposta através de métodos de estimação distintos. Além disso, a estimação através dos programas foi realizada de duas maneiras, primeiro sem fornecer matriz semente e depois com a matriz 
semente. Ademais, a matriz semente fornecida foi alterada, a fim de atender a outro objetivo específico: analisar os efeitos causados pelo uso da matriz semente.

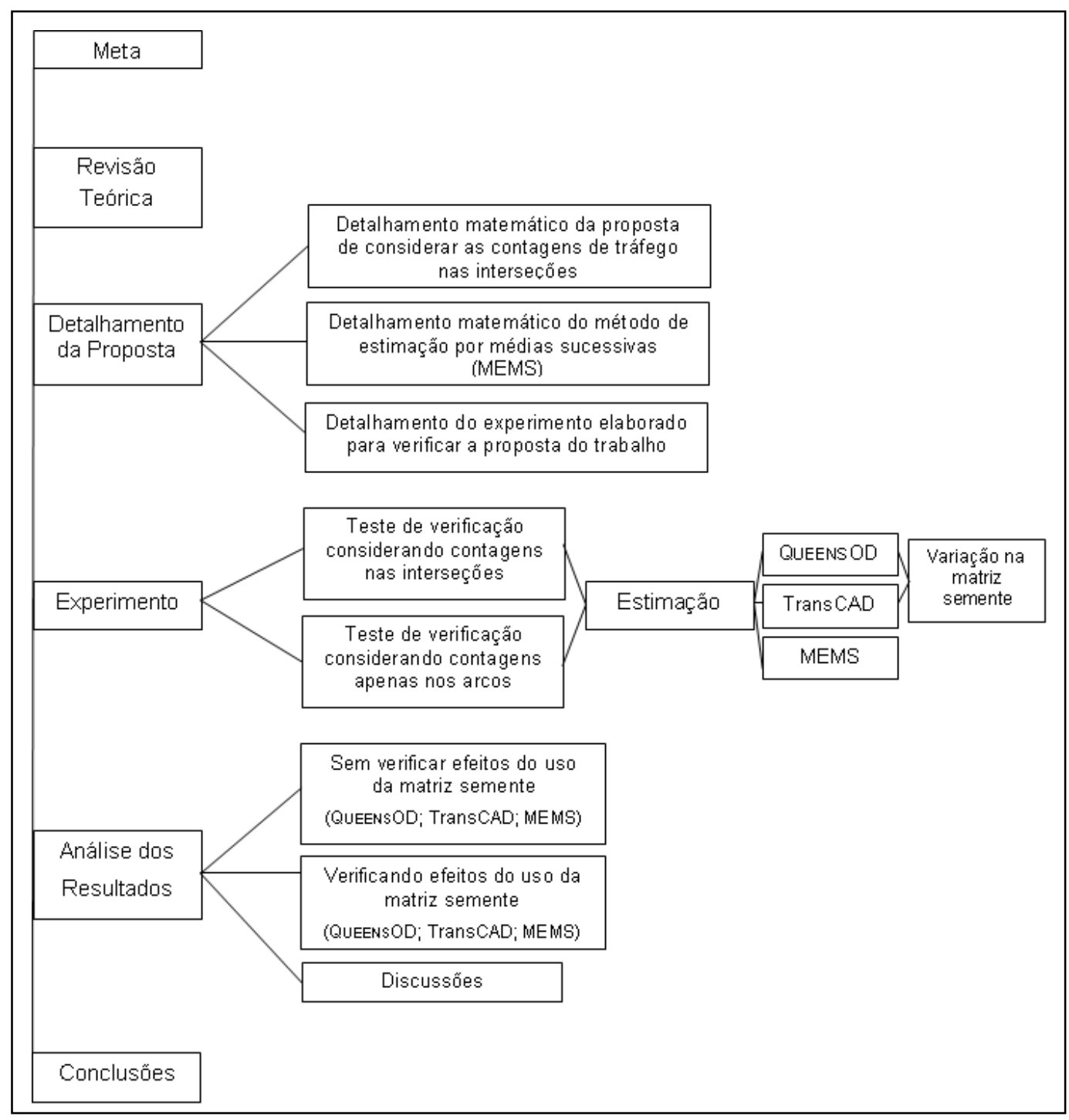

Figura 1. 1: Síntese do método

As matrizes estimadas foram analisadas de maneira comparativa em relação à matriz "real". Por fim, são apresentadas as conclusões obtidas, fechando as etapas desta pesquisa de caráter exploratório.

\subsection{JUSTIFICATIVA PARA O ESTUDO}

Ao longo das últimas quatro décadas o modelo sintético foi pesquisado com o foco dirigido principalmente na resolução de algumas inconsistências: obtenção de múltiplos resultados, falta de continuidade do fluxo em arcos contíguos e desconhecimento das rotas 
de viagem (RAKHA et al, 1998). Entretanto, erros elevados ainda continuam a fazer parte do modelo, o que continua a prejudicar sua disseminação, como afirmaram Van Aerde et al (2003).

Os trabalhos de Willumsen (1978), Van Zuylen e Branston (1982), Bell (1983), Cascetta (1984), Carey e Revelli (1986) e Nielsen (1993) são os de maior destaque quanto à tentativa de solucionar os problemas ocasionados pela falta de continuidade do fluxo em arcos contíguos. Já Nguyen (1977), Gur et al (1978), Fisk (1988) e Bell et al (1993) apresentaram contribuições importantes quanto a tentativa de definir as rotas de viagem.

Em relação à questão de obtenção de múltiplos resultados, Van Zuylen e Willumsen (1980) propuseram um método que consistia em aumentar a informação através da incorporação da matriz semente ao modelo sintético. Contudo, esta idéia faz com que a estimação fique condicionada ao fornecimento desta matriz inicial. Assim, os resultados estimados dependem da qualidade e da representatividade desta matriz semente em relação aos fluxos observados (YANG et al, 1992; TIMMS, 2001).

A idéia deste trabalho é aumentar a quantidade de informação, entretanto considerando as contagens nas interseções. A consideração dos fluxos de conversão teve seus primeiros estudos iniciados no final da década de 1970, quando Turnquist, em 1977, sugeriu utilizar as porcentagens de conversão para auxiliar no processo de manutenção da continuidade dos fluxos observados (total de veículos que chega ao nó é igual ao que sai, desde que não constitua um ponto de origem/destino) e no processo de escolha das rotas.

É possível afirmar que os trabalhos que consideram fluxo de conversão, em sua maioria, foram desenvolvidos para alocação e escolha da rota, visando resolução de procedimentos dinâmicos, como programação de semáforos atuados pelo tráfego (ALIBABAI; MAHMASSANI, 2008). 
Alguns desses métodos passaram a ser utilizados em conjunto ao processo de estimação. Porém, até hoje, não surtiram melhorias significativas a ponto de modificar a abordagem adotada no processo de estimação da matriz de viagens. Prova disso é que a grande maioria das pesquisas continua a considerar o fluxo observado nos arcos e não nas interseções, como constituinte do conjunto de restrições.

O caráter inovador da presente tese é que os fluxos observados nas interseções considerando os movimentos de conversão - farão parte do processo de estimação da matriz de viagens, ao contrário do que tem sido desenvolvido, em que o objetivo é estimar fluxos e pré-dizer movimentos, que são importantes para processos dinâmicos (ALIBABAl; MAHMASSAMI, 2008).

Partindo do pressuposto que estimação consiste em técnica inversa à alocação e na tentativa de possibilitar a independência da pesquisa em relação a programas comerciais suas simplificações e seus possíveis pontos falhos - optou-se por desenvolver um método de estimação a partir das médias sucessivas.

Este método de estimação integra um dos objetivos da tese, cuja expectativa é que ele possa estimar a matriz de viagens com erros menores que os obtidos pelos softwares atualmente em uso.

Também, espera-se que ele seja uma alternativa aos métodos de estimação em redes viárias congestionadas, o que de acordo com Bell et al (1993) é um dos principais problemas a ser resolvido para aplicação do modelo sintético. Ademais, acredita-se que o método estimando viagens em redes congestionadas será capaz de estimar viagens em redes não congestionadas.

\subsection{ESTRUTURA DO TRABALHO}

O presente trabalho está dividido em seis (6) capítulos, a começar por esta introdução. 
No segundo capítulo será apresentada a revisão teórica e dela constarão: informações referentes à estimação da matriz de viagens a partir dos fluxos observados; detalhamento do modelo entrópico e da técnica de maximização da entropia para estimação da demanda; discussão sobre as técnicas implementadas nos programas QUEENSOD e TransCAD; e os métodos de estimação baseados nos fluxos de conversão.

No terceiro capítulo será apresentado o detalhamento da proposta, que será dividido em duas partes: na primeira constará a descrição matemática da proposta; e na segunda a descrição do experimento elaborado para verificá-la.

O quarto capítulo trará o experimento. No capítulo seguinte serão apresentadas as análises dos resultados obtidos, com uma breve discussão dos mesmos.

No sexto capítulo serão apresentadas as conclusões e as sugestões para trabalhos futuros. Finalizando este texto de tese têm-se as referências e os apêndices. 


\section{CAPÍTULO 2 REVISÃO TEÓRICA}

Este capítulo traz a revisão teórica sobre estimação de viagens a partir das contagens de tráfego. A idéia é mostrar o desenvolvimento dos principais expedientes de estimação da matriz $O D$ desenvolvidos ao longo das últimas décadas, além de apresentar os métodos de estimação dos programas utilizados para o desenvolvimento deste trabalho e as principais abordagens sobre estimação considerando os fluxos de conversão.

\subsection{ESTIMAÇÃO DAS VIAGENS A PARTIR DAS CONTAGENS DE TRAFEGO}

Informações fundamentais para planejadores de transportes e para o gerenciamento e controle de tráfego são a magnitude dos fluxos de viagens e a distribuição destes na rede em termos de origem e destino (CREMER; KELLER, 1987).

A magnitude dos fluxos pode ser obtida através de contagens de tráfego em seções de vias. Tais contagens podem ser realizadas através de sensores permanentes, no caso de redes monitoradas por uma central de controle de tráfego, através de filmagem e de sensores portáteis, ou mesmo através de contagens manuais, no caso de redes não monitoradas.

Já a distribuição dos fluxos na rede em função das origens e destinos de viagem, comumente expressos de forma matricial, denominada matriz de viagens ou matriz OD, pode ser obtida direta ou indiretamente. 
A distribuição é obtida diretamente através de levantamentos como contagens de tráfego, entrevistas individuais, fotografias aéreas, monitoramento de imagens e através do controle das placas dos veículos que entram e saem de determinada zona (ORTÚZAR; WILLUMSEN, 1994). São processos que demandam tempo e recursos humanos e financeiros (WILLUMSEN, 1981).

Também é possível obter a matriz de viagens através de métodos indiretos, por exemplo, estimar demandas a partir dos totais de viagens geradas em função das atividades dos indivíduos de uma região (ORTÚZAR; WILLUMSEN, 1994). Método este que requer realização de pesquisas origem-destino (OD) através de entrevistas domiciliares ou em pontos de controle e que também demanda tempo e recursos humanos e financeiros (WILLUMSEN, 1981).

Alternativamente há uma terceira opção, derivada dos métodos diretos, que consiste em estimar a matriz de viagens a partir das contagens de tráfego. Neste processo, as demandas são estimadas a partir do fluxo de tráfego observado nas vias que, ao contrário da alocação, estima fluxo a partir do conhecimento da demanda. Tal idéia surgiu da necessidade de obter a matriz de viagens de forma mais econômica e rápida. Os primeiros trabalhos nesta linha datam da década de 1970 (WILLUMSEN, 1981).

Os trabalhos desenvolvidos, de modo geral, podem ser agrupados em categorias, conforme a maneira como concebidos. No entanto, não existe uma divisão fixa, que permita classificar os métodos de estimação.

Willumsen (1981), por exemplo, afirma que existem três grandes grupos: (i) métodos baseados nos modelos de gravidade, assumem que as viagens são explicadas em função de fatores de produção e atração de viagens e do custo de viagem. O problema é que além de utilizar fluxos observados em trechos de vias, é necessária a calibração de fatores e isso, via de regra, requer a realização de outras pesquisas, como entrevistas domiciliares; (ii) métodos baseados no equilíbrio, levam em consideração os efeitos do congestionamento da 
rede e consistem em estimar a matriz OD cujos fluxos satisfaçam as condições de equilíbrio. Apesar de Willumsen ter destacado esse método em uma categoria específica, é preciso ressaltar que, atualmente, após os avanços apresentados nas pesquisas de Nguyen (1977) e Turnkist e Gur (1979), a manutenção do equilíbrio está inserida em todos os métodos de estimação. Em uma nova classificação esses métodos não devem ser agrupados em uma categoria exclusiva, pois atualmente os métodos de estimação consideram um processo iterativo que visa garantir o equilíbrio; e (iii) métodos de maximização da entropia, são derivados das correntes apresentadas por Wilson (1970).

Abrahamsson (1998) apresenta uma revisão sobre estimação de matrizes utilizando contagens de tráfego. Para ele, os métodos de estimação devem ser divididos em dois grandes grupos: (i) trabalhos baseados em modelagem do tráfego, que a partir das observações de tráfego procuram criar o modelo capaz de estimar a demanda, como os modelos de gravidade e de entropia; e (ii) trabalhos baseados em inferência estatística, que consistem em obter a matriz através da estimação de parâmetros da distribuição de probabilidades. Para Abrahamsson, devem ser enquadrados nessa segunda categoria: a máxima verossimilhança; método dos mínimos quadrados, pelo qual a matriz semente é igual à matriz a ser estimada adicionada a um termo probabilístico de erro; inferência Bayesiana, que considera que a matriz semente é a função de probabilidade a priori da matriz OD a ser estimada; e técnicas baseadas em gradiente, em que ocorre um processo iterativo cuja matriz semente é a solução inicial para o problema de estimação da matriz OD.

Em 2001, Paul Timms sugeriu um novo arranjo dos trabalhos, sob ponto de vista filosófico. Ele analisou a fundamentação de cada um dos principais métodos de estimação e os classificou em quatro grandes grupos: (i) racionalista, consiste em usar dados referentes à geração de viagens para calibrar os modelos, destaque para os modelos de gravidade; (ii) neo-realista empirista, engloba os métodos que trabalham com manipulação estatística das observações de tráfego nos arcos e das matrizes OD semente, portanto são melhor justificados cientificamente, pois dependem da amostragem dos dados observados. Os 
métodos explicados por esta corrente são da máxima verossimilhança e dos mínimos quadrados; (iii) neo-realista balanceado, métodos que combinam a estimação da matriz com as observações de tráfego nos arcos e matrizes semente, cuja maior dificuldade é explicar os pesos que as observações terão e a importância dada à matriz semente. Fariam parte deste grupo métodos como mínimos quadrados e máxima verossimilhança; e (iv) subjetivo balanceado, de acordo com Timms é muito parecido com o neo-realista balanceado, a diferença é que o subjetivo não considera que apenas as contagens de tráfego sejam exatas. A maximização da entropia é um dos métodos pertencentes a esta classificação, os métodos bayesianos também fazem parte deste grupo.

Para Sherali et al. (2003), que tomaram por base o trabalho de O'Neill (1987), a divisão dos métodos de estimação está restrita a duas categorias: (i) técnicas de calibração de parâmetros, composta por métodos que utilizam regressão linear e não linear para construir modelos de demanda, derivados dos modelos de gravidade. O problema é que para calibrar esses parâmetros são necessárias informações a respeito das zonas de tráfego e não apenas as contagens feitas nos arcos; (ii) métodos de estimação da matriz, que subdividissem em: (iia) métodos de estimação estatísticos, baseados no conhecimento de informação inicial, empregando técnicas de inferência Bayesiana, como a proposta por Maher (1983), ou usando modelos de mínimos quadrados como os de Carey et al (1981), Cascetta (1984), McNeil e Hendrickson (1985), O’Neil (1987) e Bell (1991); ou (iib) métodos de estimação matemáticos baseados na maximização da entropia de Willumsen (1978) e minimização da informação de Van Zuylen (1978), ou a combinação desses dois métodos proposta por Van Zuylen e Willumsen (1980).

De modo geral, a chave para os métodos de estimação é identificar os pares de origem e destino das viagens e as rotas utilizadas por elas (WILLUMSEN, 1978). A partir disto é possível afirmar que: caso uma viagem entre a origem (i) e o destino (j) utilize determinado arco, parte do total de viagens entre ij corresponderá a uma parcela do fluxo observado nesse arco. Assim, o fluxo observado no arco a $\left(\mathrm{V}_{\mathrm{obs}}^{a}\right)$ é dado pela soma das 
parcelas de fluxo entre ij que utilizam $a\left(0 \leq \mathrm{p}_{\mathrm{ij}}^{a} \leq 1\right)$, multiplicada pelo total de viagens entre ij $\left(Q_{i j}\right)$, conforme [2.1].

$\mathrm{V}_{\mathrm{obs}}^{a}=\sum_{\mathrm{ij}} \mathrm{p}_{\mathrm{ij}}^{a} \mathrm{Q}_{\mathrm{ij}}$

Willumsen (1981) define [2.1] como a equação fundamental do problema de estimação das viagens a partir dos fluxos observados. Porém, é muito difícil que o fluxo estimado $\left(\sum_{\mathrm{ij}} \mathrm{p}_{\mathrm{ij}}^{a} \cdot \mathrm{Q}_{\mathrm{ij}}\right)$ corresponda exatamente ao observado $\left(\mathrm{V}_{\mathrm{obs}}^{a}\right)$, devido a uma série de fatores, tais como os observados por TIMMS (2001):

- Geralmente, as viagens intrazonais são desconsideradas. Daí a afirmar que parte dos fluxos observados aos arcos pode corresponder às viagens intrazonais;

- Há imprecisões provenientes das contagens, por exemplo, quando a contagem inicia, alguns veículos podem estar trafegando na rede e deixam de ser observados em determinada seção à montante, o que pode levar a falta de continuidade dos fluxos;

- Simplificações e suposições apresentadas pelos métodos de estimação podem não condizer com a realidade, fazendo com que o fluxo estimado seja diferente do observado;

- A maneira como $\mathrm{p}_{\mathrm{ij}}^{a}$ é calculado pode não representar a forma como a escolha da rota é feita na situação real e isso implicaria distorções do valor estimado em relação ao real;

- Métodos que utilizam informação inicial, por exemplo, matriz semente, podem resultar na não observância da equação [2.1], pois o padrão da distribuição de viagens da matriz semente pode não corresponder aos fluxos observados.

Essas questões tornam a estimação de viagens uma técnica imprecisa (TIMMS, 2001). Willumsen (1978) afirmou que por se tratar de um modelo, está implícito que a 
resposta conterá algum tipo de erro, mas que o objetivo é aprimorar a técnica para que a imprecisão seja cada vez menor. Sendo [2.1] uma restrição, é matematicamente esperado que ela seja satisfeita. Na prática, problemas como os descritos por Timms (2001) e o fato de ser um problema indeterminado, não permitem que o fluxo observado seja exatamente igual ao estimado.

Abrahamson (1998) assegurou que a indeterminação ocorre porque a quantidade de incógnitas tende a ser maior que a de informação e, muito dificilmente, a matriz estimada será igual a real, de onde não satisfazer a restrição.

Hazelton (2001) alegou que muitos autores investigam técnicas para estimar ou reconstruir a matriz OD a partir de um conjunto de fluxos observados. Ele demonstra matematicamente que estimação é diferente de reconstrução. Reconstrução seria a obtenção de viagens entre o par OD ij que recupere a rota original e as contagens de tráfego, um processo que demandaria, além das contagens de tráfego, informações referentes à escolha da rota; estimação leva em consideração as observações de tráfego em cada arco e a utilização destes por parte das viagens. Isso ocorre todas as vezes que se busca encontrar a matriz mais provável (HAZELTON, 2001).

$\mathrm{Na}$ realidade, dificilmente será possível recuperar a rede original apenas com contagens de tráfego nos arcos, por se tratar de um problema em que o número de incógnitas (viagem entre ij e rota utilizada) é menor de o que o de informações; portanto é um processo indeterminado, com múltiplas soluções. É possível fazer com que a matriz se aproxime da real, desde que a quantidade de informações não redundantes - representadas pelas contagens de tráfego ou uso de matriz semente - se aproxime do número de incógnitas, representadas pela viagem entre a origem (i) e o destino (j). 


\subsection{MÉTODOS DE ESTIMAÇÃO}

Tomando por base a equação [2.1] é possível dizer que para determinar a quantidade de viagens realizadas entre diferentes pares OD a partir de contagens de fluxo, é preciso resolver um problema composto por tantas equações quanto o número de observações de fluxo (WILLUMSEN, 1981), o qual pode ser expresso em notação matricial, conforme [2.2]:

$$
\mathbf{V}=\mathbf{P} \times \mathbf{Q}
$$

em que:

V: vetor de fluxos observados na rede;

$\mathbf{P}$ : porcentagens de viagens $Q_{\mathrm{ij}}$ que utilizam cada um dos arcos; e

Q: matriz de viagens na rede.

O escalonamento da matriz aumentada $[\mathbf{P} \mid \mathbf{V}]$ possibilitará obter a matriz canônica (reduzida). Com isso, utilizando o método de Gauss-Jordan (NOBLE, 1969) é possível determinar se o conjunto de equações terá múltiplas soluções como resposta (DEMARCHI et al, 2004).

De acordo com Noble (1969), toda vez que o posto do escalonamento da matriz aumentada $[\mathbf{P} \mid \mathbf{V}]$ for igual ao da matriz $\mathbf{P}$ e o posto do escalonamento da matriz $[\mathbf{P} \mid \mathbf{V}]$ for menor que o número de incógnitas, haverá múltiplas soluções. De modo empírico seria possível chegar à mesma conclusão verificando se o número de incógnitas é maior que o de informações não redundantes (ou fluxos). Via de regra, as redes de transporte das médias e grandes cidades são problemas típicos de múltiplas soluções, pois a indeterminação é muito maior que a quantidade de informações.

Através de análise combinatória entre o número total de viagens e as viagens entre os pares OD é possível obter o total de combinações que retornarão determinada configuração de viagem, conforme mostrou Paramahamsan (1999). Qual entre estas 
soluções seria a mais correta? Para isso existem expedientes que objetivam encontrar a solução.

Analisando os trabalhos de Willumsen (1981), Abrahamsson (1998), Timms (2001) e Sherali et al (2003), é proposto que os expedientes são derivados de três correntes: (i) modelos de gravidade; (ii) inferência estatística; (iii) modelo entrópico.

\subsubsection{Modelos de gravidade}

Talvez não seja correto definir tais modelos como modelos de gravidade. O modelo newtoniano considera um campo de força de energia que caracteriza os movimentos das partículas e não suas intenções (SCHNEIDER, 1959), como no caso do "modelo gravitacional" utilizado para distribuição de viagens.

Este tipo de modelo busca estimar a matriz OD em função do total de viagens produzidas em cada zona de tráfego, do total de viagens que a zona de tráfego atraiu e dos custos para que as viagens ocorram. Geralmente, os métodos derivados desta corrente demandam outras pesquisas (como entrevistas domiciliares), além das contagens de tráfego (WILLUMSEN, 1981).

Willumsen (1981) mostra que esses modelos podem ser generalizados conforme a expressão [2.3]:

$Q_{i j}=b_{1} \cdot O_{i} \cdot D_{j} \cdot c_{i j}^{-d}$

em que, $Q_{i j}$ é a quantidade de viagem entre a origem (i) e o destino (j) a ser estimada; $b_{1}$ e d são parâmetros a serem calibrados; $O_{i}$ é o total de viagens originadas em na zona i; $D_{j}$ é o total de viagens com destino j; e $c_{i j}$ é o custo de viagem entre i e j.

O fluxo observado contribuiria para a calibração do modelo e, em geral, é matematicamente representado como em [2.4] (WILLUMSEN, 1981). 
$\mathrm{V}_{\mathrm{obs}}^{\mathrm{a}}=\mathrm{b}_{0}+\sum_{\mathrm{ij}} \mathrm{Q}_{\mathrm{ij}} \cdot \mathrm{p}_{\mathrm{ij}}^{\mathrm{a}}$

Nesta expressão, $b_{0}$ corresponde à parcela de fluxo intrazonal, mas em alguns modelos esse fator é descartado, por ser de difícil obtenção (WILLUMSEN, 1981). Os demais termos da expressão [2.4] são como os anteriormente mencionados. A calibração ocorreria através da obtenção de parâmetros para [2.3], que satisfizessem [2.4].

Os trabalhos desenvolvidos seguem esta tendência. Low (1972) adotou regressão linear para calibração de um modelo gravitacional utilizando dados do tamanho populacional e da quantidade de empregos entre as zonas.

Em 1975, Robillard propôs um trabalho pioneiro para estimação da matriz a partir das contagens de tráfego. Seu modelo seria uma generalização do gravitacional e dependeria de uma função para o custo de viagem, bem como dos parâmetros das zonas de origem e destino. Esses parâmetros seriam função do conhecimento a priori sobre a força de atração ou produção de viagens em cada zona de tráfego. O modelo é expresso matematicamente da seguinte maneira:

$Q_{i j}=A_{i} \cdot D_{j} \cdot C_{i j}^{-d}$

$\mathrm{V}_{\mathrm{obs}}^{\mathrm{a}}=\sum_{\mathrm{ij}} \mathrm{p}_{\mathrm{ij}}^{\mathrm{a}} \cdot \mathrm{A}_{\mathrm{i}} \cdot \mathrm{D}_{\mathrm{j}} \cdot \mathrm{C}_{\mathrm{ij}}^{-\mathrm{d}}$

Para Robillard os parâmetros $A_{i}, D_{j}$ e d devem ser calibrados de forma que a soma da diferença quadrática entre o fluxo observado e o estimado atinja valor mínimo.

Seguindo esta linha, Hogberg (1976), Holm et al (1976) e Symons et al (1976) também apresentaram contribuição à estimação de viagens considerando modelo de gravidade. Esses trabalhos consistiram em verificar quais parâmetros socioeconômicos seriam mais representativos para calibração mais precisa do modelo de Robillard (1975). 
Os modelos de gravidade têm como vantagem a consideração de parâmetros populacionais que permitem correlação entre viagens e características socioeconômicas dos indivíduos, agregados por zonas. Eles impõem ao modelo caráter racionalista (TIMMS, 2001), pois a definição de quais parâmetros considerar fica a cargo do planejador, resultando uma parcela de subjetivismo ao modelo. Em complementação é possível afirmar que o uso desse tipo de modelo tem o inconveniente de necessitar grande quantidade de dados para sua calibração. Isso faz com que o ganho proporcionado pela idéia de utilizar um método que dependa de poucas informações (como apenas as informações de fluxo observado nos arcos) não ocorra.

\subsubsection{Inferência estatística}

Ao contrário dos métodos matemáticos que objetivam encontrar a matriz OD que seja consistente com o fluxo de tráfego observado e similar as viagens de uma matriz semente, os métodos baseados em inferência estatística assumem que os fluxos apresentam distribuição aleatória e procuram, então, estimar parâmetros que especifiquem a distribuição desses fluxos. De modo geral, é assumido que os fluxos seguem uma distribuição de Poisson. O uso desse expediente é o mais recente entre os três apresentados neste trabalho.

Os trabalhos de Maher (1983), Cascetta (1984), Bell (1984) apresentaram modelos derivados da inferência estatística. Posteriormente, Spiess (1987 e 1990), Bell (1991), Yang et al (1992), Bierlaire e Toint (1994), Yang et al (1994), propuseram adaptações aos modelos.

Entre os métodos estatísticos vale destacar a inferência Bayesiana. Ela considera que os parâmetros devem ser tomados como aleatórios e tenta incorporar, da melhor forma possível, a informação inicial, através do teorema de Bayes [2.7]. 
$p(\theta \mid y)=\frac{f(y \mid \theta) \cdot p(\theta)}{\int f(y \mid \theta) \cdot p(\theta) d \theta}$

Em que $p(\theta)$ é a densidade de probabilidade a priori do parâmetro $\theta ; f(y \mid \theta)$ é a verossimilhança da observação y; e $\mathrm{p}(\theta \mid \mathrm{y})$ é a distribuição de probabilidade a posteriori de $\theta$.

Maher (1983) foi quem deu início às pesquisas para estimação de viagens seguindo esta teoria. Propôs a combinação de probabilidade normal multivariada com a distribuição da média dos fluxos da matriz semente.

O método considera ser conhecida a distribuição de probabilidade a priori da matriz OD $(\operatorname{Pr}(\mathrm{Q}))$, obtida a partir de uma matriz OD semente. As contagens de tráfego constituem outra fonte de informação a respeito de $Q$, com distribuição de probabilidade $\xi\left(V_{\text {obs }} \mid \mathrm{Q}\right)$. Então, através da teoria de Bayes é possível um método que combine essas duas fontes de informação. Assim, a probabilidade a posteriori $\mathrm{f}\left(\mathrm{Q} \mid \mathrm{V}_{\mathrm{obs}}\right)$ de observar $\mathrm{Q}$ condicional às contagens de tráfego e à distribuição a priori é expressa conforme [2.8].

$\mathrm{f}\left(\mathrm{Q} \mid \mathrm{V}_{\mathrm{obs}}\right) \approx \xi\left(\mathrm{V}_{\mathrm{obs}} \mid \mathrm{Q}\right) \cdot \operatorname{Pr}(\mathrm{Q})$

Os fluxos observados, em geral, seguem uma distribuição de probabilidade de Poisson ou uma normal multivariada. Já a função de probabilidade a priori para $Q(\operatorname{Pr}(Q))$ pode assumir uma distribuição multinomial ou uma distribuição normal multivariada (MAHER, 1983).

Maher (1983) assumiu que a distribuição de probabilidade das contagens de tráfego segue uma normal multivariada e mostra que, neste caso, a matriz OD estimada também apresentará uma distribuição a posteriori normal multivariada. Isso demonstra que o modelo é sensível à distribuição de probabilidade adotada. Por isso, ao aplicar essa técnica o planejador deverá estar seguro quanto às informações a respeito da distribuição de probabilidades a priori, principalmente referentes à matriz semente. Isso faz com que o 
método apresente caráter subjetivo balanceado, dependendo menos das contagens e mais da distribuição a priori da matriz OD (TIMMS, 2001).

Tebaldi e West (1998) adotaram os fluxos seguindo uma distribuição Poissoniana, baseados no modelo frequentista de Vardi (1996). Mais recentemente, Hazelton (2001) propôs um modelo que resolve diferentes problemas, denominado estimador da matriz OD e estimador do fluxo médio. Para Hazelton, o método proposto consiste em uma técnica de reconstrução e não de estimação, pois além de estimar a matriz OD a técnica busca recompor o conjunto de caminhos utilizados pelas viagens. Ainda assim, a matriz reconstruída não está livre de erros e pode apresentar diferença em comparação com a matriz real (HAZELTON, 2001).

Outro método estatístico consiste na minimização das diferenças quadráticas. Le Blanc e Farhangian (1982), Cascetta (1984), Cascetta e Nguyen (1988), Bell (1991), Yang et al (1992) e Bierlaire e Toint (1994) desenvolveram pesquisas levando em consideração este método de estimação.

De acordo com este método, a matriz OD semente ou objetivo (S) é dada pela soma da matriz $\mathrm{OD}(\mathrm{Q})$ com um termo de erro probabilístico $(\eta): S=Q+\eta$. De maneira geral, é assumido que o erro probabilístico ( $\eta$ ) é igual a zero, desde que $Q$ seja definida pela média. Ao assumir esse erro probabilístico nulo é necessário definir as matrizes de variância e covariância, que para $\eta$ será $M$.

Assim o estimador de mínimos quadrados pode ser expresso, genericamente, pela equação de minimização apresentada em [2.9].

$\min W=\frac{(S-Q) \cdot(S-Q)}{M}$

Sendo minW sujeito a $Q_{i j} \geq 0$ e $Q_{i j}$ correspondendo ao total de viagens entre a origem (i) e o destino (j), pertencente a matriz $Q$. 
Caso as contagens de tráfego e a matriz objetivo descrevam uma distribuição normal multivariada, Cascetta e Nguyen (1988) mostraram matematicamente que o problema coincidirá com a máxima verossimilhança (ABRAHAMSSON, 1998).

Para Cascetta (1984), o método dos mínimos quadrados é capaz de produzir melhores resultados do que a maximização da entropia. A vantagem é que será conhecida a distribuição probabilística dos resultados estimados. O problema dependerá da qualidade da matriz objetivo e da precisão quanto às rotas utilizadas pelas viagens.

O método proposto por Cascetta (1984) assumiu a existência de diferenças entre as contagens de tráfego observadas e as estimadas. Assim, ele estabelece que as quantidades de viagem entre os pares OD sejam estimadas (por qualquer método de estimação), tal que a diferença entre os valores estimados e observados seja uma restrição a ser minimizada. Isso faria com que os fluxos resultantes da estimação fiquem o mais próximo possível dos respectivos fluxos observados.

A máxima verossimilhança é considerada outro método estatístico. Conhecendo a distribuição probabilística das contagens de tráfego e dos fluxos entre os pares OD, para um conjunto de observações é possível obter uma função de verossimilhança $(L)$, desde que as contagens de tráfego e os fluxos sejam estatisticamente independentes, conforme [2.10].

$$
\left.L\left(\left\{\mathrm{~V}_{\mathrm{obs}}\right\},\left\{\mathrm{s}_{\mathrm{ij}}\right\} /\left\{\mathrm{Q}_{\mathrm{ij}}\right\}\right)=\mathrm{L}\left(\left\{\mathrm{V}_{\mathrm{obs}}\right\} /\left\{\mathrm{Q}_{\mathrm{ij}}\right\}\right) \cdot \mathrm{L}\left(\left\{\mathrm{s}_{\mathrm{ij}}\right\}\right\}\left\{\mathrm{Q}_{\mathrm{ij}}\right\}\right)
$$

Maximizando a expressão [2.10], em função de $Q_{i j}$, é possível encontrar os valores mais prováveis para $\left\{Q_{i j}\right\}$. Essa maximização resulta na expressão [2.11].

$$
\mathrm{Q}_{\mathrm{ij}}=\frac{\mathrm{S}_{\mathrm{ij}}}{\rho_{\mathrm{ij}}+\sum_{a} \mathrm{p}_{\mathrm{ij}}^{a} \cdot \kappa_{a}}
$$

Sendo $\mathrm{s}_{\mathrm{ij}} \mathrm{O}$ valor da viagem entre a origem (i) e o destino (j) contida na matriz OD semente; $\rho_{\mathrm{ij}}$ fator de amostragem das contagens e $\kappa_{a}$ um fator de balanceamento e pode ser tomado 
como zero desde que as viagens da matriz objetivo sejam internamente compatíveis com as contagens de fluxo nos arcos. Assim, a expressão [2.11] se reduz a [2.12].

$$
\mathrm{Q}_{\mathrm{ij}}=\frac{\mathrm{s}_{\mathrm{ij}}}{\rho_{\mathrm{ij}}}
$$

Caso não tenha elementos suficientes para conhecer a distribuição de $\mathrm{V}_{\text {obs }}$, Spiees (1987) propõe uma generalização ao problema, apresentada na equação [2.13].

$$
\min \left(\sum_{\mathrm{ij}}\left(\rho_{\mathrm{ij}} \cdot \mathrm{Q}_{\mathrm{ij}}-\mathrm{S}_{\mathrm{ij}} \cdot \log \left(\mathrm{Q}_{\mathrm{ij}}\right)\right)+\sum_{a}\left(\rho_{a} \cdot \mathrm{V}_{\mathrm{obs}}^{a}-\mathrm{K}_{a} \cdot \log \left(\mathrm{V}_{\mathrm{obs}}^{a}\right)\right)\right)
$$

sendo $\rho_{a}$ um amostrador do fluxo no arco $a$ e $\mathrm{K}_{a}$ contém as observações mutuamente independentes que seguem uma distribuição de Poisson, cujas variáveis aleatórias possuem média igual a $\left\{\rho_{a} \cdot \mathrm{V}_{\mathrm{obs}}\right\}$.

De forma geral, a maximização da verossimilhança consiste em obter o valor máximo da multiplicação das probabilidades de determinado evento ocorrer. A questão é que a relação entre o fluxo observado no arco e o fluxo entre o par OD, ao ser multiplicada pela relação entre fluxo OD semente e fluxo OD, faz com que o processo seja condicionado a semente.

Abrahamsson (1998) afirmou que a técnica de inferência Bayesiana possui propriedades comuns com a minimização das diferenças quadráticas e a maximização da verossimilhança. De fato as técnicas apresentam similaridade, primeiro porque todas atribuem peso maior à matriz OD semente no processo de estimação, e levam em consideração a distribuição da dispersão da matriz semente e das contagens. A diferença entre elas é que $Q_{i j}$ para máxima verossimilhança e minimização das diferenças quadráticas são parâmetros de uma função probabilística, enquanto que para inferência Bayesiana são variáveis aleatórias com uma distribuição a priori (CASCETTA; NGUYEN, 1988). 
O que diferencia a inferência estatística dos demais expedientes para estimação de matrizes OD é o fato de o resultado obtido por inferência ser a distribuição de probabilidades da matriz, e não o valor das viagens da matriz OD. Fica a cargo do planejador adotar a média como sendo a matriz OD mais provável.

Os trabalhos voltados à estimação da matriz OD dinâmica, via de regra, fazem uso da inferência estatística, porque com a distribuição de probabilidade é possível conhecer a variação da demanda ao longo do tempo (SHERALI et al, 2003). Aqui é preciso abrir parêntese para uma breve contextualização sobre o que seja matriz OD dinâmica.

\subsubsection{Matriz OD dinâmica}

Matrizes dinâmicas são formas de representar as viagens em função da variação temporal ocorrida na demanda ao longo do dia. Pelo fato de a demanda poder variar significativamente ao longo do dia, teoricamente, a matriz dinâmica reflete melhor a realidade, principalmente em áreas congestionadas.

Assim, é possível identificar os carregamentos na rede e programar as estratégias operacionais para intervenção nesses pontos. Isso pode ser feito com base em observações dos fluxos de tráfego registrados em diferentes intervalos (WILLUMSEN, 1984).

O estudo de matrizes dinâmicas ganhou notoriedade na década de 1990, principalmente devido à possibilidade de coletar dados em tempo real e a disseminação dos sistemas ITS (Intelligent Transport System).

Apesar disso, existem razões para ainda usar e estudar matrizes OD estáticas (aquelas que não são capazes de representar a variação temporal da demanda): é um problema mais fácil de ser modelado, bem como a transição de um modelo estático para um dinâmico é mais fácil de ser realizada (HELLINGA, 1994). 
Por essas razões, no presente trabalho a intenção é propor um método para estimação da matriz OD estática, baseado no paradigma de maximização da entropia. Por isso, a terceira corrente (modelo entrópico) será discutida em um item a parte.

\subsection{MODELO ENTRÓPICO}

O conceito de entropia é utilizado por diversas áreas do conhecimento, principalmente pelas ciências não sociais (JAYNES, 1957). Wilson, na década de 1970, foi o primeiro autor a mostrar que a entropia teria aplicação no estudo de sistemas urbanos e regionais.

Entropia representa os estados do sistema, mas como defini-los? De acordo com Wilson (1967), o estado do sistema é definido por uma descrição completa, detalhada, microscópica.

No caso, por exemplo, de um gás, o estado pode ser descrito em função das coordenadas e velocidades de cada partícula. Contudo, são muitas partículas envolvidas (mais de $10^{23}$ partículas por mol) e situações como esta são difíceis de serem analisadas. Uma possibilidade seria através da física newtoniana (WILSON, 1967).

Wilson (1967) afirma que as partículas de um gás podem ser agrupadas em três estados:

(i) Macroestado - quantidade total de moléculas de gás no sistema;

(ii) Meso-estado - como as moléculas estão distribuídas no sistema;

(iii) Microestado - combinação das moléculas.

Os estados estão representados de forma gráfica na Figura 2. 1. 


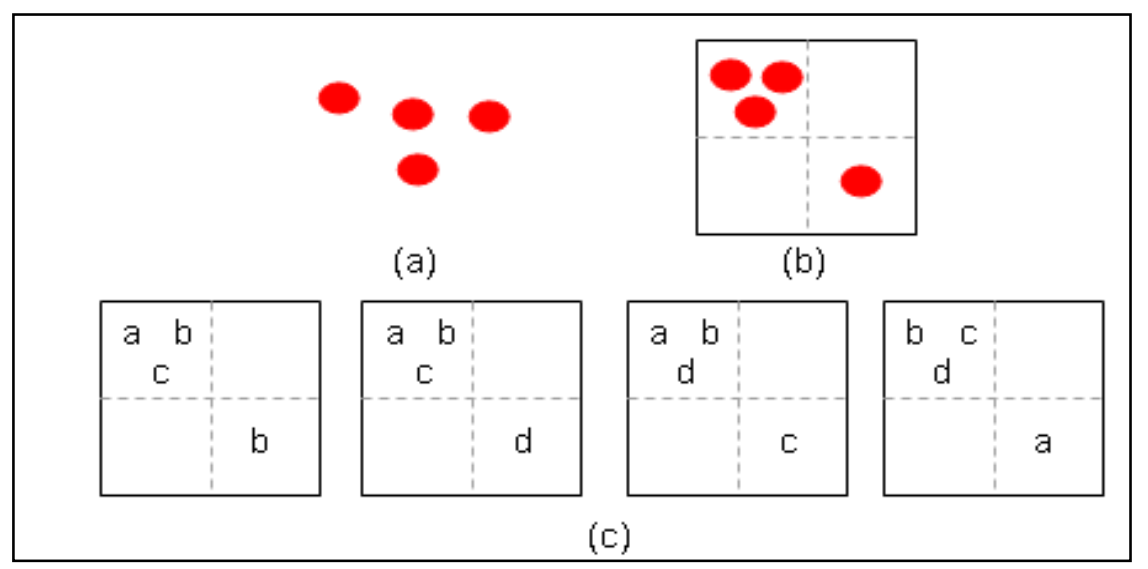

Figura 2. 1: Representação dos três estados de comportamento das moléculas de um gás: (a) macroestado; (b) meso-estado; (c) microestado

Um determinado macroestado pode estar associado a diversos meso-estados, que por sua vez, estão relacionados a diversos microestados. Se todos os microestados são igualmente prováveis, é possível encontrar um meso-estado que ocorra com maior freqüência. Então, basta calcular o número de microestados associados a cada mesoestado, sujeitos a um conjunto de restrições (WILSON, 1967). O meso-estado associado ao maior número de microestados é o que ocorrerá com maior freqüência. A situação em que as partículas estão espalhadas é a que apresenta maior freqüência de ocorrência, conforme pode ser observado na Figura 2.2.

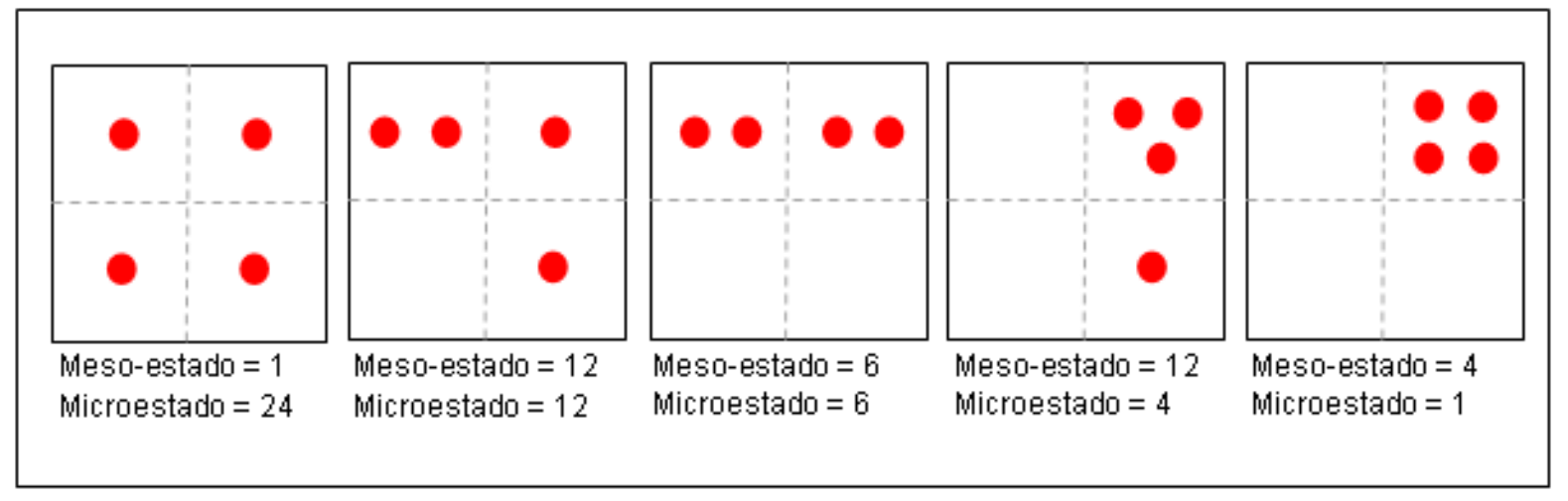

Figura 2. 2: Quantidade de meso e microestados

Wilson (1967) afirmou que um sistema urbano é tão difícil de ser explicado quanto o de um gás, e que é possível fazer analogia entre um sistema urbano com o comportamento físico das moléculas de gás. Para ele, tanto as viagens quanto os gases apresentam os mesmos estados de divisão. 
Neste caso, o macroestado representaria a quantidade total de viagens no sistema, o meso-estado corresponderia à distribuição de viagens entre os pares OD e o microestado, mais desagregado, equivaleria à distribuição individual de cada viagem entre as origens e os destinos da rede.

Considere, então, o sistema urbano constituído por trabalhadores que viajam de suas residências, para os respectivos postos de trabalho. São conhecidos os totais de viagens produzidas e atraídas em cada zona de tráfego. Como essas viagens estão distribuídas entre as zonas de tráfego?

Para responder este questionamento, Wilson (1967) através da analogia com o comportamento físico dos gases - em que diversos microestados podem gerar o mesmo meso-estado, sendo cada microestado com a mesma probabilidade de ocorrência - propôs um modelo capaz de encontrar o estado que gera a distribuição mais provável de ocorrer.

Assim, Wilson (1967) mostrou que para estimar o valor da viagem entre a origem (i) e o destino (j) (denominada $Q_{i j}$ ) bastaria que três restrições fossem atendidas:

$$
\begin{aligned}
& \sum_{i} Q_{i j}=O_{i} \\
& \sum_{j} Q_{i j}=D_{j} \\
& \sum_{i j} Q_{i j} \cdot C_{i j}=C
\end{aligned}
$$

Em que: $O_{i}$ representa o número total de indivíduos que viajam a partir da zona i; $D_{j}$ é a quantidade de indivíduos que viajam para a zona j; $c_{i j}$ é o custo generalizado para realizar viagem entre ij; C consiste no total gasto para realizar as viagens. 
A meta é encontrar um meso-estado $\left(Q_{i j}-\right.$ distribuição de viagens entre a origem i e o destino j) que maximize o número de microestados a ele associados. Considerando $\mathrm{Q}=\sum_{\mathrm{ij}} \mathrm{Q}_{\mathrm{ij}}$, como o número total de viagens no sistema.

Conforme proposto por Wilson, selecionando $Q_{11}$ de $Q, Q_{12}$ de $Q-Q_{11}$ etc, o número de maneiras de seleção de $Q_{11}$ de $Q$, é expresso por análise combinatória $C_{Q_{11}}^{Q}$ (combinação de $Q_{11}, Q$ a $Q$ ), já a seleção de $Q_{12}$ do conjunto que sobra $\left(Q-Q_{11}\right)$ seria $\mathrm{C}_{\mathrm{Q}_{12}}^{\mathrm{Q} \mathrm{Q}_{11}}$ e assim por diante. Portanto, multiplicando todas estas combinações obtêm-se o valor de $Z\left(Q_{i j}\right)$.

$$
\begin{aligned}
& Z\left(Q_{i j}\right)=C_{Q_{11}}^{Q} \cdot C_{Q_{12}}^{Q-Q_{11}} \cdot C_{Q_{13}}^{Q-Q_{11}-Q_{12}} \ldots \\
& Z\left(Q_{i j}\right)=\frac{Q !}{Q_{11} ! \cdot\left(Q-Q_{11}\right) !} \cdot \frac{\left(Q-Q_{11}\right) !}{Q_{12} ! \cdot\left(Q-Q_{11}-Q_{12}\right) !} \cdot \frac{\left(Q-Q_{11}-Q_{12}\right) !}{Q_{13} ! \cdot\left(Q-Q_{11}-Q_{12}-Q_{13}\right) !} \cdots \\
& Z\left(Q_{i j}\right)=\frac{Q !}{\prod_{i j} Q_{i j} !}
\end{aligned}
$$

Aplicando logaritmo natural na equação [2.19], de forma a tornar mais fácil a sua maximização, é obtida a equação linearizada apresentada em [2.20].

$$
\ln Z\left(Q_{i j}\right)=\ln \left(\frac{Q !}{\prod_{i j}\left(Q_{i j} !\right)}\right)=\ln Q !-\sum_{i j} \ln Q_{i j} !
$$

A derivação de um logaritmo natural de fatorial consiste em processo complexo. Para solucionar essa questão adota-se a aproximação de Stirling, como mostrou Wilson:

$$
\ln X !=X \ln X-X
$$

Com isso, o problema apresenta uma solução mais fácil. Então, a função de entropia passa a ser expressa como [2.22]. 
$Z\left(Q_{i j}\right)=Q \ln Q-Q-\sum_{i j}\left(Q_{i j} \ln Q_{i j}-Q_{i j}\right)$

Assumindo $Q$ constante, os primeiros dois termos podem ser retirados da equação, o que resulta em uma equação mais simples [2.23].

$Z\left(Q_{i j}\right)=-\sum_{i j}\left(Q_{i j} \ln Q_{i j}-Q_{i j}\right)$

Maximizando a expressão [2.23] sujeita as restrições [2.14] - [2.16] estabelecidas para o sistema é possível obter uma expressão para calcular a distribuição das viagens $\left(Q_{i j}\right)$.

De acordo com Wilson (1970), a expressão [2.26] parece com os modelos gravitacionais, pois leva em consideração os fatores de atração e produção de viagens. A diferença é que o modelo gravitacional é uma função potência e não exponencial, como no modelo entrópico.

$$
\begin{aligned}
& F=\sum_{i j}\left(Q_{i j} \ln Q_{i j}-Q_{i j}\right)+\lambda_{1}\left[\left(\sum_{i} Q_{i j}\right)-O_{i}\right]+\lambda_{2}\left[\left(\sum_{j} Q_{i j}\right)-D_{j}\right]+\lambda_{3}\left[\left(\sum_{i j} Q_{i j} \cdot c_{i j}\right)-C\right] \\
& \frac{\partial F}{\partial Q_{i j}}=0 \\
& Q_{i j}=A_{i} \cdot B_{j} \cdot O_{i} \cdot D_{j} \cdot \exp \left(-\beta \cdot c_{i j}\right)
\end{aligned}
$$

Com $A_{i}$ e $B_{j}$ fatores referentes a produção de viagens na zona de origem i e atração de viagens na zona de destino j, respectivamente.

Para a mecânica estatística, o equivalente a lnZ é a entropia do sistema. Já para Wilson, InZ seria a probabilidade que a distribuição ocorra. Assim, a entropia é mono tonicamente dada como a probabilidade de algo ocorrer em função de um conjunto de restrições (WILSON, 1970).

A entropia mede a incerteza que recai sobre os estados do sistema, especialmente sobre os microestados. O objetivo é encontrar a distribuição mais provável, capaz de 
resultar no maior número de microestados dadas as restrições (WILSON, 1970). Portanto, a entropia definirá uma região cuja distribuição reduzirá a incerteza, dado um conjunto de restrições. Quanto à maximização da entropia, pode ser dito que não consiste, apenas, em uma aplicação das leis da física, mas sim em um método de cálculo que garante que nenhum pressuposto arbitrário e inconsistente foi introduzido (JAYNES, 1957). De acordo com Timms (2001) o método de Wilson se enquadra no caráter subjetivo balanceado, pois faz adaptações das ciências físicas, para aplicar no contexto social.

Wilson, ao responder a questão "qual o comportamento esperado para a distribuição das viagens?", considerou que a sociedade ao se deslocar no meio urbano tende ao espalhamento, como ocorre com os gases. A ordem como este espalhamento é feito dependerá das restrições apresentadas ao problema e são essas restrições que irão moldar a resposta (WILSON, 1970).

Para Wilson (1967), o uso da entropia em transportes não fica restrito apenas à distribuição de viagens, mas também pode ser aplicado à outras situações, como divisão modal (principalmente quando houver vários modos envolvidos).

\subsection{ESTIMAÇÃO DA MATRIZ OD A PARTIR DE FLUXOS DE TRÁFEGO UTILIZANDO MAXIMIZAÇÃO DA ENTROPIA}

Uma das aplicações do modelo entrópico no contexto de sistemas urbanos ou regionais é como expediente para estimação da matriz de viagens a partir dos fluxos observados nos arcos da rede viária, conforme proposto por Willumsen em 1978, modificando as restrições apresentadas por Wilson (1970). Ao invés dos totais de viagens produzidas e atraídas pelas zonas de tráfego, Willumsen utilizou as contagens de tráfego nas vias e denominou o método como modelo sintético, por sintetizar a informação na estimação da matriz. O modelo foi formulado associando o microestado $\left(Z\left(Q_{i j}\right)\right)$, que representa as informações de cada viajante individualmente - origem, destino, modo e tempo de viagem - ao meso-estado $\left(Q_{\mathrm{ij}}\right)$, que geralmente é representado pelo número total 
de viajantes entre cada origem e cada destino. De acordo com esta idéia, as viagens tendem a se distribuir uniformemente pela rede de tráfego, sujeitas a um conjunto de restrições.

Este modelo pode ser representado através da equação [2.19] levando em consideração os fundamentos de análise combinatória (ORTÚZAR; WILLUMSEN, 1994). Para isso, deve-se maximizar [2.23], sujeito às restrições: [2.27] que representa chave do processo; [2.28] que garante a existência do número não negativo de viagens; e [2.29] correspondente a continuidade e preservabilidade das viagens, sendo Q o total de viagens na rede de tráfego:

$$
\begin{aligned}
& V_{o b s}^{a}=\sum_{i j} p_{i j}^{a} Q_{i j} \\
& Q_{i j} \geq 0 \quad \forall i, j \\
& Q=\sum_{i j} Q_{i j}
\end{aligned}
$$

De acordo com Willumsen, os valores de $Q_{i j}$, que maximizam a equação da entropia em função dessas restrições, representam a solução mais provável, não necessariamente real, de acontecer em função dos fluxos de tráfego observados. De acordo com Willumsen (1981), para utilizar o modelo entrópico é necessário que os fluxos observados sejam consistentes e não necessariamente independentes.

A maximização da expressão [2.23] sujeita às restrições [2.27 a 2.29] resulta na representação formal do modelo proposto por Willumsen [2.30]. Para isto, é necessário o uso de multiplicadores de Lagrange $\left(\lambda_{a}\right)$ que permitem incorporar as restrições à função a ser maximizada.

$$
\mathrm{Q}_{\mathrm{ij}}=\prod_{a}\left(\mathrm{e}^{-\lambda_{a}}\right)^{\mathrm{p}_{\mathrm{ij}}^{a}}
$$


A solução mais provável refletirá as restrições, no caso os fluxos observados nos arcos. Isso não quer dizer que a solução que tenha probabilidade alta seja a matriz que representará, na realidade, o deslocamento de uma população. Para que isso ocorra, é necessário atrelar ao modelo mais informações. Por ser um problema em que a indeterminação é maior que a quantidade de informação, é possível garantir que a solução se acerque da real à medida que o número de informações aumenta.

Van Zuylen (1978) afirmou que a informação contida nas contagens de tráfego nos arcos é insuficiente para determinar uma matriz OD. Então, ele propôs utilizar, além das contagens de tráfego, uma mínima quantidade de informação auxiliar, utilizando o conceito de medida da informação de Brillouin (1956). De acordo com este conceito, a informação (I) contida em um conjunto de observações $(N)$, quando um estado $k$ foi observado $n_{k}$ vezes é definida como:

$I=\ln N ! \cdot \prod_{k}\left[\frac{\left(\text { prob }_{k}\right)^{n_{k}}}{n_{k} !}\right]$

Sendo $\operatorname{prob}_{\mathrm{k}}$ a probabilidade a priori de observar o estado $\mathrm{k}$.

Se as observações são contagens de tráfego em um arco $a$ e o estado ij representa todos os veículos observados trafegando da origem i para o destino j, é possível expressar matematicamente o número de vezes em que ij foi observado da seguinte forma:

$$
\mathrm{n}_{\mathrm{ij}}^{a}=\mathrm{Q}_{\mathrm{ij}} \cdot \mathrm{p}_{\mathrm{ij}}^{a}
$$

Para Van Zuylen (1978) a melhor maneira de expressar a probabilidade a priori de observar o estado ij para o $\operatorname{arco} a\left(\mathrm{r}_{\mathrm{ij}}^{a}\right)$ é em função do conhecimento prévio de uma viagem semente entre a origem i e o destino j $\left(s_{i j}\right)$, expressa conforme [2.33]. Esse conhecimento prévio da viagem pode ser obtido a partir de uma antiga matriz OD da rede de transportes.

$$
\operatorname{prob}_{\mathrm{ij}}^{a}=\frac{\mathrm{s}_{\mathrm{ij}} \mathrm{p}_{\mathrm{ij}}^{a}}{\sum_{\mathrm{ij}} \mathrm{s}_{\mathrm{ij}} \mathrm{p}_{\mathrm{ij}}^{a}}
$$


Portanto, a informação contida nas contagens de tráfego $\left(V_{\mathrm{obs}}^{a}\right)$ é expressa por:

$\mathrm{I}_{a}=\ln \mathrm{V}_{\mathrm{obs}}^{a} ! \prod\left[\frac{\left(\frac{\mathrm{s}_{\mathrm{ijj}} \mathrm{p}_{i \mathrm{j}}^{a}}{\sum_{\mathrm{ij}} \mathrm{s}_{\mathrm{ij}} \mathrm{p}_{\mathrm{ij}}^{a}}\right)^{\mathrm{Q}_{\mathrm{ip}} \mathrm{p}_{i j}^{a}}}{\mathrm{Q}_{\mathrm{ij}} \mathrm{p}_{\mathrm{ij}}^{a} !}\right]$

Utilizando a aproximação de Stirling, a equação [2.35] é expressa conforme [2.36].

$$
\mathrm{I}_{a}=\sum_{\mathrm{ij}} \mathrm{Q}_{\mathrm{ij}} \mathrm{p}_{\mathrm{ij}}^{a} \ln \left[\frac{\mathrm{Q}_{\mathrm{ij}}\left(\sum_{\mathrm{ij}} \mathrm{s}_{\mathrm{ij}} \mathrm{p}_{\mathrm{ij}}^{a}\right)}{\mathrm{V}_{\mathrm{obs}}^{a} \cdot \mathrm{s}_{\mathrm{ij}}}\right]
$$

Tomando $\sum_{\mathrm{ij}} \mathrm{s}_{\mathrm{ij}} \mathrm{p}_{\mathrm{ij}}^{a}=\mathrm{S}$ e todos os arcos da rede viária, a quantidade de informações passa a ser representada por:

$$
\mathrm{I}_{a}=\sum_{a} \sum_{\mathrm{ij}} \mathrm{Q}_{\mathrm{ij}} \cdot \mathrm{p}_{\mathrm{ij}}^{a} \ln \left(\frac{\mathrm{Q}_{\mathrm{ij}} \cdot \mathrm{S}}{\mathrm{V}_{\mathrm{obs}}^{a} \cdot \mathrm{S}_{\mathrm{ij}}}\right)
$$

Minimizando a equação [2.37] sujeita as restrições [2.38] é possível obter a expressão formal [2.39] para o modelo de minimização da quantidade de informação.

$$
\begin{aligned}
& \mathrm{V}_{\mathrm{obs}}^{a}=\sum_{\mathrm{ij}} \mathrm{p}_{\mathrm{ij}}^{a} \mathrm{Q}_{\mathrm{ij}} \text { e } \mathrm{Q}_{\mathrm{ij}} \geq 0 \\
& \mathrm{Q}_{\mathrm{ij}}=\mathrm{S}_{\mathrm{ij}} \cdot \prod\left\{\frac{\mathrm{V}_{\mathrm{obs}}^{a}}{\mathrm{~S}} \cdot e^{-\left(1+\lambda_{a}\right)}\right\}_{a}^{\sum_{a i j}^{a}} \mathrm{p}_{i j}^{a}
\end{aligned}
$$

Willumsen (1981) afirmou que a entropia e a minimização da quantidade de informação apresentam propriedades similares e o mesmo algoritmo pode ser usado para solução. A estrutura do modelo proposto por Willumsen (1978) e a do proposto por Van 
Zuylen (1978) são parecidas. A diferença é que para o modelo de Willumsen o meso-estado é representado pelas viagens, já para o de Van Zuylen as contagens de tráfego é que compõem o meso-estado.

Em 1980, Van Zuylen e Willumsen propuseram uma mudança de paradigma ao unificar seus modelos. Foi incorporada quantidade adicional de informação à proposta de Willumsen (1978) representada pela probabilidade a priori de a contagem de tráfego conter um veículo que se desloca da origem i, para o destino j.

A probabilidade a priori de uma viagem individual ocorrer entre os pares OD (ij) $\left(\right.$ prob $\left._{\mathrm{ij}}\right)$ pode ser apresentada conforme a equação [2.40]. Conseqüentemente, a probabilidade de ocorrer as $Q_{i j}$ viagens entre i e j é expressa pela equação [2.41].

$$
\begin{aligned}
& \operatorname{prob}_{i j}=\frac{s_{i j}}{\sum_{i j} s_{i j}} \\
& \operatorname{prob}_{i j}^{Q_{i j}}=\left(\frac{s_{i j}}{\sum_{i j} s_{i j}}\right)^{Q_{i j}}
\end{aligned}
$$

O modelo de Van Zuylen e Willumsen é representado conforme [2.42] e leva em consideração a probabilidade de ocorrência de $Q_{i j}$ viagens em função da matriz OD semente.

$$
Z\left(Q_{i j}, s_{i j}\right)=\frac{Q !}{\prod_{i j}\left(Q_{i j} !\right)} \cdot \prod_{i j}\left(\frac{s_{i j}}{S}\right)^{Q_{i j}}
$$

em que, $Q=\sum_{i j} Q_{i j}$ : soma das demandas que serão estimadas; $Q_{i j}$ : fluxo entre i e j; $s_{i j}$ : fluxo entre i e j fornecido na matriz semente; $S=\Sigma s_{\mathrm{ij}}$ : total de viagens da matriz semente. 
As demandas veiculares são então estimadas maximizando a equação [2.43] sujeita às restrições expressas em [2.44].

$$
\begin{aligned}
& \ln Z\left(Q_{i j}, s_{i j}\right)=Q \cdot \ln Q-Q \cdot \ln S-\sum_{i j}\left(Q_{i j} \cdot \ln Q_{i j}-Q_{i j} \cdot \ln s_{i j}\right) \\
& V_{o b s}^{a}=\sum_{i j} p_{i j}^{a} \cdot Q_{i j} ; Q_{i j} \geq 0 \quad \forall i, j ; Q=\sum_{i j} Q_{i j}
\end{aligned}
$$

A expressão formal do modelo de Van Zuylen e Willumsen (1980) é apresentada conforme [2.45].

$$
\mathrm{Q}_{\mathrm{ij}}=\mathrm{s}_{\mathrm{ij}} \cdot \prod\left[\left(\sum_{\mathrm{ij}} \mathrm{s}_{\mathrm{ij}}\right)^{\frac{1}{\sigma}} \cdot \mathrm{e}^{-\lambda_{a}}\right]^{\mathrm{p}_{\mathrm{ij}}^{a}}
$$

sendo 0 o número total de arcos onde houve contagem de tráfego e $\lambda_{a} \circ$ multiplicador lagrangeano.

De acordo com Van Zuylen e Willumsen (1980) a tendência é que os resultados sejam mais precisos, em comparação com os obtidos sem considerar matriz semente. Todavia, esta precisão está condicionada à qualidade da matriz semente utilizada (YANG et al, 1992).

Pela estrutura dos modelos tem-se que a probabilidade de uma viagem estimada entre ij ocorrer, será a mesma apresentada pela viagem entre ij contida na matriz semente. Assim, se a probabilidade de ocorrer determinada viagem ij na matriz OD semente for elevada, a probabilidade da viagem ij estimada será elevada. Com isso, a matriz OD que maximiza a função objetivo assumirá valores maiores para as demandas semente com alta probabilidade e valores menores para as com baixa probabilidade. $\mathrm{O}$ condicionante para determinar o maior número de micro-estados será a matriz semente e não apenas o mesoestado, como proposto por Willumsen. 
É possível concluir que a estimação torna-se sensível à qualidade da matriz OD semente, conforme observou Yang et al (1992) e o resultado será melhor se a matriz semente e o conjunto de fluxo observado forem internamente consistentes. Nesse ponto, o modelo entrópico se iguala aos modelos estatísticos, pois ambos ficam moldados pela informação a priori.

O problema é que os planejadores, muito dificilmente, têm à disposição matrizes semente de qualidade. Além disso, não há como garantir que as viagens tenham a mesma distribuição ao longo do tempo, pois o crescimento das viagens entre as zonas de tráfego não é uniforme, e o uso da matriz semente induz a isso. Ou seja, se, por exemplo, o planejador quiser atualizar uma matriz OD obtida há 10 anos, a partir das contagens de tráfego atuais, ele assume que a matriz estimada para o ano atual terá a mesma distribuição de viagens que tinha 10 anos antes e isso não, necessariamente, condiz com a realidade.

Outra questão é se o planejador não tiver a disposição uma matriz OD semente, o que fazer? Poderá utilizar matriz semente uniforme, como aquelas em que as células são iguais a 1 veic/h (RAHKA et al, 1998). Neste caso, o valor de $Q_{i j}$ que apresenta maior probabilidade de ocorrer é o mesmo quando não se conhece a matriz semente. Souza (2007) apresentou um exemplo em que isso é observado. Por serem uniforme, todas as demandas terão a mesma probabilidade de ocorrer (calculada conforme [2.27]) e isso não interfere no termo adicionado na formulação proposta por Van Zuylen e Willumsen (1980). Assim, o problema retoma à situação original de Willumsen (1978) e será o conjunto de fluxos observados que moldará a resposta.

Quanto aos modelos entrópicos, Timms (2001) afirmou que apresentam caráter subjetivo balanceado, pois Willumsen (1978), ao assumir que a distribuição das viagens na rede pode ser representada pela entropia e reconstruída a partir das contagens de tráfego, impõs ao problema um caráter subjetivo, assim como ocorre com os modelos de inferência 
bayesiana. A diferença é que os modelos de inferência dependem menos da qualidade das contagens de tráfego, o foco é voltado à matriz OD semente.

A vantagem do modelo entrópico, em comparação com os modelos gravitacionais, é depender de quantidade menor de informações (basicamente contagens de tráfego e matriz OD semente). O que atende perfeitamente a idéia de desenvolver um modelo para estimar a matriz de viagens sem despender recursos com pesquisas de entrevista domiciliar, por exemplo, como ocorre com o modelo gravitacional.

Em relação aos métodos estatísticos é possível afirmar que para eles, a informação inicial não é expressa na forma de um valor, mas sim como uma distribuição, com média e variância especificadas, ao contrário dos modelos de entropia. Portanto, são sensíveis à qualidade da distribuição a priori. Para Maher (1983), os resultados obtidos por inferência podem ser similares aos gerados por entropia, a diferença é que a inferência gera uma distribuição e cabe ao planejador adotar a média como a matriz OD estimada. O fato de não conhecer a distribuição de probabilidades da matriz OD estimada é um ponto questionável do modelo entrópico.

Outro ponto questionável é preconizar que as viagens tendem a se espalhar pela rede de transportes. Entretanto, é crível que o aumento de informações de tráfego funcione como estacas que moldarão a resposta, fazendo com que os resultados fiquem mais próximos à situação real e é nesse ponto que o presente trabalho formulou sua hipótese.

\subsubsection{Outros trabalhos de estimação baseados no modelo entrópico}

Os trabalhos de Nguyen (1977), Turniquist e Gur (1979) e Gur et al (1980), além dos trabalhos de Willumsen (1978), Van Zuylen (1978) e Van Zuylen e Willumsen (1980), têm grande destaque dentre os que utilizam o conceito de entropia.

Nguyen (1977), Turniquist e Gur (1979), Gur et al (1980) e Fisk (1988) incorporaram ao modelo o conceito de equilíbrio do usuário, conforme definido por Wardrop (1952). Tal 
idéia é feita através de um processo iterativo que relaciona estimação e definição da rota, com isso é possível obter a matriz OD mais representativa.

Willumsen (1981) inclusive propôs uma categoria de métodos de estimação considerando as técnicas de equilíbrio. Hoje, praticamente todos os métodos são fundamentados nesta premissa. Antigamente era considerado que as rotas para determinado deslocamento eram conhecidas a priori e isso limitava o uso dos métodos à situações em que a rede não estava congestionada. Para redes congestionadas, a matriz OD e a escolha das rotas tornam-se interdependentes (ORTUZAR; WILLUMSEN, 1994). Daí o uso de técnicas de alocação mais realistas em conjunto com a estimação. Quem deu início a esta técnica (denominada bi-nível) foi Nguyen (1977), mas foi Fisk (1988) quem obteve melhor resultado ao usar o modelo de Van Zuylen e Willumsen (1980) junto à alocação por equilíbrio, em um processo em que alocação e estimação eram realizadas iterativamente.

\subsection{ESTIMAÇÃO DA MATRIZ DE VIAGENS UTILIZANDO PROGRAMAS COMPUTACIONAIS}

A implementação do método de estimação de viagens em softwares foi importante para disseminar o uso dessa técnica. Entretanto, Demarchi et al (2004) afirmaram que a aplicação dos métodos de estimação da matriz OD a partir das contagens de fluxo ainda não são muito difundidos; para Van Aerde et al (2003) os motivos são o desconhecimento teórico e as dificuldades práticas encontradas no processo de estimativa da demanda.

Os softwares EMME2, SATURN e TransCAD, de acordo com Timms (2001) apresentam melhor desempenho e são mundialmente utilizados.

O EMME2 é um programa de planejamento de transportes e uma de suas funções é a modelagem da demanda. Uma das técnicas é a estimação da matriz a partir das observações de fluxo (EMME2, 1990). O EMME2 tem como vantagem a possibilidade de os 
pesquisadores implementarem macros para resolver seus problemas, como Spiess (1990). Florian e Chen (1993) e Chen (1994), utilizaram em seus trabalhos as técnicas de solução baseadas em gradientes, com auxílio do EMME2 (ABRAHAMSSON, 1998).

No SATURN, Van Vliet e Hall (1998) implementaram o método de estimação ME2 proposto por Willumsen (1984), que simula impedância em redes congestionadas de forma mesoscópica.

Nesta tese os programas utilizados serão o QUEENSOD e o TransCAD, pois ambos são licenciados para uso em pesquisas acadêmicas no STT-EESC/USP. A seguir é apresentado um detalhamento sobre estes dois programas.

\subsubsection{QUEENSOD}

É um software desenvolvido por Michel Van Aerde (1998) para estimação da matriz OD a partir da contagem de fluxo nos arcos, para dar suporte ao microssimulador de tráfego INTEGRATION, no processo de estimação da matriz OD sintética.

Tanto o QUEENSOD (QOD), quanto o INTEGRATION, compartilham a mesma estrutura de dados e arquivos de entrada. Entretanto, o uso do INTEGRATION independe do QUEENSOD e vice-versa.

Basicamente são necessárias as seguintes informações: características geométricas da rede; parâmetros de tráfego (capacidade, fluxo de saturação, fluxo); e elementos de controle da rede (semáforos e placas do tipo PARE ou Dê a Preferência). Todas estas informações são codificadas em arquivos do tipo texto (".dat; ${ }^{*}$.txt).

Os arquivos são divididos em dois grupos: (i) obrigatórios: fundamentais para estimação da matriz de viagens, sem eles o processo não pode ser realizado; (ii) opcionais: ativam comandos extras, codificados para prover melhoria aos resultados (VAN AERDE, 1998). Na Figura 2. 3 é apresentada a estrutura dos arquivos de entrada em que se pode perceber a relação entre os arquivos utilizados pelo INTEGRATION e pelo QUEENSOD. 


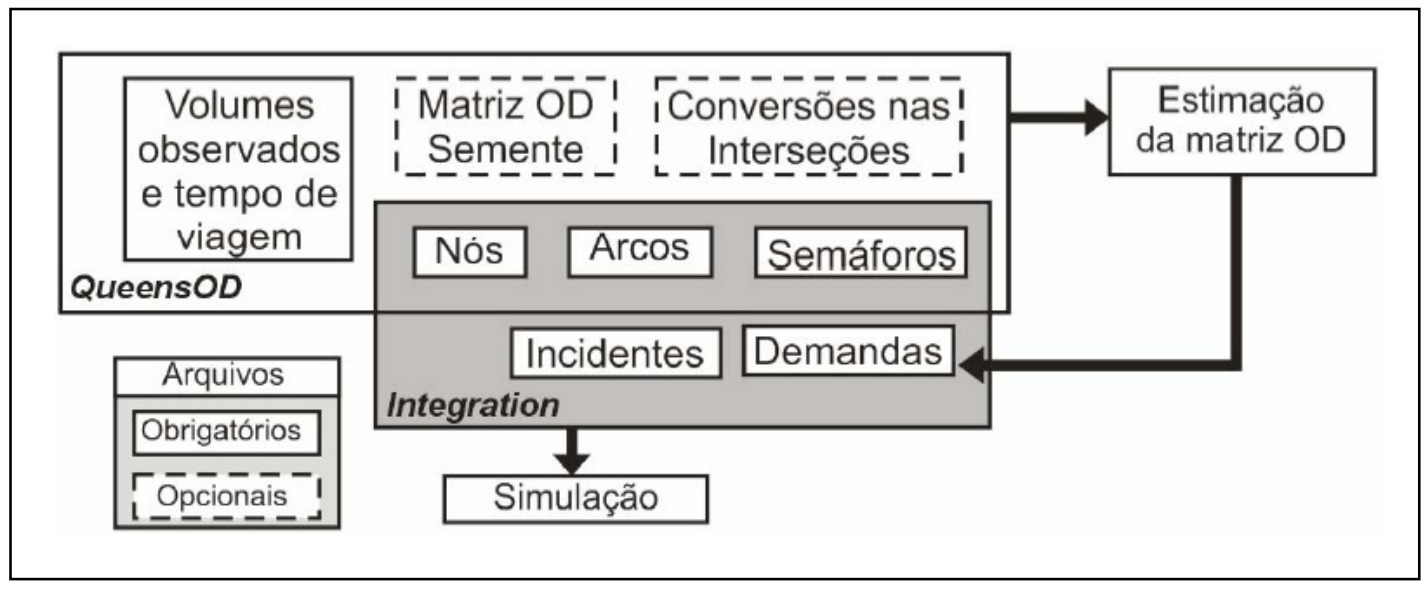

Figura 2. 3: Arquivos utilizados pelo QUEENSOD e pelo INTEGRATION (Fonte: Demarchi et al, 2004)

Quanto aos arquivos opcionais, a matriz semente fornecida pelo usuário traz qualidade ao resultado, conforme afirmam Rakha et al (1998) e Watson e Prevedouros (2006). Contudo, se esta matriz não for disponibilizada pelo usuário, o próprio programa se encarregará de criar uma matriz semente do tipo uniforme, sendo que todos os pares OD terão viagens entre si (VAN AERDE, 1998).

De acordo com Van Aerde (1998) apesar de matematicamente eficaz, o arquivo de movimento de conversão é incapaz de fazer com que os resultados estimados sejam próximos aos observados, dando indício de que esta função pode não estar corretamente programada. Teoricamente o arquivo de movimentos de conversão tem como principal função auxiliar no processo de conservação dos movimentos e definição das rotas (PARAMAHAMSAN, 1999; RAKHA et al, 200X).

A formulação para maximização da entropia que está inserida no QOD é a mesma desenvolvida por Van Zuylen e Willumsen (1980) [2.46], entretanto a diferença está na restrição [2.47]. Isso mostra que os resultados estimados devem ser sensíveis à qualidade da matriz OD semente empregada: quanto mais proporcional à real, melhor deverá ser a matriz estimada. 
$\operatorname{Max} . Z\left(Q_{i j}, s_{i j}\right)=\frac{Q !}{\prod_{i j}\left(Q_{i j} !\right)} \prod\left(\frac{s_{i j}}{\sum_{i j} s_{i j}}\right)^{Q_{i j}}$

$\mathrm{E}=\sum_{a}\left(\mathrm{~V}_{\mathrm{obs}}^{a}-\mathrm{p}_{\mathrm{ij}}^{a} \mathrm{Q}_{\mathrm{ij}}\right)^{2} \mathrm{w}^{a}$

Sendo $\mathbf{w}^{a}$ fator de ponderação que varia conforme o tipo de critério de minimização de erro:

- LSE: critério que considera a minimização pelo método dos mínimos quadrados. Consiste na soma simples das diferenças quadráticas entre os fluxos observados e estimados, para este critério $\mathrm{w}^{a}=1$

- LRE: critério do erro mínimo relativo. O erro a ser minimizado corresponde à soma das diferenças quadráticas entre os fluxos observados e estimados, relativamente aos fluxos observados, para este critério $\mathrm{w}^{a}=\frac{1}{\mathrm{~V}_{\mathrm{obs}}^{a}}$

- LPE: erro mínimo Poissoniano. Consiste no meio termo entre os critérios apresentados. Por ele, o erro a ser minimizado é calculado pela soma das diferenças quadráticas entre fluxo observado e estimado, divididas pela raiz quadrada do respectivo fluxo observado $\mathrm{w}^{a}=\frac{1}{\sqrt{\mathrm{V}_{\mathrm{obs}}^{a}}}$.

De acordo com Watson e Prevedouros (2006), a incorporação de $w^{a}$ no conjunto restrição inserido no QOD é a principal contribuição do método de estimação implementado no programa.

2.5.1.1 Funcionamento do método 
O método de estimação do QUEENSOD depende do conhecimento da matriz semente $\left(s_{\mathrm{ij}}\right)$, que é a base para a busca da solução e pode ser fornecida pelo usuário, ou gerada pelo programa, que cria uma matriz semente uniforme (WATSON;PREVEDOUROS, 2006).

Inicialmente $\mathrm{s}_{\mathrm{ij}}$ é alocada à rede de tráfego, seguindo o método do tudo-ou-nada, aos caminhos de custo mínimo. Em função desta matriz - que pode ser estabelecida pelo usuário ou criada pelo próprio programa - do resultado da alocação $\left(\mathrm{p}_{\mathrm{ij}}\right)$ e do critério de minimização do erro, a matriz OD será estimada.

Esta nova matriz é alocada à rede viária seguindo os mesmos princípios anteriores, no entanto objetivando atingir o equilíbrio do usuário na rede viária. Com isto, nova matriz de porcentagem de utilização do arco será definida e o processo se repetirá até completar o número de iterações definidos pelo usuário ou até a diferença entre fluxos observados e estimados (E) atingir o valor mínimo estabelecido pelo usuário como variável de entrada.

Se em alguma iteração o caminho mínimo se tornar congestionado, uma porcentagem das viagens, a ser definida no arquivo mestre, que utilizam este caminho será retirada e alocada ao segundo caminho definido como mínimo, modificando desta forma a matriz de utilização do arco. A versão média do QUEENSOD permite a realização de no máximo 1.000 iterações (VAN AERDE, 1998).

O QUEENSOD permite o estudo de até 5 caminhos por par OD e a divisão em até 100 partes das viagens alocadas aos arcos para, dessa forma, evitar a questão do congestionamento da rede.

A estrutura básica de funcionamento do QOD pode ser visualizada na Figura 2. 4, que pretende refletir as características de funcionamento apresentadas em seu manual. 


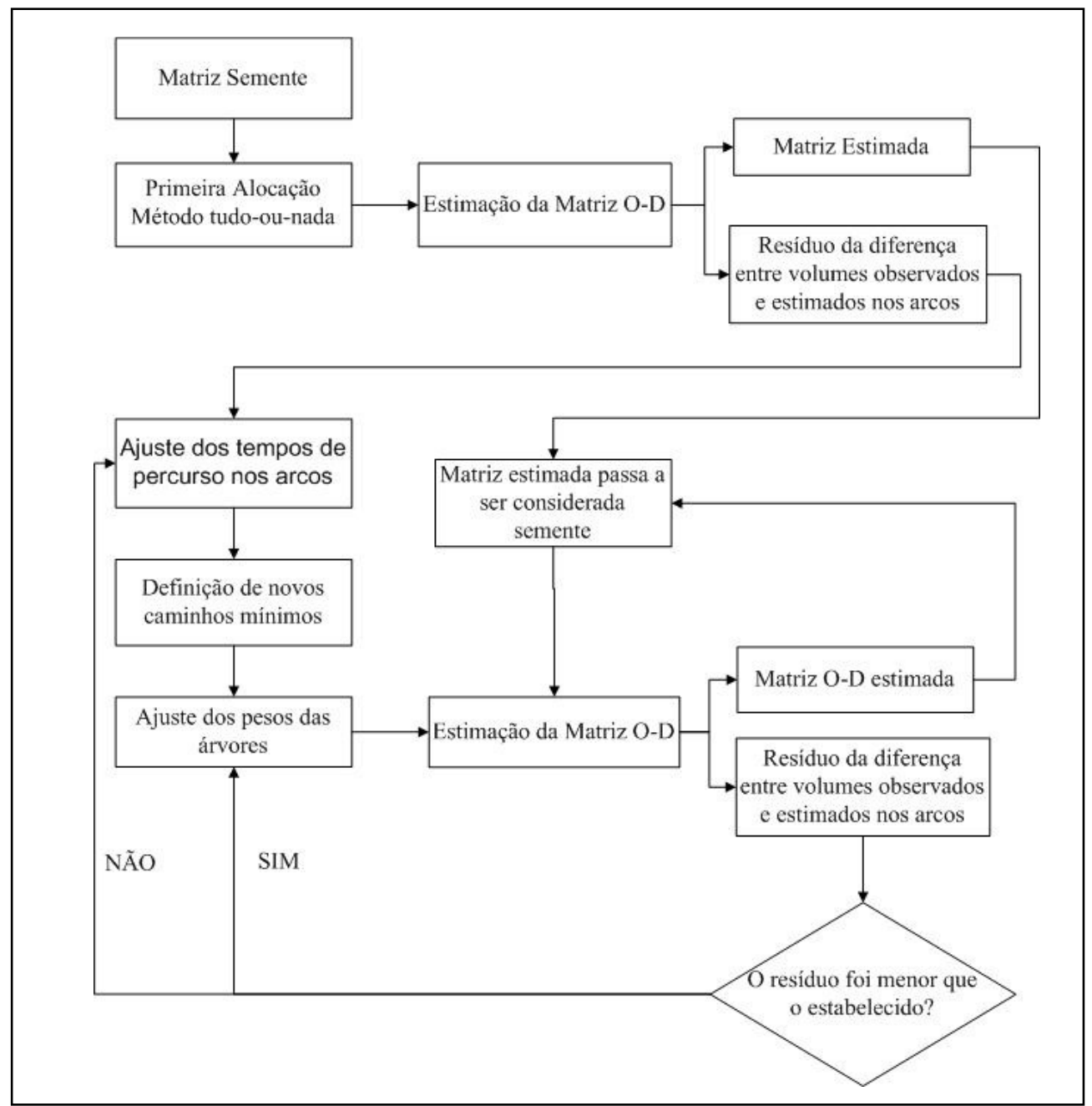

Figura 2. 4: Estrutura de funcionamento do QUEENSOD (Fonte: Manual do usuário do QUEENSOD, VAN AERDE, 1998)

Os resultados estimados pelo QUEENSOD foram considerados satisfatórios por Paramahamsan (1999) e Tesekeris e Stathopoulos (2008). Rakha et al (1998) utilizaram o QUEENSOD para estimar a matriz OD na rede viária de Salt Lake City (EUA). As análises mostraram que o fornecimento de uma matriz semente trouxe maior precisão ao resultado, ainda assim não ficou livre de erros.

Já Watson e Prevedouros (2006) afirmaram que métodos, como utilizado pelo QUEENSOD, que buscam aproximar o resultado estimado do observado - no caso através da minimização da diferença entre fluxo estimado e observado - tendem a apresentar erros elevados. 
Watson e Prevedouros (2006) afirmaram ainda, que os resultados estimados dificilmente mantêm a conservação do fluxo. Não que isso seja um problema, pois tal fato pode ser contornado, mas pode interferir na convergência e até mesmo no resultado. Souza (2007) observou no estudo desenvolvido considerando uma área da cidade de Fortaleza CE que o erro entre fluxo observado e estimado foi pequeno, no entanto ao fornecer uma matriz semente constante, mesmo com grande quantidade de arcos com contagem de tráfego, o QOD não foi capaz de estimar bons resultados. Quando foi fornecida uma matriz semente amostral os resultados obtidos apresentaram melhora.

\subsubsection{TransCAD}

O TransCAD é um programa baseado em Sistema de Informações Geográficas na área de transportes (SIG-T), desenvolvido pela Caliper Corporation. É uma ferramenta de modelagem da demanda baseada na plataforma SIG amplamente utilizada em planejamento e operação de transportes.

Entre as ferramentas disponíveis para modelagem da demanda, há a estimação da matriz OD a partir de contagens de tráfego. O método implementado em 1996 foi proposto por Nielsen (1993), que desenvolveu um procedimento de estimação de matrizes OD baseado no método iterativo.

A vantagem deste método está em tratar os fluxos como uma variável estocástica (NIELSEN, 1993). O objetivo é minimizar a diferença média entre o fluxo observado e o estimado, em cada caminho mínimo entre os pares OD (NIELSEN, 1993). O problema da estimação busca determinar a matriz OD que, quando alocada à rede, se aproxime dos fluxos observados.

Por se tratar de uma técnica em dois níveis, a estimação sempre estará associada a um método de alocação. Nielsen (1993) afirmou que o método alcança melhor desempenho quando utilizado em conjunto com as técnicas de alocação de equilíbrio do usuário. 
No caso do TransCAD há disponível seis métodos de alocação: tudo-ou-nada; incremental; restrição de capacidade; equilíbrio do usuário; equilíbrio estocástico do usuário; e otimização do sistema.

O método permite ainda a utilização da matriz turning movement, que contém as porcentagens de conversão em cada um dos nós da rede viária. Seu uso é opcional e o usuário deverá selecionar essa opção avançada e fornecer a matriz com as porcentagens de conversão (CALIPER, 1996).

Uma das principais aplicações do método consiste na atualização da matriz OD a partir dos fluxos atuais (NIELSEN, 1998). O método de Nielsen, assim como os de Van Zuylen e Willumsen (1980), é sensível à qualidade da matriz semente.

\subsubsection{Funcionamento do método}

O processo iterativo desenvolvido tem início com a alocação da matriz OD semente $\left(\mathrm{s}_{\mathrm{ij}}\right)$ à rede de tráfego. Desta forma, é obrigatório o fornecimento da matriz OD semente (mesmo que uniforme), pois o programa não cria automaticamente esta matriz.

Nesta primeira iteração é considerado que a rede opere na condição de fluxo livre. Com a matriz de utilização dos arcos já definida e com os fluxos observados nos arcos, é então realizada a estimação da primeira matriz OD, conforme [2.48].

$$
\mathrm{Q}_{\mathrm{ij}}=\frac{\mathrm{N}_{a}}{\sum_{a} \frac{1}{\mathrm{Q}_{(\mathrm{E}) \mathrm{ij}}^{a}}}
$$

Em que o valor de $\mathrm{Q}_{(\mathrm{E}) \mathrm{ij}}^{a}$ é calculado conforme [2.49].

$$
\mathrm{Q}_{(\mathrm{E}) \mathrm{ij}}^{a}=\frac{\mathrm{V}_{\mathrm{obs}}^{a}}{\mathrm{~V}_{\mathrm{aloc}}^{a}} \mathbf{S}_{\mathrm{ij}}
$$


Sujeito a: Min $\left|\mathrm{V}_{\mathrm{obs}}^{a}-\mathrm{V}_{\text {aloc }}^{a}\right|$

Sendo: $\mathrm{N}_{a}$, o número de viagens realizadas pelo caminho mínimo; $\mathrm{Q}_{(\mathrm{E}) \mathrm{j}}^{a}$ expectativa de demanda entre ij que passam pelo $\operatorname{arco} a$; e $\mathrm{V}_{\text {aloc }}^{a}$ o fluxo alocado ao $\operatorname{arco} a \cdot \mathrm{Q}_{\mathrm{ij}}, \mathrm{V}_{\mathrm{obs}}^{a}$ e $\mathrm{s}_{\mathrm{ij}}$, foram definidos anteriormente.

A matriz $Q_{i j}$ será alocada à rede, não mais considerando que opere em regime fluxo livre. Neste caso, é considerada a função de impedância do método do BPR (1964), após definidos os novos caminhos haverá estimação de próxima matriz de viagens.

Este processo iterativo continua até que o número de iterações se complete ou até que a diferença entre a matriz estimada na etapa (n) e a estimada na etapa (n-1) atinja o mínimo estipulado pelo usuário.

O número máximo de iterações a ser utilizado irá variar em função do critério de alocação adotado, e o valor do erro máximo é definido em função dos critérios e necessidades de cada usuário.

De acordo com Nielsen (1998), mesmo que o fluxo observado seja inconsistente, a matriz OD estimada não será afetada como ocorre em outros métodos. O método procura a cada iteração corrigir essa inconsistência e pelo equacionamento é possível notar que a matriz semente é quem tem maior impacto nos resultados estimados.

Como os dois programas que foram utilizados no desenvolvimento desta tese possuem código fechado e seus métodos de estimação fazem uso da matriz OD semente, foi estabelecido que outro produto do presente trabalho seria propor e verificar um método de estimação, cujo detalhamento está descrito no próximo Capítulo. 
A seguir, será apresentada uma revisão sobre os principais trabalhos que levam em consideração a estimação em função dos fluxos de conversão, finalizando, então, a revisão teórica dos temas estudados nesta tese.

\subsection{CONSIDERAÇÃO DOS MOVIMENTOS DE CONVERSÃO PARA ESTIMAÇÃO DA MATRIZ DE VIAGENS}

Alguns pesquisadores têm proposto métodos para estimar os fluxos de conversão, principalmente através de técnicas de alocação de tráfego dinâmicas DTA (do inglês, Dynamic Traffic Assignment), por consistir importante informação para Engenharia de Tráfego (ALIBABAI; MAHMASSANI, 2008).

Muitos desses trabalhos utilizam o termo estimação da matriz de viagens em função dos movimentos de conversão, quando na realidade a tarefa consiste em estimar o fluxo de tráfego de acordo com os movimentos de conversão permitidos no cruzamento (esquerda, reto, direita) (ALIBABAI; MAHMASSANI, 2008).

Em 1977, Turnquist sugeriu utilizar as porcentagens de conversão para auxiliar no processo de escolha da rota, trazendo maior precisão ao processo de estimação da matriz OD pois, até então, muitos autores o simplificavam considerando que cada viagem ocorria em uma única rota.

Em 1978, Gur deu início a uma série de trabalhos considerando estimação da matriz, com uma técnica similar ao que se conhece de alocação dinâmica de tráfego. Vale destacar o trabalho de Turnquist e Gur (1979), cujo método considera as porcentagens dos movimentos e impõe que o fluxo estimado mantenha a mesma proporção, mesmo que o valor total estimado seja diferente do observado. Para eles, a proposta contribui para o processo de determinação da porcentagem de utilização dos arcos pelas viagens.

O conhecimento dos fluxos de conversão também foi utilizado para estimação de matrizes quando havia falta de continuidade de fluxos de tráfego, ou seja, o total de fluxo 
que chega em determinado nó é diferente do total de fluxo que sai deste nó, desde que não constitua um ponto de origem e/ou destino de viagens. Nesta linha tem destaque o trabalho de Van Zuylen e Willumsen (1980), que consideraram o comportamento estocástico do fluxo de tráfego e a estimação ocorreu através da maximização da verossimilhança.

Para Van Zuylen e Willumsen, o fluxo de tráfego observado em determinado arco da rede segue uma distribuição de Poisson com média igual ao fluxo observado. A probabilidade de estimar um fluxo de tráfego com valor igual à média em determinada rede é expresso conforme [2.50]. O conjunto de fluxos que maximizem essa expressão seria o melhor estimador.

$\mathrm{P}=\prod_{a} \frac{\mathrm{e}^{-\mathrm{V}_{\mathrm{obs}}^{\mathrm{a}} \cdot \mathrm{V}_{\mathrm{obs}}^{a} \mathrm{~V}_{\mathrm{est}}^{a}}}{\mathrm{~V}_{\mathrm{est}}^{a} !}$

É realmente necessária a manutenção da continuidade entre fluxos? Os veículos ao trafegarem pela rede podem estacionar, podem sair de um estacionamento e entrar na rede, e isso contribui para que o fluxo que entra em determinado arco, seja diferente do fluxo que dele sai. A descontinuidade deveria ser assumida como parte do sistema e não como premissa dos modelos, como feito até então.

Cremer e Keller (1981) apresentaram um método que consegue determinar os fluxos observados a partir de sensores, incluindo suas conversões. A importância desse método está no processo de obtenção dos fluxos, que são importantes para simulação de tráfego e estimação de matrizes.

Em 1983, Bell propôs uma modificação ao modelo de estimação definido por Willunsem (1978). A idéia consistiu em inserir informação sobre os movimentos de conversão, representados na forma de pesos que auxiliam o processo de escolha da rota.

Hellinga (1994), em sua tese apresentou uma nova maneira de estimar a matriz de viagens, levando em consideração a manutenção do princípio de conservação dos fluxos 
nos nós. Bastaria saber o fluxo que entra em cada arco, bem como a porcentagem de conversão. Fazendo isso em todas as interseções, seria possível determinar a matriz de viagens, sem utilizar os expedientes de estimação da matriz de viagens (HELLINGA, 1994).

Este problema pode ser expresso matematicamente conforme [2.51].

$$
\mathrm{V}_{\mathrm{obs}}^{\mathrm{kS}}=\sum_{\mathrm{x}}\left(\mathrm{p}_{\mathrm{x}}^{\mathrm{k}} \cdot \mathrm{V}_{\mathrm{obs}}^{\mathrm{xE}}\right)
$$

Sendo, $V_{o b s}^{k S}$ o fluxo observado que sai do arco $k ; p_{x}^{k}$ proporção de fluxo que entra no $\operatorname{arco} x$ e sai no arco k; $V_{o b s}^{x E}$ fluxo observado que entra no arco $x$.

Para Hellinga (1994), se a continuidade de fluxo existir, existirá ao menos uma solução exata. Ainda assim, esse é um problema em que o número de incógnitas é maior que o de informações, porém mais simples de resolver, pois apenas é preciso calcular a porcentagem de conversão (HELLINGA, 1994).

Uma quantidade significativa de pesquisas sob esse enfoque foi desenvolvida, Hellinga (1994) citou os trabalhos de Jeffreys e Norman (1977), Van Zuylen (1978), Norman et al (1979), Bell (1984) e Martin e Bell (1992).

Bar-Gera et al (2005) propuseram um método baseado em um modelo Markoviano para representar os fluxos de tráfego, seguindo a lógica ITP (do inglês Independent Turning Probalities). Essa técnica foi desenvolvida para alocação do tráfego e alguns estudos tentaram adaptá-la no processo de estimação da matriz OD.

Esse método cria derivações no fluxo observado, definindo, assim, a quantidade de fluxo em cada movimento (esquerda, reto e direita). Alguns programas de simulação utilizam essa lógica ITP, com destaque para: CORSIM, VISSIM, AIMSUN e TRANSYT. O objetivo é permitir que as viagens sejam realizadas seguindo rotas eficientes e menos onerosas; para isso elas acabam por ser distribuídas ao longo de vários caminhos. 
O ITP define as rotas de forma cíclica, primeiro calcula a probabilidade de o arco fazer parte da rota, utilizando uma cadeia de Markov; depois define o valor para $p_{i j}$ de transição, levando também em consideração os possíveis fluxos de conversão e, por fim, estima a matriz OD de acordo com o fluxo alocado.

Essa proposta de Bar-Gera et al (2005) revelou ser inviável e, conforme eles mesmo concluíram, quanto maior a quantidade de arcos, piores são os resultados.

Recentemente, Alibabai e Mahmassani (2008) propuseram um método para estimação da matriz OD dinâmica, baseado na alocação dinâmica de tráfego. O método consiste em um processo iterativo bi-nível, cuja principal proposta seria minimizar uma função objetivo ponderada entre diferença quadrática do fluxo estimado e do fluxo observado e diferença quadrática entre a matriz estimada e a semente, conforme [2.52].

$\min F=(1-w) \cdot \sum_{a}\left(p_{i j}^{a} \cdot Q_{i j}-V_{o b s}^{a}\right)^{2}+(w) \cdot \sum_{i j}\left(Q_{i j}-s_{i j}\right)^{2}$

na qual w é o valor do peso a ser obtido iterativamente; $\mathrm{p}_{\mathrm{ij}}^{a}$ é a porcentagem de utilização do $\operatorname{arco} a$ pela viagem ij; e $\mathrm{s}_{\mathrm{ij}}$ a viagem semente.

Os pesos para a ponderação seriam adotados a partir de um processo iterativo capaz de gerar melhor resultado (ALIBABAI; MAHMASSANI, 2008). O método leva em consideração a porcentagem de cada viagem que utilizou determinado arco em função do movimento de conversão (ALIBABAI; MAHMASSANI, 2008).

A crítica a tal idéia é que ao considerar uma função objetivo que combina o desvio do fluxo do arco e o desvio da demanda, são combinados conceitos diferentes. Além disso, conforme a proposta apresentada, os pesos tendem a incidir mais sobre a demanda. Dessa forma, quanto maior a diferença entre a demanda maior será o valor de F. Somado a isso, vale lembrar que a função objetivo não foi formulada de acordo com um conjunto de 
restrições, como os próprios autores afirmaram, o que cria o problema de não saber se a matriz estimada é, de fato, a esperada.

Aparentemente Alibabai e Mahmassani unificaram os trabalhos de Cascetta (1984) minimização da diferença quadrática entre fluxo estimado e fluxo observado - e de Le Blanc e Farhangian (1982) - minimização da diferença quadrática entre a matriz OD estimada e a matriz OD semente - e atribuíram pesos a cada procedimento.

Quanto aos trabalhos que consideram movimentos de conversão é possível afirmar que a grande maioria foi desenvolvida para alocação e escolha da rota, visando resolução de procedimentos dinâmicos, como programação de semáforos atuados pelo tráfego, e para manutenção da continuidade entre os fluxos que entram e saem de determinado arco.

A maioria dos modelos de estimação desenvolvida não usa os movimentos de conversão pois, na opinião de seus autores, tais fluxos são mais difíceis de serem obtidos que os fluxos nos arcos. Via de regra, é necessário mais de um observador na interseção para contar os fluxos, ou um trabalho de equivalência caso existam detectores de tráfego o que dificulta o uso desse tipo de informação (BELL, 1991). Em alguns trabalhos, como no de Hellinga (1994) e Alibabai e Mahmassani (2008), os fluxos de conversão passaram a ser utilizados em conjunto com o processo de estimação, todavia não obtiveram melhorias significativas a ponto de se tornar uma regra no processo de estimação, pois a grande maioria das pesquisas continua a considerar o fluxo observado nos arcos como constituinte do conjunto de restrições.

A utilização de informações referentes ao movimento de conversão no processo de estimação da matriz OD poderá trazer benefícios, entretanto alguns paradigmas devem ser alterados. Por exemplo, não limitar essa informação apenas para a continuidade de fluxo nos nós. É preciso ter uma proposta menos limitada e que incida diretamente no processo de estimação. Basta considerar que para cada fluxo observado haverá uma informação 
adicional, referente ao caminho que ele irá escolher. Considere o exemplo apresentado na Figura 2. 5.

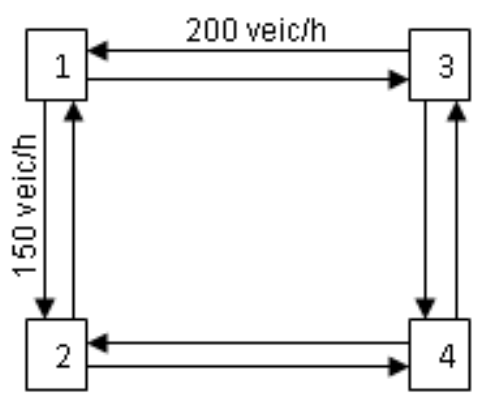

(a)

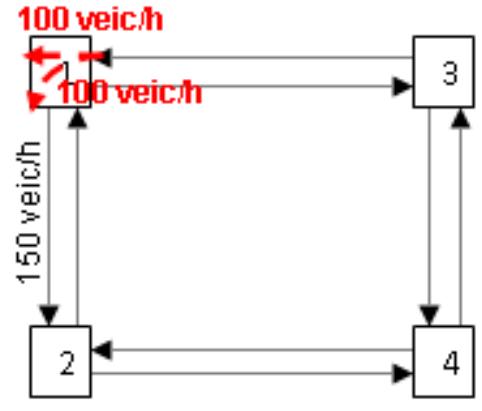

(b)

Figura 2. 5: (a) fluxos observados nos arcos; (b) fluxos observados nos nós

Quando forem realizadas apenas contagens nos arcos (Figura 2. 5 (a)) seria possível dizer que 200 veículos que passam pelo arco com início em 3 e final em 1 têm por destino o nó 1 , ou que 150 terão como destino o nó 1 e os 50 restantes seguirão viagem pelo arco com início em 1 e final em 2, por exemplo. Mas há diversas outras possibilidades que satisfazem esse problema.

Quando a contagem é realizada no nó (Figura 2. 5 (b)) é possível saber que 100 veículos observados no arco com início em 3 e final em 1 têm por destino o nó 1 e o restante segue viagem pelo arco com origem em 1 e final em 2, além disso, 50 viagens são produzidas pelo nó 1 . De certa forma houve redução na indeterminação.

No próximo capítulo será apresentado o detalhamento do método que leva em consideração os fluxos observados nos nós, conforme o movimento de conversão, para estimação da matriz OD, que constitui a proposta desta tese. 


\title{
CAPÍTULO 3 \\ DETALHAMENTO DA PROPOSTA
}

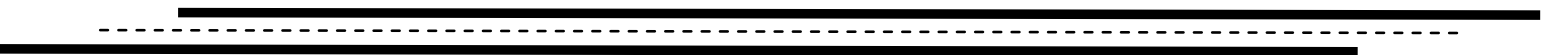

\begin{abstract}
Este capitulo apresenta o detalhamento da proposta elaborada para atingir os objetivos da tese. Está dividido em três partes: (1) Considerações iniciais; (2) Formulação da proposta; e (3) Detalhamento do experimento.
\end{abstract}

\subsection{CONSIDERAÇÕES INICIAIS}

A meta deste trabalho é propor e verificar se a contagem de tráfego nas interseções, ao invés de contagem de tráfego somente nos arcos, reduz significativamente a indeterminação e faz com que a matriz estimada seja mais precisa. Para tanto, no presente capítulo será descrito o método proposto para atingir os objetivos desta pesquisa.

O detalhamento da proposta está dividido em duas etapas, na primeira etapa será apresentada a formulação que, por sua vez, também será dividida em duas partes: (i) descrição matemática da proposta de consideração dos fluxos de tráfego observados nas interseções para estimação da matriz OD sintética; (ii) descrição matemática do método de estimação da matriz OD em função do método de médias sucessivas. Posteriormente será descrito o procedimento para verificar o desempenho da proposta. O fluxograma apresentado na Figura 3.1 sintetiza as tarefas desenvolvidas ao longo desta tese. 


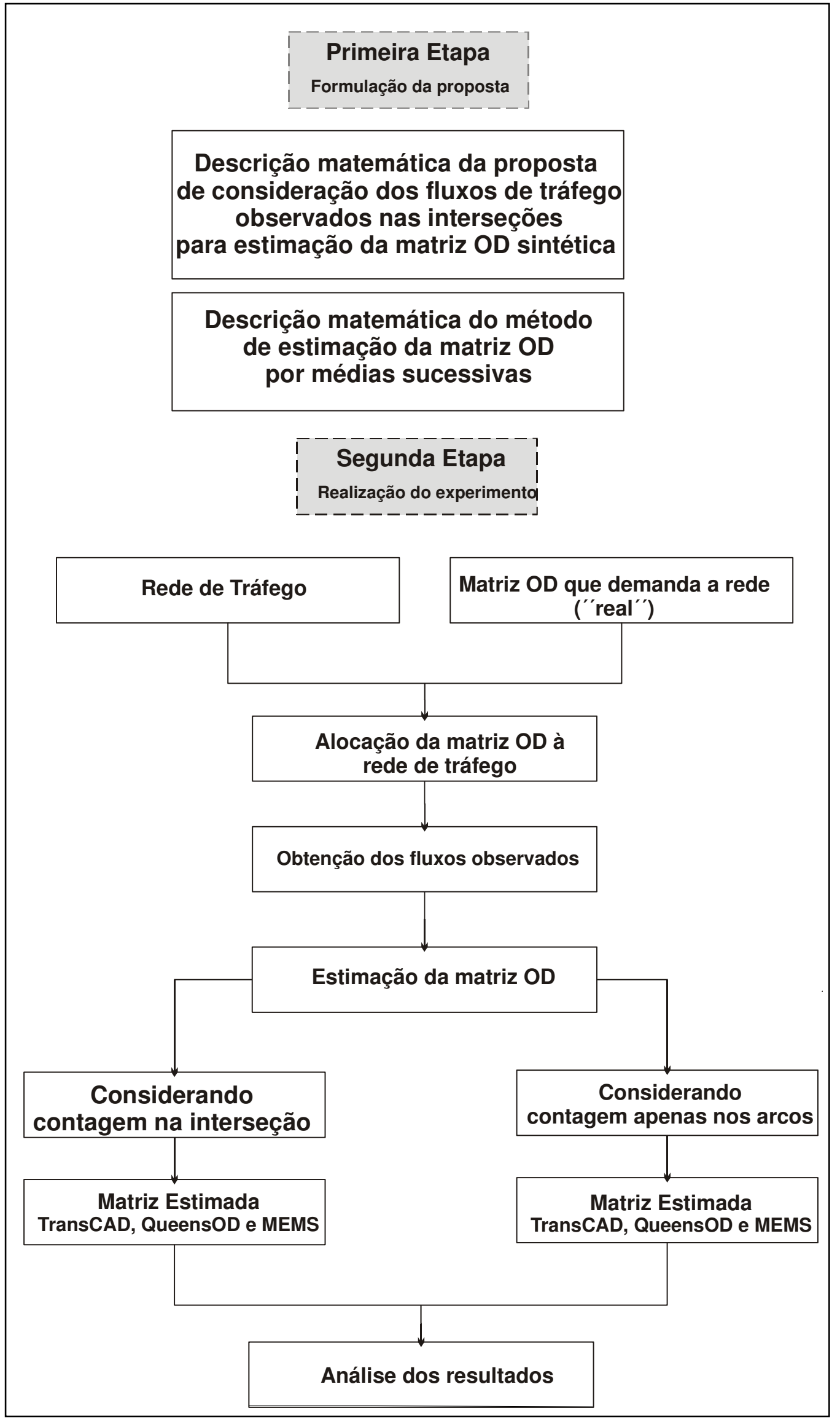

Figura 3. 1: Fluxograma do detalhamento da proposta elaborado para atingir os objetivos da pesquisa 


\subsection{PRIMEIRA ETAPA: FORMULAÇÃO DA PROPOSTA}

\subsubsection{Descrição matemática da proposta de consideração dos fluxos de tráfego observados nas interseções para estimação da matriz OD sintética}

Considere $\mathrm{Rd}(\mathrm{N}, \mathrm{A})$ uma rede de transporte composta por um conjunto $\mathrm{N}$ de nós e um conjunto $A$ de arcos orientados (com origem em $n_{0}$ e final em $n_{f}$ ). Considere também que $M$ representa o conjunto de movimentos possíveis em um nó $M=(e, r e, d)$ - e squerda, $\underline{\text { reto, }}$ direita.

Seja $N_{c} \subset \mathrm{N}$ o conjunto contendo nós cujos fluxos foram observados e $\mathrm{V}=\left(\mathrm{V}_{1}^{\mathrm{M}}, \mathrm{V}_{2}^{\mathrm{M}}, \ldots, \mathrm{V}_{n}^{\mathrm{M}}\right)$ o conjunto de fluxos observados no nó $n \in N_{C}$, conforme o movimento (M).

Os fluxos observados contidos no conjunto V serão alocados a "arcos virtuais", criados exclusivamente para essa função. De acordo com Martin (1995), Glover et al (1977) propuseram o uso de nós e arcos artificiais para facilitar a obtenção de respostas da programação linear desenvolvida para estimar os fluxos de conversão em interseções: tal informação seria utilizada para controle de tráfego. Os nós e arcos artificiais servem para dar suporte a alguma função a ser realizada e não interferem no comportamento da rede; vale mencionar que para Glover et al (1977) a capacidade desses arcos seria infinita.

A idéia, no presente trabalho, ao fazer uso de "arcos virtuais" é permitir que possam ser utilizados programas de estimação que não foram desenvolvidos para estimação da matriz de viagens levando em consideração fluxos observados de acordo com os movimentos nos nós.

Portanto haverá um "arco virtual" para receber o fluxo que faz conversão à esquerda, outro que corresponderá ao fluxo que faz movimento reto e outro para conversão à direita, conforme os movimentos permitidos na interseção. 
Assim, $L=\left(a v_{1}, a v_{2}, \ldots, a v_{a}\right)$ é o conjunto de arcos virtuais que receberão os fluxos observados conforme movimento. Como recurso auxiliar, será criado o conjunto $Y=\left(I_{1}, I_{2}\right.$, $\ldots, I_{n}$ ) de nós auxiliares que darão a direção de cada arco pertencente a $L$. Assim, um "arco virtual" com origem no nó auxiliar $k$ e final no nó auxiliar $m$ é definido como $\operatorname{av}_{a}\left(l_{k}, I_{m}\right)$, mas um "arco virtual" também pode ter como origem um nó real e terminar em um "nó virtual", ou vice-versa.

Dessa forma, O representa o conjunto de todos os arcos da rede $\mathrm{R}$ (reais e virtuais), tal que $O \equiv(A ; L)$.

Conhecidos os valores dos fluxos observados nos arcos $(a)$ pertencentes ao conjunto $O$ da rede e as rotas utilizadas para as viagens, é válido afirmar que a relação entre as demandas que utilizam um dado arco $\left(\mathrm{p}_{\mathrm{ij}}^{a} \cdot \mathrm{Q}_{\mathrm{ij}}\right)$ e o fluxo observado neste arco $\left(\mathrm{V}_{\mathrm{obs}}^{a}\right)$ é expressa como:

$\mathrm{V}_{\mathrm{obs}}^{a}=\sum_{\mathrm{ij}} \mathrm{p}_{\mathrm{ij}}^{a} \cdot \mathrm{Q}_{\mathrm{ij}} \quad a \in O$

Pode ser afirmado que o fluxo de tráfego que passa pelo arco $a \in \mathrm{A}$, com nó inicial $\mathrm{n}_{\mathrm{o}}$ e final $\mathrm{n}_{\mathrm{f}}\left(\mathrm{n}_{\mathrm{f}} \in N_{c}\right)$, é dado pela soma dos fluxos observados no nó $\mathrm{n}_{\mathrm{f}}$ pertencente a $\mathrm{V}$ :

$$
\mathrm{V}_{\mathrm{obs}}^{a\left(\mathrm{n}_{\mathrm{o}}, \mathrm{n}_{\mathrm{f}}\right)}=\mathrm{V}_{\mathrm{n}_{\mathrm{f}}}^{\mathrm{e}}+\mathrm{V}_{\mathrm{n}_{\mathrm{f}}}^{\mathrm{re}}+\mathrm{V}_{\mathrm{n}_{\mathrm{f}}}^{d}
$$

Assim, o fluxo observado nos arcos pertencentes ao conjunto A, caso a contagem tenha sido realizada no nó, poderá ser representado por:

$$
\mathrm{V}_{\mathrm{obs}}^{a\left(\mathrm{n}_{\mathrm{o}}, \mathrm{n}_{\mathrm{f}}\right)}=\sum_{\mathrm{M}} \mathrm{V}_{\mathrm{n}_{\mathrm{f}}}^{\mathrm{M}}
$$

Os fluxos $Q_{i j}$ podem ser estimados pelo princípio da maximização da entropia, bastando obter a solução para o problema de maximização do tipo: 
Maximizar $\sum_{\mathrm{i}, \mathrm{j}}\left(-\mathrm{Q}_{\mathrm{ij}} \cdot \ln \mathrm{Q}_{\mathrm{ij}}+\mathrm{Q}_{\mathrm{ij}}\right)$, sujeito a [3.1]

Teoricamente as vantagens da proposta são: (i) aumento na quantidade de informação de fluxo; (ii) a idéia poderá ser utilizada por qualquer programa comercial de estimação.

\subsubsection{Descrição matemática do método de estimação da matriz OD por médias sucessivas}

Entre um determinado par OD (ij) há certo número de rotas possíveis (r). Cada rota é formada por um conjunto de arcos orientados contidos em $O$. Cada arco tem associado um custo para percorrê-lo; assim, o custo para percorrer determinada rota é dado pela soma dos custos para percorrer cada um dos arcos que a constituem.

Supondo-se o custo para percorrer $a \in O$ seja dado apenas pelo tempo de viagem, então o tempo mínimo de percurso $\left(T_{\mathrm{ij}}^{\mathrm{min}}\right)$ entre i e j pelo caminho de custo mínimo $\left(\mathrm{r}_{\mathrm{ij}}^{\mathrm{min}}\right)$ $\left[\mathrm{r}_{\mathrm{ij}}^{\min }=\min \left(\mathrm{R}_{\mathrm{ij}}\right)\right]-$ onde $\mathrm{R}_{\mathrm{ij}} \subset O$ representa o conjunto de caminhos alternativos de i para $\mathrm{j}-$ é a soma dos tempos nos arcos $a \in \mathrm{R}_{\mathrm{ij}}$ que compõem o caminho mínimo, ou seja:

$\mathrm{T}_{\mathrm{ij}}^{\min }=\sum_{a \in \mathrm{c}_{\mathrm{ij}}^{\min }} \mathrm{t}_{a}$

em que,

$\mathrm{t}_{a}=\mathrm{t}_{a}\left(\mathrm{~V}_{a}, \mathrm{C}_{a}\right)$ : é o tempo de viagem no arco $a$, dependente da relação entre fluxo e capacidade do arco;

$\mathrm{V}_{a}$ : é o fluxo no arco orientado $a$;

$\mathrm{C}_{a}$ : é a capacidade do arco orientado $a$. 
Na primeira etapa $(k=1)$, os tempos de percurso nos arcos são calculados para condição de fluxo livre e permitem encontrar os caminhos mínimos entre ij. Para se obter a primeira matriz $\mathrm{OD}\left(\mathrm{Q}_{1}\right)$, é utilizado o princípio da maximização da entropia, supondo que todas as viagens sejam feitas pelo caminho mínimo, isto é: se o arco $a$ integra o conjunto de caminhos de custo mínimo e os fluxos $\mathrm{Q}_{\mathrm{ij}}$ utilizam esse arco, $\mathrm{p}_{\mathrm{ij}}^{a^{\mathrm{K}}}=1$; senão $\mathrm{p}_{\mathrm{ij}}^{a^{k}}=0$.

$\mathrm{Na}$ segunda etapa $(\mathrm{k}=2)$, é preciso corrigir o(s) erro(s) proveniente(s) de um carregamento excessivo. Para isso, devem ser calculados os tempos de viagem nos arcos da rede, considerando os carregamentos da primeira etapa. Assim, é obtida a matriz auxiliar $Q_{2}$, em função dos caminhos mínimos estabelecidos após a primeira etapa e das contagens realizadas nos arcos. $A$ matriz $Q_{2}$ também é estimada pelo princípio da maximização da entropia.

A partir das matrizes $Q_{1}$ e $Q_{2}$ é obtida uma terceira matriz, que corresponde à média ponderada com peso $\left(1-\phi_{2}\right)$ e $\phi_{2}$, respectivamente. Esta média equivale a subtrair da matriz $Q_{1}$ uma parcela $\phi_{2} \cdot Q_{1}$ e somar outra parcela $\phi_{2} \cdot Q_{2}$. Ao reduzir a matriz $Q_{1}$, indiretamente são reduzidos os fluxos resultantes nos caminhos mínimos da primeira etapa $(k=1)$ e, ao somar a parcela $\phi_{2} \cdot Q_{2}$, são adicionados fluxos nos caminhos mínimos da segunda etapa $(k=2)$. Ou seja, de certa forma é transferida uma parte do fluxo $Q_{i j}$ do caminho mínimo da primeira etapa para o caminho mínimo da segunda etapa.

No caso de a rede não estar congestionada, o caminho mínimo da primeira etapa coincide com o caminho mínimo da segunda etapa e, portanto, a parcela de fluxo extraída de um caminho será devolvida ao mesmo caminho.

Vale lembrar que nem sempre a parcela subtraída é igual à parcela adicionada, pois em redes congestionadas, $Q_{1}$ é geralmente diferente de $Q_{2}$. 
Genericamente, na k-ésima etapa a subtração e o acréscimo podem ser feitos de acordo com fator de ponderação $\phi_{k} \quad\left(0 \leq \phi_{k} \leq 1\right)$, calculado em função da etapa (k) como segue:

$\phi_{\mathrm{k}}=\frac{1}{\mathrm{k}}$

Assim, a matriz OD média será definida como:

$\overline{\mathrm{Q}}_{\mathrm{k}}=\left(1-\phi_{\mathrm{k}}\right) \cdot \overline{\mathrm{Q}}_{\mathrm{k}-1}+\phi_{\mathrm{k}} \cdot \mathrm{Q}_{\mathrm{k}}$

$\overline{\mathrm{Q}}_{\mathrm{k}}$ corresponde à matriz média de viagens estimada na etapa $\mathrm{k}$.

Desta forma:

$\overline{\mathrm{Q}}_{1}=\mathrm{Q}_{1}$

$\overline{\mathrm{Q}}_{2}=\left(1-\phi_{2}\right) \cdot \overline{\mathrm{Q}}_{1}+\phi_{2} \cdot \mathrm{Q}_{2}$

$\overline{\mathrm{Q}}_{3}=\left(1-\phi_{3}\right) \cdot \overline{\mathrm{Q}}_{2}+\phi_{3} \cdot \mathrm{Q}_{3}$

Adotando:

$\phi_{\mathrm{k}}^{\prime}=\left(1-\phi_{\mathrm{k}}\right)$

Têm-se:

$\phi_{\mathrm{k}}^{\prime} \cdot \phi_{\mathrm{k}-1}^{\prime} \cdots \phi_{2}^{\prime} \cdot \overline{\mathrm{Q}}_{1}=\phi_{\mathrm{k}}^{\prime} \cdot \phi_{\mathrm{k}-1}^{\prime} \cdots \phi_{2}^{\prime} \cdot \mathrm{Q}_{1}$

$\phi_{\mathrm{k}}^{\prime} \cdot \phi_{\mathrm{k}-1}^{\prime} \cdots \phi_{3}^{\prime} \cdot \overline{\mathrm{Q}}_{2}=\phi_{\mathrm{k}}^{\prime} \cdot \phi_{\mathrm{k}-1}^{\prime} \cdots \phi_{2}^{\prime} \cdot \overline{\mathrm{Q}}_{1}+\phi_{\mathrm{k}}^{\prime} \cdot \phi_{\mathrm{k}-1}^{\prime} \cdots \phi_{3}^{\prime} \cdot\left(1-\phi_{2}^{\prime}\right) \cdot \mathrm{Q}_{2}$

$\phi_{\mathrm{k}}^{\prime} \cdot \phi_{\mathrm{k}-1}^{\prime} \cdots \phi_{4}^{\prime} \cdot \overline{\mathrm{Q}}_{3}=\phi_{\mathrm{k}}^{\prime} \cdot \phi_{\mathrm{k}-1}^{\prime} \cdots \phi_{3}^{\prime} \cdot \overline{\mathrm{Q}}_{2}+\phi_{\mathrm{k}}^{\prime} \cdot \phi_{\mathrm{k}-1}^{\prime} \cdots \phi_{4}^{\prime} \cdot\left(1-\phi_{3}^{\prime}\right) \cdot \mathrm{Q}_{3}$ 
$\phi_{\mathrm{k}}^{\prime} \cdot \phi_{\mathrm{k}-1}^{\prime} \cdots \phi_{5}^{\prime} \cdot \overline{\mathrm{Q}}_{4}=\phi_{\mathrm{k}}^{\prime} \cdot \phi_{\mathrm{k}-1}^{\prime} \cdots \phi_{4}^{\prime} \cdot \overline{\mathrm{Q}}_{3}+\phi_{\mathrm{k}}^{\prime} \cdot \phi_{\mathrm{k}-1}^{\prime} \cdots \phi_{5}^{\prime} \cdot\left(1-\phi_{4}^{\prime}\right) \cdot \mathrm{Q}_{4}$

$\phi_{\mathrm{K}}^{\prime} \cdot \overline{\mathrm{Q}}_{\mathrm{K}-1}=\phi_{\mathrm{K}}^{\prime} \cdot \phi_{\mathrm{K}-1}^{\prime} \cdot \overline{\mathrm{Q}}_{\mathrm{K}-2}+\phi_{\mathrm{K}}^{\prime} \cdot\left(1-\phi_{\mathrm{K}-1}^{\prime}\right) \cdot \mathrm{Q}_{\mathrm{K}-1}$

$\overline{\mathrm{Q}}_{\mathrm{k}}=\phi_{\mathrm{k}}^{\prime} \cdot \overline{\mathrm{Q}}_{\mathrm{k}-1}+\left(1-\phi_{\mathrm{k}}^{\prime}\right) \cdot \mathrm{Q}_{\mathrm{k}}$

Fazendo o somatório membro a membro obtêm-se a expressão [3.10]:

$\bar{Q}_{k}=\prod_{n=2}^{k} \phi_{n}^{\prime} \cdot Q_{1}+\prod_{n=3}^{k} \phi_{n}^{\prime} \cdot\left(1-\phi_{2}^{\prime}\right) \cdot Q_{2}+\ldots+\prod_{n=k-1}^{k} \phi_{n}^{\prime} \cdot\left(1-\phi_{k-2}^{\prime}\right) \cdot Q_{k-2}+\prod_{n=k}^{k} \phi_{n}^{\prime} \cdot\left(1-\phi_{k-1}^{\prime}\right) \cdot Q_{k-1}$ [3.10] $+\left(1-\phi_{\mathrm{k}}^{\prime}\right) \cdot Q_{\mathrm{k}}$

Sabendo que:

\begin{tabular}{ccc}
\hline$\phi_{2}=\frac{1}{2}$ & $\longrightarrow$ & $\phi_{2}^{\prime}=\frac{1}{2}$ \\
\hline$\phi_{3}=\frac{1}{3}$ & $\longrightarrow$ & $\phi_{3}^{\prime}=\frac{2}{3}$ \\
\hline$\phi_{4}=\frac{1}{4}$ & $\longrightarrow$ & $\phi_{4}^{\prime}=\frac{3}{4}$ \\
\hline$\ldots$ & & $\ldots$ \\
\hline$\phi_{n}=\frac{1}{n}$ & $\longrightarrow$ & $\phi_{n}^{\prime}=\frac{n-1}{n}$ \\
\hline
\end{tabular}

Generalizando, é possível expressar a matriz média estimada na k-ésima etapa da seguinte maneira:

$\overline{\mathrm{Q}}_{\mathrm{k}}=\frac{1}{\mathrm{k}} \cdot \sum_{\mathrm{n}=1}^{\mathrm{k}} \mathrm{Q}_{\mathrm{n}}$

A matriz estimada na k-ésima iteração é a média aritmética das matrizes estimadas em cada uma das $\mathrm{k}$ etapas consideradas.

O método descrito, denominado Método de Estimação pelas Médias Sucessivas (MEMS), garante que as viagens estimadas em cada etapa $\mathrm{k}$ utilizarão sempre os caminhos 
mínimos, distribuindo esse carregamento, a cada iteração, às demais rotas do conjunto $C_{i j}$ de acordo com uma taxa $\phi$. Na Figura 3.2 é apresentado o fluxograma do método MEMS.

Portanto, embora não haja garantia que a matriz $\bar{Q}_{k}$ estimada pelo MEMS converge para a matriz OD real, por se tratar de uma matriz obtida com um número de informações menor do que o de incógnitas, um conjunto solução é encontrado usando o expediente da maximização da entropia. A matriz resultante $\bar{Q}_{k}$ converge para uma matriz cujos elementos são expressos conforme [3.11], e, à medida que o número de informações não redundantes aumenta, a matriz estimada acerca-se cada vez mais da matriz OD real, pois a solução é, de certa forma, moldada pelas informações.

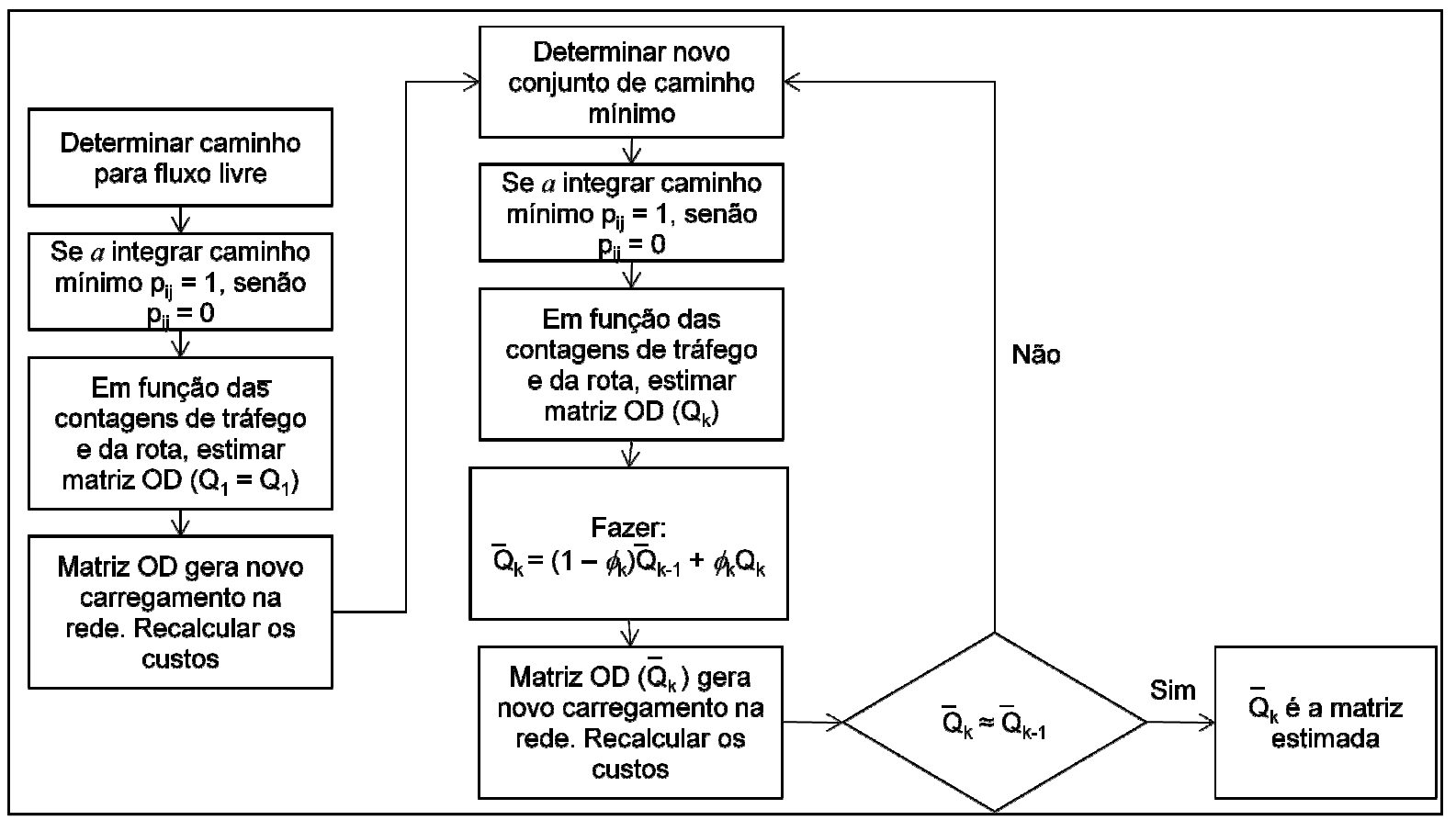

Figura 3. 2: Fluxograma do funcionamento do método MEMS

\subsection{SEGUNDA ETAPA: PROCEDIMENTO EMPREGADO PARA VERIFICAR 0 DESEMPENHO DA PROPOSTA}

Para verificar o desempenho do método proposto (Figura 3.1) foi elaborado um experimento composto pelas seguintes etapas: a) adoção de uma rede viária e de uma matriz OD que a demanda, ambas hipotéticas; b) alocação da matriz OD à rede; c) 
contagem hipotética de tráfego; d) estimação da matriz OD a partir da contagem hipotética de tráfego. Este item, por sua vez, será desmembrado em dois subitens: d1) estimação da matriz OD considerando os fluxos observados nas interseções, com a inserção dos "arcos virtuais"; d2) estimação da matriz OD considerando apenas observação de fluxos aos arcos; e e) comparação entre matrizes e análise dos resultados.

\subsubsection{Adoção de uma rede viária e de uma matriz OD que a demanda, hipotéticas}

Neste trabalho foram adotadas uma rede viária e uma matriz OD hipotéticas, sendo que a matriz contém uma quantidade elevada de viagens buscando representar uma situação de congestionamento, em geral os métodos de estimação apresentam resultados ruins quando aplicados à redes de transporte congestionadas (BELL et al, 1993). A opção por utilizar um cenário hipotético é justificada conforme os argumentos apresentados a seguir.

O modelo sintético para estimação de matriz OD a partir da contagem de tráfego é baseado na suposição que, se uma matriz OD gera fluxos nos arcos de uma rede de tráfego, então deve ser possível obter a matriz OD a partir da contagem desses fluxos nos arcos.

Assim, como a maioria dos modelos utilizados em Planejamento de Transportes e Engenharia de Tráfego, os modelos de matriz sintética também são fundamentados em premissas listadas a seguir:

- o fluxo em cada arco é contínuo: não há variação brusca de fluxo ao longo de cada $\operatorname{arco}$

- os nós estão equilibrados: a soma de todos os fluxos que chegam a um nó é igual à soma de todos os fluxos que de lá saem - desde que o referido nó não constitua par OD; 
- quando se tratar de modelo estático, o fluxo em cada arco da rede ao longo do tempo é constante; e

- a maneira como as rotas de viagem são escolhidas, pelos usuários, bem como o custo generalizado percebido pelo usuário ao utilizar determinado caminho, são previamente conhecidos.

No entanto, é sabido que essas premissas são apenas simplificações da realidade. De fato, fluxo no arco pode sofrer grandes variações se, ao longo do arco, houver escolas, supermercados, hospitais, bancos etc. Essas variações, momentos mais tarde, são observadas em cruzamentos, as quais, dependendo do método da contagem e do período de contagem, transparecem como desequilíbrios nos nós.

Portanto, a verificação da estrutura lógica e da especificação do modelo, bem como a verificação do desempenho do modelo serão enormemente facilitadas se forem efetuadas nas condições retratadas pelas premissas.

Caso essas verificações sejam efetuadas com dados reais será muito difícil afirmar se uma eventual diferença observada entre a matriz OD estimada usando o modelo e a matriz OD "real" seja devida a falhas na representação da matriz "real"; na coleta dos fluxos no arco; na estrutura lógica do modelo; na especificação do modelo; do algoritmo utilizado para o cálculo numérico; na especificação da técnica utilizada para definição dos caminhos; na concepção de como o custo para utilizar um caminho é percebido pelo usuário; ou ao excesso na simplificação das hipóteses, entre muitas outras possibilidades.

Ao utilizar uma rede de transportes hipotética, bem como uma matriz OD hipotética na verificação do desempenho do modelo, é possível eliminar os problemas de falta de continuidade de fluxo nos arcos, de comum ocorrência quando contagens são realizadas in loco, que podem acarretar má estimação da matriz OD. Também fica garantido que os fluxos alocados representarão a matriz OD "real"; ao fazer o processo inverso, é esperado 
que a matriz estimada retorne a matriz "real", desde que o número de incógnitas seja igual ao de informações.

Outra vantagem do uso de uma rede viária hipotética, e da sua respectiva matriz OD, é que o método para escolha da rota utilizado para obtenção dos fluxos é igual ao adotado no processo de estimação, ou seja, não são feitas suposições que interfiram no resultado. Também são conhecidos os custos generalizados para escolha da rota.

Não significa que possíveis falhas não tenham que ser verificadas e recebam atenção em algum momento. Mas, no estágio em que o estado da arte sobre o assunto se encontra - com os modelos apresentando resultados ruins mesmo quando confrontados com casos idealizados - parece inócuo tentar compará-los com casos reais. Por isso, a adoção de uma rede viária e a matriz OD hipotéticas.

\subsubsection{Alocação da matriz OD à rede viária}

Os métodos de alocação de tráfego mais comumente encontrados na grande maioria dos programas voltados à Engenharia e ao Planejamento de Transportes são: tudo-ou-nada; estocástico; incremental; restrição de capacidade; equilíbrio do usuário; equilíbrio estocástico do usuário; e otimização do sistema.

Alguns métodos, por exemplo, o de alocação tudo-ou-nada, ignoram o fato de o tempo de viagem em um arco depender da possível variação do fluxo, ao longo do tempo, nele observado.

Em contrapartida, os métodos baseados na teoria do equilíbrio (WARDROP, 1952) buscam, de alguma forma, fazer com que a alocação do tráfego siga uma tendência mais realista, procurando representar a variação do fluxo ao longo do tempo. Em suma, estes métodos consideram que o tempo de viagem seja dependente do fluxo observado no arco e procuram fazer com que sejam equivalentes os tempos de viagem, pelos caminhos utilizados para ir de uma origem para um destino. Atualmente os métodos baseados no 
equilíbrio dividem-se em dois conjuntos, os que consideram equilíbrio do usuário e os que usam o equilíbrio estocástico do usuário (ORTÚZAR; WILLUMSEN, 1994).

O equilíbrio do usuário possui como princípio o fato que todo usuário tenha conhecimento prévio dos caminhos e alternativas da rede em estudo e que sempre escolha a rota que minimiza os custos de viagem (Ex.: tempo, monetário etc). O primeiro a propor este princípio foi Wardrop (1952), segundo o qual, um viajante não poderia individualmente possuir o menor custo de viagem em um caminho.

Devido aos problemas causados pelos métodos do tudo-ou-nada e de equilíbrio quando se deseja alocar um fluxo elevado a um arco com baixa capacidade - possivelmente o fluxo acaba não sendo devidamente alocado - foram desenvolvidos algoritmos de alocação iterativos (ORTÚZAR E WILLUMSEN, 1999).

Entre esses algoritmos o método de alocação pelas médias sucessivas, proposto por Sheffi (1984), é o que gera melhores resultados; aos fluxos alocados por esse método são verificadas as condições de equilíbrio (ORTÚZAR; WILLUMSEN, 1999).

Tal processo, matematicamente expresso conforme [3.12], leva em consideração uma combinação de fluxos, a qual será calculada em função de: (i) fluxo corrente calculado em uma iteração prévia; e (ii) fluxo auxiliar, resultante de uma alocação tudo-ou-nada.

$\mathrm{V}_{\mathrm{n}}=(1-\phi) \cdot \mathrm{V}_{\mathrm{n}-1}+\phi \cdot \mathrm{F}_{\mathrm{a}}$

em que $V_{n}$ é o fluxo corrente alocado na iteração $n$; $\phi$ é o fator de ajuste para corrigir o conjunto de fluxos alocados; $V_{n-1}$ é o conjunto de fluxos alocados na etapa anterior; $F_{a}$ é o fluxo auxiliar, obtido pela alocação tudo-ou-nada da matriz OD aos caminhos de custo mínimo na etapa (n), sendo que o custo deve ser corrigido em função do carregamento resultante da etapa anterior $(n-1)$. 
Sheffi (1984) afirma que se os fluxos forem alocados de acordo com o tudo-ou-nada, os resultados tendem a convergir ao correto equilíbrio do usuário mesmo que a média móvel não seja otimizada, desde que $\phi=1 / \mathrm{n}$. Entretanto, essa convergência é mais lenta que a obtida utilizando processos convexos, probit ou logit, para determinar a probabilidade da escolha da rota (SHEFFI, 1984). O inconveniente de utilizar modelos convexos consiste na necessidade de sua calibração (SHEFFI, 1984).

Neste trabalho foram consideradas duas alocações: (i) equilíbrio do usuário, cujos fluxos serão utilizados em testes envolvendo os métodos de estimação dos programas comerciais, que são baseados no equilíbrio; (ii) médias sucessivas, que foi utilizada quando a estimação for feita pelo método proposto (MEMS). Evita-se, assim, qualquer tipo de interferência nos métodos estudados.

\subsubsection{Contagem hipotética de tráfego}

Para efeito da verificação proposta, os fluxos resultantes da alocação foram considerados como se tivessem sido obtidos através da contagem. A idéia que está por trás da consideração é: se a alocação da matriz OD à rede de transportes resultou nos fluxos da rede, e se os fundamentos teóricos do modelo sintético estiverem corretos, deve ser obtida a mesma matriz OD que originou esta hipotética contagem dos fluxos - desde que a mesma relação de tempo em função de $\mathrm{V} / \mathrm{C}$ seja utilizada tanto na alocação quanto na obtenção da matriz OD a partir dos fluxos.

Aos fluxos observados são garantidas as condições referentes à continuidade e ao equilíbrio, requisitos para serem obtidos resultados de qualidade ao utilizar o método iterativo para estimação de matriz OD (YANG et al., 1992).

\subsubsection{Contagem hipotética de tráfego nas interseções}

Essa adaptação baseou-se em uma analogia com a Lei de Kirchoff para fluxo elétrico, que preconiza que a soma dos fluxos elétricos que entram em um nó deve ser igual 
a soma dos fluxos que deixam esse nó, desde que ele seja apenas de passagem. Um exemplo que ilustra o princípio da conservação dos fluxos é apresentado na Figura 3.3.

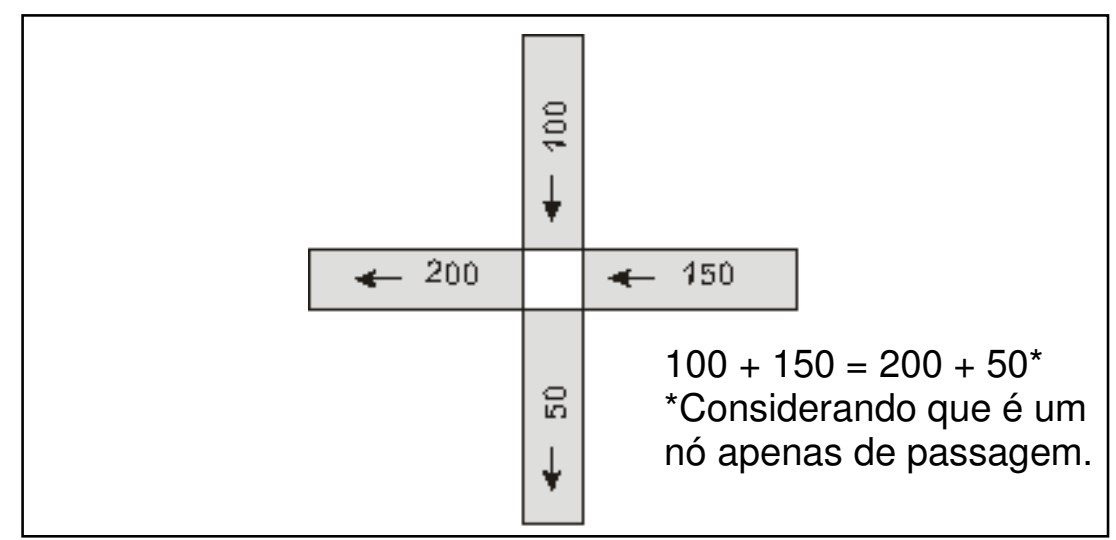

Figura 3. 3: Exemplo para ilustrar a Lei de Kirchoff

O fluxo ao final de cada arco, decomposto conforme movimento, é tomado como fluxo contado na interseção. Esse processo é feito tanto para o fluxo alocado de acordo com equilíbrio do usuário, quanto para o fluxo alocado pelas médias sucessivas.

Os fluxos observados conforme o movimento são posteriormente alocados aos respectivos "arcos virtuais". O processo adotado para inserir esses "arcos" é exemplificado na Figura 3.4.

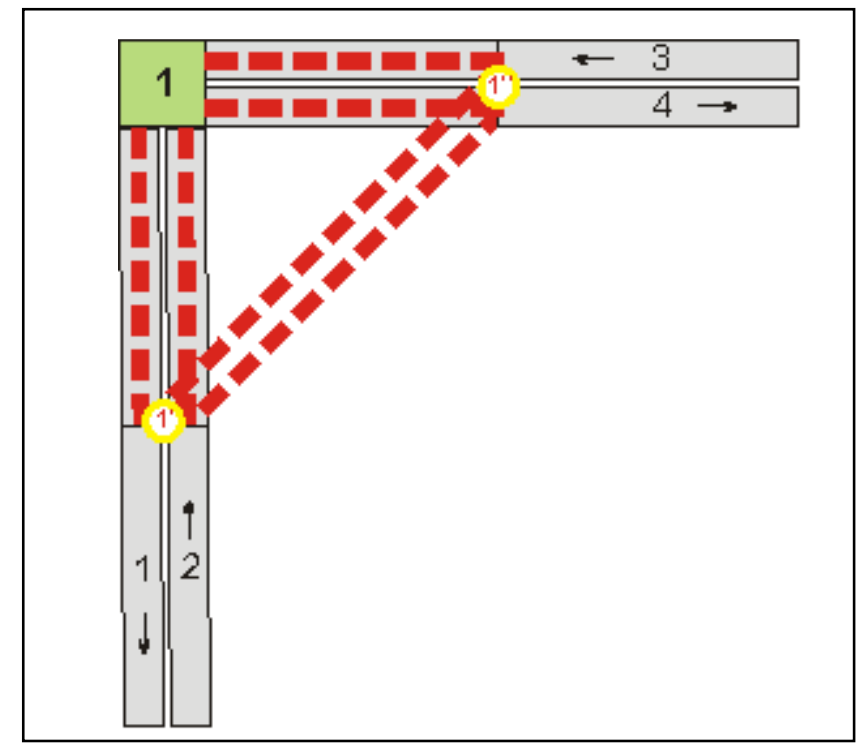

Figura 3. 4: Inserção de "arcos virtuais" 
Sabendo que no nó 1 houve contagem de tráfego, são criados nós auxiliares (1'e 1"). A ligação entre os nós será feita através de "arcos virtuais" que, na Figura 3.4, são as linhas tracejadas.

O fluxo observado no nó 1 , que passa pelo arco 3 e faz conversão à esquerda, será alocado ao "arco virtual" com início em 1" e final em 1'. Esse procedimento repete-se em toda a rede.

Vale ressaltar, que a posição dos nós auxiliares fica a critério do usuário, mas é recomendado ter atenção quanto ao comprimento mínimo dos arcos, caso utilize programas comerciais para estimação.

\subsubsection{Estimação da matriz OD em função das contagens de tráfego}

O processo de estimação da matriz OD foi dividido em duas etapas, a fim de cumprir com os objetivos propostos no trabalho: (1) estimação considerando contagem de fluxo nas interseções; e (2) estimação considerando apenas contagens nos arcos.

A estimação da matriz em cada etapa ( 1 e 2) foi realizada utilizando três métodos distintos:

(i) Estimação utilizando o QUEENSOD (QOD);

(ii) Estimação utilizando o TransCAD, considerando o equilíbrio do usuário;

(iii) Estimação utilizando o método de estimação por médias sucessivas (MEMS).

O objetivo de utilizar três métodos de estimação distintos não é apenas estabelecer comparação direta entre eles, mas sim verificar o desempenho da proposta da tese aplicada a métodos diferentes. 
3.3.4.1 Estimação utilizando os métodos embutidos nos programas TransCAD e QUEENSOD

O Departamento de Engenharia de Transportes, da Escola de Engenharia de São Carlos, da Universidade de São Paulo, possui a licença para uso acadêmico do QUEENSOD versão médio e do TransCAD versão 4.8. Os dois programas foram escolhidos, primeiro por serem os únicos que estimam matriz sintética com liberação de uso para pesquisas no Departamento e, depois, porque há o interesse de verificar o desempenho da proposta deste trabalho, quando utilizada em programas comerciais. Além disso, são pacotes mundialmente utilizados para estimação de matrizes.

Para que o QUEENSOD e o TransCAD estimem matrizes OD, é necessário que sejam estabelecidos alguns parâmetros: número de iterações; erro máximo entre o fluxo observado e o estimado; critérios a serem utilizados para minimização do erro; número de caminhos entre cada par OD; e o critério de alocação a ser utilizado. Também é necessário que uma matriz OD semente seja adotada. A seguir, são detalhados os valores dos parâmetros adotados.

- Número de iterações:

Foi estabelecida a utilização de 1.000 iterações, tanto para o QUEENSOD, quanto para o TransCAD. O motivo da escolha deveu-se ao fato deste ser o número máximo permitido para a versão disponível do QUEENSOD. Porém, caso algum critério de parada seja atingido, antes de completar as 1.000 iterações, o processo de estimação será interrompido.

- Erro máximo desejado entre a diferença dos volumes observados e estimados:

A proporção entre o fluxo estimado e o observado nos arcos constitui o segundo critério de parada para o QUEENSOD. O valor adotado para este erro foi $1 \%$. 
- Erro máximo desejado entre matriz estimada:

Para o TransCAD, um dos critérios de parada é o erro máximo entre a diferença da matriz OD estimada na iteração $(n)$ e na iteração $(n-1)$. O valor adotado para esse erro foi $1 \%$.

- Critérios adotados para minimização dos erros:

O QUEENSOD solicita que seja definido o critério para minimização dos erros. Tal critério está relacionado com a minimização do erro adotado para a estimativa das viagens e dos fluxos. Existem três opções possíveis: (i) erro quadrático (código 1); (ii) erro Poissoniano (código 2); e (iii) erro relativo (código 3). O TransCAD não requer este critério no seu método de estimação.

De acordo com Demarchi et al (2004), os melhores resultados, em termos de coeficiente de correlação entre volume observado e estimado, são obtidos quando se utiliza a combinação "31", que considera um erro relativo [3.13] para as viagens e erro quadrático [3.14] para os fluxos.

$$
\begin{aligned}
& \mathrm{ER}=\sum_{a}\left(\mathrm{~V}_{\mathrm{obs}}^{a}-\mathrm{p}_{\mathrm{ij}}^{a} \mathrm{Q}_{\mathrm{ij}}\right)^{2} \cdot \frac{1}{\mathrm{~V}_{\mathrm{obs}}^{a}} \\
& \mathrm{EQ}=\sum_{a}\left(\mathrm{~V}_{\mathrm{obs}}^{a}-\mathrm{p}_{\mathrm{ij}}^{a} \mathrm{Q}_{\mathrm{ij}}\right)^{2} \cdot 1
\end{aligned}
$$

\section{Em que,}

ER: erro relativo (código 3). Critério adotado para minimizar o erro entre a matriz semente e a estimada;

EQ: erro quadrático (código 1). Critério adotado para minimizar o erro volumétrico;

$\mathrm{V}_{\mathrm{obs}}^{a}$ : volume observado no $\operatorname{arco} a$; 
$\mathrm{p}_{\mathrm{ij}}^{a}$ : porcentagem de utilização do arco $a$ pelas viagens $\mathrm{ij}$;

$Q_{\mathrm{ij}}$ : quantidade estimada de viagem entre ij.

- Quantidade de caminhos a ser verificada a cada iteração:

O QUEENSOD requer a definição da quantidade de caminhos alternativos, entre cada par OD, que deverá ser verificada a cada iteração. Rakha et al. (1998) mencionam que o valor do coeficiente de correlação entre fluxos observados e estimados, para diferentes períodos do dia na região metropolitana de Salt Lake City nos Estados Unidos, aumentou em média 0,01 quando duas rotas para cada par OD foram consideradas, em comparação ao uso de um único conjunto de rotas. Desta maneira foi adotado, para este estudo, que o QUEENSOD poderá avaliar até 5 possibilidades de caminhos, sendo que esta é a quantidade máxima permitida pela versão disponível do programa.

Para o TransCAD, não é necessária tal informação.

- Método de alocação a ser utilizado:

O QUEENSOD trabalha primeiramente com a alocação tudo-ou-nada e, com o transcorrer das iterações, procura atingir o equilíbrio da rede. Já o TransCAD permite a escolha de até nove formas diferentes de alocação. Neste trabalho foi adotada a técnica de equilíbrio do usuário, com a função de impedância desenvolvida pelo BPR (1964).

- Matriz semente:

Três tipos de matriz semente serão utilizadas, tanto para o QUEENSOD, quanto para o TransCAD:

(a) Matriz semente unitária: em que as viagens interzonais receberão 1 e as intrazonais 0 . Esse tipo de matriz seria equivalente à situação em que não é fornecida matriz semente pois, por ser uniforme, todas as demandas terão a mesma probabilidade de 
ocorrer. Mas, como os programas dependem do fornecimento de uma matriz semente, Rakha (1998) recomenda que, na falta de uma, utilize a matriz semente uniforme;

(b) Matriz semente proporcional a $70 \%$ da matriz "real" $\left(S_{70}\right)$ : É representada por uma situação em que o crescimento ao longo do tempo das viagens entre os pares OD é constante, mantendo com isso proporcionalidade em relação à matriz atual. Usar esta matriz como semente gera condição amplamente favorável pois, além de os fluxos de tráfego refletirem os dados de viagem da matriz "real", a matriz semente apresenta uma proporcionalidade com a matriz "real" e com os fluxos observados. Uma matriz semente como esta é capaz de fornecer informação de qualidade, o que contribui para o processo de estimação. Porém, muito dificilmente há matriz OD semente como esta disponível nos municípios brasileiros, mesmo porque a taxa de crescimento não é uniforme.

(c) Matriz semente não proporcional: Como o crescimento das viagens entre os pares OD não é constante ao longo do tempo, a matriz semente disponível para os planejadores dificilmente é proporcional a "real". Foram consideradas duas matrizes deste tipo, a primeira denominada $\operatorname{Sem}_{10}$ é obtida através de uma variação aleatória (na) em torno dos valores de $S_{70}$ de até $\pm 10 \%$, o que implica em um desvio médio de $\pm 5 \%$ e a segunda, denominada $S_{20}$, terá uma variação de até $\pm 20 \%$, em torno dos valores de $S_{70}$, resultando em um desvio de $\pm 10 \%$. Essas matrizes, expressas respectivamente conforme [3.15] e [3.16], foram utilizadas apenas em três testes: no que considera contagem de fluxo em todos os nós da rede viária; no que considera apenas contagem nos arcos; e no que utiliza a opção turning movement. O objetivo é observar o efeito causado na matriz estimada, ao considerar outros tipos de matriz semente.

$$
\begin{aligned}
& \text { Sem }_{10}=\left[\frac{(0,5-n a)}{5}+1\right] \cdot S_{70} \\
& \text { Sem }_{20}=\left[\frac{(0,5-n a)}{2,5}+1\right] \cdot S_{70}
\end{aligned}
$$


3.3.4.2 Estimação considerando o método de estimação por médias sucessivas (MEMS)

O método proposto foi implementado em planilha Microsoft Excel e através do suplemento solver, é feita a maximização da entropia.

As seguintes etapas constituem o processo do MEMS:

$1^{\circ}$ ) Definir o custo para percorrer o arco na condição de fluxo livre e tomar $k=0$;

$\left.2^{\circ}\right)$ Construir o conjunto de caminhos mínimos (CM) entre cada um dos pares OD;

$\left.3^{\circ}\right)$ Fazer $\mathrm{k}=1$ : se arco $a$ fizer parte do conjunto de CM entre $\mathrm{ij}, \mathrm{p}_{\mathrm{ij}}^{a^{\mathrm{k}}}=1$; senão $\mathrm{p}_{\mathrm{ij}}^{a^{\mathrm{k}}}=0$;

$\left.4^{\circ}\right)$ Estimar a matriz OD através da maximização da entropia:

$$
Z\left(Q_{i j}\right)=\max \left[-\sum_{i j}\left(Q_{i j} \cdot \ln Q_{i j}-Q_{i j}\right)\right]
$$

Sujeito a

$$
\mathrm{V}_{\mathrm{obs}}^{\mathrm{a}}=\sum_{\mathrm{ij}} \mathrm{p}_{\mathrm{ij}}^{\mathrm{a}^{\mathrm{k}-1}} \cdot \mathrm{Q}_{\mathrm{ij}}
$$

5을 Adotar $\phi_{\mathrm{k}}=1 / \mathrm{k}$ e $\phi_{\mathrm{K}}^{\prime}=\left(1-\phi_{\mathrm{K}}\right)$

6º) Fazer a correção da matriz OD, calculando a matriz média:

$$
\overline{\mathrm{Q}}_{\mathrm{K}}=\phi_{\mathrm{K}}^{\prime} \cdot \overline{\mathrm{Q}}_{\mathrm{K}-1}+\left(1-\phi_{\mathrm{K}}^{\prime}\right) \cdot \mathrm{Q}_{\mathrm{K}}
$$

$\left.7^{\circ}\right)$ Com os novos fluxos, provenientes da matriz média, calcular os tempos nos arcos e construir o novo conjunto de caminhos mínimos;

$\left.8^{\circ}\right)$ Retornar ao passo 3, fazendo $\mathrm{k}=\mathrm{k}+1$. 
O processo deverá ser interrompido quando não houver diferenças entre a matriz estimada na etapa k-1 e a estimada na etapa k. Por se tratar de um trabalho de verificação de uma proposta e por ter sido desenvolvido um processo semi-automatizado, foi decidido que nos testes experimentais serão realizadas 250 iterações.

\section{(1) Parte A - Estimação considerando contagens nas interseções}

Foram feitos testes considerando várias configurações de cenários nos quais se realizaram as contagens em interseções, as quais permitiram analisar o efeito causado pela localização dos pontos de contagem nos resultados.

\section{(2) Parte B - Estimação considerando contagens nos arcos}

Foi realizada da maneira tradicional e tem como objetivo fornecer resultados que serviram como referência para comparação e verificação da proposta do presente trabalho.

Também foi realizado um teste, considerando apenas os programas QUEENSOD e TransCAD, no qual a matriz será estimada considerando a opção turning movement disponível em cada pacote. O objetivo é mostrar que os resultados obtidos através desta opção são diferentes dos estimados em (d1).

\subsubsection{Comparação entre matrizes e análise dos resultados}

Este item corresponde ao Capítulo 5 da presente tese. As análises serão divididas em duas partes:

(i) Análise comparativa dos resultados estimados: Permite verificar o desempenho da proposta da tese e analisar a performance do método MEMS em relação a dos programas (QUEENSOD e TransCAD), com os softwares utilizando matriz semente uniforme. As análises contemplam: 
$\Rightarrow \quad$ Análise das diferenças dos valores da matriz OD estimada a partir do fluxo observado nas interseções em relação à matriz OD "real";

$\Rightarrow \quad$ Análise comparativa das diferenças dos valores da matriz OD estimada a partir do fluxo observado nos arcos em relação à matriz OD "real".

(ii) Análise comparativa para verificar os efeitos causados pela variação da matriz semente: Além de verificar a proposta da tese, permite verificar os efeitos causados na estimação ao utilizar os programas, quando se modifica a matriz semente. Dois tipos de análise serão realizados:

$\Rightarrow \quad$ Análise das diferenças dos valores da matriz OD estimada a partir do fluxo observado nas interseções em relação à matriz OD "real";

$\Rightarrow \quad$ Análise comparativa das diferenças dos valores da matriz OD estimada a partir do fluxo observado nos arcos em relação à matriz OD "real".

Serão inicialmente apresentados os valores totais das viagens geradas pelos métodos considerados e estes serão comparados com o total de viagens geradas na situação "real".

$\mathrm{Na}$ seqüência, serão apresentados gráficos de dispersão entre os valores das viagens estimadas e os "reais", permitindo com isso observar o quão distante estão os valores estimados dos "reais". E será aplicada uma regressão a esses valores.

Posteriormente, haverá uma análise entre os valores das viagens estimadas e os valores "reais", da seguinte forma:

a) verificação das diferenças absolutas obtidas entre o valor "real" e o valor estimado [3.20], sendo feita uma análise através da média, dada pela razão entre a somatória total das diferenças absolutas pelo número total de viagens "real" [3.21]. Essa razão é denominada diferença absoluta média (DAM). 
$\left|\Delta Q_{i j}\right|=\left|Q_{i j}^{\text {real }}-Q_{i j}^{\text {est }}\right|$

$D A M=\frac{\sum_{i j}\left|\Delta Q_{i j}\right|}{Q^{\text {real }}}$

Sendo $\left|\Delta Q_{i j}\right|$ a diferença absoluta entre matriz "real" e estimada e $Q^{\text {real }}=\sum_{i j} Q_{i j}^{\text {real }} 0$ total de viagens "real".

b) verificação da diferença relativa entre as viagens. Será calculado de acordo com a equação [3.22].

$e_{r}^{Q_{i j}}=\frac{Q_{i j}^{\text {real }}-Q_{i j}^{\text {est }}}{Q_{i j}^{\text {real }}}$

Sendo,

$\Rightarrow \quad e_{r}^{Q_{i j}}:$ diferença relativa referente as viagens entre $\mathrm{ij}$;

$\Rightarrow \quad Q_{i j}^{\text {real }}$ : valor da viagem entre i e j "real"; e

$\Rightarrow \quad Q_{i j}^{\text {est }}:$ valor da viagem entre i e j estimado.

Para a comparação entre os métodos serão tomados os valores máximos, em módulo, das diferenças relativas, de forma a verificar qual o maior erro obtido em cada método. Também será feita uma análise quanto às viagens terem sido superestimadas (quando o valor estimado é superior ao "real"), ou subestimadas (quando o valor estimado é inferior ao "real"). Posteriormente, a diferença relativa será agrupada em dois tipos de freqüência: (i) absoluta: expressa o número de ocorrências dentro do intervalo considerado; (ii) acumulada: representada pela soma das freqüências relativas, até o intervalo de distribuição considerado. Será analisada a distribuição de freqüências dos erros relativos, entre os valores observados e estimados. A faixa para distribuição dos erros relativos será escolhida em função da que melhor representar a distribuição. 


\title{
CAPÍTULO 4 EXPERIMENTO
}

\author{
O capitulo traz o experimento elaborado para verificar os \\ objetivos da tese. Primeiramente é feita a descrição do experimento \\ e em seguida são detalhados os testes de verificação.
}

\subsection{DESCRIÇÃO DO EXPERIMENTO}

Os testes experimentais constituem um conjunto de etapas cujo objetivo é a obtenção dos dados necessários para que o desempenho do método proposto por este trabalho possa ser verificado. A seqüência apresentada a seguir é equivalente ao conjunto de procedimentos definidos na segunda etapa do método, com exceção das análises, que serão apresentadas no próximo capítulo.

\subsubsection{Adoção de uma rede viária e de uma matriz OD que a demanda, hipotéticas}

Considere a rede de transportes $R_{d}(N, A)$ composta por um conjunto com 9 nós $(N)$ e um conjunto com 24 arcos orientados (A) conforme apresentada na Figura 4. 1. Vale ressaltar que todos os nós são do tipo origem e destino.

Desconsiderando as viagens intrazonais, há 72 incógnitas, caso apenas uma possibilidade de caminho entre cada par OD seja considerada, e 24 informações de fluxo, provenientes das contagens nos arcos. O número de incógnitas é maior que o de informações, portanto não há garantias que a matriz estimada recupere a original. Se todas as possibilidades de caminho entre os pares OD forem consideradas, o número de incógnitas será 605. Neste experimento, apenas os caminhos com tempo de percurso até 
1,50 vezes o tempo do caminho mínimo na condição de fluxo livre foram considerados, assim a indeterminação passa a ser 139. A diferença entre o número de incógnitas e a quantidade de informação resultará no grau (ou índice) de indeterminação.

Cada arco da presente rede tem associado um tempo de viagem que varia em função da relação fluxo/capacidade (V/C) conforme equação [4.1] proposta pelo BPR (1964). No presente trabalho será suposto que este é o único custo percebido pelo usuário.

$\mathrm{t}_{a}=\mathrm{T}_{\mathrm{o}}\left(1+\alpha \cdot\left(\frac{\mathrm{V}_{\mathrm{obs}}^{a}}{\mathrm{C}_{\mathrm{ap}}^{a}}\right)^{\beta}\right)$

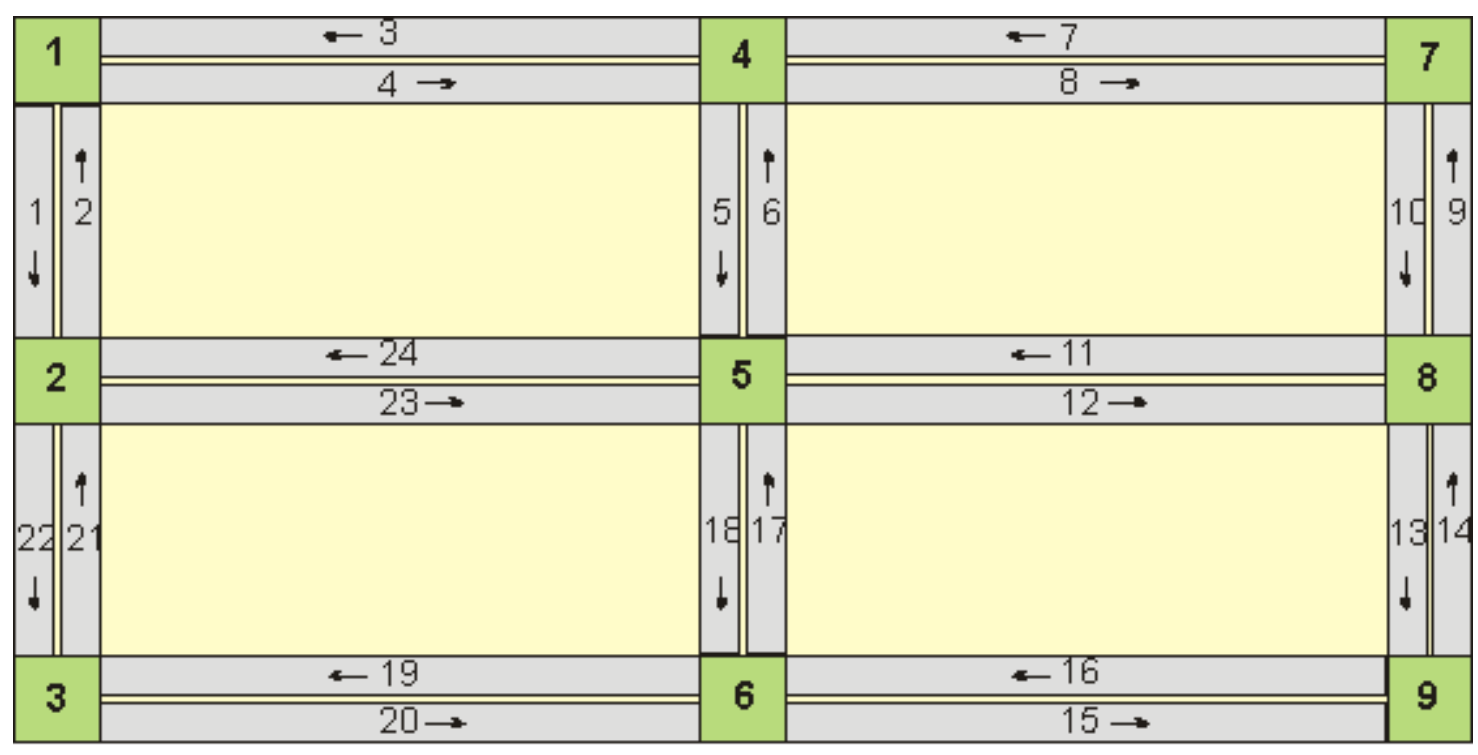

$\square$ Nó do tipo origem e destino

Figura 4. 1: Rede de transportes utilizada para os experimentos

A demanda nesta rede é dada pela matriz OD, denominada "real", apresentada na Tabela 4. 1. Esta matriz foi adotada sem qualquer critério específico, além da imposição de que contenha uma quantidade grande de viagens para simular uma rede congestionada. Ela possui dois objetivos: (i) fornecer os fluxos nos arcos da rede, os quais serão considerados como fluxos contados in loco; (ii) servir como referência na comparação das matrizes OD resultantes, o que permitiria mensurar os erros resultantes. 
Além da matriz OD "real”, é considerado que haja o conhecimento de uma matriz OD semente, obtida há cerca de 10 anos e, considerando uma taxa de crescimento igual a 2,7\% aa, tal matriz seria equivalente a $70 \%$ da matriz "real". Os valores da matriz semente $\left(S_{70}\right)$ estão na Tabela 4. 2.

Tabela 4. 1: Matriz OD "real"

\begin{tabular}{c|ccccccccc|c}
\hline O\D & $\mathbf{1}$ & $\mathbf{2}$ & $\mathbf{3}$ & $\mathbf{4}$ & $\mathbf{5}$ & $\mathbf{6}$ & $\mathbf{7}$ & $\mathbf{8}$ & $\mathbf{9}$ & $\boldsymbol{\Sigma}$ \\
\hline $\mathbf{1}$ & - & 406 & 464 & 330 & 418 & 175 & 276 & 159 & 371 & $\mathbf{2 . 5 9 9}$ \\
$\mathbf{2}$ & 204 & - & 386 & 415 & 233 & 225 & 416 & 219 & 484 & $\mathbf{2 . 5 8 2}$ \\
$\mathbf{3}$ & 176 & 377 & - & 351 & 419 & 187 & 245 & 246 & 288 & $\mathbf{2 . 2 8 9}$ \\
$\mathbf{4}$ & 334 & 203 & 309 & - & 487 & 231 & 204 & 213 & 210 & $\mathbf{2 . 1 9 1}$ \\
$\mathbf{5}$ & 337 & 414 & 246 & 184 & - & 199 & 466 & 260 & 328 & $\mathbf{2 . 4 3 4}$ \\
$\mathbf{6}$ & 455 & 462 & 226 & 371 & 311 & - & 165 & 320 & 353 & $\mathbf{2 . 6 6 3}$ \\
$\mathbf{7}$ & 407 & 428 & 179 & 172 & 347 & 451 & - & 323 & 434 & $\mathbf{2 . 7 4 1}$ \\
$\mathbf{8}$ & 284 & 282 & 275 & 359 & 475 & 265 & 401 & - & 326 & $\mathbf{2 . 6 6 7}$ \\
$\mathbf{9}$ & 444 & 268 & 364 & 350 & 476 & 477 & 310 & 298 & - & $\mathbf{2 . 9 8 7}$ \\
\hline $\boldsymbol{\Sigma}$ & $\mathbf{2 . 6 4 1}$ & $\mathbf{2 . 8 4 0}$ & $\mathbf{2 . 4 4 9}$ & $\mathbf{2 . 5 3 2}$ & $\mathbf{3 . 1 6 6}$ & $\mathbf{2 . 2 1 0}$ & $\mathbf{2 . 4 8 3}$ & $\mathbf{2 . 0 3 8}$ & $\mathbf{2 . 7 9 4}$ & $\mathbf{2 3 . 1 5 3}$ \\
\hline
\end{tabular}

Tabela 4. 2: Matrizes semente equivalente a $70 \%$ da "real" $\left(S_{70}\right)$

\begin{tabular}{c|ccccccccc|c}
\hline O\D & $\mathbf{1}$ & $\mathbf{2}$ & $\mathbf{3}$ & $\mathbf{4}$ & $\mathbf{5}$ & $\mathbf{6}$ & $\mathbf{7}$ & $\mathbf{8}$ & $\mathbf{9}$ & $\boldsymbol{\Sigma}$ \\
\hline $\mathbf{1}$ & - & 284 & 325 & 231 & 293 & 123 & 193 & 111 & 260 & $\mathbf{1 . 8 2 0}$ \\
$\mathbf{2}$ & 143 & - & 270 & 291 & 163 & 158 & 291 & 153 & 339 & $\mathbf{1 . 8 0 8}$ \\
$\mathbf{3}$ & 123 & 264 & - & 246 & 293 & 131 & 172 & 172 & 202 & $\mathbf{1 . 6 0 3}$ \\
$\mathbf{4}$ & 234 & 142 & 216 & - & 341 & 162 & 143 & 149 & 147 & $\mathbf{1 . 5 3 4}$ \\
$\mathbf{5}$ & 236 & 290 & 172 & 129 & - & 139 & 326 & 182 & 230 & $\mathbf{1 . 7 0 4}$ \\
$\mathbf{6}$ & 319 & 323 & 158 & 260 & 218 & - & 116 & 224 & 247 & $\mathbf{1 . 8 6 5}$ \\
$\mathbf{7}$ & 285 & 300 & 125 & 120 & 243 & 316 & - & 226 & 304 & $\mathbf{1 . 9 1 9}$ \\
$\mathbf{8}$ & 199 & 197 & 193 & 251 & 333 & 186 & 281 & - & 228 & $\mathbf{1 . 8 6 8}$ \\
$\mathbf{9}$ & 311 & 188 & 255 & 245 & 333 & 334 & 217 & 209 & - & $\mathbf{2 . 0 9 2}$ \\
\hline $\boldsymbol{\Sigma}$ & $\mathbf{1 . 8 5 0}$ & $\mathbf{1 . 9 8 8}$ & $\mathbf{1 . 7 1 4}$ & $\mathbf{1 . 7 7 3}$ & $\mathbf{2 . 2 1 7}$ & $\mathbf{1 . 5 4 9}$ & $\mathbf{1 . 7 3 9}$ & $\mathbf{1 . 4 2 6}$ & $\mathbf{1 . 9 5 7}$ & $\mathbf{1 6 . 2 1 3}$ \\
\hline
\end{tabular}

\subsubsection{Alocação da matriz OD à rede viária e contagem hipotética de tráfego}

Para efeito da verificação proposta, os fluxos nos arcos, resultantes da alocação, são aqui considerados como se tivessem sido obtidos através da contagem.

Para os testes utilizando os programas TransCAD e QUEENSOD, a matriz OD foi alocada utilizando o método de alocação do equilíbrio do usuário. 
Para alocação pelo equilíbrio do usuário foram utilizadas as ferramentas disponíveis no TransCAD. A função de impedância utilizada para o cálculo do custo de percurso do arco é a proposta pelo Bureau of Public Roads - BPR (BPR, 1964), que relaciona o tempo de viagem com o fluxo e com a capacidade (V/C) no arco, conforme apresentado na equação [4.1], adotando $\alpha=0,15$ e $\beta=4$. Os valores resultantes dessa alocação encontram-se na Tabela 4. 3.

Tabela 4. 3: Fluxos alocados pelo método do equilíbrio do usuário do TransCAD

\begin{tabular}{cccc|cccc}
\hline Arco & $\mathbf{V}_{\text {obs }}$ & $\mathbf{T}_{\mathbf{0}}$ & Capacidade & Arco & $\mathbf{V}_{\text {obs }}$ & $\mathbf{T}_{\mathbf{0}}$ & Capacidade \\
\hline 1 & 1.825 & 32 & 1.520 & 13 & 1.795 & 32 & 1.520 \\
2 & 1.812 & 32 & 1.520 & 14 & 1.797 & 32 & 1.520 \\
3 & 1.836 & 36 & 1.610 & 15 & 1.742 & 36 & 1.610 \\
4 & 1.781 & 36 & 1.610 & 16 & 1.933 & 36 & 1.610 \\
5 & 2.344 & 27 & 1.650 & 17 & 2.404 & 27 & 1.650 \\
6 & 2.258 & 27 & 1.650 & 18 & 2.133 & 27 & 1.650 \\
7 & 2.031 & 36 & 1.610 & 19 & 1.926 & 36 & 1.610 \\
8 & 1.550 & 36 & 1.610 & 20 & 1.552 & 36 & 1.610 \\
9 & 1.926 & 32 & 1.520 & 21 & 1.902 & 32 & 1.520 \\
10 & 1.703 & 32 & 1.520 & 22 & 1.688 & 32 & 1.520 \\
11 & 2.339 & 28 & 1.530 & 23 & 2.123 & 28 & 1.530 \\
12 & 1.931 & 28 & 1.530 & 24 & 2.155 & 28 & 1.530 \\
\hline
\end{tabular}

Para testes utilizando o método de estimação por médias sucessivas (MEMS) a alocação foi desenvolvida em uma rotina criada em planilha Microsoft Excel, que usou o método de alocação por médias sucessivas.

Foi estabelecido que o único custo percebido pelo usuário para utilizar determinado caminho seria o tempo de viagem expresso conforme BPR (1964), apresentado em [4.1], adotando $\alpha=0,15$ e $\beta=4$ e que o fator de ponderação dos fluxos utilizado no método e alocação por médias sucessivas seria o mesmo definido por Sheffi (1984) $-\phi=1 / n$.

O processo é bastante simples, bastando determinar o caminho mínimo e fazer as correções no fluxo, conforme algoritmo proposto por Sheffi (1984). Após 72 iterações não foi observada variação significativa no fluxo alocado, então, de acordo com os critérios de parada apresentados no algoritmo, as iterações foram interrompidas e o resultado obtido está apresentado na Tabela 4. 4. 
É interessante observar que não houve variações significativas nos fluxos alocados pelo TransCAD e pelo método das médias sucessivas, sendo que as maiores diferenças foram observadas nos arcos 5 e 18. Nas duas situações os fluxos refletem as condições de equilíbrio.

Tabela 4. 4: Fluxos alocados aos arcos pelo método das médias sucessivas

\begin{tabular}{cccc|cccc}
\hline Arco & $\mathbf{V}_{\text {obs }}$ & $\mathbf{T}_{\mathbf{0}}$ & Capacidade & Arco & $\mathbf{V}_{\text {obs }}$ & $\mathbf{T}_{\mathbf{0}}$ & Capacidade \\
\hline 1 & 1.831 & 32 & 1.520 & 13 & 1.788 & 32 & 1.520 \\
2 & 1.779 & 32 & 1.520 & 14 & 1.789 & 32 & 1.520 \\
3 & 1.834 & 36 & 1.610 & 15 & 1.732 & 36 & 1.610 \\
4 & 1.739 & 36 & 1.610 & 16 & 1.924 & 36 & 1.610 \\
5 & 2.279 & 27 & 1.650 & 17 & 2.397 & 27 & 1.650 \\
6 & 2.258 & 27 & 1.650 & 18 & 2.068 & 27 & 1.650 \\
7 & 2.029 & 36 & 1.610 & 19 & 1.917 & 36 & 1.610 \\
8 & 1.572 & 36 & 1.610 & 20 & 1.602 & 36 & 1.610 \\
9 & 1.896 & 32 & 1.520 & 21 & 1.857 & 32 & 1.520 \\
10 & 1.697 & 32 & 1.520 & 22 & 1.702 & 32 & 1.520 \\
11 & 2.350 & 28 & 1.530 & 23 & 2.116 & 28 & 1.530 \\
12 & 1.919 & 28 & 1.530 & 24 & 2.166 & 28 & 1.530 \\
\hline
\end{tabular}

Todos os arcos apresentaram relação fluxo/capacidade (V/C) maior que 1,00, seja pelo método do equilíbrio do usuário, seja pelo método das médias sucessivas. Isso indica que a rede está sobrecarregada, em termos de fluxo, e implica dificuldade maior ao processo de estimação, por se tratar de uma rede congestionada. Sabe-se que matriz estimada em redes congestionadas geralmente apresenta erros elevados e, atualmente, é um dos pontos mais estudados; o que fez surgir a utilização de procedimentos iterativos, como a técnica bi-nível (NGUYEN, 1977).

Essa situação torna-se interessante para testar a eficiência das propostas (aumentar a informação com a contagem nas interseções e o método de estimação por medidas sucessivas), por se tratar de uma situação desfavorável, conforme afirmam Bell et al (1993).

\subsubsection{Contagem hipotética de tráfego nas interseções}

Estes dados podem ser obtidos a partir da tabela de $p_{\mathrm{ij}}$ assumindo que o total de fluxos que chega ao nó seria igual ao total que sai - respeitando, obviamente, as viagens 
que originam ou destinam ao respectivo nó - obedecendo com isso a uma analogia com a lei de Kirchoff para fluxo elétrico. Isso foi possível porque se conhecia a porcentagem de utilização dos arcos pelas viagens.

Os fluxos conforme movimento foram alocados a "arcos virtuais", conforme Figura 4. 2. Os valores dos fluxos em cada um dos "arcos" estão apresentados na Tabela 4. 5. Os tempos de percurso nos "arcos virtuais", expressos conforme BPR (1964), na condição de fluxo livre são iguais a $1 \times 10^{-15}$ u.t., para que não interfiram na escolha da rota, porque os mesmos não integram de fato a rede.

Mas, se for desejado, pode ser atribuído a um "arco virtual" o acréscimo no tempo de viagem gerado pela conversão à esquerda, à direita, movimento reto, espera no semáforo, entre outros.

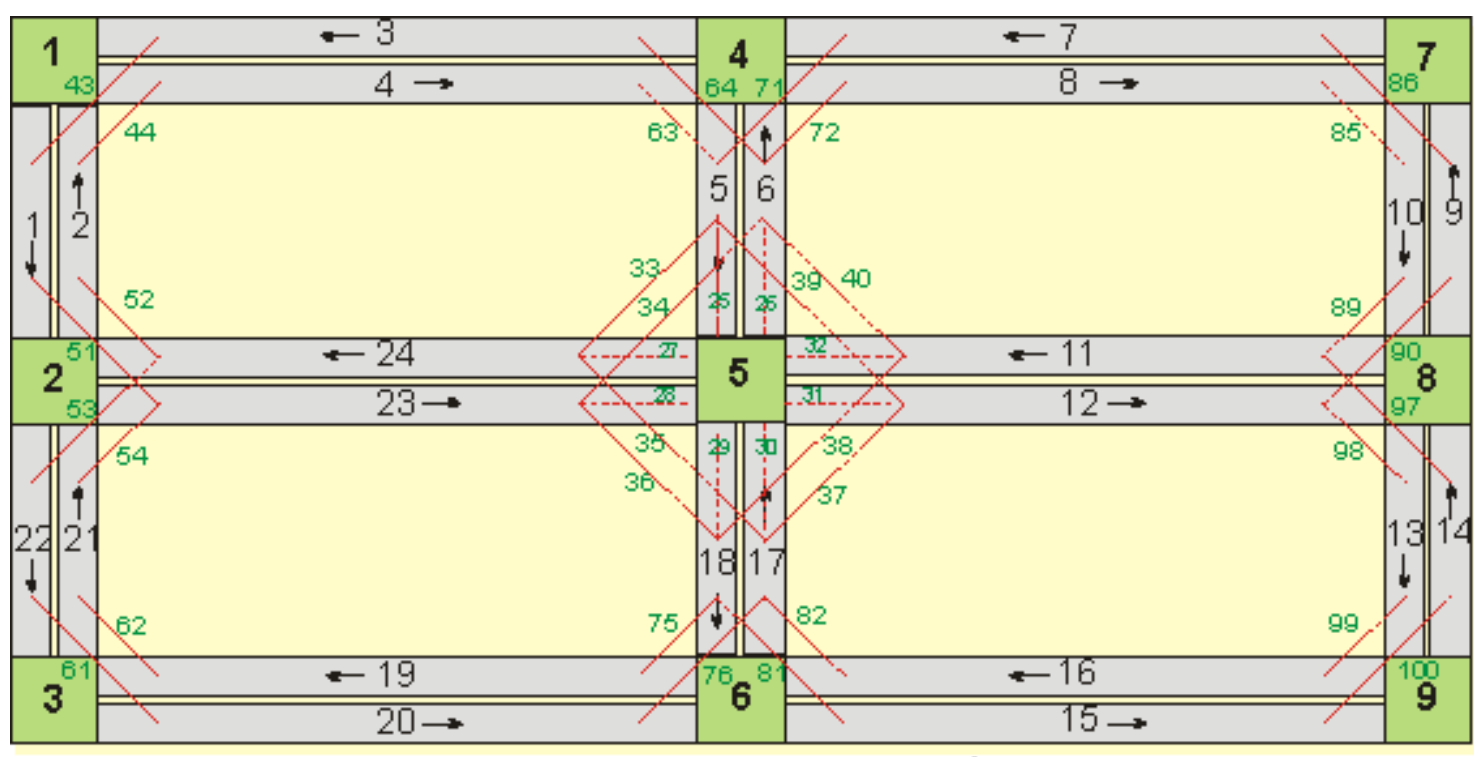

- =-1=" "Árco virtual"

$\square$ Nó onde houve contagem de fluxo

Figura 4. 2: Rede com os "arcos virtuais"

Observe na Figura 4. 2 que em alguns nós o movimento reto não foi representado por um "arco virtual". A explicação é que essa informação seria redundante, pois pode ser obtida de outras maneiras, e isso traria prejuízos à resposta. 
Tome como exemplo a Figura 4. 3, o fluxo no "arco virtual" entre 1 e 1 ' pode ser obtido através da diferença entre o fluxo observado no arco 1 e o fluxo do "arco virtual" 1"'-1', assim a presença do "arco virtual" 1-1' é desnecessária.

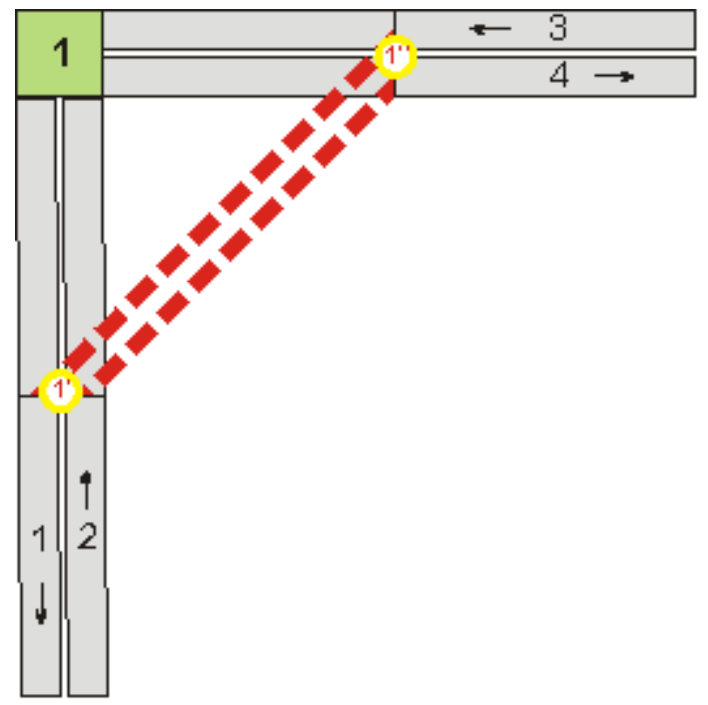

Figura 4. 3: Exemplo de "arco virtual" não redundante

Tabela 4. 5: Fluxos alocados aos "arcos virtuais"

\begin{tabular}{ccc|ccc}
\hline \multirow{2}{*}{ “Arco Virtual” } & \multicolumn{2}{c|}{ Método de Alocação } & \multirow{2}{*}{ “Arco Virtual” } & \multicolumn{2}{c}{ Método de Alocação } \\
\cline { 2 - 3 } & Equilíbrio & Médias Sucessivas & & Equilíbrio & Médias Sucessivas \\
\hline \hline 25 & 875 & 1949 & 53 & 264 & 296 \\
26 & 1314 & 1430 & 54 & 454 & 440 \\
27 & 1195 & 1298 & 61 & 472 & 477 \\
28 & 716 & 1426 & 62 & 691 & 694 \\
29 & 1447 & 1342 & 63 & 435 & 425 \\
30 & 741 & 1590 & 64 & 460 & 434 \\
31 & 1344 & 1427 & 71 & 645 & 573 \\
32 & 668 & 1487 & 72 & 523 & 527 \\
33 & 326 & 332 & 75 & 509 & 476 \\
34 & 477 & 426 & 76 & 510 & 507 \\
35 & 483 & 535 & 81 & 516 & 428 \\
36 & 304 & 264 & 82 & 492 & 511 \\
37 & 383 & 272 & 85 & 330 & 324 \\
38 & 397 & 462 & 86 & 664 & 660 \\
39 & 204 & 219 & 89 & 481 & 522 \\
40 & 467 & 401 & 90 & 500 & 427 \\
43 & 389 & 395 & 97 & 472 & 513 \\
44 & 618 & 579 & 98 & 609 & 537 \\
51 & 454 & 440 & 99 & 412 & 352 \\
52 & 532 & 527 & 100 & 331 & 374 \\
\hline
\end{tabular}

A diferença entre valores alocados é mais acentuada ao considerar os "arcos virtuais", devido as diferenças nos caminhos escolhidos, que acaba refletindo nos movimentos de conversão. 


\subsubsection{Estimação da matriz OD em função das contagens de tráfego}

A estimação da matriz OD será feita utilizando os métodos embutidos nos programas TransCAD e QUEENSOD e, também, o método de estimação por médias sucessivas (MEMS) proposto neste trabalho.

Este item será dividido em duas etapas: (i) A estimação foi realizada considerando a principal proposta do trabalho que é aumentar a quantidade de informação com contagens realizadas nas interseções; (ii) A estimação foi feita da forma tradicional, considerando os fluxos observados apenas nos arcos.

4.1.3.1 Parte A - Estimação considerando as contagens de tráfego realizadas nas interseções

Foram propostos sete testes de verificação, de forma a analisar várias combinações de pontos de contagem.

\section{$\Rightarrow \quad$ Teste $1(\mathrm{~T} 1)$ :}

Simula a situação em que contagens são realizadas nos nós 1, 3, 7 e 9 . Nessa situação é possível obter duas informações não redundantes de fluxo em cada interseção. Assim, o número total de informações adicionais para esse teste foi igual a oito. Foram inseridos oito "arcos virtuais", conforme mostra a Figura 4. 4.

Além das 24 informações de fluxo observados nos arcos, este teste possibilita obtenção de outras oito, fazendo com que o número máximo de informações não redundantes de fluxo para a configuração do Teste 1 seja 32. 


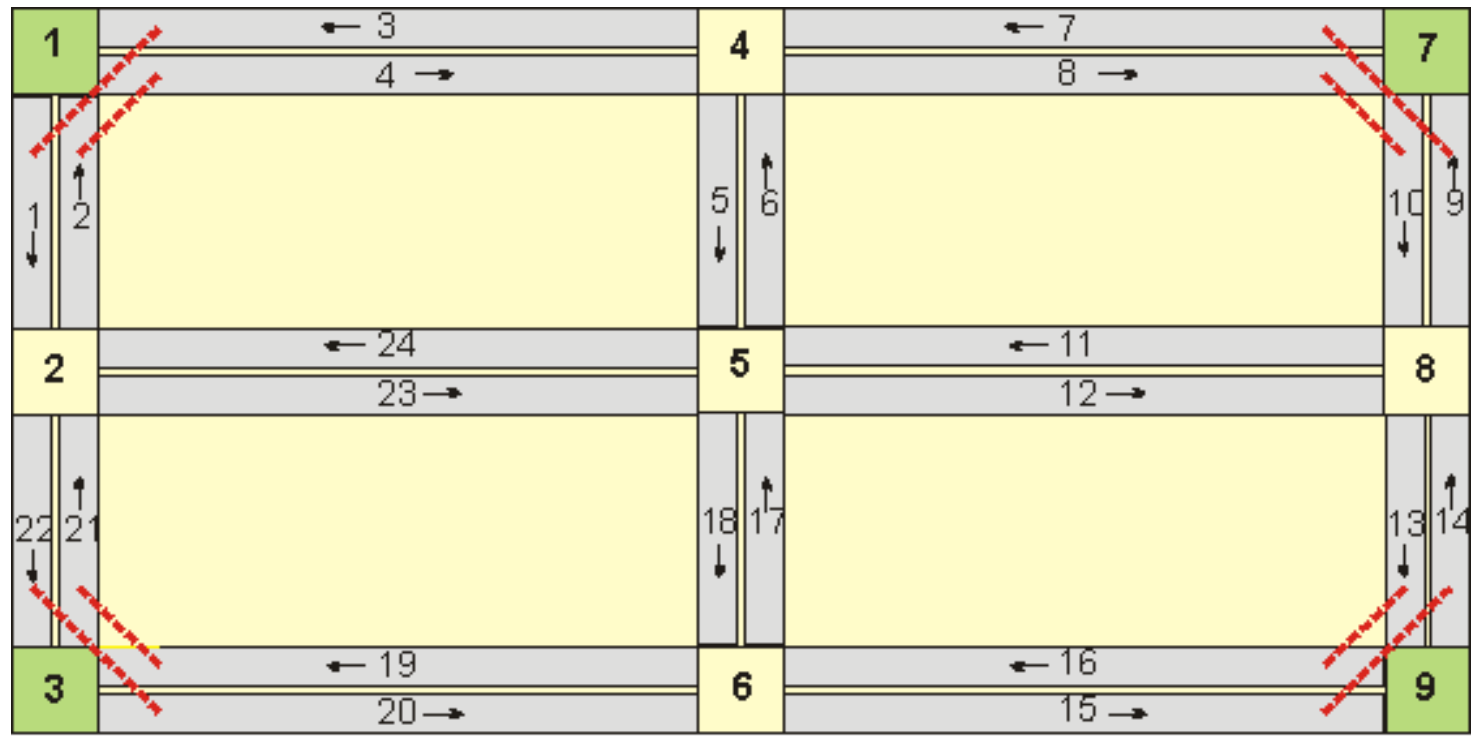

-n=-1 "Arco virtual"

$\square$ Nó onde houve contagem de fluxo

Figura 4. 4: Configuração da rede hipotética para o Teste 1

O grau indeterminação da rede que era igual a 139, passa a ser 107 após a inserção dos "arcos virtuais", uma redução de $23 \%$.

Caso as contagens não sejam automáticas, um mesmo observador consegue contar o tráfego em mais de uma aproximação, desde que ele seja bem treinado e o fluxo não seja intenso (DNIT, 2006). Para esta tese será estabelecido que um mesmo observador é capaz de anotar o tráfego em uma única aproximação. Caso as contagens sejam feitas nos arcos o observador é capaz de anotar o tráfego em apenas um arco. Se houver contagem no nó inicial ou final de um arco, não será necessário contagem no mesmo.

Nestas circunstâncias, o Teste 1 demandará 16 observadores para obtenção dos fluxos. Caso fossem realizadas contagens apenas nos arcos, seriam necessários 24 observadores para obtenção desses fluxos. Isso contraria o argumento de Bell (1991), que afirma serem necessários mais observadores caso a contagem seja feita na interseção.

Na Tabela 4. 6 são apresentadas as matrizes estimadas considerando o QUEENSOD, o TransCAD (ambos com matriz semente unitária) e o método das médias sucessivas. 
Tabela 4. 6: Matriz estimada para o Teste 1

\begin{tabular}{|c|c|c|c|c|c|c|c|c|c|c|}
\hline O\D & 1 & 2 & 3 & 4 & 5 & 6 & 7 & 8 & 9 & $\Sigma$ \\
\hline \multirow{4}{*}{1} & - & 406 & 464 & 330 & 418 & 175 & 276 & 159 & 371 & 2.599 \\
\hline & - & 1.237 & 193 & 430 & 0 & 274 & 825 & 0 & 0 & 2.959 \\
\hline & - & 411 & 329 & 470 & 211 & 320 & 476 & 155 & 226 & 2.598 \\
\hline & - & 396 & 474 & 192 & 378 & 209 & 291 & 184 & 468 & 2.593 \\
\hline \multirow{4}{*}{2} & 204 & - & 386 & 415 & 233 & 225 & 416 & 219 & 484 & 2.582 \\
\hline & 1.043 & - & 1.297 & 583 & 0 & 365 & 71 & 198 & 281 & 3.838 \\
\hline & 223 & - & 260 & 551 & 175 & 398 & 296 & 187 & 259 & 2.349 \\
\hline & 201 & - & 288 & 213 & 203 & 278 & 584 & 194 & 542 & 2.503 \\
\hline \multirow{4}{*}{3} & 176 & 377 & - & 351 & 419 & 187 & 245 & 246 & 288 & 2.289 \\
\hline & 313 & 1.200 & - & 292 & 0 & 465 & 0 & 0 & 690 & 2.959 \\
\hline & 276 & 337 & - & 328 & 182 & 359 & 218 & 169 & 489 & 2.358 \\
\hline & 184 & 255 & - & 503 & 220 & 143 & 363 & 350 & 197 & 2.215 \\
\hline \multirow{4}{*}{4} & 334 & 203 & 309 & - & 487 & 231 & 204 & 213 & 210 & 2.191 \\
\hline & 267 & 468 & 0 & - & 66 & 184 & 463 & 421 & 0 & 1.869 \\
\hline & 596 & 349 & 255 & - & 648 & 550 & 481 & 216 & 269 & 3.364 \\
\hline & 236 & 188 & 370 & - & 446 & 200 & 292 & 121 & 308 & 2.159 \\
\hline \multirow{4}{*}{5} & 337 & 414 & 246 & 184 & - & 199 & 466 & 260 & 328 & 2.434 \\
\hline & 0 & 0 & 0 & 0 & - & 0 & 0 & 0 & 0 & 0 \\
\hline & 192 & 154 & 184 & 464 & - & 464 & 201 & 122 & 216 & 1.997 \\
\hline & 285 & 251 & 275 & 221 & - & 186 & 288 & 156 & 264 & 1.926 \\
\hline \multirow{4}{*}{6} & 455 & 462 & 226 & 371 & 311 & - & 165 & 320 & 353 & 2.663 \\
\hline & 0 & 512 & 42 & 278 & 0 & - & 1 & 526 & 776 & 2.134 \\
\hline & 332 & 476 & 498 & 540 & 625 & - & 258 & 291 & 650 & 3.670 \\
\hline & 531 & 431 & 156 & 189 & 215 & - & 240 & 260 & 366 & 2.388 \\
\hline \multirow{4}{*}{7} & 407 & 428 & 179 & 172 & 347 & 451 & - & 323 & 434 & 2.741 \\
\hline & 1.287 & 20 & 0 & 0 & 0 & 432 & - & 1.279 & 51 & 3.069 \\
\hline & 574 & 211 & 194 & 553 & 217 & 287 & - & 343 & 327 & 2.706 \\
\hline & 438 & 324 & 224 & 240 & 445 & 369 & - & 251 & 352 & 2.643 \\
\hline \multirow{4}{*}{8} & 284 & 282 & 275 & 359 & 475 & 265 & 401 & - & 326 & 2.667 \\
\hline & 89 & 395 & 26 & 439 & 0 & 387 & 1.151 & - & 1.177 & 3.665 \\
\hline & 323 & 248 & 254 & 621 & 184 & 455 & 288 & - & 310 & 2.683 \\
\hline & 315 & 313 & 245 & 320 & 393 & 200 & 186 & - & 264 & 2.236 \\
\hline \multirow{4}{*}{9} & 444 & 268 & 364 & 350 & 476 & 477 & 310 & 298 & - & 2.987 \\
\hline & 0 & 0 & 1.555 & 82 & 0 & 0 & 242 & 1.236 & - & 3.115 \\
\hline & 271 & 258 & 550 & 354 & 229 & 605 & 317 & 347 & - & 2.931 \\
\hline & 488 & 329 & 448 & 522 & 328 & 292 & 296 & 272 & $\therefore$ & 2.974 \\
\hline \multirow{4}{*}{$\Sigma$} & 2.641 & 2.840 & 2.449 & 2.532 & 3.166 & 2.210 & 2.483 & 2.038 & 2.794 & 23.153 \\
\hline & 2.999 & 3.832 & 3.113 & 2.104 & 67 & 2.108 & 2.754 & 3.660 & 2.974 & 23.609 \\
\hline & 2.787 & 2.444 & 2.524 & 3.881 & 2.471 & 3.438 & 2.535 & 1.830 & 2.746 & 24.656 \\
\hline & 2.677 & 2.487 & 2.480 & 2.400 & 2.628 & 1.878 & 2.540 & 1.786 & 2.760 & 21.636 \\
\hline
\end{tabular}

Obs: A primeira linha de cada origem contém os valores das viagens "reais", na segunda linha estão os resultados estimados pelo QUEENSOD, na terceira linha estão os resultados estimados pelo TransCAD e na quarta linha estão os resultados estimados pelo MEMS.

Dos três métodos o TransCAD foi o que mais estimou viagens, um total de 24.656, um aumento de $6,5 \%$ no total de viagens "reais". O QUEENSOD estimou uma quantidade $2 \%$ 
superior ao total "real", porém com quantidade considerável de viagens igual a zero. Já o MEMS estimou $6,5 \%$ viagens a menos que o esperado.

Foi também suposto que se conhecia uma matriz semente equivalente a $70 \%$ da matriz "real" $\left(S_{70}\right)$. É uma situação bastante favorável, pois a matriz semente é proporcional à que originou os fluxos observados. Além disso, há fluxos observados em todos os arcos da rede viária e há informações adicionais. A estimação utilizou o TransCAD e o QUEENSOD, Na Tabela 4. 7 estão os resultados estimados ao usar a matriz semente $\mathrm{S}_{70}$.

Tabela 4. 7: Matriz estimada para o Teste 1 , considerando matriz $70 \%$ da "real" $\left(S_{70}\right)$

\begin{tabular}{|c|c|c|c|c|c|c|c|c|c|c|}
\hline O\D & 1 & 2 & 3 & 4 & 5 & 6 & 7 & 8 & 9 & $\Sigma$ \\
\hline \multirow{3}{*}{1} & - & 406 & 464 & 330 & 418 & 175 & 276 & 159 & 371 & 2.599 \\
\hline & - & 0 & 657 & 713 & 811 & 602 & 737 & 0 & 259 & 3.778 \\
\hline & - & 461 & 436 & 278 & 397 & 164 & 268 & 139 & 344 & 2.487 \\
\hline \multirow{3}{*}{2} & 204 & - & 386 & 415 & 233 & 225 & 416 & 219 & 484 & 2.582 \\
\hline & 0 & - & 0 & 910 & 0 & 793 & 0 & 0 & 607 & 2.310 \\
\hline & 162 & - & 298 & 491 & 240 & 319 & 477 & 232 & 614 & 2.834 \\
\hline \multirow{3}{*}{3} & 176 & 377 & - & 351 & 419 & 187 & 245 & 246 & 288 & 2.289 \\
\hline & 826 & 0 & - & 661 & 0 & 599 & 3 & 0 & 768 & 2.857 \\
\hline & 177 & 472 & - & 346 & 382 & 140 & 232 & 200 & 254 & 2.202 \\
\hline \multirow{3}{*}{4} & 334 & 203 & 309 & - & 487 & 231 & 204 & 213 & 210 & 2.191 \\
\hline & 1 & 0 & 808 & - & 0 & 336 & 672 & 408 & 517 & 2.743 \\
\hline & 368 & 194 & 305 & - & 513 & 239 & 225 & 158 & 199 & 2.200 \\
\hline \multirow{3}{*}{5} & 337 & 414 & 246 & 184 & - & 199 & 466 & 260 & 328 & 2.434 \\
\hline & 0 & 549 & 0 & 150 & - & 0 & 160 & 0 & 0 & 859 \\
\hline & 351 & 386 & 266 & 183 & - & 201 & 496 & 192 & 331 & 2.407 \\
\hline \multirow{3}{*}{6} & 455 & 462 & 226 & 371 & 311 & - & 165 & 320 & 353 & 2.663 \\
\hline & 418 & 0 & 0 & 362 & 0 & - & 764 & 0 & 777 & 2.321 \\
\hline & 439 & 406 & 252 & 374 & 318 & - & 159 & 279 & 364 & 2.591 \\
\hline \multirow{3}{*}{7} & 407 & 428 & 179 & 172 & 347 & 451 & - & 323 & 434 & 2.741 \\
\hline & 608 & 7 & 40 & 4 & 5 & 708 & - & 343 & 754 & 2.468 \\
\hline & 398 & 402 & 184 & 149 & 343 & 444 & - & 327 & 385 & 2.631 \\
\hline \multirow{3}{*}{8} & 284 & 282 & 275 & 359 & 475 & 265 & 401 & - & 326 & 2.667 \\
\hline & 805 & 300 & 0 & 102 & 0 & 591 & 0 & - & 123 & 1.921 \\
\hline & 326 & 293 & 346 & 424 & 509 & 359 & 318 & - & 253 & 2.829 \\
\hline \multirow{3}{*}{9} & 444 & 268 & 364 & 350 & 476 & 477 & 310 & 298 & - & 2.987 \\
\hline & 165 & 103 & 1.604 & 618 & 100 & 6 & 747 & 200 & - & 3.542 \\
\hline & 418 & 238 & 352 & 371 & 448 & 395 & 289 & 326 & - & 2.837 \\
\hline \multirow{3}{*}{$\Sigma$} & 2.641 & 2.840 & 2.449 & 2.532 & 3.166 & 2.210 & 2.483 & 2.038 & 2.794 & 23.153 \\
\hline & 2.823 & 959 & 3.109 & 3.518 & 916 & 3.635 & 3.083 & 951 & 3.805 & 22.798 \\
\hline & 2.641 & 2.852 & 2.440 & 2.614 & 3.150 & 2.261 & 2.463 & 1.853 & 2.746 & 23.020 \\
\hline
\end{tabular}

Obs: A primeira linha de cada origem contém os valores das viagens "reais", na segunda linha estão as os resultados estimados pelo QUEENSOD e na terceira linha estão os resultados estimados pelo TransCAD. 
O TransCAD estimou, ao considerar a matriz semente $S_{70}, 23.020$ viagens no total, isto é $0,6 \%$ menor que o total "real". Já o QUEENSOD estimou um total igual a 22.798 viagens, $1,53 \%$ menor que o total de viagens "real" e $3,43 \%$ inferior ao total estimado quando fez uso de matriz semente unitária.

$\Rightarrow \quad$ Teste 2 (T2):

O Teste 2 simula a situação em que se realiza contagem apenas na interseção com maior quantidade de viagens trafegando. Na rede em estudo, o nó 5 entre os nove é o que apresenta o maior total de viagens, $66 \%$ das viagens da rede trafegam por esse nó.

Além dos fluxos observados nos arcos, foram obtidas 16 informações não redundantes de fluxo. Então, à rede, foram inseridos 16 "arcos virtuais", conforme Figura 4. 5. O grau de indeterminação passa a ser 99 e o número de observadores necessários para realização das contagens seria 20.

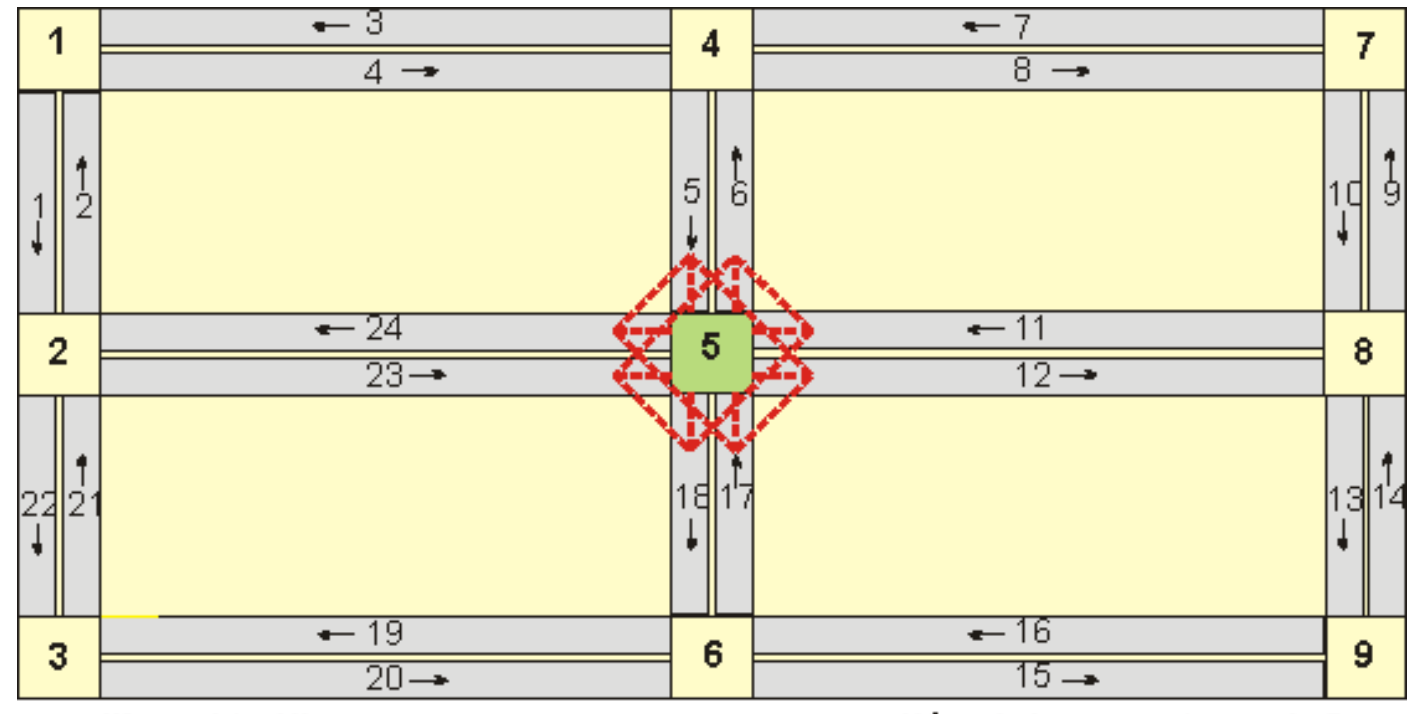

-n-- "Árco virtual"

$\square$ Nó onde howve contagem de fluxo

Figura 4. 5: Configuração da rede hipotética para o Teste 2

As matrizes estimadas estão apresentadas na Tabela 4. 8. Neste caso a estimação pelos programas fez uso de matriz semente uniforme. 
Tabela 4. 8: Matriz estimada para o Teste 2

\begin{tabular}{|c|c|c|c|c|c|c|c|c|c|c|}
\hline O\D & 1 & 2 & 3 & 4 & 5 & 6 & 7 & 8 & 9 & $\Sigma$ \\
\hline \multirow{4}{*}{1} & - & 406 & 464 & 330 & 418 & 175 & 276 & 159 & 371 & 2.599 \\
\hline & - & 1.000 & 0 & 1.022 & 10 & 104 & 0 & 196 & 100 & 2.432 \\
\hline & - & 553 & 492 & 252 & 235 & 204 & 568 & 175 & 232 & 2.711 \\
\hline & - & 401 & 437 & 381 & 374 & 132 & 347 & 228 & 358 & 2.658 \\
\hline \multirow{4}{*}{2} & 204 & - & 386 & 415 & 233 & 225 & 416 & 219 & 484 & 2.582 \\
\hline & 243 & - & 97 & 0 & 0 & 93 & 0 & 63 & 104 & 600 \\
\hline & 472 & - & 421 & 366 & 204 & 122 & 408 & 152 & 425 & 2.570 \\
\hline & 183 & - & 375 & 497 & 226 & 298 & 199 & 309 & 504 & 2.590 \\
\hline \multirow{4}{*}{3} & 176 & 377 & - & 351 & 419 & 187 & 245 & 246 & 288 & 2.289 \\
\hline & 0 & 347 & - & 0 & 159 & 67 & 0 & 268 & 100 & 941 \\
\hline & 123 & 555 & - & 197 & 501 & 268 & 233 & 173 & 646 & 2.696 \\
\hline & 155 & 219 & - & 540 & 239 & 207 & 299 & 130 & 385 & 2.175 \\
\hline \multirow{4}{*}{4} & 334 & 203 & 309 & - & 487 & 231 & 204 & 213 & 210 & 2.191 \\
\hline & 192 & 0 & 0 & - & 0 & 174 & 0 & 0 & 0 & 366 \\
\hline & 470 & 275 & 309 & - & 473 & 14 & 320 & 197 & 269 & 2.327 \\
\hline & 349 & 241 & 400 & - & 373 & 236 & 215 & 203 & 171 & 2.187 \\
\hline \multirow{4}{*}{5} & 337 & 414 & 246 & 184 & - & 199 & 466 & 260 & 328 & 2.434 \\
\hline & 85 & 13 & 0 & 158 & - & 284 & 115 & 831 & 0 & 1.486 \\
\hline & 259 & 374 & 248 & 154 & - & 167 & 309 & 211 & 311 & 2.033 \\
\hline & 160 & 505 & 298 & 170 & - & 139 & 403 & 133 & 302 & 2.111 \\
\hline \multirow{4}{*}{6} & 455 & 462 & 226 & 371 & 311 & - & 165 & 320 & 353 & 2.663 \\
\hline & 297 & 288 & 0 & 0 & 0 & - & 143 & 0 & 106 & 834 \\
\hline & 392 & 369 & 567 & 15 & 683 & - & 221 & 231 & 664 & 3.142 \\
\hline & 377 & 469 & 336 & 217 & 378 & - & 230 & 374 & 356 & 2.736 \\
\hline \multirow{4}{*}{7} & 407 & 428 & 179 & 172 & 347 & 451 & - & 323 & 434 & 2.741 \\
\hline & 0 & 137 & 0 & 451 & 26 & 0 & - & 0 & 0 & 614 \\
\hline & 747 & 413 & 257 & 118 & 233 & 304 & - & 378 & 464 & 2.914 \\
\hline & 420 & 566 & 150 & 249 & 308 & 487 & - & 399 & 231 & 2.810 \\
\hline \multirow{4}{*}{8} & 284 & 282 & 275 & 359 & 475 & 265 & 401 & - & 326 & 2.667 \\
\hline & 178 & 0 & 90 & 87 & 0 & 86 & 0 & - & 0 & 441 \\
\hline & 250 & 307 & 246 & 177 & 363 & 165 & 727 & - & 540 & 2.775 \\
\hline & 423 & 319 & 283 & 490 & 427 & 308 & 185 & - & 329 & 2.764 \\
\hline \multirow{4}{*}{9} & 444 & 268 & 364 & 350 & 476 & 477 & 310 & 298 & - & 2.987 \\
\hline & 35 & 921 & 0 & 135 & 75 & 71 & 255 & 380 & - & 1.871 \\
\hline & 275 & 225 & 234 & 125 & 308 & 842 & 610 & 483 & - & 3.102 \\
\hline & 587 & 255 & 381 & 299 & 415 & 447 & 427 & 319 & 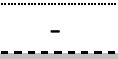 & 3.129 \\
\hline \multirow{4}{*}{$\Sigma$} & 2.641 & 2.840 & 2.449 & 2.532 & 3.166 & 2.210 & 2.483 & 2.038 & 2.794 & 23.153 \\
\hline & 1.029 & 2.706 & 187 & 1.852 & 270 & 880 & 513 & 1.738 & 410 & 9.586 \\
\hline & 2.988 & 3.071 & 2.774 & 1.404 & 3.000 & 2.086 & 3.396 & 2.000 & 3.551 & 24.270 \\
\hline & 2.653 & 2.977 & 2.659 & 2.842 & 2.740 & 2.255 & 2.304 & 2.095 & 2.636 & 23.160 \\
\hline
\end{tabular}

Obs: A primeira linha de cada origem contém os valores das viagens "reais", na segunda linha estão os resultados estimados pelo QUEENSOD, na terceira linha estão os resultados estimados pelo TransCAD e na quarta linha estão os resultados estimados pelo MEMS.

O total de viagens estimadas pelo TransCAD foi $4,82 \%$ maior que o total "real", uma melhoria em relação ao Teste 1. Já o QUEENSOD estimou uma quantidade de viagens bem 
abaixo da observada (9.586). O MEMS estimou 23.160 viagens, muito próximo ao total "real".

Considerando o uso da matriz semente $S_{70}$, os resultados estimados pelos programas QUEENSOD e TransCAD encontram-se apresentados na Tabela 4. 9.

Em relação ao total de viagens, o TransCAD estimou 23.034, aproximadamente 0,5\% menor que o total observado, enquanto que o QUEENSOD estimou 15.686 viagens.

Tabela 4. 9: Matriz estimada para o Teste 2 , considerando matriz $70 \%$ da "real" $\left(\mathrm{S}_{70}\right)$

\begin{tabular}{|c|c|c|c|c|c|c|c|c|c|c|}
\hline O\D & 1 & 2 & 3 & 4 & 5 & 6 & 7 & 8 & 9 & $\Sigma$ \\
\hline \multirow{3}{*}{1} & - & 406 & 464 & 330 & 418 & 175 & 276 & 159 & 371 & 2.599 \\
\hline & - & 400 & 204 & 637 & 461 & 130 & 42 & 148 & 25 & 2.047 \\
\hline & - & 411 & 403 & 392 & 443 & 119 & 277 & 178 & 332 & 2.556 \\
\hline \multirow{3}{*}{2} & 204 & - & 386 & 415 & 233 & 225 & 416 & 219 & 484 & 2.582 \\
\hline & 509 & - & 322 & 0 & 323 & 110 & 5 & 897 & 0 & 2.166 \\
\hline & 208 & - & 437 & 456 & 254 & 261 & 456 & 208 & 552 & 2.832 \\
\hline \multirow{3}{*}{3} & 176 & 377 & - & 351 & 419 & 187 & 245 & 246 & 288 & 2.289 \\
\hline & 0 & 642 & - & 700 & 167 & 501 & 700 & 512 & 0 & 3.223 \\
\hline & 183 & 330 & - & 309 & 428 & 152 & 280 & 206 & 255 & 2.144 \\
\hline \multirow{3}{*}{4} & 334 & 203 & 309 & - & 487 & 231 & 204 & 213 & 210 & 2.191 \\
\hline & 159 & 0 & 10 & - & 0 & 154 & 81 & 0 & 0 & 404 \\
\hline & 360 & 237 & 347 & - & 455 & 208 & 240 & 242 & 245 & 2.333 \\
\hline \multirow{3}{*}{5} & 337 & 414 & 246 & 184 & - & 199 & 466 & 260 & 328 & 2.434 \\
\hline & 134 & 0 & 0 & 217 & - & 136 & 138 & 195 & 0 & 819 \\
\hline & 312 & 389 & 297 & 172 & - & 238 & 469 & 242 & 332 & 2.450 \\
\hline \multirow{3}{*}{6} & 455 & 462 & 226 & 371 & 311 & - & 165 & 320 & 353 & 2.663 \\
\hline & 417 & 246 & 0 & 0 & 87 & - & 149 & 0 & 300 & 1.199 \\
\hline & 383 & 438 & 246 & 318 & 260 & - & 139 & 347 & 345 & 2.475 \\
\hline \multirow{3}{*}{7} & 407 & 428 & 179 & 172 & 347 & 451 & - & 323 & 434 & 2.741 \\
\hline & 6 & 108 & 0 & 451 & 138 & 110 & - & 78 & 0 & 891 \\
\hline & 471 & 378 & 148 & 201 & 398 & 450 & - & 304 & 497 & 2.846 \\
\hline \multirow{3}{*}{8} & 284 & 282 & 275 & 359 & 475 & 265 & 401 & - & 326 & 2.667 \\
\hline & 79 & 112 & 798 & 987 & 400 & 208 & 1.034 & - & 306 & 3.924 \\
\hline & 309 & 259 & 305 & 334 & 455 & 293 & 364 & - & 327 & 2.647 \\
\hline \multirow{3}{*}{9} & 444 & 268 & 364 & 350 & 476 & 477 & 310 & 298 & - & 2.987 \\
\hline & 37 & 143 & 0 & 142 & 97 & 184 & 112 & 300 & - & 1.014 \\
\hline & 395 & 263 & 310 & 309 & 452 & 410 & 347 & 265 & - & 2.751 \\
\hline \multirow{3}{*}{$\Sigma$} & 2.641 & 2.840 & 2.449 & 2.532 & 3.166 & 2.210 & 2.483 & 2.038 & 2.794 & 23.153 \\
\hline & 1.341 & 1.651 & 1.334 & 3.134 & 1.674 & 1.533 & 2.259 & 2.129 & 631 & 15.686 \\
\hline & 2.621 & 2.705 & 2.493 & 2.490 & 3.146 & 2.131 & 2.571 & 1.990 & 2.887 & 23.034 \\
\hline
\end{tabular}

Obs: A primeira linha de cada origem contém os valores das viagens "reais", na segunda linha estão as os resultados estimados pelo QUEENSOD e na terceira linha estão os resultados estimados pelo TransCAD. 
$\Rightarrow \quad$ Teste 3 (T3):

Considera contagens "realizadas" nos nós 2, 4, 6 e 8, o número de informações não redundantes para esta configuração é 40 (24 informações de fluxo nos arcos e 16 informações de fluxo nos "arcos virtuais"). A Figura 4. 6 apresenta a configuração para o cenário do Teste 3.

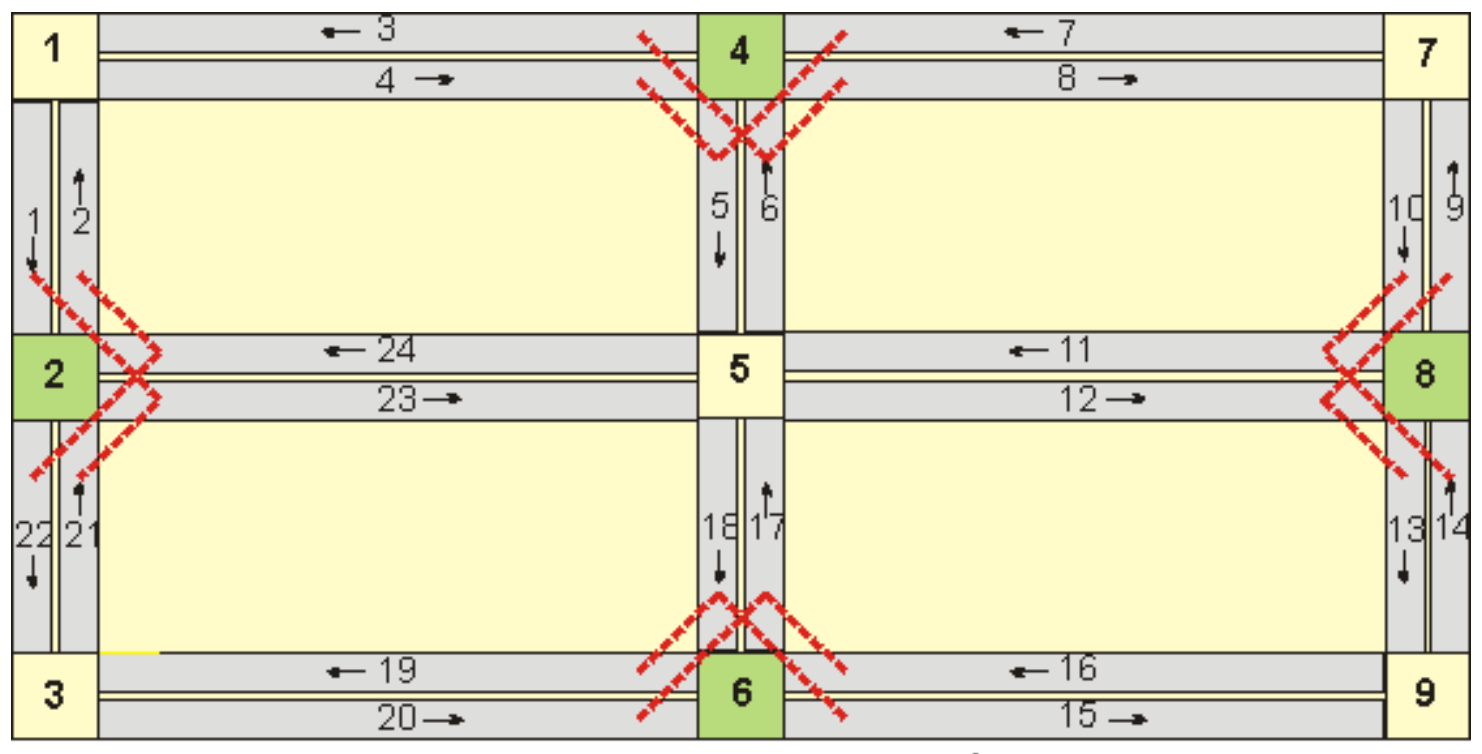

- =-1=" "Árco virtual"

$\square$ Nó onde houve contagem de fluxo

Figura 4. 6: Configuração da rede hipotética para o Teste 3

As contagens de tráfego nessas quatro interseções geraram a mesma quantidade de informações não redundantes que a contagem realizada apenas no nó 5 (Teste 2). Isso não quer dizer que os resultados estimados pelas duas situações devam ser iguais, primeiro porque é preciso observar a disposição dessas informações na rede. No caso do Teste 3, elas estão melhor distribuídas do que no Teste 2. Outro fator é o grau de indeterminação: o nó 5 integra o conjunto de caminhos mínimos de $66 \%$ das viagens da rede e isso leva a um grau de indeterminação maior nessa interseção.

Em relação ao número de observadores, seria necessário para o Teste 3 um total de 12. Nesse caso não é necessária contagem de fluxo em nenhum arco, pois das contagens nas interseções é possível obter os fluxos nos arcos. 
$\mathrm{Na}$ Tabela 4. 10 estão apresentadas as matrizes estimadas pelos métodos de estimação considerados.

Tabela 4. 10: Matriz estimada para o Teste 3

\begin{tabular}{|c|c|c|c|c|c|c|c|c|c|c|}
\hline O\D & 1 & 2 & 3 & 4 & 5 & 6 & 7 & 8 & 9 & $\Sigma$ \\
\hline \multirow{4}{*}{1} & - & 406 & 464 & 330 & 418 & 175 & 276 & 159 & 371 & 2.599 \\
\hline & - & 2 & 875 & 735 & 21 & 333 & 715 & 21 & 291 & 2.992 \\
\hline & - & 600 & 125 & 261 & 341 & 260 & 339 & 135 & 337 & 2.398 \\
\hline & - & 410 & 471 & 226 & 360 & 174 & 359 & 168 & 395 & 2.563 \\
\hline \multirow{4}{*}{2} & 204 & - & 386 & 415 & 233 & 225 & 416 & 219 & 484 & 2.582 \\
\hline & 1 & - & 12 & 4 & 6 & 7 & 91 & 99 & 11 & 231 \\
\hline & 128 & - & 204 & 214 & 311 & 215 & 485 & 197 & 408 & 2.162 \\
\hline & 200 & - & 329 & 431 & 306 & 305 & 325 & 200 & 404 & 2.500 \\
\hline \multirow{4}{*}{3} & 176 & 377 & - & 351 & 419 & 187 & 245 & 246 & 288 & 2.289 \\
\hline & 539 & 11 & - & 613 & 79 & 65 & 290 & 10 & 726 & 2.332 \\
\hline & 48 & 593 & - & 335 & 395 & 285 & 335 & 171 & 407 & 2.569 \\
\hline & 168 & 326 & - & 444 & 309 & 247 & 318 & 161 & 340 & 2.312 \\
\hline \multirow{4}{*}{4} & 334 & 203 & 309 & - & 487 & 231 & 204 & 213 & 210 & 2.191 \\
\hline & 31 & 79 & 540 & - & 47 & 412 & 195 & 1 & 65 & 1.369 \\
\hline & 587 & 235 & 331 & - & 321 & 225 & 437 & 163 & 337 & 2.636 \\
\hline & 284 & 248 & 328 & - & 322 & 154 & 278 & 286 & 225 & 2.124 \\
\hline \multirow{4}{*}{5} & 337 & 414 & 246 & 184 & - & 199 & 466 & 260 & 328 & 2.434 \\
\hline & 13 & 12 & 153 & 129 & - & 11 & 13 & 43 & 11 & 385 \\
\hline & 238 & 357 & 298 & 228 & - & 155 & 283 & 206 & 323 & 2.088 \\
\hline & 219 & 449 & 170 & 171 & - & 231 & 283 & 166 & 299 & 1.989 \\
\hline \multirow{4}{*}{6} & 455 & 462 & 226 & 371 & 311 & - & 165 & 320 & 353 & 2.663 \\
\hline & 955 & 22 & 22 & 443 & 21 & - & 288 & 11 & 819 & 2.581 \\
\hline & 298 & 253 & 563 & 292 & 372 & - & 333 & 229 & 562 & 2.902 \\
\hline & 489 & 438 & 177 & 237 & 369 & - & 235 & 380 & 386 & 2.711 \\
\hline \multirow{4}{*}{7} & 407 & 428 & 179 & 172 & 347 & 451 & - & 323 & 434 & 2.741 \\
\hline & 145 & 0 & 179 & 150 & 4 & 930 & - & 4 & 494 & 1.906 \\
\hline & 467 & 395 & 381 & 369 & 482 & 328 & - & 241 & 380 & 3.043 \\
\hline & 446 & 469 & 228 & 244 & 306 & 457 & - & 352 & 320 & 2.820 \\
\hline \multirow{4}{*}{8} & 284 & 282 & 275 & 359 & 475 & 265 & 401 & - & 326 & 2.667 \\
\hline & 180 & 195 & 169 & 120 & 99 & 98 & 11 & - & 13 & 885 \\
\hline & 195 & 295 & 183 & 242 & 323 & 188 & 278 & - & 570 & 2.274 \\
\hline & 303 & 216 & 327 & 419 & 352 & 371 & 375 & - & 236 & 2.601 \\
\hline \multirow{4}{*}{9} & 444 & 268 & 364 & 350 & 476 & 477 & 310 & 298 & - & 2.987 \\
\hline & 76 & 12 & 241 & 543 & 81 & 8 & 125 & 97 & - & 1.183 \\
\hline & 312 & 184 & 440 & 340 & 406 & 284 & 44 & 579 & - & 2.589 \\
\hline & 451 & 201 & 345 & 451 & 375 & 319 & 393 & 280 & - & 2.817 \\
\hline \multirow{4}{*}{$\Sigma$} & 2.641 & 2.840 & 2.449 & 2.532 & 3.166 & 2.210 & 2.483 & 2.038 & 2.794 & 23.153 \\
\hline & 1.940 & 333 & 2.191 & 2.737 & 358 & 1.864 & 1.727 & 285 & 2.430 & 13.864 \\
\hline & 2.273 & 2.912 & 2.525 & 2.281 & 2.951 & 1.940 & 2.534 & 1.921 & 3.324 & 22.661 \\
\hline & 2.560 & 2.758 & 2.374 & 2.624 & 2.699 & 2.258 & 2.568 & 1.992 & 2.604 & 22.438 \\
\hline
\end{tabular}

Obs: A primeira linha de cada origem contém os valores das viagens "reais", na segunda linha estão os resultados estimados pelo QUEENSOD, na terceira linha estão os resultados estimados pelo TransCAD e na quarta linha estão os resultados estimados pelo MEMS. 
O total de viagens estimadas pelo TransCAD (22.661) foi 2,12\% menor que o observado e foi um valor próximo ao estimado pelo MEMS (22.438), já o QUEENSOD estimou apenas 13.864 viagens, $40 \%$ menor que o total "real".

Ao considerar a matriz semente equivalente a $70 \%$ da matriz "real" $\left(S_{70}\right)$, os resultados obtidos são os apresentados na Tabela 4. 11 .

Tabela 4. 11: Matriz estimada para o Teste 3, considerando $S_{70}$

\begin{tabular}{|c|c|c|c|c|c|c|c|c|c|c|}
\hline O\D & 1 & 2 & 3 & 4 & 5 & 6 & 7 & 8 & 9 & $\Sigma$ \\
\hline \multirow{3}{*}{1} & - & 406 & 464 & 330 & 418 & 175 & 276 & 159 & 371 & 2.599 \\
\hline & - & 380 & 662 & 220 & 1 & 415 & 184 & 0 & 323 & 2.186 \\
\hline & - & 444 & 468 & 319 & 355 & 171 & 232 & 140 & 306 & 2.434 \\
\hline \multirow{3}{*}{2} & 204 & - & 386 & 415 & 233 & 225 & 416 & 219 & 484 & 2.582 \\
\hline & 100 & - & 0 & 101 & 0 & 541 & 103 & 28 & 99 & 972 \\
\hline & 218 & - & 341 & 428 & 226 & 273 & 480 & 240 & 501 & 2.707 \\
\hline \multirow{3}{*}{3} & 176 & 377 & - & 351 & 419 & 187 & 245 & 246 & 288 & 2.289 \\
\hline & 456 & 0 & - & 517 & 0 & 0 & 269 & 0 & 160 & 1.401 \\
\hline & 168 & 349 & - & 382 & 355 & 164 & 265 & 267 & 317 & 2.267 \\
\hline \multirow{3}{*}{4} & 334 & 203 & 309 & - & 487 & 231 & 204 & 213 & 210 & 2.191 \\
\hline & 400 & 301 & 98 & - & 0 & 379 & 0 & 679 & 384 & 2.240 \\
\hline & 376 & 231 & 344 & - & 560 & 271 & 221 & 204 & 178 & 2.386 \\
\hline \multirow{3}{*}{5} & 337 & 414 & 246 & 184 & - & 199 & 466 & 260 & 328 & 2.434 \\
\hline & 567 & 99 & 102 & 0 & - & 0 & 117 & 0 & 537 & 1.422 \\
\hline & 308 & 477 & 262 & 169 & - & 238 & 381 & 228 & 340 & 2.402 \\
\hline \multirow{3}{*}{6} & 455 & 462 & 226 & 371 & 311 & - & 165 & 320 & 353 & 2.663 \\
\hline & 610 & 0 & 0 & 257 & 0 & - & 89 & 0 & 362 & 1.318 \\
\hline & 407 & 527 & 212 & 442 & 345 & - & 160 & 398 & 379 & 2.870 \\
\hline \multirow{3}{*}{7} & 407 & 428 & 179 & 172 & 347 & 451 & - & 323 & 434 & 2.741 \\
\hline & 182 & 602 & 10 & 252 & 0 & 533 & - & 0 & 680 & 2.259 \\
\hline & 382 & 419 & 178 & 183 & 314 & 443 & - & 310 & 391 & 2.620 \\
\hline \multirow{3}{*}{8} & 284 & 282 & 275 & 359 & 475 & 265 & 401 & - & 326 & 2.667 \\
\hline & 82 & 0 & 579 & 0 & 735 & 100 & 609 & - & 0 & 2.105 \\
\hline & 286 & 279 & 250 & 377 & 446 & 247 & 369 & - & 350 & 2.605 \\
\hline \multirow{3}{*}{9} & 444 & 268 & 364 & 350 & 476 & 477 & 310 & 298 & - & 2.987 \\
\hline & 471 & 0 & 193 & 457 & 603 & 222 & 637 & 207 & - & 2.789 \\
\hline & 489 & 222 & 302 & 327 & 414 & 427 & 349 & 250 & - & 2.779 \\
\hline \multirow{3}{*}{$\Sigma$} & 2.641 & 2.840 & 2.449 & 2.532 & 3.166 & 2.210 & 2.483 & 2.038 & 2.794 & 23.153 \\
\hline & 2.868 & 1.382 & 1.644 & 1.804 & 1.339 & 2.189 & 2.008 & 914 & 2.545 & 16.693 \\
\hline & 2.634 & 2.947 & 2.357 & 2.627 & 3.015 & 2.234 & 2.457 & 2.037 & 2.762 & 23.070 \\
\hline
\end{tabular}

Obs: A primeira linha de cada origem contém os valores das viagens "reais", na segunda linha estão as os resultados estimados pelo QUEENSOD e na terceira linha estão os resultados estimados pelo TransCAD. 
O total de viagens estimadas pelo TransCAD (23.070 viagens) é 0,36\% menor em relação ao total "real". Também houve aumento no total estimado pelo QUEENSOD, 16.693 viagens, comparando com a situação em que utilizou a matriz semente unitária.

$\Rightarrow \quad$ Teste 4 (T4):

Neste teste foram "realizadas" contagens nos nós 1, 3, 5, 7 e 9 , equivalente à combinação dos Testes 1 e 2. Essas contagens permitem adicionar 24 informações não redundantes à rede, o que dobra o número de informações original. Com isso o grau de indeterminação será 91, uma redução de 35\% no índice de indeterminação original.

Para realizar as contagens de tráfego nessa rede são necessários 12 observadores, caso seja realizada contagem manual. A configuração da rede para o Teste 4 está apresentada na Figura 4. 7.

As matrizes estimadas estão apresentadas na Tabela 4.12, considerando os três métodos utilizados.

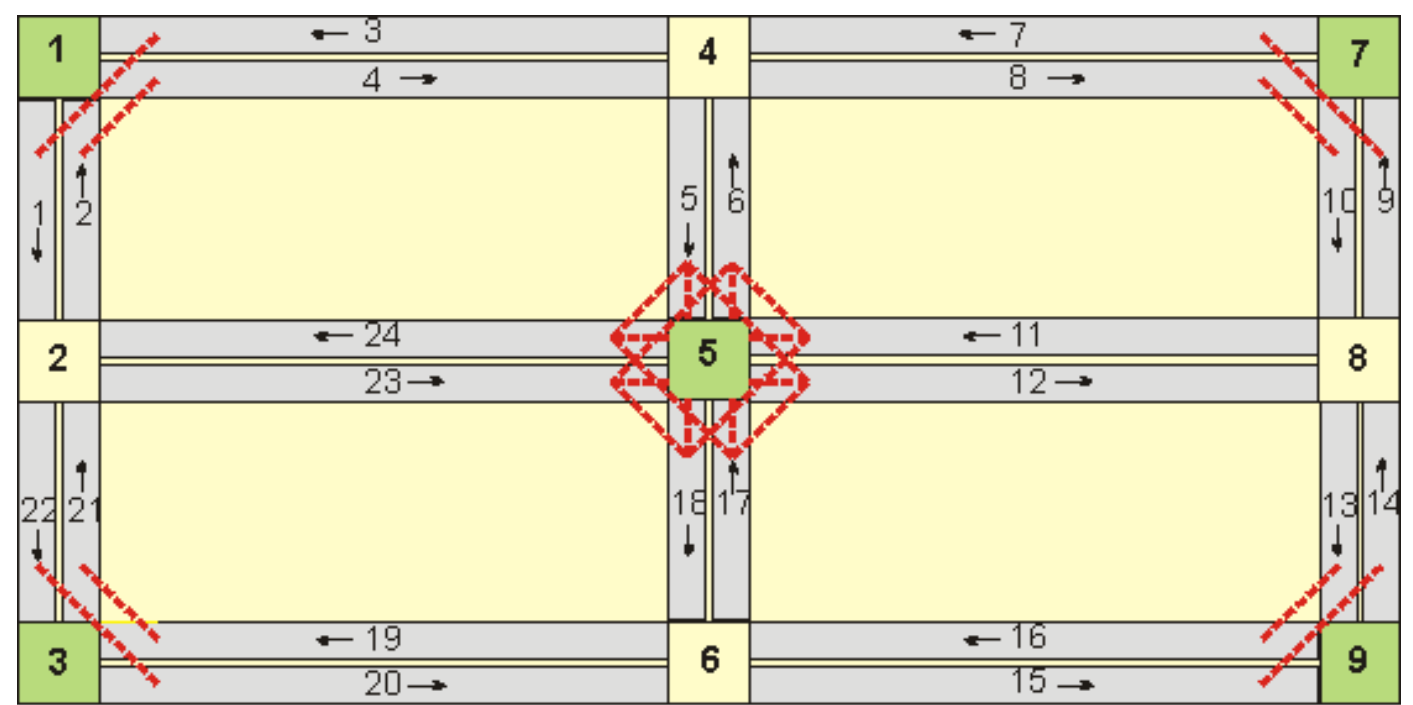

-are, "Arco virtual" $\square$ Nó onde houve contagem de fluxo

Figura 4. 7: Configuração da rede hipotética para o Teste 4 
Tabela 4. 12: Matriz estimada para o Teste 4

\begin{tabular}{|c|c|c|c|c|c|c|c|c|c|c|}
\hline OX\D & 1 & 2 & 3 & 4 & 5 & 6 & 7 & 8 & 9 & $\Sigma$ \\
\hline \multirow{4}{*}{1} & - & 406 & 464 & 330 & 418 & 175 & 276 & 159 & 371 & 2.599 \\
\hline & - & 1.000 & 20 & 83 & 527 & 49 & 2 & 77 & 526 & 2.283 \\
\hline & - & 501 & 340 & 434 & 295 & 335 & 412 & 153 & 248 & 2.718 \\
\hline & - & 408 & 497 & 315 & 407 & 116 & 353 & 136 & 363 & 2.594 \\
\hline \multirow{4}{*}{2} & 204 & - & 386 & 415 & 233 & 225 & 416 & 219 & 484 & 2.582 \\
\hline & 26 & - & 64 & 286 & 2 & 0 & 0 & 201 & 33 & 612 \\
\hline & 152 & - & 217 & 430 & 176 & 229 & 432 & 209 & 392 & 2.237 \\
\hline & 160 & - & 349 & 429 & 236 & 162 & 404 & 226 & 447 & 2.413 \\
\hline \multirow{4}{*}{3} & 176 & 377 & - & 351 & 419 & 187 & 245 & 246 & 288 & 2.289 \\
\hline & 9 & 24 & - & 6 & 120 & 25 & 189 & 185 & 352 & 911 \\
\hline & 269 & 433 & - & 330 & 355 & 298 & 245 & 158 & 415 & 2.503 \\
\hline & 126 & 372 & - & 389 & 315 & 199 & 263 & 280 & 253 & 2.198 \\
\hline \multirow{4}{*}{4} & 334 & 203 & 309 & - & 487 & 231 & 204 & 213 & 210 & 2.191 \\
\hline & 251 & 185 & 0 & - & 115 & 115 & 219 & 10 & 4 & 899 \\
\hline & 457 & 318 & 281 & - & 893 & 44 & 338 & 182 & 230 & 2.743 \\
\hline & 371 & 172 & 397 & - & 499 & 314 & 267 & 131 & 191 & 2.342 \\
\hline \multirow{4}{*}{5} & 337 & 414 & 246 & 184 & - & 199 & 466 & 260 & 328 & 2.434 \\
\hline & 193 & 21 & 0 & 61 & - & 597 & 829 & 83 & 0 & 1.784 \\
\hline & 192 & 304 & 226 & 208 & - & 204 & 362 & 262 & 308 & 2.066 \\
\hline & 344 & 260 & 317 & 163 & - & 157 & 454 & 161 & 354 & 2.209 \\
\hline \multirow{4}{*}{6} & 455 & 462 & 226 & 371 & 311 & - & 165 & 320 & 353 & 2.663 \\
\hline & 82 & 461 & 11 & 55 & 137 & - & 467 & 166 & 4 & 1.382 \\
\hline & 346 & 549 & 363 & 120 & 583 & - & 260 & 265 & 519 & 3.005 \\
\hline & 459 & 515 & 172 & 260 & 278 & - & 118 & 209 & 473 & 2.484 \\
\hline \multirow{4}{*}{7} & 407 & 428 & 179 & 172 & 347 & 451 & - & 323 & 434 & 2.741 \\
\hline & 329 & 286 & 342 & 354 & 427 & 54 & - & 43 & 7 & 1.842 \\
\hline & 532 & 294 & 211 & 338 & 187 & 314 & - & 386 & 366 & 2.628 \\
\hline & 562 & 501 & 221 & 231 & 442 & 336 & - & 293 & 381 & 2.967 \\
\hline \multirow{4}{*}{8} & 284 & 282 & 275 & 359 & 475 & 265 & 401 & - & 326 & 2.667 \\
\hline & 64 & 129 & 3 & 151 & 0 & 0 & 0 & - & 428 & 775 \\
\hline & 313 & 183 & 346 & 454 & 428 & 284 & 230 & - & 327 & 2.565 \\
\hline & 351 & 172 & 305 & 220 & 301 & 290 & 415 & - & 323 & 2.377 \\
\hline \multirow{4}{*}{9} & 444 & 268 & 364 & 350 & 476 & 477 & 310 & 298 & - & 2.987 \\
\hline & 649 & 201 & 594 & 185 & 30 & 69 & 562 & 87 & - & 2.376 \\
\hline & 345 & 267 & 492 & 325 & 382 & 572 & 359 & 517 & - & 3.259 \\
\hline & 481 & 289 & 252 & 475 & 470 & 417 & 388 & 310 & - & 3.080 \\
\hline \multirow{4}{*}{$\Sigma$} & 2.641 & 2.840 & 2.449 & 2.532 & 3.166 & 2.210 & 2.483 & 2.038 & 2.794 & 23.153 \\
\hline & 1.602 & 2.307 & 1.034 & 1.181 & 1.359 & 909 & 2.268 & 851 & 1.353 & 12.863 \\
\hline & 2.606 & 2.849 & 2.476 & 2.639 & 3.299 & 2.280 & 2.638 & 2.132 & 2.805 & 23.724 \\
\hline & 2.854 & 2.689 & 2.510 & 2.482 & 2.948 & 1.990 & 2.661 & 1.745 & 2.785 & 22.664 \\
\hline
\end{tabular}

Obs: A primeira linha de cada origem contém os valores das viagens "reais", na segunda linha estão os resultados estimados pelo QUEENSOD, na terceira linha estão os resultados estimados pelo TransCAD e na quarta linha estão os resultados estimados pelo MEMS. 
O total de viagens estimadas ao considerar o TransCAD foi $23.724,2,47 \%$ maior que o total de viagens "real". Ao considerar o MEMS foi 22.664 viagens, 2,11\% menor que o total de viagens "real" e ao considerar o QUEENSOD o total de viagens estimadas foi $12.863,44 \%$ menor que o total de viagens "real".

$\mathrm{Na}$ Tabela 4. 13 são apresentados os resultados estimados pelo TransCAD e pelo QUEENSOD considerando uma matriz semente equivalente a $70 \%$ da "real" $\left(S_{70}\right)$.

Tabela 4. 13: Matriz estimada para o Teste 4, considerando $S_{70}$

\begin{tabular}{|c|c|c|c|c|c|c|c|c|c|c|}
\hline O\D & 1 & 2 & 3 & 4 & 5 & 6 & 7 & 8 & 9 & $\Sigma$ \\
\hline \multirow{3}{*}{1} & - & 406 & 464 & 330 & 418 & 175 & 276 & 159 & 371 & 2.599 \\
\hline & - & 100 & 46 & 128 & 532 & 96 & 308 & 82 & 411 & 1.703 \\
\hline & - & 397 & 477 & 294 & 465 & 177 & 318 & 129 & 333 & 2.591 \\
\hline \multirow{3}{*}{2} & 204 & - & 386 & 415 & 233 & 225 & 416 & 219 & 484 & 2.582 \\
\hline & 23 & - & 68 & 219 & 210 & 431 & 847 & 285 & 42 & 2.125 \\
\hline & 245 & - & 370 & 440 & 209 & 241 & 497 & 238 & 421 & 2.660 \\
\hline \multirow{3}{*}{3} & 176 & 377 & - & 351 & 419 & 187 & 245 & 246 & 288 & 2.289 \\
\hline & 7 & 21 & - & 11 & 126 & 39 & 173 & 157 & 370 & 902 \\
\hline & 189 & 399 & - & 334 & 438 & 163 & 264 & 213 & 297 & 2.297 \\
\hline \multirow{3}{*}{4} & 334 & 203 & 309 & - & 487 & 231 & 204 & 213 & 210 & 2.191 \\
\hline & 267 & 87 & 404 & - & 106 & 116 & 230 & 10 & 6 & 1.226 \\
\hline & 316 & 173 & 348 & - & 488 & 215 & 201 & 246 & 210 & 2.196 \\
\hline \multirow{3}{*}{5} & 337 & 414 & 246 & 184 & - & 199 & 466 & 260 & 328 & 2.434 \\
\hline & 187 & 37 & 100 & 52 & - & 496 & 888 & 83 & 0 & 1.844 \\
\hline & 323 & 484 & 256 & 171 & - & 173 & 522 & 215 & 302 & 2.447 \\
\hline \multirow{3}{*}{6} & 455 & 462 & 226 & 371 & 311 & - & 165 & 320 & 353 & 2.663 \\
\hline & 72 & 472 & 8 & 83 & 65 & - & 416 & 223 & 624 & 1.964 \\
\hline & 374 & 497 & 270 & 359 & 317 & - & 191 & 267 & 386 & 2.661 \\
\hline \multirow{3}{*}{7} & 407 & 428 & 179 & 172 & 347 & 451 & - & 323 & 434 & 2.741 \\
\hline & 319 & 314 & 390 & 96 & 389 & 39 & - & 56 & 776 & 2.379 \\
\hline & 433 & 415 & 151 & 156 & 388 & 419 & - & 325 & 504 & 2.792 \\
\hline \multirow{3}{*}{8} & 284 & 282 & 275 & 359 & 475 & 265 & 401 & - & 326 & 2.667 \\
\hline & 78 & 105 & 569 & 171 & 801 & 457 & 703 & - & 353 & 3.237 \\
\hline & 331 & 255 & 232 & 385 & 470 & 312 & 399 & - & 356 & 2.740 \\
\hline \multirow{3}{*}{9} & 444 & 268 & 364 & 350 & 476 & 477 & 310 & 298 & - & 2.987 \\
\hline & 449 & 215 & 329 & 234 & 44 & 80 & 512 & 174 & - & 2.036 \\
\hline & 367 & 266 & 381 & 292 & 435 & 436 & 359 & 289 & - & 2.825 \\
\hline \multirow{3}{*}{$\Sigma$} & 2.641 & 2.840 & 2.449 & 2.532 & 3.166 & 2.210 & 2.483 & 2.038 & 2.794 & 23.153 \\
\hline & 1.403 & 1.351 & 1.914 & 995 & 2.272 & 1.753 & 4.077 & 1.070 & 2.580 & 17.415 \\
\hline & 2.578 & 2.886 & 2.486 & 2.431 & 3.209 & 2.136 & 2.751 & 1.922 & 2.810 & 23.208 \\
\hline
\end{tabular}

Obs: A primeira linha de cada origem contém os valores das viagens "reais", na segunda linha estão as os resultados estimados pelo QUEENSOD e na terceira linha estão os resultados estimados pelo TransCAD. 
Ao utilizar o TransCAD foram estimadas 23.208 viagens, $0,24 \%$ a mais de viagens que o total "real", enquanto que o QUEENSOD estimou 17.415 viagens, $25 \%$ viagens a menos que o "real".

$\Rightarrow \quad$ Teste 5 (T5):

Este teste simula a situação em que contagens são realizadas nos nós 1, 2, 3, 4, 6, 7, 8 e 9, representando a combinação dos Testes 1 e 3 . Essas contagens permitem a obtenção de 24 informações não redundantes, além das 24 informações de fluxo observado nos arcos. No total essa rede irá possuir 48 informações de fluxo não redundantes, com isso o grau de indeterminação reduz para 91. Em relação à quantidade de observadores, estimase que 16 sejam suficientes para contagem nesta configuração, ilustrada na Figura 4. 8.

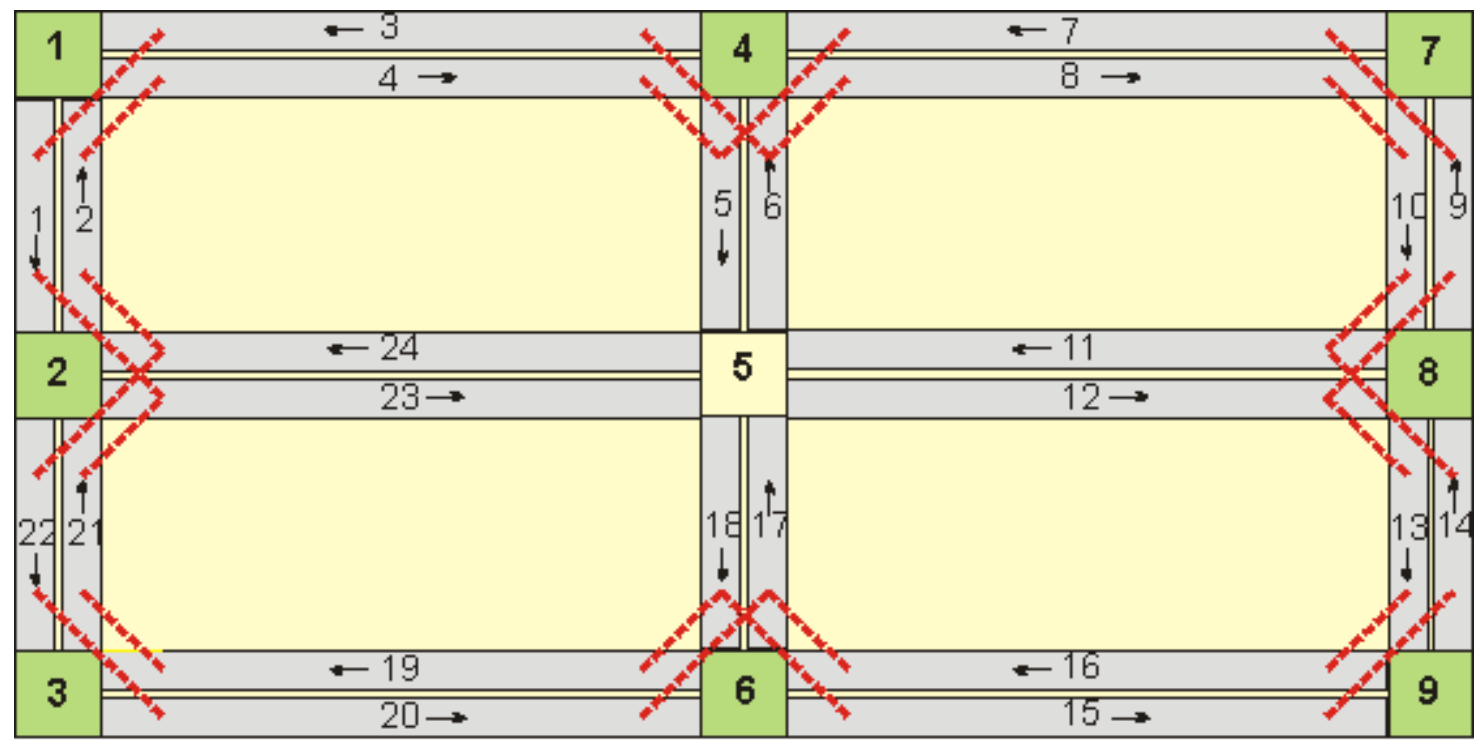

- =-E= "Arco virtual"

$\square$ Nó onde houve contagem de fluxo

Figura 4. 8: Configuração da rede hipotética para o Teste 5

As viagens estimadas considerando cada um dos métodos utilizados estão apresentadas na Tabela 4. 14.

Observe que pelo QUEENSOD foram estimadas 12.492 viagens, $46 \%$ viagens a menos que o "real". Já o TransCAD estimou 22.620 viagens, ou seja, 2,30\% viagens a 
menos que o total "real". Ao considerar o MEMS, o total de viagens estimadas foi 22.636, portanto $2,23 \%$ viagens a menos que o total "real".

Tabela 4. 14: Matriz estimada para o Teste 5

\begin{tabular}{|c|c|c|c|c|c|c|c|c|c|c|}
\hline O\D & 1 & 2 & 3 & 4 & 5 & 6 & 7 & 8 & 9 & $\Sigma$ \\
\hline \multirow{4}{*}{1} & - & 406 & 464 & 330 & 418 & 175 & 276 & 159 & 371 & 2.599 \\
\hline & - & 212 & 4 & 90 & 0 & 76 & 465 & 187 & 80 & 1.114 \\
\hline & - & 361 & 261 & 201 & 302 & 206 & 277 & 97 & 262 & 1.967 \\
\hline & - & 420 & 487 & 261 & 411 & 198 & 332 & 183 & 313 & 2.604 \\
\hline \multirow{4}{*}{2} & 204 & - & 386 & 415 & 233 & 225 & 416 & 219 & 484 & 2.582 \\
\hline & 204 & - & 420 & 6 & 101 & 13 & 103 & 234 & 91 & 1.172 \\
\hline & 259 & - & 462 & 585 & 319 & 310 & 284 & 220 & 400 & 2.839 \\
\hline & 161 & - & 401 & 453 & 215 & 277 & 317 & 192 & 495 & 2.511 \\
\hline \multirow{4}{*}{3} & 176 & 377 & - & 351 & 419 & 187 & 245 & 246 & 288 & 2.289 \\
\hline & 144 & 164 & - & 141 & 20 & 340 & 7 & 47 & 742 & 1.605 \\
\hline & 64 & 508 & - & 183 & 316 & 162 & 318 & 105 & 302 & 1.958 \\
\hline & 175 & 362 & - & 333 & 315 & 235 & 307 & 259 & 359 & 2.344 \\
\hline \multirow{4}{*}{4} & 334 & 203 & 309 & - & 487 & 231 & 204 & 213 & 210 & 2.191 \\
\hline & 44 & 27 & 97 & - & 114 & 101 & 15 & 111 & 121 & 631 \\
\hline & 550 & 213 & 262 & - & 602 & 337 & 177 & 147 & 346 & 2.634 \\
\hline & 282 & 219 & 348 & - & 364 & 252 & 232 & 175 & 260 & 2.132 \\
\hline \multirow{4}{*}{5} & 337 & 414 & 246 & 184 & - & 199 & 466 & 260 & 328 & 2.434 \\
\hline & 101 & 60 & 44 & 373 & - & 235 & 44 & 179 & 79 & 1.114 \\
\hline & 469 & 349 & 321 & 230 & - & 181 & 478 & 274 & 381 & 2.683 \\
\hline & 277 & 478 & 194 & 176 & - & 169 & 364 & 191 & 250 & 2.098 \\
\hline \multirow{4}{*}{6} & 455 & 462 & 226 & 371 & 311 & - & 165 & 320 & 353 & 2.663 \\
\hline & 3 & 0 & 74 & 182 & 138 & - & 78 & 66 & 976 & 1.517 \\
\hline & 222 & 363 & 231 & 401 & 377 & - & 263 & 196 & 534 & 2.587 \\
\hline & 464 & 401 & 199 & 303 & 339 & - & 171 & 399 & 359 & 2.636 \\
\hline \multirow{4}{*}{7} & 407 & 428 & 179 & 172 & 347 & 451 & - & 323 & 434 & 2.741 \\
\hline & 710 & 356 & 54 & 14 & 4 & 153 & - & 243 & 13 & 1.547 \\
\hline & 359 & 331 & 238 & 229 & 432 & 312 & - & 337 & 354 & 2.592 \\
\hline & 477 & 397 & 187 & 185 & 435 & 338 & - & 272 & 490 & 2.782 \\
\hline \multirow{4}{*}{8} & 284 & 282 & 275 & 359 & 475 & 265 & 401 & - & 326 & 2.667 \\
\hline & 216 & 353 & 108 & 115 & 200 & 31 & 387 & - & 356 & 1.764 \\
\hline & 331 & 359 & 177 & 433 & 394 & 312 & 652 & - & 361 & 3.019 \\
\hline & 350 & 271 & 321 & 426 & 366 & 258 & 311 & - & 292 & 2.596 \\
\hline \multirow{4}{*}{9} & 444 & 268 & 364 & 350 & 476 & 477 & 310 & 298 & - & 2.987 \\
\hline & 200 & 494 & 451 & 97 & 120 & 213 & 102 & 351 & - & 2.028 \\
\hline & 320 & 197 & 362 & 255 & 393 & 303 & 166 & 345 & - & 2.341 \\
\hline & 460 & 202 & 373 & 437 & 390 & 472 & 307 & 292 & - & 2.932 \\
\hline \multirow{4}{*}{$\Sigma$} & 2.641 & 2.840 & 2.449 & 2.532 & 3.166 & 2.210 & 2.483 & 2.038 & 2.794 & 23.153 \\
\hline & 1.622 & 1.666 & 1.251 & 1.018 & 698 & 1.162 & 1.201 & 1.418 & 2.457 & 12.492 \\
\hline & 2.574 & 2.681 & 2.314 & 2.517 & 3.135 & 2.123 & 2.615 & 1.721 & 2.940 & 22.620 \\
\hline & 2.645 & 2.751 & 2.510 & 2.573 & 2.835 & 2.201 & 2.340 & 1.962 & 2.819 & 22.636 \\
\hline
\end{tabular}

Obs: A primeira linha de cada origem contém os valores das viagens "reais", na segunda linha estão os resultados estimados pelo QUEENSOD, na terceira linha estão os resultados estimados pelo TransCAD e na quarta linha estão os resultados estimados pelo MEMS. 
Ao considerar o uso de matriz semente $\left(S_{70}\right)$ foram obtidos os resultados apresentados na Tabela 4. 15.

Considerando uma matriz semente correspondente a $70 \%$ da matriz "real", o total de viagens estimadas pelo TransCAD foi 22.843, enquanto que o QUEENSOD estimou 15.117 viagens.

Os dois métodos estimaram mais viagens após fornecer a matriz semente $S_{70}$ e finalmente o QUEENSOD foi capaz de estimar viagens entre todos os pares OD.

Tabela 4. 15: Matriz estimada para o Teste 5, considerando $S_{70}$

\begin{tabular}{|c|c|c|c|c|c|c|c|c|c|c|}
\hline OXD & 1 & 2 & 3 & 4 & 5 & 6 & 7 & 8 & 9 & $\Sigma$ \\
\hline \multirow{3}{*}{1} & - & 406 & 464 & 330 & 418 & 175 & 276 & 159 & 371 & 2.599 \\
\hline & - & 305 & 200 & 183 & 123 & 277 & 123 & 155 & 112 & 1.478 \\
\hline & - & 494 & 397 & 362 & 443 & 143 & 223 & 183 & 291 & 2.536 \\
\hline \multirow{3}{*}{2} & 204 & - & 386 & 415 & 233 & 225 & 416 & 219 & 484 & 2.582 \\
\hline & 303 & - & 117 & 19 & 117 & 38 & 113 & 61 & 96 & 864 \\
\hline & 219 & - & 356 & 410 & 248 & 263 & 479 & 264 & 500 & 2.740 \\
\hline \multirow{3}{*}{3} & 176 & 377 & - & 351 & 419 & 187 & 245 & 246 & 288 & 2.289 \\
\hline & 49 & 111 & - & 149 & 360 & 332 & 52 & 289 & 574 & 1.916 \\
\hline & 161 & 327 & - & 335 & 465 & 154 & 219 & 256 & 259 & 2.176 \\
\hline \multirow{3}{*}{4} & 334 & 203 & 309 & - & 487 & 231 & 204 & 213 & 210 & 2.191 \\
\hline & 100 & 310 & 423 & - & 510 & 61 & 155 & 25 & 301 & 1.884 \\
\hline & 383 & 222 & 316 & - & 505 & 246 & 235 & 228 & 176 & 2.311 \\
\hline \multirow{3}{*}{5} & 337 & 414 & 246 & 184 & - & 199 & 466 & 260 & 328 & 2.434 \\
\hline & 103 & 58 & 145 & 379 & - & 199 & 200 & 107 & 281 & 1.472 \\
\hline & 323 & 419 & 245 & 191 & - & 167 & 522 & 306 & 325 & 2.498 \\
\hline \multirow{3}{*}{6} & 455 & 462 & 226 & 371 & 311 & - & 165 & 320 & 353 & 2.663 \\
\hline & 187 & 109 & 55 & 86 & 223 & - & 100 & 102 & 744 & 1.605 \\
\hline & 399 & 430 & 269 & 375 & 303 & - & 143 & 312 & 324 & 2.555 \\
\hline \multirow{3}{*}{7} & 407 & 428 & 179 & 172 & 347 & 451 & - & 323 & 434 & 2.741 \\
\hline & 117 & 367 & 31 & 94 & 12 & 21 & - & 249 & 12 & 903 \\
\hline & 354 & 460 & 151 & 187 & 328 & 429 & - & 282 & 419 & 2.611 \\
\hline \multirow{3}{*}{8} & 284 & 282 & 275 & 359 & 475 & 265 & 401 & - & 326 & 2.667 \\
\hline & 214 & 67 & 261 & 36 & 13 & 243 & 361 & - & 791 & 1.986 \\
\hline & 294 & 273 & 221 & 337 & 489 & 274 & 431 & - & 304 & 2.623 \\
\hline \multirow{3}{*}{9} & 444 & 268 & 364 & 350 & 476 & 477 & 310 & 298 & - & 2.987 \\
\hline & 332 & 343 & 553 & 436 & 498 & 555 & 100 & 193 & - & 3.010 \\
\hline & 377 & 275 & 314 & 334 & 500 & 459 & 271 & 263 & $\therefore$ & 2.793 \\
\hline \multirow{3}{*}{$\Sigma$} & 2.641 & 2.840 & 2.449 & 2.532 & 3.166 & 2.210 & 2.483 & 2.038 & 2.794 & 23.153 \\
\hline & 1.404 & 1.669 & 1.785 & 1.382 & 1.856 & 1.726 & 1.203 & 1.181 & 2.911 & 15.117 \\
\hline & 2.510 & 2.900 & 2.271 & 2.532 & 3.282 & 2.135 & 2.522 & 2.094 & 2.597 & 22.843 \\
\hline
\end{tabular}

Obs: A primeira linha de cada origem contém os valores das viagens "reais", na segunda linha estão as os resultados estimados pelo QUEENSOD e na terceira linha estão os resultados estimados pelo TransCAD. 
$\Rightarrow \quad$ Teste 6 (T6):

O Teste 6 considera a combinação dos Testes 2 e 3, com isso, 32 "arcos virtuais" são inseridos à rede, conforme ilustrado na Figura 4. 9.

Para esta verificação a quantidade de informações não redundantes de fluxos é 56 , isso faz com que o grau de indeterminação passe a ser 83 , ou seja, $40 \%$ menor que a indeterminação quando não são inseridos "arcos virtuais".

Serão necessários 20 observadores para fazer a contagem de fluxo nessa rede.

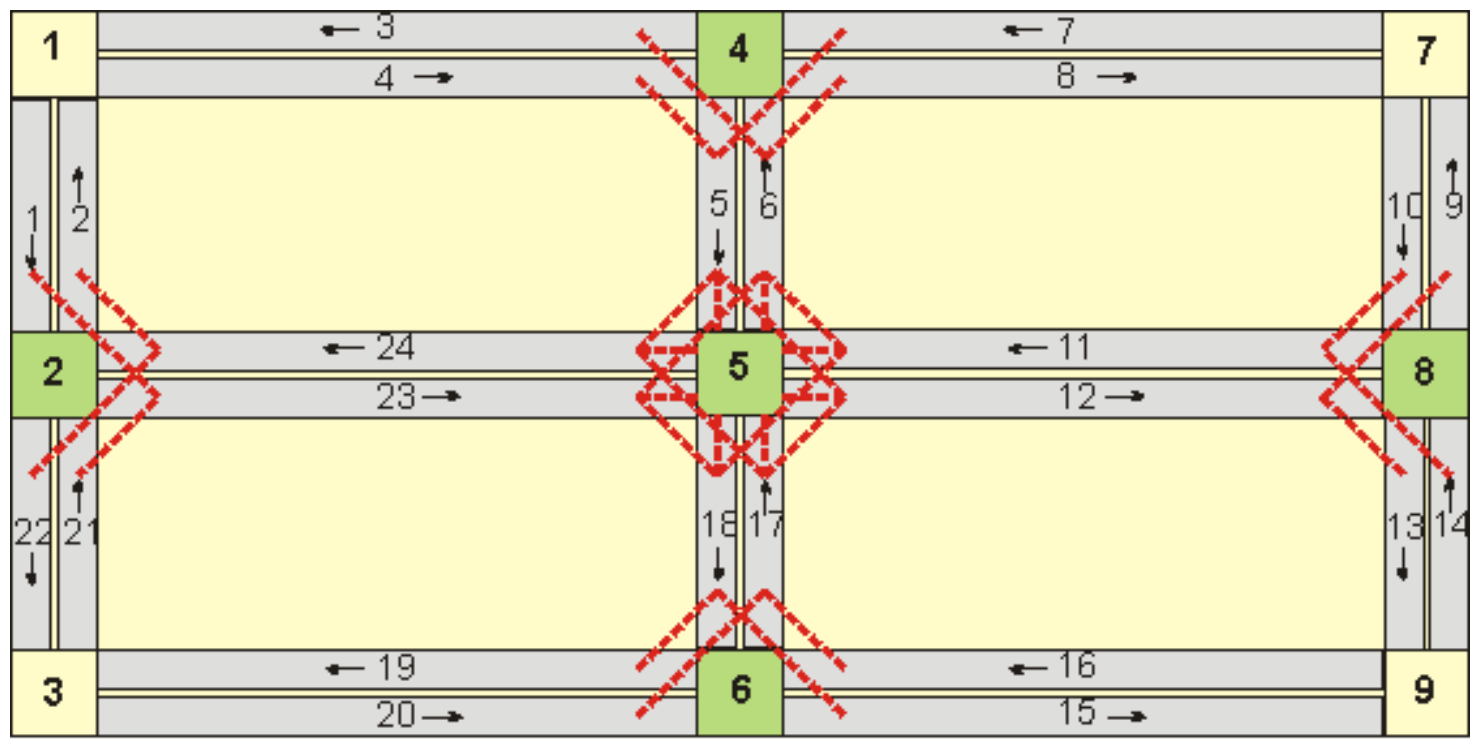

"Arco virtual"

$\square$ Nó onde houve contagem de fluxo

Figura 4. 9: Configuração da rede hipotética para o Teste 6

Na Tabela 4. 16 são apresentadas as matrizes estimadas considerando QUEENSOD, TransCAD (ambos com matriz semente unitária) e método das médias sucessivas.

A quantidade total de viagens estimadas pelo TransCAD foi $21.380,7,66 \%$ menos viagens que o total "real". O total estimado pelo QUEENSOD foi igual a 10.250 viagens, foram estimadas $56 \%$ de viagens a menos que o "real", enquanto que o MEMS estimou 22.873 viagens, um total $1,21 \%$ menor que o "real". 
Tabela 4. 16: Matriz estimada para o Teste 6

\begin{tabular}{|c|c|c|c|c|c|c|c|c|c|c|}
\hline O\D & 1 & 2 & 3 & 4 & 5 & 6 & 7 & 8 & 9 & $\Sigma$ \\
\hline \multirow{4}{*}{1} & - & 406 & 464 & 330 & 418 & 175 & 276 & 159 & 371 & 2.599 \\
\hline & - & 100 & 112 & 4 & 90 & 0 & 76 & 165 & 187 & 734 \\
\hline & - & 433 & 369 & 421 & 475 & 175 & 270 & 202 & 252 & 2.597 \\
\hline & - & 410 & 469 & 320 & 432 & 222 & 329 & 133 & 344 & 2.660 \\
\hline \multirow{4}{*}{2} & 204 & - & 386 & 415 & 233 & 225 & 416 & 219 & 484 & 2.582 \\
\hline & 80 & - & 124 & 120 & 26 & 91 & 13 & 203 & 394 & 1.051 \\
\hline & 275 & - & 324 & 288 & 163 & 269 & 241 & 218 & 368 & 2.146 \\
\hline & 216 & - & 459 & 461 & 183 & 201 & 406 & 270 & 371 & 2.566 \\
\hline \multirow{4}{*}{3} & 176 & 377 & - & 351 & 419 & 187 & 245 & 246 & 288 & 2.289 \\
\hline & 91 & 144 & - & 164 & 281 & 173 & 110 & 97 & 47 & 1.107 \\
\hline & 159 & 245 & - & 326 & 403 & 213 & 165 & 198 & 394 & 2.103 \\
\hline & 178 & 396 & - & 322 & 433 & 183 & 245 & 235 & 262 & 2.254 \\
\hline \multirow{4}{*}{4} & 334 & 203 & 309 & - & 487 & 231 & 204 & 213 & 210 & 2.191 \\
\hline & 342 & 44 & 122 & - & 102 & 174 & 53 & 15 & 76 & 929 \\
\hline & 206 & 169 & 258 & - & 723 & 224 & 287 & 149 & 267 & 2.283 \\
\hline & 373 & 182 & 247 & - & 498 & 255 & 255 & 161 & 174 & 2.143 \\
\hline \multirow{4}{*}{5} & 337 & 414 & 246 & 184 & - & 199 & 466 & 260 & 328 & 2.434 \\
\hline & 98 & 77 & 60 & 98 & - & 173 & 135 & 97 & 182 & 919 \\
\hline & 395 & 322 & 350 & 222 & - & 160 & 398 & 287 & 377 & 2.511 \\
\hline & 264 & 310 & 188 & 193 & - & 179 & 468 & 192 & 394 & 2.187 \\
\hline \multirow{4}{*}{6} & 455 & 462 & 226 & 371 & 311 & - & 165 & 320 & 353 & 2.663 \\
\hline & 110 & 13 & 50 & 74 & 220 & - & 181 & 60 & 100 & 808 \\
\hline & 481 & 239 & 191 & 244 & 356 & - & 78 & 170 & 383 & 2.142 \\
\hline & 447 & 450 & 222 & 274 & 318 & - & 206 & 278 & 432 & 2.627 \\
\hline \multirow{4}{*}{7} & 407 & 428 & 179 & 172 & 347 & 451 & - & 323 & 434 & 2.741 \\
\hline & 776 & 110 & 196 & 154 & 110 & 154 & - & 153 & 132 & 1.785 \\
\hline & 608 & 254 & 194 & 186 & 438 & 308 & - & 383 & 395 & 2.766 \\
\hline & 452 & 496 & 206 & 149 & 260 & 476 & - & 388 & 428 & 2.855 \\
\hline \multirow{4}{*}{8} & 284 & 282 & 275 & 359 & 475 & 265 & 401 & - & 326 & 2.667 \\
\hline & 162 & 230 & 393 & 108 & 123 & 33 & 131 & - & 287 & 1.466 \\
\hline & 178 & 201 & 243 & 320 & 349 & 154 & 410 & - & 286 & 2.141 \\
\hline & 333 & 261 & 340 & 412 & 361 & 263 & 323 & - & 302 & 2.597 \\
\hline \multirow{4}{*}{9} & 444 & 268 & 364 & 350 & 476 & 477 & 310 & 298 & - & 2.987 \\
\hline & 156 & 151 & 444 & 101 & 131 & 127 & 241 & 101 & - & 1.452 \\
\hline & 376 & 270 & 485 & 320 & 391 & 383 & 220 & 246 & - & 2.691 \\
\hline & 467 & 274 & 315 & 397 & 431 & 444 & 357 & 300 & - & 2.984 \\
\hline \multirow{4}{*}{$\Sigma$} & 2.641 & 2.840 & 2.449 & 2.532 & 3.166 & 2.210 & 2.483 & 2.038 & 2.794 & 23.153 \\
\hline & 1.814 & 868 & 1.501 & 822 & 1.084 & 925 & 940 & 892 & 1.405 & 10.250 \\
\hline & 2.678 & 2.133 & 2.414 & 2.327 & 3.298 & 1.886 & 2.069 & 1.853 & 2.722 & 21.380 \\
\hline & 2.730 & 2.780 & 2.447 & 2.527 & 2.916 & 2.222 & 2.588 & 1.956 & 2.707 & 22.873 \\
\hline
\end{tabular}

Obs: A primeira linha de cada origem contém os valores das viagens "reais", na segunda linha estão os resultados estimados pelo QUEENSOD, na terceira linha estão os resultados estimados pelo TransCAD e na quarta linha estão os resultados estimados pelo MEMS. 
Na Tabela 4. 17 são apresentados os resultados estimados pelo TransCAD e pelo QUEENSOD considerando uma matriz semente equivalente a $70 \%$ da "real" $\left(S_{70}\right)$.

Ao considerar o fornecimento da matriz semente $S_{70}$, o total de viagens estimadas pelo TransCAD foi 23.143, 10 viagens a menos que o total "real". Já o QUEENSOD estimou 15.696 viagens, um total $32 \%$ menor que o "real".

Tabela 4. 17: Matriz estimada para o Teste 6, considerando $S_{70}$

\begin{tabular}{|c|c|c|c|c|c|c|c|c|c|c|}
\hline O\D & 1 & 2 & 3 & 4 & 5 & 6 & 7 & 8 & 9 & $\Sigma$ \\
\hline \multirow{3}{*}{1} & - & 406 & 464 & 330 & 418 & 175 & 276 & 159 & 371 & 2.599 \\
\hline & - & 350 & 125 & 300 & 183 & 130 & 297 & 143 & 155 & 1.683 \\
\hline & - & 456 & 457 & 369 & 435 & 143 & 280 & 144 & 394 & 2.676 \\
\hline \multirow{3}{*}{2} & 204 & - & 386 & 415 & 233 & 225 & 416 & 219 & 484 & 2.582 \\
\hline & 112 & - & 133 & 157 & 419 & 170 & 338 & 113 & 601 & 2.043 \\
\hline & 237 & - & 357 & 387 & 222 & 256 & 449 & 210 & 430 & 2.549 \\
\hline \multirow{3}{*}{3} & 176 & 377 & - & 351 & 419 & 187 & 245 & 246 & 288 & 2.289 \\
\hline & 96 & 300 & - & 114 & 149 & 100 & 132 & 52 & 289 & 1.232 \\
\hline & 172 & 380 & - & 386 & 394 & 168 & 270 & 249 & 251 & 2.270 \\
\hline \multirow{3}{*}{4} & 334 & 203 & 309 & - & 487 & 231 & 204 & 213 & 210 & 2.191 \\
\hline & 377 & 179 & 203 & - & 100 & 164 & 61 & 415 & 26 & 1.524 \\
\hline & 372 & 241 & 344 & - & 416 & 229 & 203 & 244 & 231 & 2.280 \\
\hline \multirow{3}{*}{5} & 337 & 414 & 246 & 184 & - & 199 & 466 & 260 & 328 & 2.434 \\
\hline & 37 & 23 & 96 & 298 & - & 179 & 199 & 100 & 107 & 1.038 \\
\hline & 341 & 375 & 214 & 197 & - & 189 & 472 & 223 & 313 & 2.323 \\
\hline \multirow{3}{*}{6} & 455 & 462 & 226 & 371 & 311 & - & 165 & 320 & 353 & 2.663 \\
\hline & 100 & 187 & 230 & 55 & 86 & - & 203 & 225 & 340 & 1.425 \\
\hline & 494 & 446 & 231 & 343 & 344 & - & 144 & 338 & 300 & 2.642 \\
\hline \multirow{3}{*}{7} & 407 & 428 & 179 & 172 & 347 & 451 & - & 323 & 434 & 2.741 \\
\hline & 474 & 157 & 274 & 130 & 443 & 102 & - & 421 & 129 & 2.129 \\
\hline & 447 & 493 & 158 & 193 & 373 & 421 & - & 303 & 391 & 2.777 \\
\hline \multirow{3}{*}{8} & 284 & 282 & 275 & 359 & 475 & 265 & 401 & - & 326 & 2.667 \\
\hline & 100 & 103 & 487 & 100 & 420 & 13 & 233 & - & 131 & 1.587 \\
\hline & 262 & 252 & 304 & 335 & 424 & 248 & 416 & - & 365 & 2.606 \\
\hline \multirow{3}{*}{9} & 444 & 268 & 364 & 350 & 476 & 477 & 310 & 298 & - & 2.987 \\
\hline & 691 & 522 & 393 & 153 & 159 & 413 & 495 & 210 & - & 3.035 \\
\hline & 439 & 320 & 371 & 383 & 485 & 453 & 311 & 257 & - & 3.019 \\
\hline \multirow{3}{*}{$\Sigma$} & 2.641 & 2.840 & 2.449 & 2.532 & 3.166 & 2.210 & 2.483 & 2.038 & 2.794 & 23.153 \\
\hline & 1.987 & 1.820 & 1.941 & 1.307 & 1.959 & 1.270 & 1.958 & 1.678 & 1.777 & 15.696 \\
\hline & 2.764 & 2.963 & 2.436 & 2.592 & 3.094 & 2.106 & 2.545 & 1.969 & 2.675 & 23.143 \\
\hline
\end{tabular}

Obs: A primeira linha de cada origem contém os valores das viagens "reais", na segunda linha estão as os resultados estimados pelo QUEENSOD e na terceira linha estão os resultados estimados pelo TransCAD. 
$\Rightarrow \quad$ Teste 7 (T7):

Foi considerado contagens de tráfego em todas as interseções da rede viária e isso possibilitou adicionar 40 informações. Com isso, o número total de informações de fluxo é 64 e o grau de indeterminação passa a ser 75 . Este teste representa a quantidade máxima de informações não redundantes de fluxo que podem ser adicionadas à rede em estudo.

São necessários 24 observadores para fazer a contagem de fluxo nessa rede, cuja configuração está apresentada na Figura 4. 10.

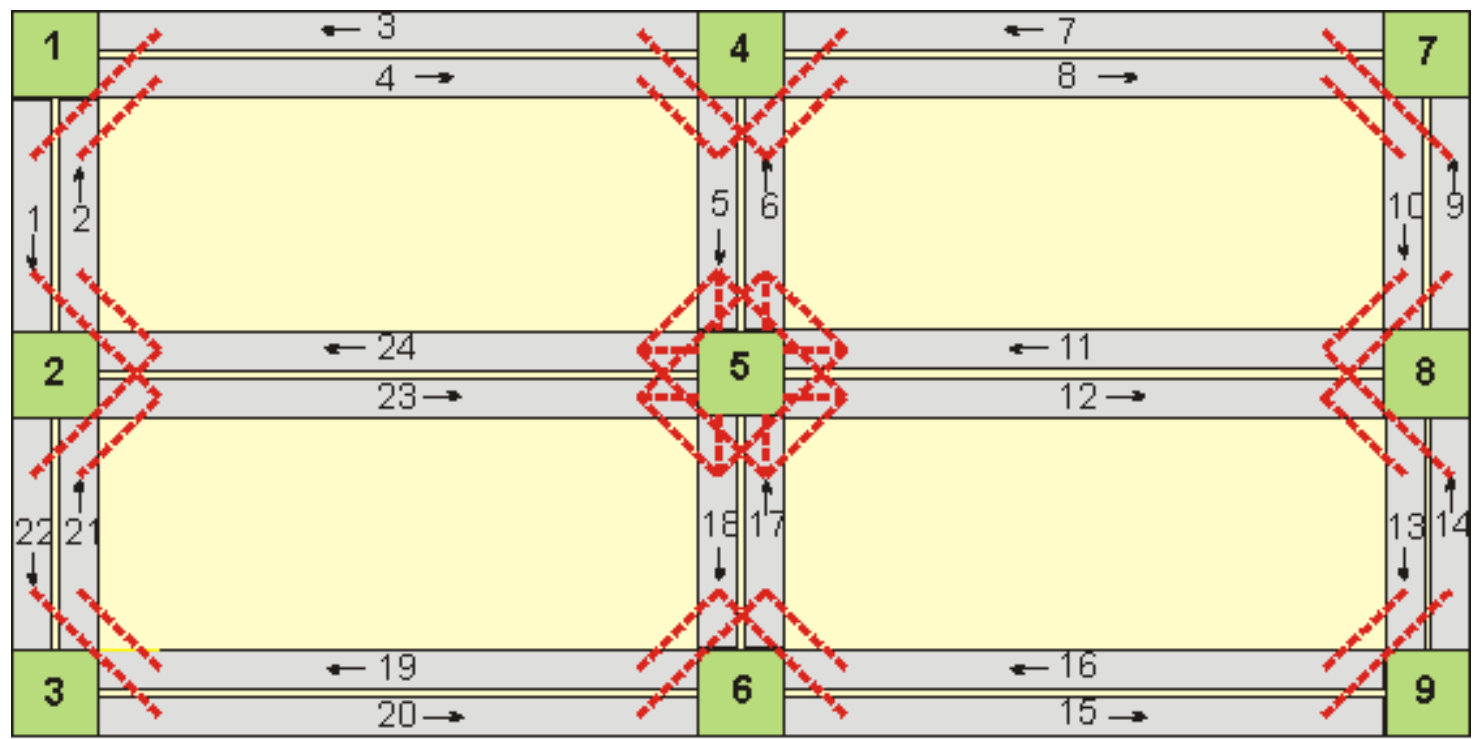

"Arco virtual"

$\square$ Nó onde houve contagem de fluxo

Figura 4. 10: Configuração da rede hipotética para o Teste 7

As matrizes estimadas ao utilizar os métodos do QUEENSOD, TransCAD (ambos com matriz semente unitária) e das médias sucessivas, estão apresentadas na Tabela 4. 18.

Acredita-se que com aumento da quantidade de informações a matriz estimada se acerque da "real". Além disso, será que o aumento da quantidade de iterações pode contribuir para obtenção de resultados melhores? Apesar de ter sido convencionado no Capítulo 3 que em todos os testes envolvendo o MEMS seriam realizadas 250 iterações, fez-se a opção por verificar neste teste os efeitos ocasionados por um número maior de iterações e foi decidido realizar 500 iterações, o dobro do que vinha sendo feito. 
É possível observar que o total de viagens estimadas pelo TransCAD foi igual a 22.225 viagens, um total $4 \%$ menor que o "real", enquanto que o MEMS estimou 22.513 viagens após 250 iterações (2,76\% menos viagens que o total "real”) e 23.020 viagens após 500 iterações $(0,57 \%$ menos viagem que o total "real"). Já o QUEENSOD estimou um total igual a 10.825 viagens, $53 \%$ de viagens a menos que o "real".

Ao fornecer uma matriz semente $70 \%$ menor que a "real" $\left(S_{70}\right)$, as matrizes estimadas pelo QUEENSOD e pelo TransCAD são as apresentadas na Tabela 4. 19. O total de viagens estimadas, ao fornecer $S_{70}$, pelo QUEENSOD foi igual a 15.515 viagens, 33\% menos viagens que o "real". Enquanto que o TransCAD estimou 23.390, 1,02\% a mais de viagens em comparação ao "real".

\section{- Variação da matriz semente}

Outra questão relacionada à matriz semente diz respeito ao efeito do crescimento desigual no tempo das viagens entre diferentes pares OD: dado que matrizes sementes geralmente não mantêm proporcionalidade com as matrizes OD atuais. Assim, uma matriz semente com a qualidade de $S_{70}$ dificilmente existiria na prática.

Então, qual efeito causado pela variação da matriz semente nas matrizes estimadas? Uma matriz semente que não seja proporcional a matriz "real" seria capaz de estimar bons resultados? Para responder a esse questionamento fez-se a opção por variar através de números aleatórios (na) a matriz semente $S_{70}$ em $\pm 10 \%$ e, com isso, gerar a matriz semente Sem $_{10}$ e em $\pm 20 \%$, que resulta na matriz semente Sem $_{20}$. As matrizes estão apresentadas na Tabela 4.20.

Nos Testes 7, 8 e 9 a variação da matriz semente será considerada, com objetivo de responder aos questionamentos apresentados. 
Tabela 4. 18: Matriz estimada para o Teste 7

\begin{tabular}{|c|c|c|c|c|c|c|c|c|c|c|}
\hline O\D & 1 & 2 & 3 & 4 & 5 & 6 & 7 & 8 & 9 & $\Sigma$ \\
\hline \multirow{5}{*}{1} & - & 406 & 464 & 330 & 418 & 175 & 276 & 159 & 371 & 2.599 \\
\hline & - & 230 & 123 & 98 & 115 & 188 & 255 & 157 & 113 & 1.279 \\
\hline & - & 362 & 361 & 223 & 335 & 155 & 209 & 179 & 309 & 2.133 \\
\hline & - & 440 & 470 & 353 & 376 & 156 & 304 & 160 & 341 & 2.600 \\
\hline & - & 384 & 443 & 353 & 430 & 176 & 269 & 148 & 337 & 2.539 \\
\hline \multirow{5}{*}{2} & 204 & - & 386 & 415 & 233 & 225 & 416 & 219 & 484 & 2.582 \\
\hline & 192 & - & 193 & 328 & 117 & 78 & 212 & 187 & 187 & 1.493 \\
\hline & 233 & - & 353 & 340 & 267 & 192 & 292 & 273 & 371 & 2.321 \\
\hline & 190 & - & 343 & 390 & 240 & 202 & 374 & 239 & 454 & 2.432 \\
\hline & 211 & - & 403 & 402 & 249 & 204 & 407 & 240 & 455 & 2.571 \\
\hline \multirow{5}{*}{3} & 176 & 377 & - & 351 & 419 & 187 & 245 & 246 & 288 & 2.289 \\
\hline & 139 & 110 & - & 103 & 141 & 59 & 137 & 220 & 262 & 1.172 \\
\hline & 179 & 341 & - & 369 & 326 & 228 & 208 & 326 & 275 & 2.252 \\
\hline & 157 & 339 & - & 386 & 377 & 201 & 234 & 259 & 308 & 2.260 \\
\hline & 167 & 365 & - & 335 & 402 & 203 & 259 & 246 & 284 & 2.261 \\
\hline \multirow{5}{*}{4} & 334 & 203 & 309 & - & 487 & 231 & 204 & 213 & 210 & 2.191 \\
\hline & 77 & 107 & 127 & - & 113 & 109 & 187 & 189 & 108 & 1.017 \\
\hline & 301 & 204 & 252 & - & 490 & 268 & 269 & 268 & 158 & 2.210 \\
\hline & 337 & 223 & 324 & - & 432 & 242 & 224 & 233 & 231 & 2.245 \\
\hline & 364 & 222 & 329 & - & 470 & 211 & 217 & 221 & 204 & 2.238 \\
\hline \multirow{5}{*}{5} & 337 & 414 & 246 & 184 & - & 199 & 466 & 260 & 328 & 2.434 \\
\hline & 123 & 167 & 98 & 110 & - & 137 & 131 & 99 & 160 & 1.025 \\
\hline & 274 & 349 & 220 & 172 & - & 162 & 301 & 185 & 402 & 2.065 \\
\hline & 321 & 376 & 249 & 180 & - & 177 & 434 & 241 & 310 & 2.288 \\
\hline & 311 & 403 & 223 & 200 & - & 206 & 470 & 249 & 333 & 2.395 \\
\hline \multirow{5}{*}{6} & 455 & 462 & 226 & 371 & 311 & - & 165 & 320 & 353 & 2.663 \\
\hline & 123 & 191 & 154 & 102 & 68 & - & 149 & 89 & 200 & 1.076 \\
\hline & 391 & 497 & 248 & 328 & 368 & - & 178 & 207 & 410 & 2.627 \\
\hline & 419 & 413 & 209 & 333 & 341 & - & 155 & 353 & 319 & 2.542 \\
\hline & 453 & 468 & 205 & 383 & 319 & - & 176 & 295 & 332 & 2.630 \\
\hline \multirow{5}{*}{7} & 407 & 428 & 179 & 172 & 347 & 451 & - & 323 & 434 & 2.741 \\
\hline & 388 & 196 & 172 & 76 & 89 & 155 & - & 159 & 118 & 1.354 \\
\hline & 248 & 335 & 178 & 186 & 341 & 373 & - & 403 & 468 & 2.532 \\
\hline & 438 & 465 & 160 & 153 & 309 & 416 & - & 300 & 400 & 2.642 \\
\hline & 420 & 444 & 195 & 168 & 323 & 437 & - & 317 & 443 & 2.748 \\
\hline \multirow{5}{*}{8} & 284 & 282 & 275 & 359 & 475 & 265 & 401 & - & 326 & 2.667 \\
\hline & 98 & 134 & 260 & 199 & 198 & 104 & 135 & - & 184 & 1.313 \\
\hline & 331 & 270 & 278 & 485 & 355 & 259 & 509 & - & 390 & 2.877 \\
\hline & 301 & 290 & 248 & 391 & 441 & 254 & 412 & - & 344 & 2.682 \\
\hline & 302 & 261 & 260 & 392 & 460 & 271 & 427 & - & 342 & 2.715 \\
\hline \multirow{5}{*}{9} & 444 & 268 & 364 & 350 & 476 & 477 & 310 & 298 & - & 2.987 \\
\hline & 129 & 146 & 140 & 266 & 149 & 118 & 73 & 77 & - & 1.097 \\
\hline & 486 & 321 & 387 & 382 & 560 & 389 & 366 & 317 & - & 3.208 \\
\hline & 406 & 257 & 337 & 367 & 451 & 431 & 294 & 279 & - & 2.822 \\
\hline & 443 & 271 & 353 & 341 & 439 & 443 & 325 & 308 & - & 2.923 \\
\hline \multirow{5}{*}{$\Sigma$} & 2.641 & 2.840 & 2.449 & 2.532 & 3.166 & 2.210 & 2.483 & 2.038 & 2.794 & 23.153 \\
\hline & 1.268 & 1.281 & 1.267 & 1.282 & 991 & 949 & 1.280 & 1.178 & 1.331 & 10.825 \\
\hline & 2.443 & 2.679 & 2.277 & 2.485 & 3.042 & 2.026 & 2.332 & 2.158 & 2.783 & 22.225 \\
\hline & 2.568 & 2.803 & 2.340 & 2.554 & 2.967 & 2.078 & 2.432 & 2.064 & 2.708 & 22.513 \\
\hline & 2.670 & 2.819 & 2.410 & 2.573 & 3.091 & 2.153 & 2.550 & 2.024 & 2.730 & 23.020 \\
\hline
\end{tabular}

Obs: A primeira linha de cada origem contém os valores das viagens "reais", na segunda linha estão os resultados estimados pelo QUEENSOD, na terceira linha estão os resultados estimados pelo TransCAD, na quarta linha estão os resultados estimados pelo MEMS com 250 iterações e na quinta linha os resultados estimados pelo MEMS com 500 iterações. 
Tabela 4. 19: Matriz estimada para o Teste 7 , considerando $S_{70}$

\begin{tabular}{|c|c|c|c|c|c|c|c|c|c|c|}
\hline O\D & 1 & 2 & 3 & 4 & 5 & 6 & 7 & 8 & 9 & $\Sigma$ \\
\hline \multirow{3}{*}{1} & - & 406 & 464 & 330 & 418 & 175 & 276 & 159 & 371 & 2.599 \\
\hline & - & 380 & 191 & 194 & 347 & 100 & 202 & 167 & 100 & 1.680 \\
\hline & - & 459 & 466 & 349 & 467 & 163 & 256 & 162 & 343 & 2.664 \\
\hline \multirow{3}{*}{2} & 204 & - & 386 & 415 & 233 & 225 & 416 & 219 & 484 & 2.582 \\
\hline & 158 & - & 228 & 432 & 246 & 59 & 99 & 137 & 258 & 1.616 \\
\hline & 183 & - & 362 & 444 & 216 & 193 & 428 & 237 & 455 & 2.518 \\
\hline \multirow{3}{*}{3} & 176 & 377 & - & 351 & 419 & 187 & 245 & 246 & 288 & 2.289 \\
\hline & 226 & 121 & - & 189 & 143 & 98 & 317 & 352 & 271 & 1.717 \\
\hline & 188 & 334 & - & 386 & 484 & 166 & 274 & 214 & 296 & 2.341 \\
\hline \multirow{3}{*}{4} & 334 & 203 & 309 & - & 487 & 231 & 204 & 213 & 210 & 2.191 \\
\hline & 279 & 170 & 201 & - & 203 & 165 & 209 & 231 & 213 & 1.671 \\
\hline & 318 & 185 & 276 & - & 470 & 250 & 223 & 236 & 211 & 2.169 \\
\hline \multirow{3}{*}{5} & 337 & 414 & 246 & 184 & - & 199 & 466 & 260 & 328 & 2.434 \\
\hline & 330 & 210 & 90 & 287 & - & 172 & 131 & 128 & 92 & 1.439 \\
\hline & 327 & 451 & 282 & 162 & - & 202 & 474 & 277 & 323 & 2.498 \\
\hline \multirow{3}{*}{6} & 455 & 462 & 226 & 371 & 311 & - & 165 & 320 & 353 & 2.663 \\
\hline & 361 & 347 & 131 & 109 & 290 & - & 287 & 100 & 203 & 1.828 \\
\hline & 479 & 443 & 228 & 332 & 331 & - & 150 & 355 & 332 & 2.650 \\
\hline \multirow{3}{*}{7} & 407 & 428 & 179 & 172 & 347 & 451 & - & 323 & 434 & 2.741 \\
\hline & 396 & 141 & 291 & 92 & 123 & 250 & - & 187 & 152 & 1.631 \\
\hline & 399 & 455 & 161 & 183 & 348 & 409 & - & 356 & 414 & 2.725 \\
\hline \multirow{3}{*}{8} & 284 & 282 & 275 & 359 & 475 & 265 & 401 & - & 326 & 2.667 \\
\hline & 129 & 398 & 366 & 400 & 112 & 76 & 222 & - & 335 & 2.038 \\
\hline & 269 & 263 & 270 & 331 & 466 & 287 & 435 & - & 346 & 2.666 \\
\hline \multirow{3}{*}{9} & 444 & 268 & 364 & 350 & 476 & 477 & 310 & 298 & - & 2.987 \\
\hline & 290 & 110 & 231 & 478 & 115 & 128 & 231 & 312 & - & 1.894 \\
\hline & 495 & 295 & 406 & 366 & 500 & 458 & 324 & 314 & - & 3.158 \\
\hline \multirow{3}{*}{$\Sigma$} & 2.641 & 2.840 & 2.449 & 2.532 & 3.166 & 2.210 & 2.483 & 2.038 & 2.794 & 23.153 \\
\hline & 2.168 & 1.876 & 1.729 & 2.179 & 1.580 & 1.048 & 1.697 & 1.614 & 1.623 & 15.515 \\
\hline & 2.658 & 2.885 & 2.451 & 2.553 & 3.282 & 2.128 & 2.564 & 2.150 & 2.719 & 23.390 \\
\hline
\end{tabular}

Obs: A primeira linha de cada origem contém os valores das viagens "reais", na segunda linha estão as os resultados estimados pelo QUEENSOD e na terceira linha estão os resultados estimados pelo TransCAD. 
Tabela 4. 20: Matrizes semente

\begin{tabular}{|c|c|c|c|c|c|c|c|c|c|c|c|}
\hline & O\D & 1 & 2 & 3 & 4 & 5 & 6 & 7 & 8 & 9 & $\Sigma$ \\
\hline \multirow{10}{*}{$\stackrel{\stackrel{乛}{\varepsilon}}{\mathcal{E}}$} & 1 & - & 269 & 317 & 225 & 287 & 120 & 200 & 106 & 284 & 1.808 \\
\hline & 2 & 151 & - & 296 & 291 & 153 & 145 & 285 & 143 & 364 & 1.828 \\
\hline & 3 & 113 & 248 & - & 224 & 281 & 144 & 171 & 189 & 221 & 1.591 \\
\hline & 4 & 225 & 131 & 203 & - & 365 & 161 & 148 & 136 & 138 & 1.507 \\
\hline & 5 & 247 & 306 & 187 & 139 & - & 139 & 349 & 165 & 231 & 1.763 \\
\hline & 6 & 347 & 311 & 163 & 266 & 230 & - & 118 & 203 & 231 & 1.869 \\
\hline & 7 & 278 & 329 & 126 & 131 & 233 & 327 & - & 221 & 317 & 1.962 \\
\hline & 8 & 214 & 180 & 183 & 237 & 327 & 201 & 291 & - & 208 & 1.841 \\
\hline & 9 & 290 & 183 & 231 & 237 & 363 & 323 & 202 & 223 & - & 2.052 \\
\hline & $\Sigma$ & 1.865 & 1.957 & 1.706 & 1.750 & 2.239 & 1.560 & 1.764 & 1.386 & 1.994 & 16.221 \\
\hline \multirow{10}{*}{ ฝి } & 1 & - & 253 & 309 & 219 & 281 & 117 & 206 & 100 & 308 & 1.793 \\
\hline & 2 & 159 & - & 321 & 292 & 143 & 132 & 279 & 133 & 390 & 1.849 \\
\hline & 3 & 103 & 231 & - & 201 & 268 & 157 & 170 & 206 & 240 & 1.576 \\
\hline & 4 & 216 & 120 & 189 & - & 390 & 160 & 154 & 124 & 129 & 1.482 \\
\hline & 5 & 257 & 322 & 202 & 149 & - & 139 & 372 & 148 & 232 & 1.821 \\
\hline & 6 & 376 & 299 & 168 & 273 & 242 & - & 120 & 182 & 216 & 1.876 \\
\hline & 7 & 270 & 357 & 126 & 141 & 224 & 337 & - & 215 & 331 & 2.001 \\
\hline & 8 & 229 & 163 & 174 & 223 & 321 & 216 & 302 & - & 188 & 1.816 \\
\hline & 9 & 270 & 178 & 207 & 229 & 393 & 313 & 188 & 237 & - & 2.015 \\
\hline & $\Sigma$ & 1.880 & 1.923 & 1.696 & 1.727 & 2.262 & 1.571 & 1.791 & 1.345 & 2.034 & 16.229 \\
\hline
\end{tabular}

Os resultados estimados pelo QUEENSOD e TransCAD considerando o uso da matriz Sem $_{10}$ estão apresentados na Tabela 4. 21.

Foram estimadas, considerando o TransCAD, um total de 22.952 viagens, $0,87 \%$ viagens estimadas a menos que o total "real". Já o QUEENSOD estimou 16.807 viagens, um total de viagens estimadas $27 \%$ menor que o "real".

Os valores estimados considerando matriz semente Sem $_{20}$ estão na Tabela 4.22.

O TransCAD, ao considerar Sem $_{20}$, estimou 22.401 viagens, $3,25 \%$ viagens a menos que o "real", enquanto que o QUEENSOD estimou 15.377, um total de $34 \%$ de viagens estimadas a menos que o "real". 
Tabela 4. 21: Matriz estimada para o Teste 7, considerando Sem $_{10}$

\begin{tabular}{|c|c|c|c|c|c|c|c|c|c|c|}
\hline O\D & 1 & 2 & 3 & 4 & 5 & 6 & 7 & 8 & 9 & $\Sigma$ \\
\hline \multirow{3}{*}{1} & - & 406 & 464 & 330 & 418 & 175 & 276 & 159 & 371 & 2.599 \\
\hline & - & 794 & 440 & 497 & 40 & 26 & 591 & 147 & 61 & 2.596 \\
\hline & - & 414 & 414 & 346 & 462 & 189 & 256 & 183 & 358 & 2.621 \\
\hline \multirow{3}{*}{2} & 204 & - & 386 & 415 & 233 & 225 & 416 & 219 & 484 & 2.582 \\
\hline & 218 & - & 404 & 75 & 200 & 13 & 131 & 449 & 97 & 1.587 \\
\hline & 176 & - & 331 & 447 & 254 & 195 & 428 & 250 & 491 & 2.573 \\
\hline \multirow{3}{*}{3} & 176 & 377 & - & 351 & 419 & 187 & 245 & 246 & 288 & 2.289 \\
\hline & 78 & 1.108 & - & 100 & 141 & 452 & 45 & 271 & 710 & 2.905 \\
\hline & 179 & 315 & - & 385 & 365 & 165 & 209 & 237 & 257 & 2.112 \\
\hline \multirow{3}{*}{4} & 334 & 203 & 309 & - & 487 & 231 & 204 & 213 & 210 & 2.191 \\
\hline & 93 & 200 & 290 & - & 1.486 & 101 & 360 & 30 & 110 & 2.670 \\
\hline & 301 & 177 & 359 & - & 460 & 261 & 229 & 192 & 199 & 2.179 \\
\hline \multirow{3}{*}{5} & 337 & 414 & 246 & 184 & - & 199 & 466 & 260 & 328 & 2.434 \\
\hline & 2 & 272 & 2 & 138 & - & 158 & 137 & 331 & 2 & 1.042 \\
\hline & 377 & 463 & 269 & 210 & - & 227 & 470 & 287 & 324 & 2.626 \\
\hline \multirow{3}{*}{6} & 455 & 462 & 226 & 371 & 311 & - & 165 & 320 & 353 & 2.663 \\
\hline & 8 & 105 & 12 & 6 & 360 & - & 100 & 90 & 355 & 1.036 \\
\hline & 415 & 421 & 258 & 365 & 312 & - & 150 & 348 & 361 & 2.629 \\
\hline \multirow{3}{*}{7} & 407 & 428 & 179 & 172 & 347 & 451 & - & 323 & 434 & 2.741 \\
\hline & 441 & 279 & 17 & 110 & 123 & 107 & - & 270 & 50 & 1.396 \\
\hline & 392 & 419 & 162 & 154 & 321 & 433 & - & 340 & 427 & 2.648 \\
\hline \multirow{3}{*}{8} & 284 & 282 & 275 & 359 & 475 & 265 & 401 & - & 326 & 2.667 \\
\hline & 124 & 449 & 25 & 39 & 284 & 91 & 366 & - & 381 & 1.759 \\
\hline & 325 & 261 & 246 & 312 & 459 & 248 & 420 & - & 306 & 2.577 \\
\hline \multirow{3}{*}{9} & 444 & 268 & 364 & 350 & 476 & 477 & 310 & 298 & - & 2.987 \\
\hline & 126 & 192 & 388 & 20 & 424 & 21 & 314 & 332 & - & 1.817 \\
\hline & 407 & 264 & 385 & 367 & 474 & 482 & 331 & 276 & $\therefore$ & 2.987 \\
\hline \multirow{3}{*}{$\Sigma$} & 2.641 & 2.840 & 2.449 & 2.532 & 3.166 & 2.210 & 2.483 & 2.038 & 2.794 & 23.153 \\
\hline & 1.090 & 3.399 & 1.578 & 984 & 3.058 & 968 & 2.043 & 1.922 & 1.766 & 16.807 \\
\hline & 2.572 & 2.734 & 2.424 & 2.586 & 3.107 & 2.200 & 2.494 & 2.113 & 2.722 & 22.952 \\
\hline \multicolumn{11}{|c|}{$\begin{array}{l}\text { Obs: A primeira linha de cada origem contém os valores das viagens "reais", na segunda linha estão } \\
\text { as os resultados estimados pelo QUEENSOD e na terceira linha estão os resultados estimados pelo } \\
\text { TransCAD. }\end{array}$} \\
\hline
\end{tabular}


Tabela 4. 22: Matriz estimada para o Teste 7, considerando $\mathrm{Sem}_{20}$

\begin{tabular}{|c|c|c|c|c|c|c|c|c|c|c|}
\hline Oㅅ & 1 & 2 & 3 & 4 & 5 & 6 & 7 & 8 & 9 & $\Sigma$ \\
\hline \multirow{3}{*}{1} & - & 406 & 464 & 330 & 418 & 175 & 276 & 159 & 371 & 2.599 \\
\hline & - & 337 & 473 & 363 & 22 & 178 & 479 & 119 & 68 & 2.038 \\
\hline & - & 421 & 457 & 356 & 470 & 138 & 222 & 183 & 149 & 2.397 \\
\hline \multirow{3}{*}{2} & 204 & - & 386 & 415 & 233 & 225 & 416 & 219 & 484 & 2.582 \\
\hline & 169 & - & 371 & 115 & 229 & 12 & 116 & 513 & 117 & 1.642 \\
\hline & 202 & - & 451 & 362 & 215 & 182 & 357 & 251 & 412 & 2.431 \\
\hline \multirow{3}{*}{3} & 176 & 377 & - & 351 & 419 & 187 & 245 & 246 & 288 & 2.289 \\
\hline & 162 & 239 & - & 82 & 67 & 485 & 20 & 185 & 363 & 1.602 \\
\hline & 163 & 350 & - & 381 & 417 & 183 & 200 & 236 & 242 & 2.172 \\
\hline \multirow{3}{*}{4} & 334 & 203 & 309 & - & 487 & 231 & 204 & 213 & 210 & 2.191 \\
\hline & 154 & 90 & 88 & - & 442 & 112 & 255 & 101 & 101 & 1.342 \\
\hline & 365 & 167 & 262 & - & 465 & 256 & 227 & 249 & 175 & 2.166 \\
\hline \multirow{3}{*}{5} & 337 & 414 & 246 & 184 & - & 199 & 466 & 260 & 328 & 2.434 \\
\hline & 127 & 311 & 340 & 139 & - & 144 & 157 & 372 & 300 & 1.889 \\
\hline & 373 & 437 & 237 & 114 & - & 206 & 389 & 277 & 357 & 2.390 \\
\hline \multirow{3}{*}{6} & 455 & 462 & 226 & 371 & 311 & - & 165 & 320 & 353 & 2.663 \\
\hline & 188 & 142 & 26 & 242 & 286 & - & 115 & 102 & 302 & 1.404 \\
\hline & 478 & 429 & 265 & 366 & 304 & - & 150 & 273 & 294 & 2.559 \\
\hline \multirow{3}{*}{7} & 407 & 428 & 179 & 172 & 347 & 451 & - & 323 & 434 & 2.741 \\
\hline & 387 & 235 & 193 & 110 & 266 & 148 & - & 202 & 15 & 1.555 \\
\hline & 469 & 427 & 154 & 130 & 330 & 413 & - & 374 & 468 & 2.764 \\
\hline \multirow{3}{*}{8} & 284 & 282 & 275 & 359 & 475 & 265 & 401 & - & 326 & 2.667 \\
\hline & 47 & 413 & 235 & 227 & 311 & 264 & 307 & - & 292 & 2.096 \\
\hline & 234 & 231 & 320 & 349 & 461 & 228 & 467 & - & 316 & 2.606 \\
\hline \multirow{3}{*}{9} & 444 & 268 & 364 & 350 & 476 & 477 & 310 & 298 & - & 2.987 \\
\hline & 262 & 247 & 475 & 18 & 52 & 349 & 211 & 195 & - & 1.809 \\
\hline & 412 & 228 & 393 & 372 & 428 & 497 & 335 & 252 & - & 2.916 \\
\hline \multirow{3}{*}{$\Sigma$} & 2.641 & 2.840 & 2.449 & 2.532 & 3.166 & 2.210 & 2.483 & 2.038 & 2.794 & 23.153 \\
\hline & 1.495 & 2.013 & 2.202 & 1.296 & 1.676 & 1.690 & 1.658 & 1.789 & 1.558 & 15.377 \\
\hline & 2.696 & 2.690 & 2.538 & 2.429 & 3.091 & 2.102 & 2.348 & 2.094 & 2.413 & 22.401 \\
\hline
\end{tabular}

Obs: A primeira linha de cada origem contém os valores das viagens "reais", na segunda linha estão as os resultados estimados pelo QUEENSOD e na terceira linha estão os resultados estimados pelo TransCAD.

Com isso, encerra-se a primeira parte das verificações, que consistiu em estimar a matriz OD em função dos fluxos observados nas interseções. Procurou-se nesta etapa verificar a idéia principal do trabalho. A seguir, será apresentada a segunda parte das verificações que consiste em estimar a matriz OD a partir dos fluxos observados apenas nos arcos. Isto permitirá verificar o desempenho do método MEMS e fornecer dados para comprovar que o uso de contagens nas interseções resulta em melhor desempenho. 
4.1.3.2 Parte B - Estimação considerando as contagens de tráfego realizadas apenas nos $\operatorname{arcos}$

Nesta etapa foram propostos outros dois testes de verificação. No primeiro (Teste 8), a estimação foi realizada utilizando o QUEENSOD, o TransCAD e o MEMS. Já no segundo teste (Teste 9) utilizou apenas o QUEENSOD e o TransCAD, pois teve como objetivo verificar a opção turning movement, disponível nesses programas.

\section{$\Rightarrow \quad$ Teste 8 (T8):}

Este teste consistiu em estimar a matriz OD como se contagens tivessem sido realizadas apenas nos arcos da rede viária, apresentada na Figura 4. 1. Na Tabela 4. 23 são apresentadas as matrizes estimadas.

Pelo TransCAD foram estimadas 25.818 viagens, $1,15 \%$ mais viagens do que o total "real". O MEMS estimou 19.785 viagens, $15 \%$ a menos que o total "real". Já o QUEENSOD estimou para este teste um total de 15.773 viagens, uma quantia $32 \%$ menor que o total "real".

Adotando uma matriz semente equivalente a $70 \%$ da matriz "real" $\left(S_{70}\right)$, os resultados estimados pelo QUEENSOD e pelo TransCAD estão apresentados na Tabela 4.24.

O TransCAD estimou 23.177 viagens, 24 viagens a mais do que o total "real" e o QUEENSOD estimou 16.093 viagens, ou seja, 30\% menos viagens em comparação com o total "real".

Os valores estimados utilizando TransCAD e QUEENSOD, considerando Sem $_{10}$ como matriz semente, estão apresentados na Tabela 4.25. 
Tabela 4. 23: Matriz estimada para o Teste 8

\begin{tabular}{|c|c|c|c|c|c|c|c|c|c|c|}
\hline O\D & 1 & 2 & 3 & 4 & 5 & 6 & 7 & 8 & 9 & $\Sigma$ \\
\hline \multirow{4}{*}{1} & - & 406 & 464 & 330 & 418 & 175 & 276 & 159 & 371 & 2.599 \\
\hline & - & 0 & 880 & 5 & 0 & 0 & 1.577 & 0 & 649 & 3.111 \\
\hline & - & 444 & 392 & 706 & 239 & 292 & 614 & 178 & 225 & 3.090 \\
\hline & - & 371 & 391 & 174 & 287 & 340 & 281 & 295 & 509 & 2.648 \\
\hline \multirow{4}{*}{2} & 204 & - & 386 & 415 & 233 & 225 & 416 & 219 & 484 & 2.582 \\
\hline & 0 & - & 0 & 0 & 0 & 0 & 0 & 0 & 0 & 0 \\
\hline & 390 & - & 345 & 272 & 141 & 241 & 185 & 139 & 177 & 1.890 \\
\hline & 244 & - & 190 & 233 & 163 & 218 & 310 & 100 & 276 & 1.734 \\
\hline \multirow{4}{*}{3} & 176 & 377 & - & 351 & 419 & 187 & 245 & 246 & 288 & 2.289 \\
\hline & 630 & 0 & - & 174 & 0 & 0 & 779 & 0 & 1.534 & 3.116 \\
\hline & 423 & 457 & - & 298 & 224 & 546 & 222 & 186 & 623 & 2.979 \\
\hline & 128 & 122 & - & 405 & 235 & 190 & 483 & 252 & 380 & 2.196 \\
\hline \multirow{4}{*}{4} & 334 & 203 & 309 & - & 487 & 231 & 204 & 213 & 210 & 2.191 \\
\hline & 0 & 0 & 1 & - & 200 & 1.430 & 0 & 0 & 0 & 1.630 \\
\hline & 693 & 295 & 299 & - & 510 & 458 & 530 & 253 & 299 & 3.337 \\
\hline & 190 & 253 & 464 & - & 190 & 358 & 134 & 175 & 371 & 2.137 \\
\hline \multirow{4}{*}{5} & 337 & 414 & 246 & 184 & - & 199 & 466 & 260 & 328 & 2.434 \\
\hline & 0 & 0 & 2 & 0 & - & 0 & 6 & 0 & 158 & 165 \\
\hline & 221 & 126 & 213 & 439 & - & 409 & 209 & 106 & 213 & 1.936 \\
\hline & 154 & 196 & 248 & 190 & - & 116 & 247 & 501 & 174 & 1.826 \\
\hline \multirow{4}{*}{6} & 455 & 462 & 226 & 371 & 311 & - & 165 & 320 & 353 & 2.663 \\
\hline & 269 & 0 & 8 & 1.288 & 0 & - & 0 & 0 & 10 & 1.575 \\
\hline & 304 & 302 & 766 & 469 & 499 & - & 297 & 280 & 707 & 3.624 \\
\hline & 364 & 245 & 169 & 380 & 190 & - & 381 & 207 & 190 & 2.127 \\
\hline \multirow{4}{*}{7} & 407 & 428 & 179 & 172 & 347 & 451 & - & 323 & 434 & 2.741 \\
\hline & 1.535 & 0 & 673 & 11 & 0 & 142 & - & 0 & 747 & 3.108 \\
\hline & 772 & 202 & 227 & 855 & 241 & 295 & - & 360 & 391 & 3.343 \\
\hline & 380 & 341 & 417 & 190 & 278 & 359 & - & 331 & 115 & 2.412 \\
\hline \multirow{4}{*}{8} & 284 & 282 & 275 & 359 & 475 & 265 & 401 & - & 326 & 2.667 \\
\hline & 0 & 0 & 0 & 0 & 0 & 0 & 0 & - & 19 & 19 \\
\hline & 214 & 167 & 199 & 316 & 155 & 282 & 507 & - & 424 & 2.264 \\
\hline & 344 & 105 & 403 & 380 & 190 & 271 & 190 & - & 154 & 2.038 \\
\hline \multirow{4}{*}{9} & 444 & 268 & 364 & 350 & 476 & 477 & 310 & 298 & - & 2.987 \\
\hline & 682 & 0 & 1.488 & 128 & 8 & 0 & 743 & 0 & - & 3.048 \\
\hline & 232 & 206 & 769 & 305 & 241 & 772 & 444 & 386 & - & 3.355 \\
\hline & 495 & 353 & 219 & 611 & 298 & 111 & 380 & 200 & $\therefore$ & 2.667 \\
\hline \multirow{4}{*}{$\Sigma$} & 2.641 & 2.840 & 2.449 & 2.532 & 3.166 & 2.210 & 2.483 & 2.038 & 2.794 & 23.153 \\
\hline & 3.115 & 0 & 3.051 & 1.606 & 208 & 1.572 & 3.104 & 0 & 3.117 & 15.773 \\
\hline & 3.249 & 2.199 & 3.210 & 3.660 & 2.250 & 3.295 & 3.008 & 1.888 & 3.059 & 25.818 \\
\hline & 2.301 & 1.987 & 2.502 & 2.564 & 1.831 & 1.964 & 2.406 & 2.060 & 2.170 & 19.785 \\
\hline
\end{tabular}

Obs: A primeira linha de cada origem contém os valores das viagens "reais", na segunda linha estão os resultados estimados pelo QUEENSOD, na terceira linha estão os resultados estimados pelo TransCAD e na quarta linha estão os resultados estimados pelo MEMS. 
Tabela 4. 24: Matriz estimada para o Teste 8 , considerando $S_{70}$

\begin{tabular}{|c|c|c|c|c|c|c|c|c|c|c|}
\hline Oㅣㅁ & 1 & 2 & 3 & 4 & 5 & 6 & 7 & 8 & 9 & $\Sigma$ \\
\hline \multirow{3}{*}{1} & - & 406 & 464 & 330 & 418 & 175 & 276 & 159 & 371 & 2.599 \\
\hline & - & 0 & 807 & 6 & 0 & 0 & 1.605 & 0 & 648 & 3.066 \\
\hline & - & 406 & 503 & 344 & 361 & 151 & 299 & 210 & 327 & 2.599 \\
\hline \multirow{3}{*}{2} & 204 & - & 386 & 415 & 233 & 225 & 416 & 219 & 484 & 2.582 \\
\hline & 0 & - & 0 & 0 & 0 & 0 & 0 & 0 & 0 & 0 \\
\hline & 212 & - & 389 & 486 & 173 & 254 & 477 & 250 & 539 & 2.780 \\
\hline \multirow{3}{*}{3} & 176 & 377 & - & 351 & 419 & 187 & 245 & 246 & 288 & 2.289 \\
\hline & 651 & 0 & - & 224 & 0 & 0 & 936 & 0 & 1.295 & 3.106 \\
\hline & 247 & 431 & - & 292 & 342 & 175 & 215 & 265 & 324 & 2.291 \\
\hline \multirow{3}{*}{4} & 334 & 203 & 309 & - & 487 & 231 & 204 & 213 & 210 & 2.191 \\
\hline & 0 & 0 & 0 & - & 386 & 1.313 & 0 & 0 & 0 & 1.699 \\
\hline & 344 & 244 & 288 & - & 408 & 219 & 213 & 331 & 188 & 2.234 \\
\hline \multirow{3}{*}{5} & 337 & 414 & 246 & 184 & - & 199 & 466 & 260 & 328 & 2.434 \\
\hline & 0 & 0 & 282 & 268 & - & 0 & 51 & 0 & 44 & 645 \\
\hline & 302 & 390 & 240 & 156 & - & 171 & 438 & 180 & 289 & 2.166 \\
\hline \multirow{3}{*}{6} & 455 & 462 & 226 & 371 & 311 & - & 165 & 320 & 353 & 2.663 \\
\hline & 0 & 0 & 203 & 975 & 0 & - & 0 & 0 & 125 & 1.303 \\
\hline & 396 & 529 & 234 & 307 & 268 & - & 148 & 366 & 418 & 2.666 \\
\hline \multirow{3}{*}{7} & 407 & 428 & 179 & 172 & 347 & 451 & - & 323 & 434 & 2.741 \\
\hline & 1.611 & 0 & 568 & 37 & 0 & 0 & - & 0 & 895 & 3.111 \\
\hline & 448 & 504 & 167 & 187 & 329 & 399 & - & 323 & 499 & 2.857 \\
\hline \multirow{3}{*}{8} & 284 & 282 & 275 & 359 & 475 & 265 & 401 & - & 326 & 2.667 \\
\hline & 0 & 0 & 0 & 0 & 0 & 0 & 0 & - & 22 & 22 \\
\hline & 338 & 270 & 277 & 447 & 475 & 261 & 414 & - & 309 & 2.790 \\
\hline \multirow{3}{*}{9} & 444 & 268 & 364 & 350 & 476 & 477 & 310 & 298 & - & 2.987 \\
\hline & 870 & 0 & 1.261 & 157 & 339 & 0 & 514 & 0 & - & 3.141 \\
\hline & 372 & 279 & 342 & 297 & 413 & 359 & 385 & 346 & - & 2.793 \\
\hline \multirow{3}{*}{$\Sigma$} & 2.641 & 2.840 & 2.449 & 2.532 & 3.166 & 2.210 & 2.483 & 2.038 & 2.794 & 23.153 \\
\hline & 3.132 & 0 & 3.121 & 1.667 & 725 & 1.313 & 3.106 & 0 & 3.029 & 16.093 \\
\hline & 2.659 & 3.053 & 2.440 & 2.515 & 2.769 & 1.989 & 2.588 & 2.272 & 2.892 & 23.177 \\
\hline
\end{tabular}

Obs: A primeira linha de cada origem contém os valores das viagens "reais", na segunda linha estão as os resultados estimados pelo QUEENSOD e na terceira linha estão os resultados estimados pelo TransCAD. 
Tabela 4. 25: Matriz estimada para o Teste 8, considerando Sem $_{10}$

\begin{tabular}{|c|c|c|c|c|c|c|c|c|c|c|}
\hline O\D & 1 & 2 & 3 & 4 & 5 & 6 & 7 & 8 & 9 & $\Sigma$ \\
\hline \multirow{3}{*}{1} & - & 406 & 464 & 330 & 418 & 175 & 276 & 159 & 371 & 2.599 \\
\hline & - & 234 & 818 & 0 & 0 & 245 & 1.494 & 0 & 613 & 3.405 \\
\hline & - & 372 & 520 & 296 & 346 & 151 & 292 & 249 & 349 & 2.576 \\
\hline \multirow{3}{*}{2} & 204 & - & 386 & 415 & 233 & 225 & 416 & 219 & 484 & 2.582 \\
\hline & 0 & - & 0 & 0 & 0 & 0 & 0 & 0 & 1 & 1 \\
\hline & 213 & - & 405 & 477 & 158 & 229 & 446 & 320 & 585 & 2.833 \\
\hline \multirow{3}{*}{3} & 176 & 377 & - & 351 & 419 & 187 & 245 & 246 & 288 & 2.289 \\
\hline & 686 & 0 & - & 682 & 0 & 0 & 131 & 0 & 1.503 & 3.002 \\
\hline & 230 & 395 & - & 284 & 361 & 308 & 230 & 289 & 321 & 2.418 \\
\hline \multirow{3}{*}{4} & 334 & 203 & 309 & - & 487 & 231 & 204 & 213 & 210 & 2.191 \\
\hline & 0 & 0 & 765 & - & 0 & 550 & 0 & 0 & 180 & 1.496 \\
\hline & 337 & 107 & 270 & - & 426 & 224 & 219 & 370 & 171 & 2.124 \\
\hline \multirow{3}{*}{5} & 337 & 414 & 246 & 184 & - & 199 & 466 & 260 & 328 & 2.434 \\
\hline & 0 & 0 & 0 & 0 & - & 0 & 0 & 0 & 0 & 0 \\
\hline & 313 & 408 & 259 & 162 & - & 161 & 498 & 142 & 283 & 2.226 \\
\hline \multirow{3}{*}{6} & 455 & 462 & 226 & 371 & 311 & - & 165 & 320 & 353 & 2.663 \\
\hline & 770 & 0 & 1 & 27 & 0 & - & 709 & 0 & 4 & 1.511 \\
\hline & 354 & 494 & 246 & 241 & 186 & - & 158 & 347 & 389 & 2.416 \\
\hline \multirow{3}{*}{7} & 407 & 428 & 179 & 172 & 347 & 451 & - & 323 & 434 & 2.741 \\
\hline & 1.406 & 0 & 68 & 7 & 0 & 727 & - & 0 & 876 & 3.084 \\
\hline & 498 & 506 & 167 & 207 & 320 & 373 & - & 307 & 504 & 2.881 \\
\hline \multirow{3}{*}{8} & 284 & 282 & 275 & 359 & 475 & 265 & 401 & - & 326 & 2.667 \\
\hline & 201 & 0 & 101 & 0 & 236 & 0 & 0 & - & 0 & 538 \\
\hline & 391 & 251 & 203 & 486 & 387 & 289 & 418 & - & 281 & 2.706 \\
\hline \multirow{3}{*}{9} & 444 & 268 & 364 & 350 & 476 & 477 & 310 & 298 & - & 2.987 \\
\hline & 93 & 0 & 1.229 & 961 & 0 & 113 & 570 & 179 & - & 3.145 \\
\hline & 343 & 227 & 319 & 279 & 350 & 339 & 434 & 382 & - & 2.674 \\
\hline \multirow{3}{*}{$\Sigma$} & 2.641 & 2.840 & 2.449 & 2.532 & 3.166 & 2.210 & 2.483 & 2.038 & 2.794 & 23.153 \\
\hline & 3.156 & 234 & 2.983 & 1.678 & 236 & 1.636 & 2.905 & 179 & 3.176 & 16.182 \\
\hline & 2.679 & 2.761 & 2.389 & 2.434 & 2.535 & 2.073 & 2.695 & 2.406 & 2.884 & 22.855 \\
\hline
\end{tabular}

Obs: A primeira linha de cada origem contém os valores das viagens "reais", na segunda linha estão as os resultados estimados pelo QUEENSOD e na terceira linha estão os resultados estimados pelo TransCAD.

Ao considerar Sem 10 , o TransCAD estimou 22.855 viagens, enquanto o QUEENSOD estimou 16.182 viagens.

Os valores estimados considerando $\mathrm{Sem}_{20}$ como matriz semente podem ser observados na Tabela 4. 26. 
Tabela 4. 26: Matriz estimada para o Teste 8, considerando $\mathrm{Sem}_{20}$

\begin{tabular}{|c|c|c|c|c|c|c|c|c|c|c|}
\hline O\D & 1 & 2 & 3 & 4 & 5 & 6 & 7 & 8 & 9 & $\Sigma$ \\
\hline \multirow{3}{*}{1} & - & 406 & 464 & 330 & 418 & 175 & 276 & 159 & 371 & 2.599 \\
\hline & - & 119 & 564 & 0 & 203 & 90 & 1.012 & 0 & 1.283 & 3.270 \\
\hline & - & 346 & 488 & 330 & 336 & 151 & 290 & 223 & 391 & 2.554 \\
\hline \multirow{3}{*}{2} & 204 & - & 386 & 415 & 233 & 225 & 416 & 219 & 484 & 2.582 \\
\hline & 0 & - & 0 & 0 & 0 & 0 & 150 & 0 & 201 & 351 \\
\hline & 229 & - & 421 & 506 & 143 & 213 & 439 & 305 & 586 & 2.843 \\
\hline \multirow{3}{*}{3} & 176 & 377 & - & 351 & 419 & 187 & 245 & 246 & 288 & 2.289 \\
\hline & 728 & 1 & - & 922 & 0 & 173 & 221 & 0 & 936 & 2.981 \\
\hline & 219 & 372 & - & 257 & 365 & 210 & 220 & 319 & 339 & 2.301 \\
\hline \multirow{3}{*}{4} & 334 & 203 & 309 & - & 487 & 231 & 204 & 213 & 210 & 2.191 \\
\hline & 0 & 0 & 769 & - & 0 & 7 & 147 & 0 & 293 & 1.216 \\
\hline & 315 & 179 & 256 & - & 378 & 234 & 203 & 371 & 160 & 2.097 \\
\hline \multirow{3}{*}{5} & 337 & 414 & 246 & 184 & - & 199 & 466 & 260 & 328 & 2.434 \\
\hline & 114 & 0 & 213 & 0 & - & 0 & 0 & 237 & 0 & 564 \\
\hline & 313 & 431 & 283 & 128 & - & 105 & 467 & 126 & 279 & 2.132 \\
\hline \multirow{3}{*}{6} & 455 & 462 & 226 & 371 & 311 & - & 165 & 320 & 353 & 2.663 \\
\hline & 150 & 0 & 0 & 2 & 0 & - & 744 & 0 & 0 & 896 \\
\hline & 453 & 401 & 260 & 298 & 312 & - & 144 & 229 & 267 & 2.365 \\
\hline \multirow{3}{*}{7} & 407 & 428 & 179 & 172 & 347 & 451 & - & 323 & 434 & 2.741 \\
\hline & 1.391 & 7 & 683 & 11 & 0 & 331 & - & 0 & 489 & 2.912 \\
\hline & 412 & 542 & 102 & 225 & 302 & 340 & - & 265 & 491 & 2.678 \\
\hline \multirow{3}{*}{8} & 284 & 282 & 275 & 359 & 475 & 265 & 401 & - & 326 & 2.667 \\
\hline & 101 & 0 & 140 & 0 & 0 & 104 & 0 & - & 0 & 345 \\
\hline & 418 & 210 & 270 & 463 & 370 & 314 & 491 & - & 221 & 2.755 \\
\hline \multirow{3}{*}{9} & 444 & 268 & 364 & 350 & 476 & 477 & 310 & 298 & - & 2.987 \\
\hline & 578 & 140 & 1.077 & 439 & 0 & 208 & 932 & 234 & - & 3.609 \\
\hline & 318 & 266 & 310 & 264 & 369 & 353 & 410 & 407 & - & 2.697 \\
\hline \multirow{3}{*}{$\Sigma$} & 2.641 & 2.840 & 2.449 & 2.532 & 3.166 & 2.210 & 2.483 & 2.038 & 2.794 & 23.153 \\
\hline & 3.063 & 266 & 3.445 & 1.374 & 203 & 914 & 3.206 & 471 & 3.203 & 16.144 \\
\hline & 2.679 & 2.746 & 2.389 & 2.470 & 2.576 & 1.920 & 2.663 & 2.246 & 2.734 & 22.422 \\
\hline
\end{tabular}

Obs: A primeira linha de cada origem contém os valores das viagens "reais", na segunda linha estão as os resultados estimados pelo QUEENSOD e na terceira linha estão os resultados estimados pelo TransCAD.

Foram estimadas pelo TransCAD 22.422 viagens, ao considerar Sem 20 . Já pelo QUEENSOD, foram estimadas 16.144 viagens, $30 \%$ de viagens a menos que o total "real".

Os programas TransCAD e QUEENSOD apresentam a opção para estimação em função dos movimentos de conversão, denominados turning movement, conforme descrito no Capítulo 2 deste trabalho. 
Para mostrar que o turning movement é diferente da proposta deste trabalho, foi proposto o Teste 9. Neste teste foram consideradas as porcentagens de conversão ao final de todos os arcos da rede hipotética, seria uma situação similar a descrita pelo Teste 7, que considerou os fluxos observados em todas as interseções, em função da sua conversão. Os resultados estimados encontram-se apresentados na Tabela 4. 27, foi considerada uma matriz semente unitária.

Tabela 4. 27: Matriz estimada para o Teste 9

\begin{tabular}{|c|c|c|c|c|c|c|c|c|c|c|}
\hline OO\D & 1 & 2 & 3 & 4 & 5 & 6 & 7 & 8 & 9 & $\Sigma$ \\
\hline \multirow{3}{*}{1} & - & 406 & 464 & 330 & 418 & 175 & 276 & 159 & 371 & 2.599 \\
\hline & - & 0 & 265 & 0 & 0 & 1.320 & 354 & 26 & 0 & 1.965 \\
\hline & - & 268 & 362 & 533 & 419 & 272 & 396 & 181 & 263 & 2.694 \\
\hline \multirow{3}{*}{2} & 204 & - & 386 & 415 & 233 & 225 & 416 & 219 & 484 & 2.582 \\
\hline & 0 & - & 135 & 0 & 0 & 305 & 4 & 287 & 1.117 & 1.848 \\
\hline & 230 & - & 211 & 598 & 131 & 351 & 294 & 75 & 210 & 2.100 \\
\hline \multirow{3}{*}{3} & 176 & 377 & - & 351 & 419 & 187 & 245 & 246 & 288 & 2.289 \\
\hline & 0 & 80 & - & 0 & 310 & 29 & 308 & 1.251 & 107 & 2.085 \\
\hline & 364 & 290 & - & 320 & 435 & 364 & 285 & 184 & 392 & 2.634 \\
\hline \multirow{3}{*}{4} & 334 & 203 & 309 & - & 487 & 231 & 204 & 213 & 210 & 2.191 \\
\hline & 0 & 52 & 0 & - & 1.465 & 254 & 83 & 41 & 0 & 1.895 \\
\hline & 491 & 372 & 306 & - & 385 & 524 & 411 & 297 & 324 & 3.110 \\
\hline \multirow{3}{*}{5} & 337 & 414 & 246 & 184 & - & 199 & 466 & 260 & 328 & 2.434 \\
\hline & 0 & 0 & 0 & 0 & - & 0 & 0 & 0 & 198 & 198 \\
\hline & 347 & 123 & 354 & 270 & - & 274 & 461 & 99 & 428 & 2.356 \\
\hline \multirow{3}{*}{6} & 455 & 462 & 226 & 371 & 311 & - & 165 & 320 & 353 & 2.663 \\
\hline & 67 & 0 & 1.278 & 0 & 68 & - & 22 & 294 & 1.483 & 3.212 \\
\hline & 314 & 664 & 547 & 425 & 356 & - & 302 & 328 & 509 & 3.445 \\
\hline \multirow{3}{*}{7} & 407 & 428 & 179 & 172 & 347 & 451 & - & 323 & 434 & 2.741 \\
\hline & 337 & 12 & 107 & 0 & 0 & 0 & - & 1.170 & 192 & 1.818 \\
\hline & 538 & 219 & 314 & 576 & 528 & 375 & - & 206 & 402 & 3.158 \\
\hline \multirow{3}{*}{8} & 284 & 282 & 275 & 359 & 475 & 265 & 401 & - & 326 & 2.667 \\
\hline & 0 & 506 & 89 & 0 & 0 & 0 & 0 & - & 10 & 605 \\
\hline & 304 & 80 & 169 & 626 & 149 & 378 & 292 & - & 246 & 2.244 \\
\hline \multirow{3}{*}{9} & 444 & 268 & 364 & 350 & 476 & 477 & 310 & 298 & - & 2.987 \\
\hline & 348 & 1.429 & 48 & 0 & 186 & 1.119 & 0 & 0 & - & 3.130 \\
\hline & 271 & 314 & 458 & 324 & 418 & 554 & 358 & 250 & - & 2.947 \\
\hline \multirow{3}{*}{$\Sigma$} & 2.641 & 2.840 & 2.449 & 2.532 & 3.166 & 2.210 & 2.483 & 2.038 & 2.794 & 23.153 \\
\hline & 752 & 2.079 & 1.922 & 0 & 2.029 & 3.027 & 771 & 3.069 & 3.107 & 16.756 \\
\hline & 2.859 & 2.330 & 2.721 & 3.672 & 2.821 & 3.092 & 2.799 & 1.620 & 2.774 & 24.688 \\
\hline
\end{tabular}

Obs: A primeira linha de cada origem contém os valores das viagens "reais", na segunda linha estão as os resultados estimados pelo QUEENSOD e na terceira linha estão os resultados estimados pelo TransCAD. 
Pelo TransCAD foram estimadas 24.688 viagens no total, $6,7 \%$ mais viagens que na situação "real", já o QUEENSOD estimou 16.756 viagens, 27,63\% viagens a menos que o total de viagens "real".

$\mathrm{Na}$ Tabela 4. 28 são apresentados os resultados estimados considerando uma matriz semente equivalente a $70 \%$ da "real" $\left(S_{70}\right)$.

Tabela 4. 28: Matriz estimada para o Teste 9, considerando $S_{70}$

\begin{tabular}{|c|c|c|c|c|c|c|c|c|c|c|}
\hline O\D & 1 & 2 & 3 & 4 & 5 & 6 & 7 & 8 & 9 & $\Sigma$ \\
\hline \multirow{3}{*}{1} & - & 406 & 464 & 330 & 418 & 175 & 276 & 159 & 371 & 2.599 \\
\hline & - & 0 & 1.103 & 2 & 0 & 116 & 1.327 & 457 & 59 & 3.064 \\
\hline & - & 427 & 488 & 351 & 404 & 260 & 309 & 192 & 366 & 2.797 \\
\hline \multirow{3}{*}{2} & 204 & - & 386 & 415 & 233 & 225 & 416 & 219 & 484 & 2.582 \\
\hline & 0 & - & 0 & 71 & 0 & 0 & 265 & 0 & 326 & 662 \\
\hline & 219 & - & 406 & 444 & 181 & 211 & 459 & 215 & 498 & 2.633 \\
\hline \multirow{3}{*}{3} & 176 & 377 & - & 351 & 419 & 187 & 245 & 246 & 288 & 2.289 \\
\hline & 1.071 & 0 & - & 121 & 0 & 292 & 85 & 226 & 1.253 & 3.048 \\
\hline & 191 & 415 & - & 323 & 398 & 193 & 242 & 256 & 325 & 2.342 \\
\hline \multirow{3}{*}{4} & 334 & 203 & 309 & - & 487 & 231 & 204 & 213 & 210 & 2.191 \\
\hline & 195 & 0 & 0 & - & 0 & 1.236 & 222 & 0 & 0 & 1.653 \\
\hline & 366 & 218 & 289 & - & 417 & 201 & 238 & 181 & 201 & 2.111 \\
\hline \multirow{3}{*}{5} & 337 & 414 & 246 & 184 & - & 199 & 466 & 260 & 328 & 2.434 \\
\hline & 0 & 0 & 0 & 0 & - & 0 & 0 & 0 & 0 & 0 \\
\hline & 328 & 385 & 245 & 158 & - & 176 & 477 & 194 & 348 & 2.310 \\
\hline \multirow{3}{*}{6} & 455 & 462 & 226 & 371 & 311 & - & 165 & 320 & 353 & 2.663 \\
\hline & 35 & 254 & 0 & 1.321 & 0 & - & 52 & 19 & 269 & 1.950 \\
\hline & 420 & 506 & 246 & 316 & 263 & - & 163 & 332 & 434 & 2.679 \\
\hline \multirow{3}{*}{7} & 407 & 428 & 179 & 172 & 347 & 451 & - & 323 & 434 & 2.741 \\
\hline & 1.412 & 42 & 482 & 0 & 0 & 102 & - & 0 & 1.114 & 3.152 \\
\hline & 448 & 464 & 143 & 191 & 342 & 415 & - & 353 & 453 & 2.810 \\
\hline \multirow{3}{*}{8} & 284 & 282 & 275 & 359 & 475 & 265 & 401 & - & 326 & 2.667 \\
\hline & 372 & 0 & 195 & 173 & 0 & 1 & 0 & - & 0 & 741 \\
\hline & 305 & 269 & 268 & 382 & 448 & 243 & 409 & - & 275 & 2.599 \\
\hline \multirow{3}{*}{9} & 444 & 268 & 364 & 350 & 476 & 477 & 310 & 298 & - & 2.987 \\
\hline & 10 & 419 & 1.324 & 4 & 0 & 221 & 1.050 & 0 & - & 3.028 \\
\hline & 401 & 170 & 351 & 302 & 402 & 401 & 330 & 331 & - & 2.688 \\
\hline \multirow{3}{*}{$\Sigma$} & 2.641 & 2.840 & 2.449 & 2.532 & 3.166 & 2.210 & 2.483 & 2.038 & 2.794 & 23.153 \\
\hline & 3.095 & 715 & 3.104 & 1.692 & 0 & 1.968 & 3.001 & 702 & 3.021 & 17.298 \\
\hline & 2.678 & 2.855 & 2.435 & 2.467 & 2.855 & 2.101 & 2.627 & 2.054 & 2.899 & 22.969 \\
\hline
\end{tabular}

Obs: A primeira linha de cada origem contém os valores das viagens "reais", na segunda linha estão as os resultados estimados pelo QUEENSOD e na terceira linha estão os resultados estimados pelo TransCAD. 
Foram estimadas 22.969 viagens no total pelo TransCAD ao utilizar $\mathrm{S}_{70}$ como semente, $0,79 \%$ menos viagens que o total "real". Já o QUEENSOD estimou 17.298 viagens no total, $25 \%$ viagens a menos que o total "real".

Pelo TransCAD, ao utilizar Sem $_{10}$, foram estimadas 23.128 viagens, $0,11 \%$ de viagens estimadas a menos que o total "real", enquanto que pelo QUEENSOD foram estimadas 16.254 viagens, $30 \%$ de viagens a menos que o "real". Na Tabela 4.29 são apresentados os resultados estimados quando foi utilizada a matriz semente Sem $_{10}$.

Tabela 4. 29: Matriz estimada para o Teste 9, considerando Sem 10

\begin{tabular}{|c|c|c|c|c|c|c|c|c|c|c|}
\hline OlD & 1 & 2 & 3 & 4 & 5 & 6 & 7 & 8 & 9 & $\Sigma$ \\
\hline \multirow{3}{*}{1} & - & 406 & 464 & 330 & 418 & 175 & 276 & 159 & 371 & 2.599 \\
\hline & - & 11 & 1.092 & 13 & 0 & 127 & 1.316 & 446 & 70 & 3.075 \\
\hline & - & 388 & 472 & 349 & 405 & 157 & 327 & 155 & 394 & 2.647 \\
\hline \multirow{3}{*}{2} & 204 & - & 386 & 415 & 233 & 225 & 416 & 219 & 484 & 2.582 \\
\hline & 0 & - & 109 & 82 & 103 & 0 & 276 & 11 & 337 & 919 \\
\hline & 223 & - & 455 & 441 & 165 & 197 & 451 & 198 & 531 & 2.662 \\
\hline \multirow{3}{*}{3} & 176 & 377 & - & 351 & 419 & 187 & 245 & 246 & 288 & 2.289 \\
\hline & 1.060 & 0 & - & 132 & 11 & 281 & 96 & 237 & 1.242 & 3.059 \\
\hline & 171 & 382 & - & 298 & 397 & 217 & 245 & 282 & 352 & 2.344 \\
\hline \multirow{3}{*}{4} & 334 & 203 & 309 & - & 487 & 231 & 204 & 213 & 210 & 2.191 \\
\hline & 206 & 0 & 0 & - & 0 & 1.225 & 211 & 11 & 11 & 1.664 \\
\hline & 341 & 194 & 267 & - & 469 & 197 & 253 & 194 & 183 & 2.098 \\
\hline \multirow{3}{*}{5} & 337 & 414 & 246 & 184 & - & 199 & 466 & 260 & 328 & 2.434 \\
\hline & 11 & 11 & 0 & 0 & - & 134 & 0 & 11 & 110 & 277 \\
\hline & 334 & 405 & 253 & 166 & - & 162 & 511 & 177 & 328 & 2.333 \\
\hline \multirow{3}{*}{6} & 455 & 462 & 226 & 371 & 311 & - & 165 & 320 & 353 & 2.663 \\
\hline & 46 & 265 & 11 & 1.310 & 11 & - & 63 & 30 & 280 & 2.016 \\
\hline & 455 & 478 & 250 & 324 & 287 & - & 108 & 300 & 387 & 2.589 \\
\hline \multirow{3}{*}{7} & 407 & 428 & 179 & 172 & 347 & 451 & - & 323 & 434 & 2.741 \\
\hline & 1.401 & 53 & 471 & 0 & 11 & 113 & - & 0 & 103 & 2.152 \\
\hline & 442 & 507 & 174 & 218 & 345 & 434 & - & 335 & 470 & 2.925 \\
\hline \multirow{3}{*}{8} & 284 & 282 & 275 & 359 & 475 & 265 & 401 & - & 326 & 2.667 \\
\hline & 361 & 11 & 206 & 184 & 11 & 12 & 11 & - & 11 & 807 \\
\hline & 334 & 247 & 257 & 375 & 441 & 360 & 437 & - & 302 & 2.751 \\
\hline \multirow{3}{*}{9} & 444 & 268 & 364 & 350 & 476 & 477 & 310 & 298 & - & 2.987 \\
\hline & 21 & 408 & 1.313 & 15 & 11 & 232 & 139 & 147 & - & 2.286 \\
\hline & 375 & 262 & 319 & 297 & 452 & 400 & 314 & 360 & - & 2.780 \\
\hline \multirow{3}{*}{$\Sigma$} & 2.641 & 2.840 & 2.449 & 2.532 & 3.166 & 2.210 & 2.483 & 2.038 & 2.794 & 23.153 \\
\hline & 3.106 & 759 & 3.202 & 1.736 & 158 & 2.124 & 2.112 & 893 & 2.164 & 16.254 \\
\hline & 2.674 & 2.862 & 2.447 & 2.468 & 2.962 & 2.123 & 2.646 & 2.001 & 2.946 & 23.128 \\
\hline
\end{tabular}

Obs: A primeira linha de cada origem contém os valores das viagens "reais", na segunda linha estão as os resultados estimados pelo QUEENSOD e na terceira linha estão os resultados estimados pelo TransCAD. 
$\mathrm{Na}$ Tabela 4.30 estão as matrizes estimadas quando a semente foi $\mathrm{Sem}_{20}$. Ao considerar o uso de $\mathrm{Sem}_{20}$, foram estimadas pelo TransCAD 22.992 viagens, $0,70 \%$ de viagens estimadas a menos que o total "real", enquanto que pelo QUEENSOD foram estimadas 16.595 viagens, $28 \%$ de viagens a menos que o "real".

Tabela 4. 30: Matriz estimada para o Teste 9, considerando Sem$_{20}$

\begin{tabular}{|c|c|c|c|c|c|c|c|c|c|c|}
\hline O\D & 1 & 2 & 3 & 4 & 5 & 6 & 7 & 8 & 9 & $\Sigma$ \\
\hline \multirow{3}{*}{1} & - & 406 & 464 & 330 & 418 & 175 & 276 & 159 & 371 & 2.599 \\
\hline & - & 0 & 1.086 & 19 & 136 & 133 & 1.310 & 440 & 76 & 3.200 \\
\hline & - & 379 & 456 & 343 & 401 & 155 & 327 & 142 & 435 & 2.638 \\
\hline \multirow{3}{*}{2} & 204 & - & 386 & 415 & 233 & 225 & 416 & 219 & 484 & 2.582 \\
\hline & 0 & - & 17 & 88 & 0 & 0 & 282 & 17 & 343 & 749 \\
\hline & 240 & - & 466 & 450 & 153 & 172 & 437 & 182 & 564 & 2.664 \\
\hline \multirow{3}{*}{3} & 176 & 377 & - & 351 & 419 & 187 & 245 & 246 & 288 & 2.289 \\
\hline & 1.054 & 0 & - & 138 & 17 & 275 & 102 & 243 & 1.236 & 3.065 \\
\hline & 157 & 354 & - & 265 & 375 & 228 & 237 & 305 & 383 & 2.304 \\
\hline \multirow{3}{*}{4} & 334 & 203 & 309 & - & 487 & 231 & 204 & 213 & 210 & 2.191 \\
\hline & 212 & 0 & 0 & - & 0 & 1.219 & 205 & 0 & 177 & 1.812 \\
\hline & 325 & 180 & 251 & - & 503 & 199 & 248 & 167 & 175 & 2.049 \\
\hline \multirow{3}{*}{5} & 337 & 414 & 246 & 184 & - & 199 & 466 & 260 & 328 & 2.434 \\
\hline & 177 & 17 & 0 & 0 & - & 18 & 0 & 0 & 0 & 212 \\
\hline & 345 & 429 & 278 & 171 & - & 167 & 516 & 150 & 343 & 2.399 \\
\hline \multirow{3}{*}{6} & 455 & 462 & 226 & 371 & 311 & - & 165 & 320 & 353 & 2.663 \\
\hline & 52 & 271 & 0 & 1.304 & 0 & - & 69 & 36 & 286 & 2.019 \\
\hline & 492 & 461 & 260 & 328 & 304 & - & 166 & 271 & 378 & 2.660 \\
\hline \multirow{3}{*}{7} & 407 & 428 & 179 & 172 & 347 & 451 & - & 323 & 434 & 2.741 \\
\hline & 1.395 & 59 & 465 & 0 & 17 & 119 & - & 0 & 197 & 2.252 \\
\hline & 425 & 553 & 174 & 232 & 330 & 445 & - & 307 & 452 & 2.918 \\
\hline \multirow{3}{*}{8} & 284 & 282 & 275 & 359 & 475 & 265 & 401 & - & 326 & 2.667 \\
\hline & 355 & 0 & 212 & 190 & 17 & 18 & 174 & - & 172 & 1.139 \\
\hline & 355 & 222 & 240 & 351 & 429 & 281 & 453 & - & 245 & 2.575 \\
\hline \multirow{3}{*}{9} & 444 & 268 & 364 & 350 & 476 & 477 & 310 & 298 & - & 2.987 \\
\hline & 27 & 402 & 1.307 & 21 & 17 & 238 & 133 & 0 & - & 2.145 \\
\hline & 353 & 259 & 294 & 291 & 504 & 406 & 294 & 385 & - & 2.785 \\
\hline \multirow{3}{*}{$\Sigma$} & 2.641 & 2.840 & 2.449 & 2.532 & 3.166 & 2.210 & 2.483 & 2.038 & 2.794 & 23.153 \\
\hline & 3.272 & 750 & 3.087 & 1.761 & 206 & 2.021 & 2.275 & 737 & 2.487 & 16.595 \\
\hline & 2.693 & 2.837 & 2.419 & 2.430 & 2.999 & 2.052 & 2.678 & 1.909 & 2.976 & 22.992 \\
\hline
\end{tabular}

Obs: A primeira linha de cada origem contém os valores das viagens "reais", na segunda linha estão as os resultados estimados pelo QUEENSOD e na terceira linha estão os resultados estimados pelo TransCAD. 


\title{
CAPÍTULO 5 ANÁLISES DOS RESULTADOS
}

\begin{abstract}
Apresentado o detalhamento matemático da proposta, realizados os experimentos e obtidos os resultados, a próxima etapa do método consiste na realização das análises. Este capitulo traz as análises dos resultados obtidos, para os nove testes experimentais propostos.
\end{abstract}

\subsection{CONSIDERAÇÕES}

No capítulo anterior os testes experimentais foram descritos e divididos em dois grupos: (i) Estimação considerando as contagens de tráfego realizadas nas interseções (Testes 1 a 7); e (ii) Estimação considerando as contagens de tráfego apenas nos arcos (Testes 8 e 9). Ao todo nove testes experimentais foram realizados e, em cada um, a matriz OD foi estimada por três métodos distintos (QUEENSOD - QOD, TransCAD - TCD e MEMS). No presente capítulo são analisados os resultados obtidos em cada teste.

Para tanto, este capítulo encontra-se estruturado em quatro partes, incluída esta introdução, seguida por: (i) Análise dos resultados estimados; (ii) Análises dos resultados quanto a qualidade da matriz semente; e (iii) Discussões dos resultados. Na Figura 5. 1 é apresentado um esquema da maneira como as análises foram programadas e executadas. O processo esquematizado na referida figura será realizado primeiramente para a parte (i) e depois para a (ii). 


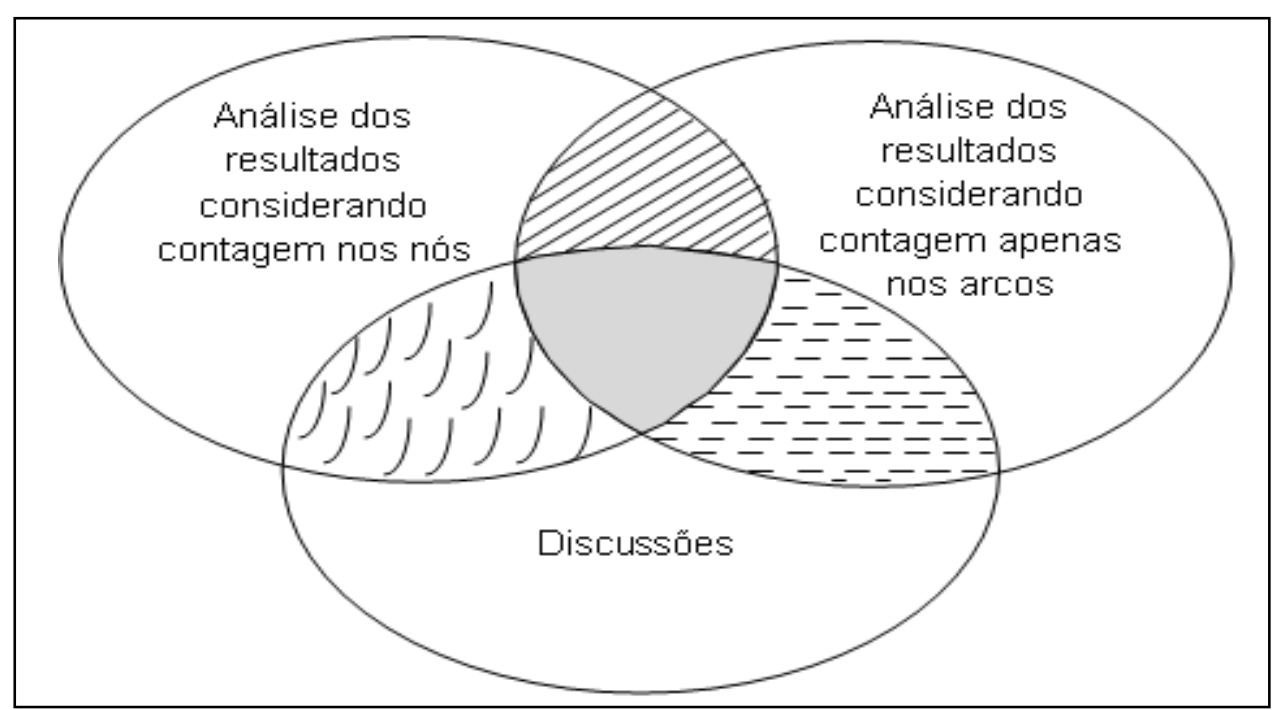

Figura 5. 1: Estrutura proposta para as análises dos resultados

As análises estão divididas em:

$\Rightarrow$ Análise comparativa das diferenças entre os valores das viagens da matriz OD estimada em relação aos valores das viagens da matriz OD "real";

$\Rightarrow$ Análise da diferença absoluta média;

$\Rightarrow$ Análise da distribuição de freqüências das diferenças relativas.

Cada uma destas análises está acompanhada de discussões, de forma a atingir os objetivos do trabalho. Ao final há uma discussão sobre os principais pontos observados.

\subsection{ANÁLISE DOS RESULTADOS ESTIMADOS}

Neste item, as análises consideram apenas os resultados estimados por QOD e TCD, quando utilizaram matriz semente unitária e pelo MEMS. Os valores estimados em cada teste experimental são confrontados com os valores das viagens "reais". Ao todo foram realizados nove testes de verificação, divididos em duas partes: Parte A - consideraram contagens realizadas nas interseções (Teste 1 a 7 ); Parte $B$ - consideraram contagens apenas nos arcos. Na Tabela 5. 1 há um resumo dos testes e a Tabela 5. 2 apresenta as principais medidas de desempenho obtidas. 
Uma proposta de estimação da matriz OD a partir dos fluxos de tráfego observados nas interseções da rede de transportes

Tabela 5. 1: Resumo das principais informações sobre os testes

\begin{tabular}{|c|c|c|c|c|c|c|c|c|c|}
\hline \multirow{3}{*}{ Critério } & \multicolumn{9}{|c|}{ Testes } \\
\hline & \multicolumn{7}{|c|}{ Parte A } & \multicolumn{2}{|c|}{ Parte B } \\
\hline & 1 & 2 & 3 & 4 & 5 & 6 & 7 & 8 & 9 \\
\hline $\begin{array}{l}\text { Nós em que a } \\
\text { contagem foi } \\
\text { realizada }\end{array}$ & $1 ; 3 ; 7 ; 9$ & 5 & $2 ; 4 ; 6 ; 8$ & $1 ; 3 ; 5 ; 7 ; 9$ & $1 ; 2 ; 3 ; 4 ; 6 ; 7 ; 8 ; 9$ & $2 ; 4 ; 5 ; 6 ; 8$ & Todos & - & - \\
\hline $\begin{array}{l}\text { Quantidade de } \\
\text { arcos com } \\
\text { contagem de } \\
\text { fluxo }\end{array}$ & 24 & 24 & 24 & 24 & 24 & 24 & 24 & 24 & 24 \\
\hline $\begin{array}{l}\text { Quantidade de } \\
\text { informações } \\
\text { adicionais } \\
\text { ("arcos virtuais") }\end{array}$ & 8 & 16 & 16 & 24 & 24 & 32 & 40 & 0 & 0 \\
\hline $\begin{array}{l}\text { Quantidade total } \\
\text { de informações } \\
\text { não redundantes }\end{array}$ & 32 & 40 & 40 & 48 & 48 & 56 & 64 & 24 & 24 \\
\hline $\begin{array}{l}\text { Grau de } \\
\text { indeterminação }\end{array}$ & 107 & 99 & 99 & 91 & 91 & 83 & 75 & 139 & 139 \\
\hline $\begin{array}{l}\text { Sentido da } \\
\text { redução da } \\
\text { indeterminação }\end{array}$ & & & & & & & & - & - \\
\hline $\begin{array}{l}\text { Número de } \\
\text { observadores }\end{array}$ & 16 & 20 & 12 & 12 & 16 & 20 & 24 & 24 & 24 \\
\hline
\end{tabular}

Do Teste 1 em direção ao 7 houve aumento da quantidade de informação e, conseqüentemente, redução no grau de indeterminação, obtido pela diferença entre a indeterminação - viagem + rota utilizada (CREMER; KELLER, 1987) - e a quantidade de informações. Ainda assim, o número de informações de fluxo veicular não foi igual ao de incógnitas; portanto, dificilmente a matriz estimada recupere a rede original.

Os Testes 8 e 9 tiveram contagens realizadas apenas nos arcos, com isso não houve acréscimo na quantidade de informações não redundantes. A diferença entre esses dois testes é que no Teste 9 a matriz foi estimada apenas pelos programas (QOD e TCD) e fez uso do arquivo opcional turning movement disponível nesses softwares. 
Tabela 5. 2: Resumo das medidas que serão analisadas

\begin{tabular}{|c|c|c|c|c|c|c|c|c|c|}
\hline \multirow[b]{2}{*}{ Teste } & \multirow{2}{*}{$\begin{array}{l}\text { Total de } \\
\text { Viagens } \\
\text { Estimadas }\end{array}$} & \multirow{2}{*}{$\begin{array}{c}\text { DAM } \\
\text { (\%) }\end{array}$} & \multicolumn{3}{|c|}{ Dif. Relativa (\%) } & \multicolumn{4}{|c|}{ Est. da Regressão } \\
\hline & & & $\begin{array}{l}\text { Mín. } \\
\text { (neg) }\end{array}$ & Máx. & $\begin{array}{l}\text { Máx. } \\
\text { Abs }\end{array}$ & R-mult & $\mathbf{R}^{2}$ & $R^{2}$ ajust & $\begin{array}{c}\text { Erro } \\
\text { Padrão } \\
\end{array}$ \\
\hline \multirow{3}{*}{ T1 } & 23.609 & 106,61 & -411 & 100 & 411 & 0,0816 & 0,0067 & $-0,007$ & 431,143 \\
\hline & 24.656 & 42,49 & -222 & 63 & 222 & 0,0804 & 0,0065 & $-0,008$ & 144,653 \\
\hline & 21.636 & 23,68 & -49 & 54 & 54 & 0,6143 & 0,3773 & 0,368 & 86,717 \\
\hline \multirow{3}{*}{ T2 } & 9.586 & 84,98 & -244 & 100 & 244 & 0,0658 & 0,0043 & $-0,009$ & 226,38 \\
\hline & 24.270 & 37,48 & -151 & 96 & 151 & 0,4386 & 0,0773 & 0,181 & 160,60 \\
\hline & 23.160 & 20,90 & -54 & 54 & 54 & 0,6657 & 0,4431 & 0,4352 & 86,64 \\
\hline \multirow{3}{*}{ T3 } & 13.864 & 81,80 & -206 & 100 & 206 & 0,0872 & 0,0076 & $-0,007$ & 260,22 \\
\hline & 22.661 & 34,59 & -149 & 86 & 149 & 0,2780 & 0,1923 & 0,064 & 123,76 \\
\hline & 22.438 & 18,53 & -42 & 39 & 42 & 0,7169 & 0,5139 & 0,507 & 65,14 \\
\hline \multirow{3}{*}{ T4 } & 12.863 & 72,20 & -200 & 100 & 200 & 0,1384 & $3,49 \mathrm{E}-6$ & 0,005 & 217,70 \\
\hline & 23.724 & 28,58 & -97 & 81 & 97 & 0,5176 & 0,2679 & 0,257 & 114,38 \\
\hline & 22.664 & 16,21 & -38 & 39 & 39 & 0,8117 & 0,6590 & 0,6541 & 67,55 \\
\hline \multirow{3}{*}{ T5 } & 12.492 & 67,54 & -176 & 100 & 176 & 0,0019 & 0,0191 & $-0,014$ & 186,65 \\
\hline & 22.620 & 26,57 & -65 & 64 & 65 & 0,5616 & 0,3154 & 0,306 & 98,68 \\
\hline & 22.636 & 13,68 & -26 & 27 & 27 & 0,8464 & 0,7163 & 0,712 & 52,18 \\
\hline \multirow{3}{*}{ T6 } & 10.250 & 61,03 & -91 & 100 & 100 & 0,1577 & 0,0248 & 0,011 & 115,43 \\
\hline & 21.380 & 22,61 & -49 & 53 & 53 & 0,6717 & 0,4513 & 0,443 & 84,67 \\
\hline & 22.873 & 11,49 & -27 & 26 & 27 & 0,8926 & 0,7967 & 0,7938 & 46,84 \\
\hline \multirow{4}{*}{ T7 } & 10.825 & 53,36 & 7 & 78 & 78 & 0,1586 & 0,0251 & 0,011 & 60,60 \\
\hline & 22.225 & 16,81 & -35 & 39 & 39 & 0,7736 & 0,5985 & 0,5928 & 60,96 \\
\hline & 22.513 & 7,49 & -10 & 11 & 11 & 0,9657 & 0,9327 & 0,932 & 23,83 \\
\hline & 23.020 & 4,62 & -9 & 9 & 9 & 0,9848 & 0,9699 & 0,969 & 16,52 \\
\hline \multirow{3}{*}{ T8 } & 15.773 & 118,89 & -519 & 100 & 519 & 0,0553 & 0,0030 & $-0,011$ & 447,9 \\
\hline & 25.818 & 51,71 & -397 & 70 & 397 & 0,0293 & 0,0008 & $-0,013$ & 185,7 \\
\hline & 19.785 & 38,67 & -133 & 77 & 133 & 0,0721 & 0,0052 & $-0,009$ & 115,1 \\
\hline \multirow{2}{*}{ T9 } & 16.756 & 106,49 & -654 & 100 & 654 & 0,0606 & 0,0036 & $-0,010$ & 425,0 \\
\hline & 24.688 & 37,82 & -235 & 72 & 235 & 0,1964 & 0,0385 & 0,024 & 129,9 \\
\hline
\end{tabular}

Obs: A primeira linha de cada teste contém as medidas referentes aos resultados estimados pelo QUEENSOD, a segunda linha refere-se aos resultados estimados pelo TransCAD e na terceira linha estão as medidas considerando os resultados estimados pelo MEMS. A quarta linha no Teste 7 refere-se aos resultados estimados considerando o método MEMS com 500 iterações.

$\Rightarrow \quad$ Total de viagens estimadas e estatística da regressão:

No gráfico apresentado na Figura 5. 2 estão os valores da relação entre o total de viagens estimadas, pelo número total de viagens "reais". É possível observar se houve superestimação ou subestimação de viagens em cada teste. Os valores positivos indicam que o total de viagens estimado é maior do que o total "real", os valores negativos representam o oposto. 


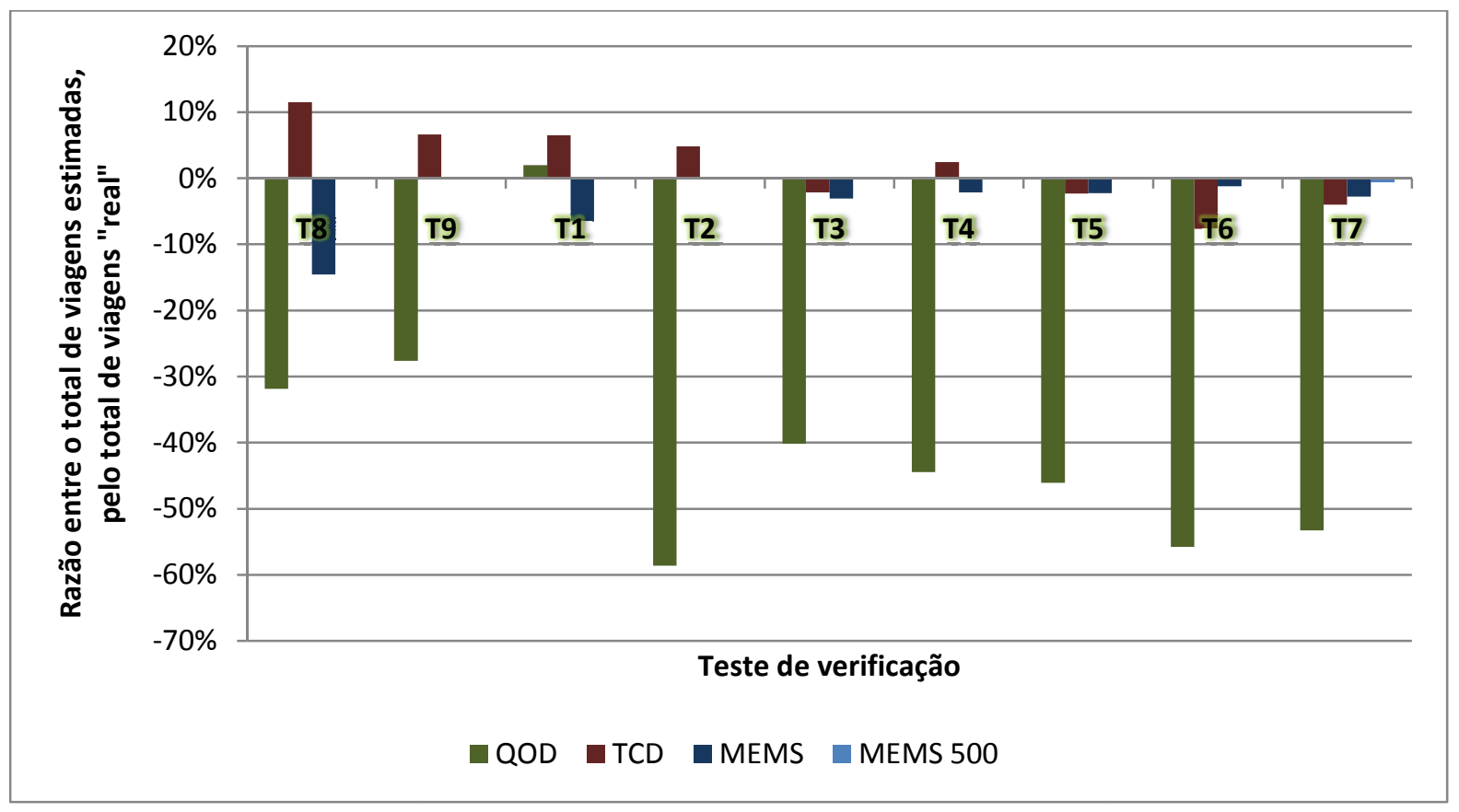

Figura 5. 2: Relação entre o total de viagens estimada pelo total de viagens "real"

Os totais de viagens estimados não apresentam um padrão de comportamento que permita dizer que determinado método, por exemplo, apenas superestima ou subestima viagens, ou ainda, que o aumento da quantidade de informação faz com que ocorra apenas subestimação ou superestimação.

No entanto, é possível observar que o método de estimação do programa QUEENSOD subestimou viagens na maioria dos testes e a variação, em relação ao valor "real" de viagens, foi mais acentuada do que a obtida pelos outros métodos. Apenas no Teste 1 o QOD estimou um total de viagens próximo ao total "real" $(1,97 \%$ viagens a mais que o total "real"). No Teste 2 a quantidade de viagens estimadas foi $59 \%$ menor do que número de viagens "real", isso mostra que a variação nos totais estimados pelo QOD foi alta.

Para os totais de viagens estimadas pelo TransCAD, a variação ocorreu entre -10 e 15\%, em comparação com o total de viagens "reais". Em números puros é o mesmo que dizer que os totais estimados em cada teste variam entre 21.700 a 24.700 viagens. Em cinco testes houve superestimação do total de viagem e nos demais subestimação. 
Entre os métodos analisados o que apresenta menor variação entre o total de viagem estimado em relação ao total "real" é o MEMS. A faixa de variação está entre -10 e $1 \%$, indicando que o método foi capaz de estimar o total de viagem mais próximo ao "real".

Todavia, apenas o número total de viagens estimadas não constitui bom parâmetro para verificar o desempenho de um método, pois pode ser estimada uma quantidade de viagens próxima a "real", entretanto concentrada em alguns pares OD. Prova disso é que o QUEENSOD no Teste 1 estimou um total de viagens próximo ao "real", mas em 27 pares OD foram estimadas zero viagem. Isso mostra ter havido uma concentração da estimação de viagens em alguns pares e, caso a análise fosse apenas sobre o número total de viagens estimadas, poderia resultar em conclusão equivocada. Assim, é necessário ser feita uma análise das viagens estimadas em cada par OD.

A primeira verificação envolvendo viagens estimadas entre pares OD foi feita através da análise de regressão, envolvendo os valores das viagens estimadas e os "reais"; o resumo para cada teste está na Tabela 5. 2.

Tomando os valores de $\mathrm{R}^{2}$ obtidos pela estatística de regressão apresentada na Tabela 5. 2 foi possível constatar quão dispersos estão os valores das viagens estimadas, em relação aos "reais". Na Figura 5. 3 está apresentado um gráfico com os valores de $\mathrm{R}^{2}$ obtidos em cada teste pelos métodos de estimação utilizados. Pode ser observado que $\mathrm{R}^{2}$ tende a aumentar à medida que são inseridas informações adicionais de fluxo, indicando diminuição na dispersão entre os valores estimados e "reais" das viagens.

Outra constatação é que não apenas o aumento da quantidade de informação é importante, mas também sua distribuição na rede. Os Testes 2 e 3 e Testes 4 e 5, possuem a mesma quantidade de informação adicionada (16 e 24, respectivamente), porém, nos Testes 3 e 5 as informações estão distribuídas e isso resultou melhor desempenho, independente do método de estimação utilizado. 
Uma proposta de estimação da matriz OD a partir dos fluxos de tráfego observados nas interseções da rede de transportes

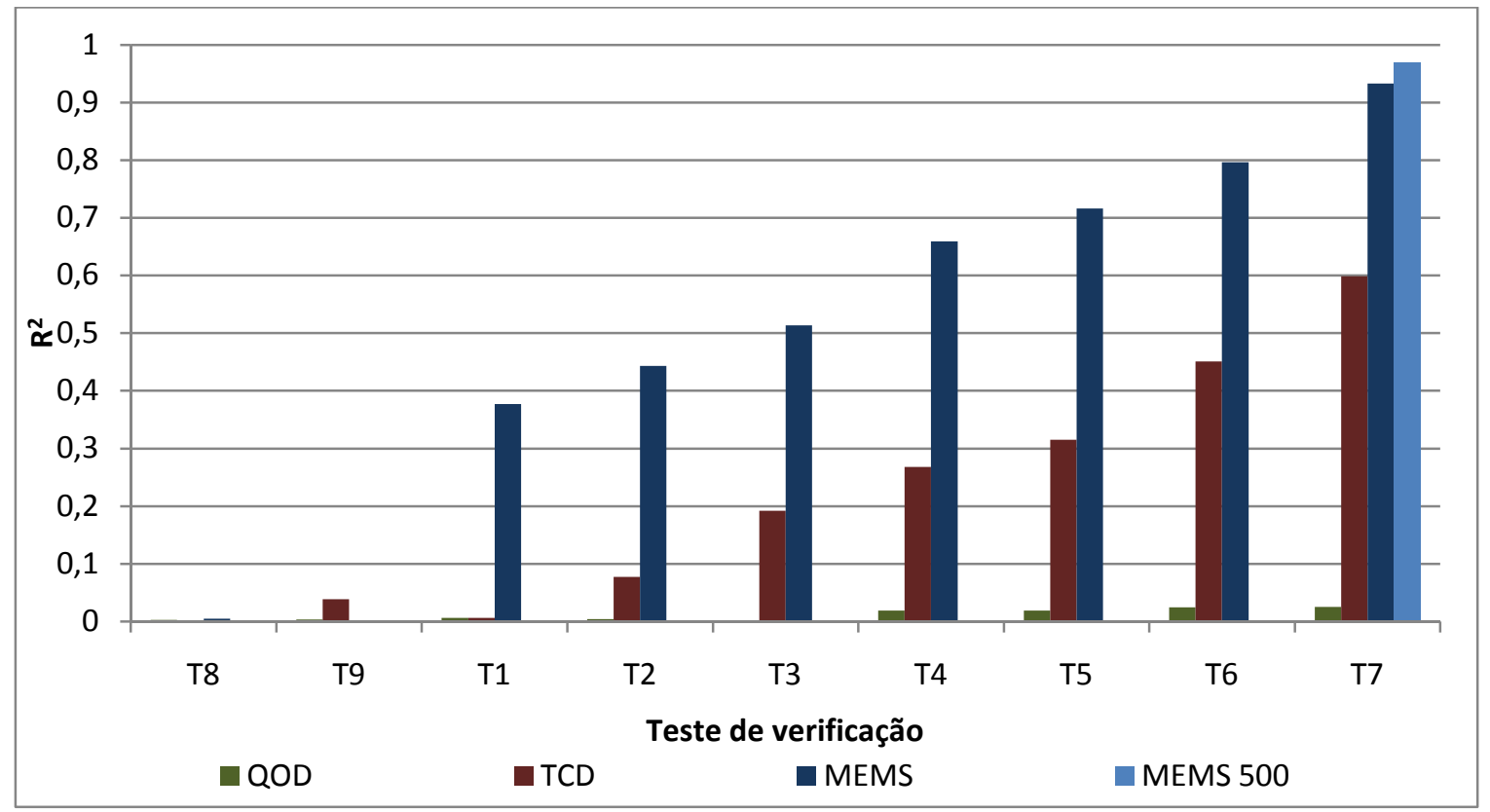

Figura 5. 3: Valor do $R^{2}$ da reta ajustada do diagrama de dispersão

Quando foram consideradas apenas contagens nos arcos (Teste 8), os valores de $\mathrm{R}^{2}$ obtidos para as viagens estimadas em comparação com as "reais" foram muito baixos, indicando que os valores estimados estavam dispersos. Isso ocorreu com os três métodos de estimação utilizados (QOD, TCD e MEMS).

Entre os três métodos, o do QUEENSOD foi o que apresentou pior desempenho. Os resultados estimados por este método são os que apresentam maior dispersão. No Teste 1 , por exemplo, as viagens estimadas entre 10 pares OD apresentaram valor superior a 1.000 viagens e em 27 pares OD o total de viagem estimado foi nulo, isso fez com que os valores de $R^{2}$ fossem muito baixos. Nos demais testes o QOD repetiu esse comportamento, o maior valor de $R^{2}$ foi obtido no Teste 7 (igual a 0,025 ), que não apresentou par OD com zero viagem estimada e foram inseridos 40 "arcos virtuais". Esse aumento no valor de $R^{2}$ não foi significativo, no entanto a tendência é significativa.

Os resultados estimados pelo TransCAD apresentaram valores de $\mathrm{R}^{2}$ maiores que os obtidos pelo QOD, entretanto o valor máximo foi aproximadamente 0,6 , o que é baixo. Pode ser observado que $\mathrm{R}^{2}$ aumentou em função do aumento do número de informações. Por exemplo, no Teste 8 , em que contagens foram realizadas apenas nos arcos, o valor de $\mathrm{R}^{2}$ 
foi 0,0008; no Teste 1, ao inserir 8 "arcos virtuais", esse valor atingiu 0,0065; no Teste 5, com 24 "arcos virtuais", chegou a 0,31; e no Teste 7 aumentou para 0,59.

Entre os três métodos, o desempenho do MEMS foi melhor, pois os resultados estimados são menos dispersos. À medida que o número de informações aumentou, $R^{2}$ cresceu, e o valor máximo foi obtido no Teste 7 (0,93 para 250 iterações e 0,97 para 500). Quanto a essa variação no número de iterações, foi afirmado no Capítulo 3 que, por se tratar da verificação de uma proposta e pelo fato de o método de estimação estar programado de maneira semi-automatizada, foi feita a opção por realizar 250 iterações. Porém no Teste 7, que considera a situação com maior quantidade de informação adicional, foi decidido realizar mais iterações, de forma a verificar os efeitos causados. Por isso, este teste possui resultados estimados com 500 iterações, conforme descrito no Capítulo 4. A conclusão é que o aumento do número de iterações permitiu ao método MEMS estimar uma matriz OD mais próxima à "real".

Na Figura 5. 4 são apresentados os gráficos com o diagrama de dispersão entre os valores de viagens estimadas e os "reais". Os gráficos representam apenas os Testes 8 e 7 , que ilustram as situações com menor e maior quantidade de informações de fluxo, respectivamente. Observando esses diagramas é possível notar que a dispersão é menor quando são consideradas informações adicionais (Teste 7). Os gráficos dos demais testes estão apresentados no Apêndice A. 
Uma proposta de estimação da matriz OD a partir dos fluxos de tráfego observados nas interseções da rede de transportes

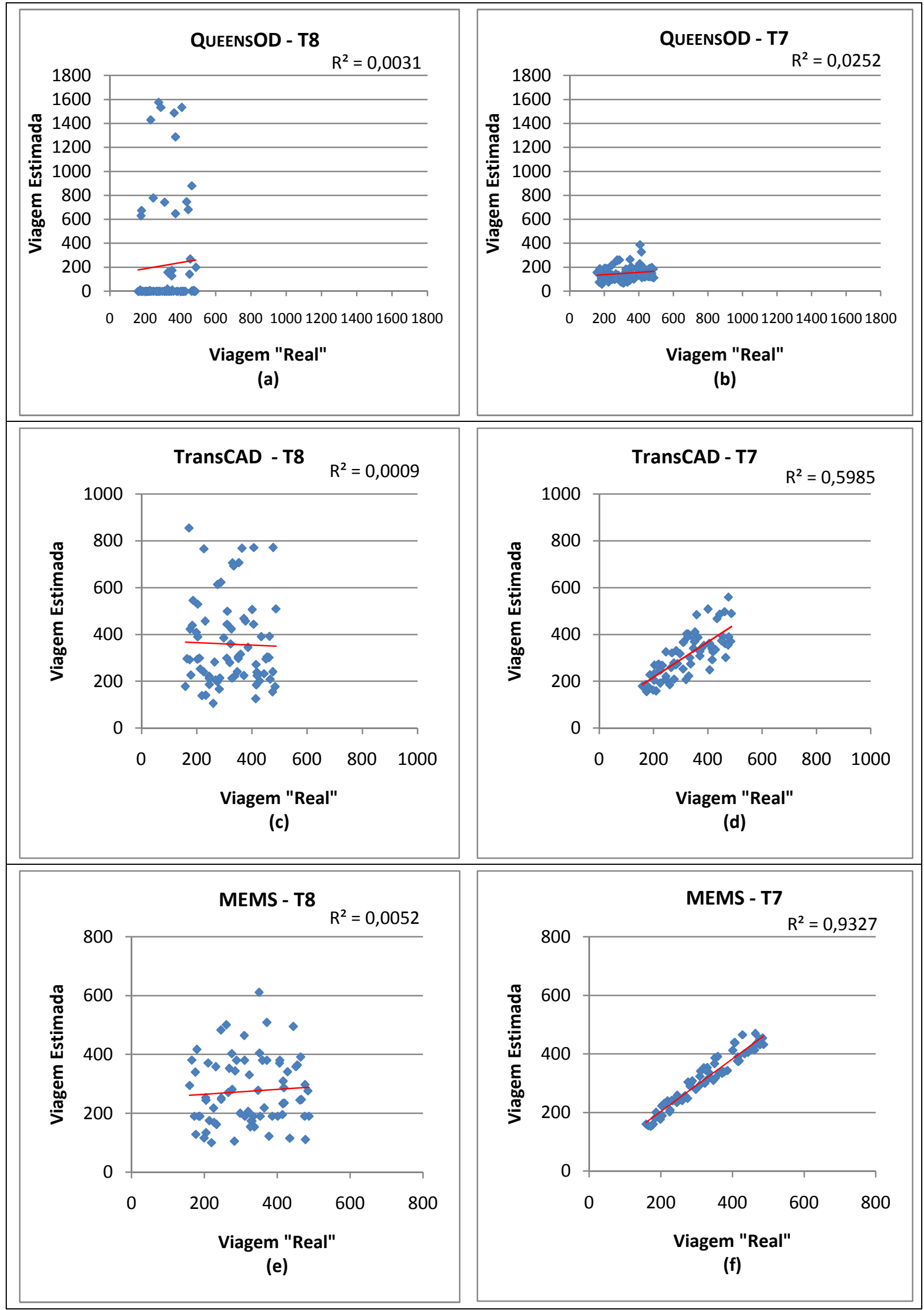

Figura 5. 4: Diagrama de dispersão e regressão das viagens estimadas em relação as "reais" 


\section{$\Rightarrow \quad$ Diferença absoluta média (DAM):}

O valor médio representado pela razão entre a somatória total das diferenças absolutas, pelo número total de viagens "real", mostra na média quão distante estão os valores estimados dos "reais".

Na Figura 5.5 é apresentado o gráfico com os valores da razão para cada um dos testes de verificação. Pode ser observado que o comportamento é decrescente à medida que aumentam o número de informações e sua distribuição na rede. Isto indica que, na média, as viagens estimadas se aproximam das "reais".

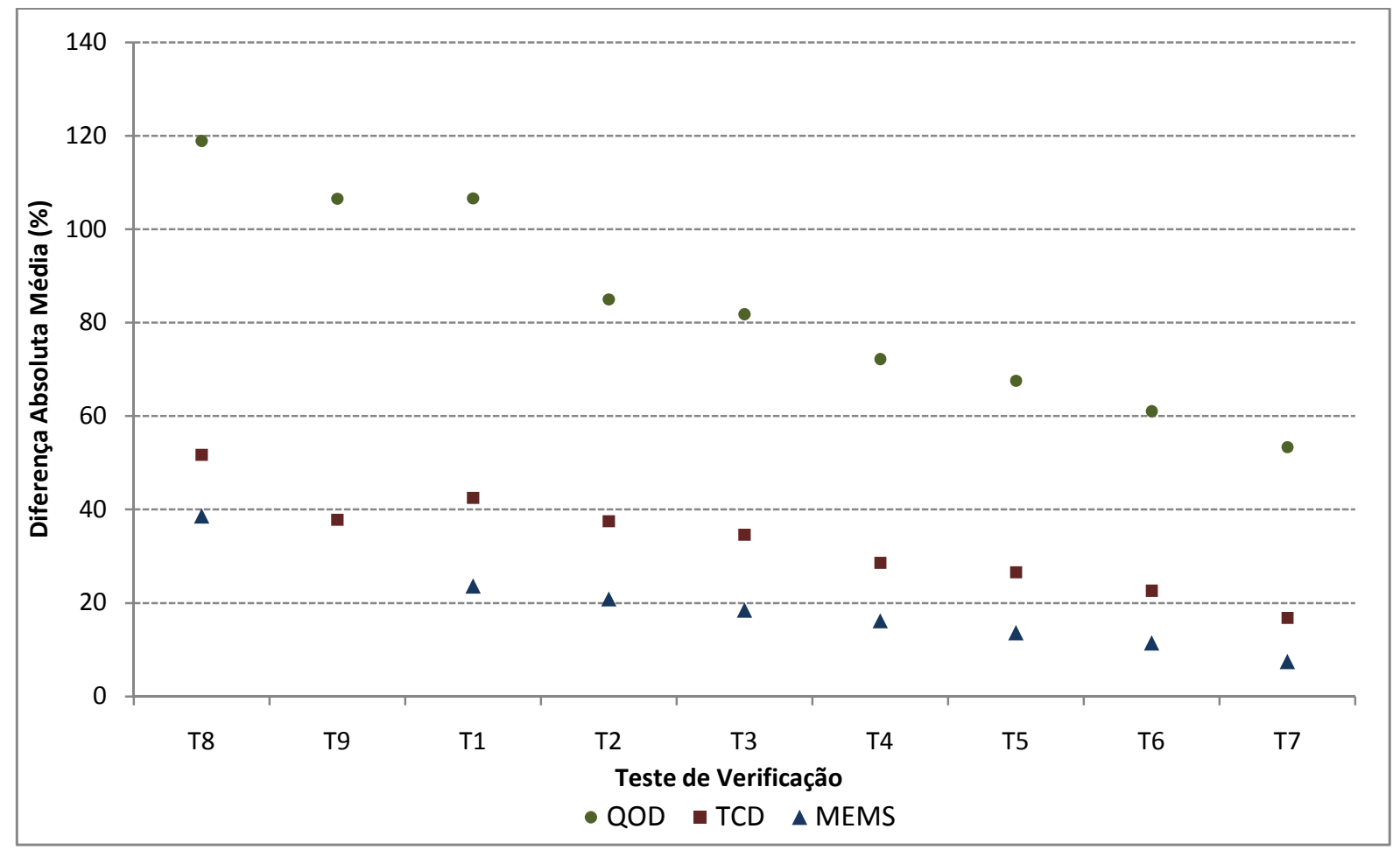

Figura 5. 5: Diferença absoluta média

Em relação aos métodos de estimação utilizados, as viagens estimadas pelo QUEENSOD foram as que apresentaram maiores valores para a diferença absoluta média, enquanto as viagens estimadas pelo MEMS foram as que apresentam menores valores para esta medida. 
O Teste 8, que não possui informações adicionais, apresentou maior valor para razão, igual a 119\%, ao utilizar o QOD. Quando foi inserido o número máximo de informações não redundantes (Teste 7), o valor deste parâmetro (considerando o QUEENSOD) passou a ser $53 \%$, ou seja, redução de $55 \%$. O Teste 9 , que considera o uso do arquivo turning movement, apresentou valor para DAM praticamente igual ao obtido para o Teste 1. Embora o QOD tenha apresentado valores elevados para este índice, pode ser percebida uma tendência de redução deste valor à medida que aumenta a quantidade de informação e sua distribuição na rede.

Analisando os valores estimados pelo TransCAD, é possível dizer que para o Teste 8 o valor da DAM foi igual a $52 \%$ e para o Teste 7 foi igual a $17 \%$. Novamente o aumento do número de informações não redundantes reduziu o tamanho da razão entre a somatória das diferenças absolutas pelo número total de viagens "real"; neste caso específico, a redução foi igual a $67 \%$. O valor da DAM para o Teste 9 foi apenas $1 \%$ menor que o obtido para o Teste 1. A redução no valor da razão ao considerar o TCD foi maior que o obtido pelo QOD, indicando que o TCD apresenta um método de estimação mais eficiente.

Considerando os valores estimados através do MEMS, pode-se verificar que o valor da razão entre o somatório das diferenças absolutas pelo número total de viagens "real" passou de 39\% no Teste 8 , para 7\% no Teste 7, com redução do valor da razão da ordem de $82 \%$. Além disso, observando os Testes 1 a 7 é possível notar que o valor da razão diminui, conforme aumenta a quantidade de informações e sua distribuição na rede.

Se forem considerados os valores estimados pelo MEMS no Teste 7 após 500 iterações, é possível perceber que o desempenho melhora, pois o valor da razão passa a ser $5 \%$, conforme apresentado na Tabela 5. 2. Isso é $91 \%$ menor que o valor obtido, neste mesmo teste, ao usar o QOD e 71\% menor com a estimação feita pelo TCD. No entanto, a redução do valor da media ao considerar 500 iterações, em comparação com o valor obtido após 250, não foi tão acentuada, indicando que ele deve estar próximo à convergência. 
Na Figura 5. 6 é possível observar a evolução a cada iteração do valor da razão entre a somatória das diferenças absolutas pelo número total de viagens "real", considerando os resultados estimado pelo método MEMS.

Nas primeiras iterações do método MEMS, os resultados apresentam erros elevados, mas que reduzem ao longo das etapas. Após 250 iterações as curvas ainda apresentam tendência de decrescimento. Prova disto é que no Teste 7, após 500 iterações, o valor obtido para diferença absoluta média apresentou redução. Ainda assim, a tendência da curva indica que o valor tende a reduzir com mais iterações. Quando o MEMS estiver programado em um processo automático de estimação é esperado que os valores estimados sejam melhores, pois serão realizadas tantas iterações, quantas forem necessárias para a convergência ser atingida.

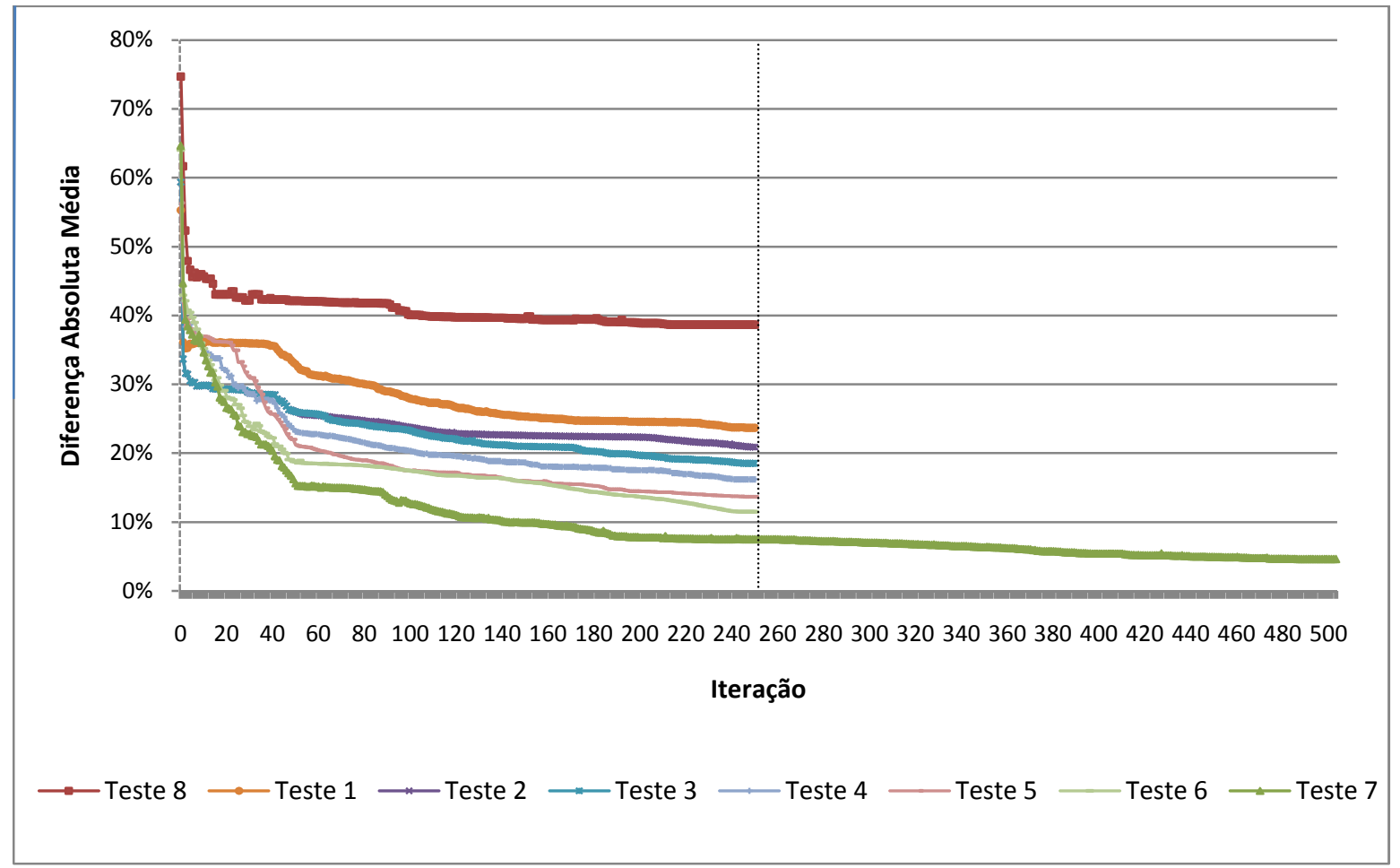

Figura 5. 6: Evolução da razão entre somatório das diferenças absolutas pelo total de viagens "real" a cada iteração, pelo método MEMS 
$\Rightarrow \quad$ Diferenças relativas:

A análise das diferenças relativas entre os totais de viagem estimadas em cada par OD, pelo total de viagens "real" nos pares OD, possibilitou verificar quão distantes das viagens "reais" estão as estimadas.

$\mathrm{Na}$ Tabela 5. 2, são apresentados os valores extremos dessa medida (mínimo e máximo) e o maior valor em módulo, entre eles. O Apêndice B traz as tabelas com os valores das diferenças relativas de cada teste e para cada par OD.

A Figura 5. 7 apresenta, em termos absolutos, os maiores valores da diferença relativa. Pode ser notado que a diferença relativa diminui à medida que aumenta a quantidade de informação não redundante. Este fato repete o comportamento que os índices anteriormente analisados haviam mostrado.

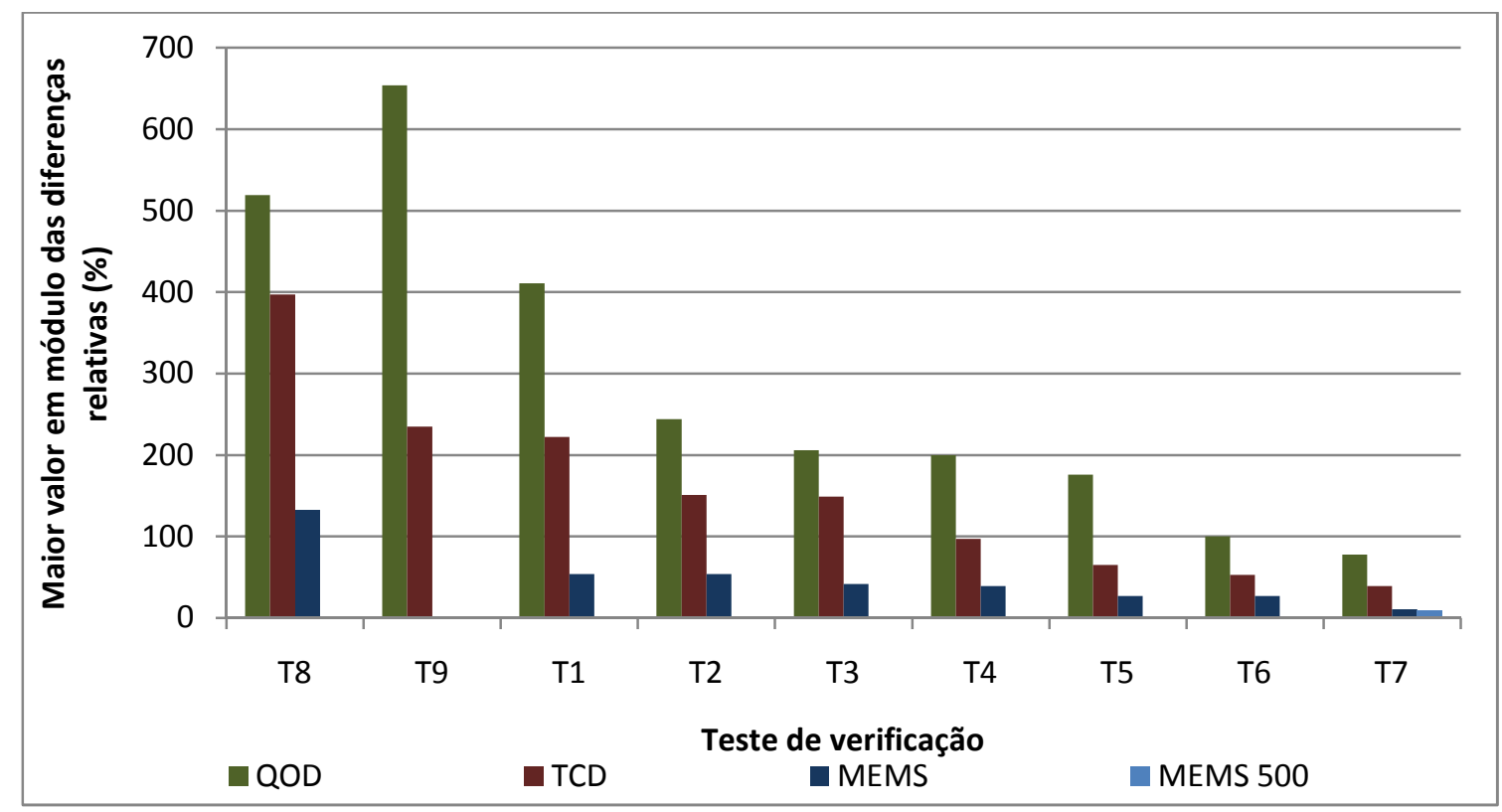

Figura 5. 7: Diferença relativa máxima

O maior valor (em módulo) da diferença relativa dos resultados estimados pelo QUEENSOD ocorreu no Teste 9 e foi igual a 654\%, observado no par OD 1-6. Além disso, em 32 pares OD não houve estimação de viagens. Teoricamente, o desempenho do QOD no Teste 9 teria que ser melhor que o obtido no Teste 8 pois, além de o fluxo observado no 
arco, faz uso do arquivo de turning movement, porém o que se observou foi aumento de $28 \%$ no valor máximo do erro relativo.

Para o Teste 8, com uso do QOD, que considerou apenas os fluxos observados nos arcos, o maior valor para diferença relativa foi igual a 519\%, devido à superestimação de viagens no par OD 4-6. Neste teste, 43 pares OD tiveram zero viagem estimada. Ao aumentar a quantidade de informação, é reduzido o valor do maior erro relativo e, no Teste 7, foi atingido o menor valor (igual a 78\%), observado no par OD 6-5 e motivado por uma subestimação de viagens; além disso entre todos os pares OD houve estimação de viagens. A comparação dos Testes 8 e 7, revelou redução de $85 \%$ no valor máximo das diferenças relativas. Mais importante que isto foi o comportamento apresentado, que indicou que com o aumento da quantidade de informação o erro relativo tende a diminuir.

Pelo TransCAD, quando foi utilizada a semente unitária, o valor máximo da diferença relativa foi igual a 397\%, a qual corresponde ao par OD 7-4, quando considerado o Teste 8. Entre todos os pares OD foram estimadas viagens. Já para o Teste 7, o maior valor da diferença relativa foi igual a 39\%, referente a uma subestimação de viagens ocorrida no par OD 7-1.

Quanto ao MEMS, o valor máximo da diferença relativa, observada no Teste 8 , foi igual a $133 \%$ e ocorreu no par OD 7-3, devido à superestimação de viagens. A comparação desse valor máximo com os obtidos por QOD e TCD utilizando matriz semente unitária, a diferença relativa máxima obtida ao usar o MEMS foi $74 \%$ e $66 \%$ menor que diferença relativa máxima obtida por QOD e TCD para este mesmo teste, respectivamente. À medida que a quantidade de informação não redundante de fluxo aumentou, o valor do erro diminuiu, sendo que no Teste 7 esse valor passou a ser igual a 11\%, com redução de $92 \%$, em comparação com o erro obtido no Teste 8. Considerando os resultados obtidos no Teste 7 após 500 iterações, a maior diferença relativa foi igual a $9 \%$ - redução da ordem de $18 \%$ em comparação com os valores obtidos neste Teste ao realizar 250 iterações. 
$\mathrm{Na}$ Tabela 5.3 são apresentados as porcentagens de pares OD que tiveram viagens super ou subestimadas.

Tabela 5. 3: Porcentagem de pares OD com viagens superestimadas e subestimadas em cada teste

\begin{tabular}{|c|c|c|c|c|}
\hline \multirow{2}{*}{ Teste } & \multicolumn{4}{|c|}{ Método de estimação } \\
\hline & QUEENSOD & TransCAD & MEMS & MEMS (500) \\
\hline \multirow{2}{*}{ T1 } & 37 & 51 & 58 & $n / c$ \\
\hline & 63 & 49 & 42 & $\mathrm{n} / \mathrm{c}$ \\
\hline \multirow{2}{*}{ T2 } & 14 & 42 & 54 & $n / c$ \\
\hline & 86 & 58 & 46 & $\mathrm{n} / \mathrm{c}$ \\
\hline \multirow{2}{*}{ T3 } & 25 & 39 & 51 & $\mathrm{n} / \mathrm{c}$ \\
\hline & 75 & 61 & 49 & $\mathrm{n} / \mathrm{c}$ \\
\hline \multirow{2}{*}{ T4 } & 68 & 51 & 51 & $n / c$ \\
\hline & 32 & 49 & 49 & $n / c$ \\
\hline \multirow{2}{*}{ T5 } & 24 & 53 & 49 & $n / c$ \\
\hline & 76 & 47 & 51 & $\mathrm{n} / \mathrm{c}$ \\
\hline \multirow{2}{*}{ T6 } & 11 & 37 & 49 & $n / c$ \\
\hline & 89 & 63 & 51 & $n / c$ \\
\hline \multirow{2}{*}{ T7 } & 1 & 47 & 40 & 53 \\
\hline & 99 & 53 & 60 & 47 \\
\hline \multirow{2}{*}{ T8 } & 40 & 50 & 42 & $\mathrm{n} / \mathrm{c}$ \\
\hline & 60 & 50 & 58 & $\mathrm{n} / \mathrm{c}$ \\
\hline \multirow{2}{*}{ T9 } & 35 & 58 & & $n / c$ \\
\hline & 65 & 42 & & $\mathrm{n} / \mathrm{c}$ \\
\hline
\end{tabular}

Obs: A primeira linha de cada teste apresenta a porcentagem de viagens superestimadas para o teste e na segunda linha há a porcentagem de viagens subestimadas. ${ }^{*} \mathrm{n} / \mathrm{c}$ não houve teste com essa quantidade de iterações.

Na maioria das observações (17 no total), houve predominância da subestimação. Pelo método do QOD, por exemplo, das nove verificações, em apenas uma houve predominância da superestimação e ocorreu no Teste 4 , no qual $68 \%$ dos pares OD tiveram mais viagens estimadas do que o total "real". Tanto nos resultados estimados pelo TransCAD, quanto nos estimados pelo MEMS, houve equilíbrio entre testes com predominância da superestimação e da subestimação de viagens. Não é possível afirmar que um destes métodos tenda a superestimar ou a subestimar as viagens, assim como não foi possível traçar relação entre a quantidade de informação adicional de fluxo, com o fato de super ou subestimar viagens.

A análise dos valores máximos serviu para mostrar que à medida que a quantidade de informação aumenta, a diferença relativa diminui. Porém, mais importante que esta constatação é analisar como as diferenças relativas estão distribuídas, por permitir verificar 
as freqüências com que esses erros ocorrem. Foram adotadas arbitrariamente as seguintes faixas: $e_{r} \leq 10 \%, 10 \%<e_{r} \leq 15 \%, 15 \%<e_{r} \leq 20 \%, 20 \%<e_{r} \leq 25 \%, 25 \%<e_{r} \leq 30 \%$, $30 \%<e_{r} \leq 40 \%, 40 \%<e_{r} \leq 50 \%, 50 \%<e_{r} \leq 60 \%, 60 \%<e_{r} \leq 70 \%, 70 \%<e_{r} \leq 80 \%$, $80 \%<e_{r} \leq 90 \%, e_{r}>90 \%$.

Na Figura 5. 8 é apresentado o histograma da distribuição das diferenças relativas em freqüências absolutas, considerando os valores estimados pelo QUEENSOD, quando fornecida matriz semente unitária. Ao analisar os resultados estimados no Teste 8 - que considera apenas as informações provenientes das contagens nos arcos - apenas 1 par OD apresentou valor da diferença relativa inferior a 50\% e está contido na faixa de 40 a 50\%.

Os resultados estimados no Teste 7 apresentaram maior concentração de diferenças relativas inferiores a 10\%. Ao todo são 10 observações e não há par OD com diferença relativa superior a 80\%. Os Testes 1, 2, 3 e 9 apresentam 2 observações inferiores a 10\%. Já o Teste 4 apresenta 4 observações inferiores a 10\%, o Teste 5 apresenta 5 observações nessa faixa e o Teste 6 possui 6 . Pode-se afirmar que à medida que a quantidade de informação aumenta, as diferenças relativas tornam-se menores.

Na Figura 5. 9 é apresentado o histograma da distribuição das diferenças relativas em freqüências absolutas dos resultados estimados pelo TransCAD, quando fornecida matriz semente unitária. Considerando a matriz OD estimada no Teste 7, não houve valor da diferença relativa superior a 40 e 23 pares OD apresentaram diferença relativa inferior a $10 \%$.

No caso do Teste 9, 10 pares OD apresentaram valor inferior a 10\%; desempenho esse, equivalente ao obtido pelo Teste 1, quando foram realizadas contagens em 4 interseções apenas (foram inseridos 8 "arcos virtuais"). 
Ao considerar contagens nas interseções, o comportamento apresentado é melhor. Além disso, o método de estimação do TransCAD revelou ser mais eficiente que o QUEENSOD, por apresentar maior quantidade de diferenças relativas nas faixas com menores erros menores.

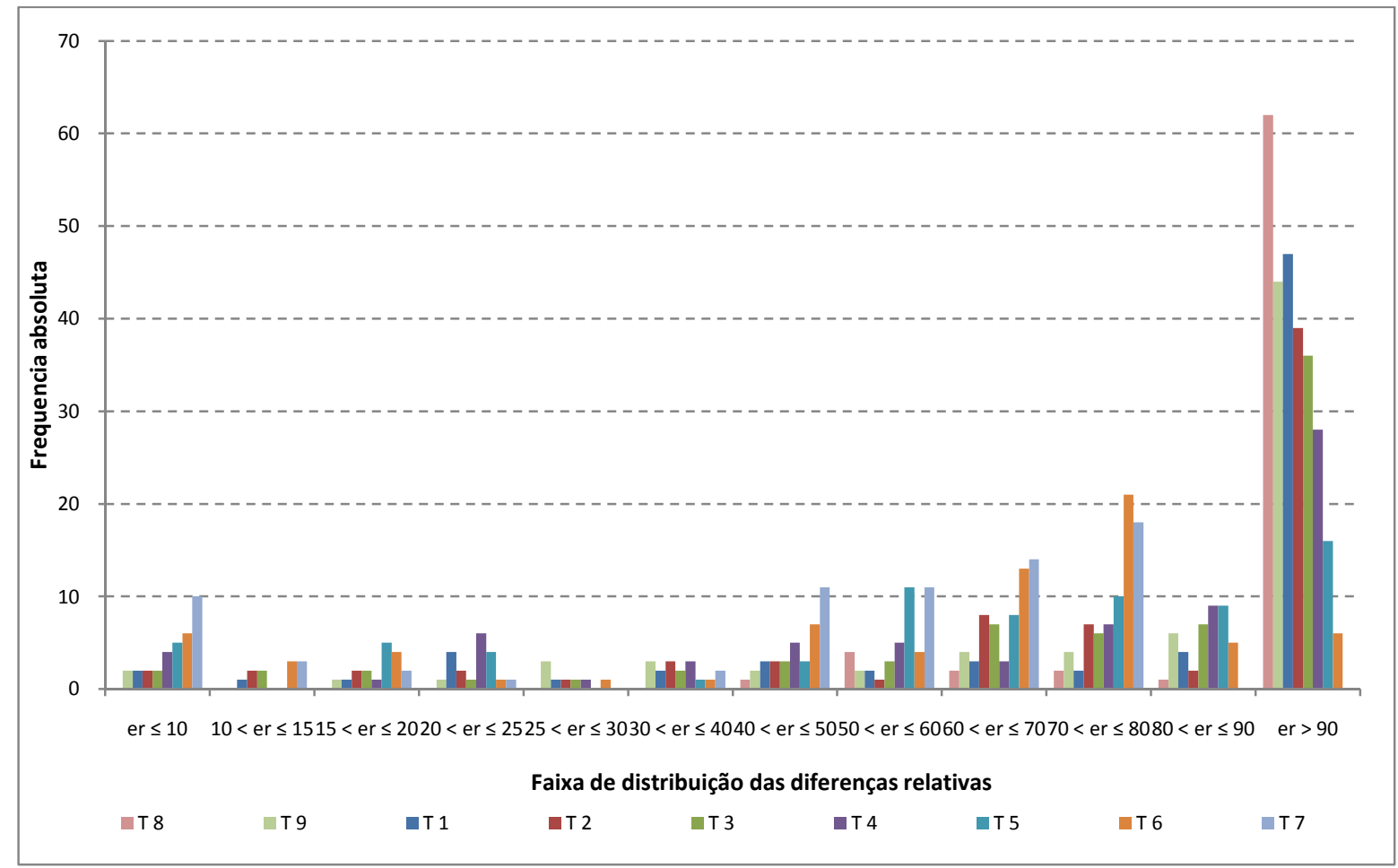

Figura 5. 8: Histograma da distribuição absoluta das diferenças relativa entre viagens QUEENSOD

O histograma das freqüências absolutas da distribuição de diferenças relativas considerando os resultados estimados pelo MEMS está apresentado na Figura 5. 10. Ao considerar o Teste 7 , todos os pares OD apresentaram erro relativo com valor inferior a 15\%. Para o Teste 8, 50 pares OD apresentaram erro relativo inferior a $50 \%$, dos quais 12 tiveram erro inferior a $10 \%$. Para o Teste 1 , a quantidade de pares OD com erro inferior a $10 \%$ foi 15; para os Testes 2 e 3 foi 26; 28 para os Testes 4 e 5; e 33 para o Teste 6 . Melhor desempenho entre os métodos estudados. 


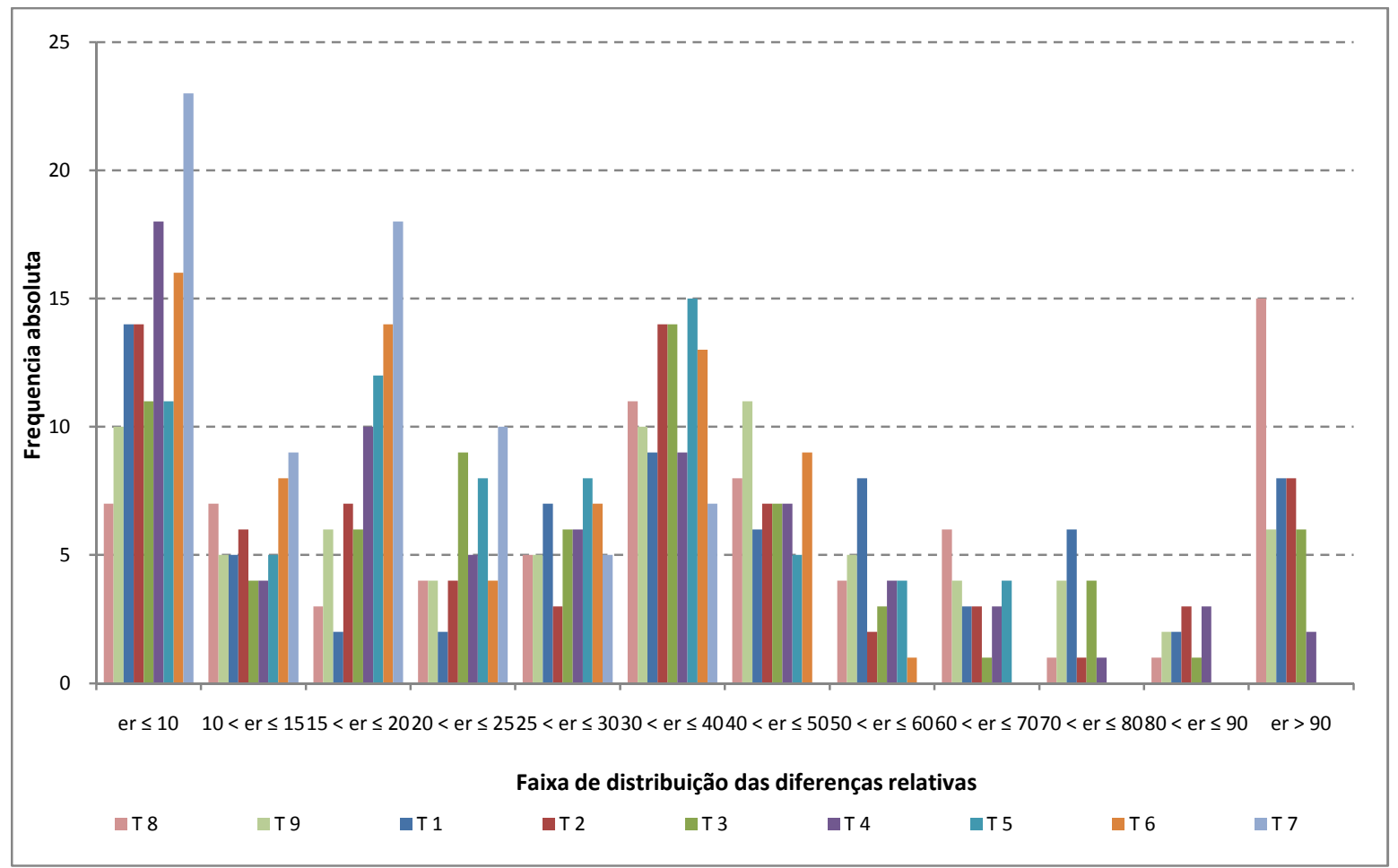

Figura 5. 9: Histograma da distribuição absoluta das diferenças relativa entre viagens TransCAD

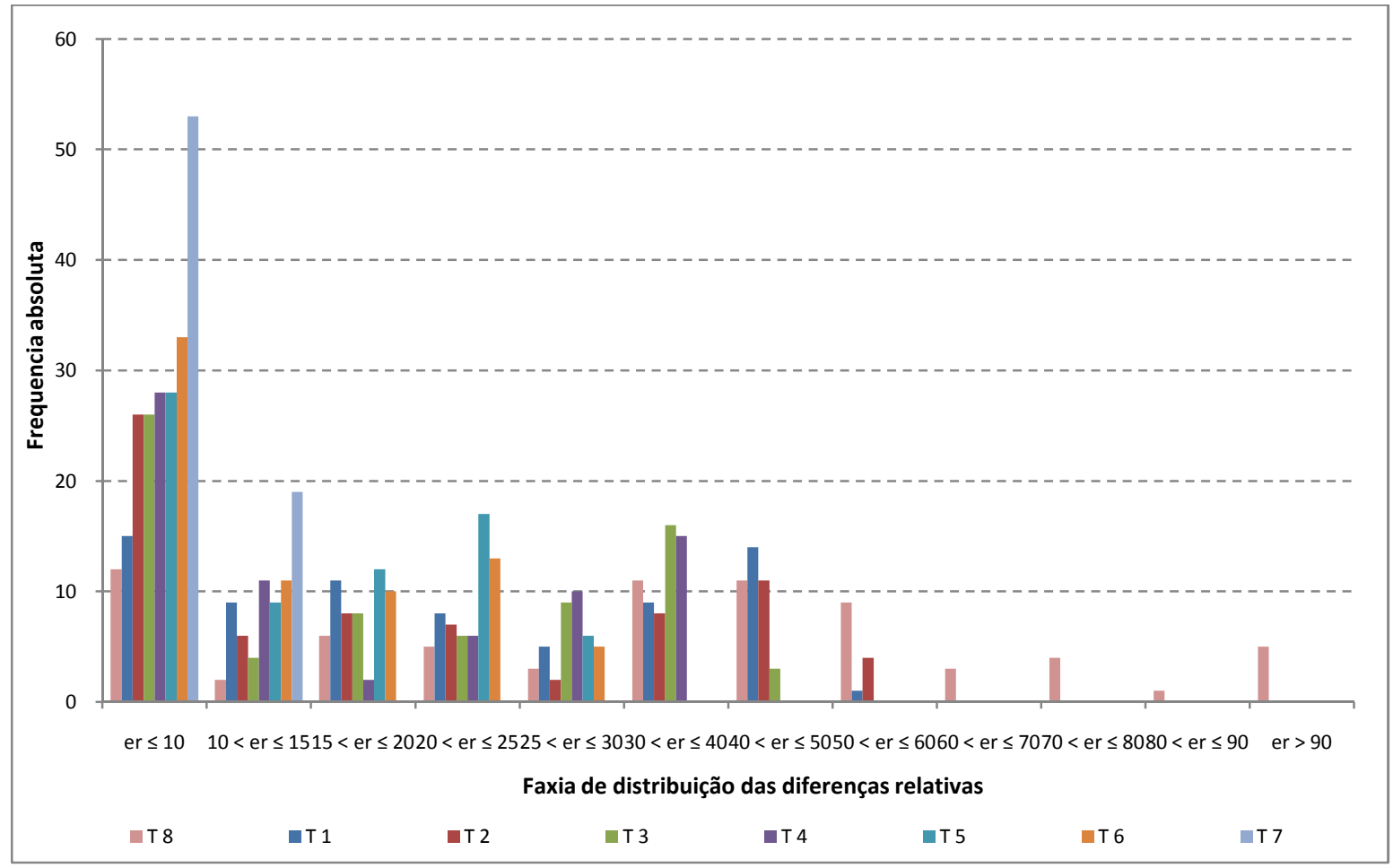

Figura 5. 10: Histograma da distribuição absoluta das diferenças relativa entre viagens MEMS

Outra verificação foi feita através da freqüência acumulada da distribuição dos erros relativos. Na Figura 5. 11 são apresentados os gráficos com esta freqüência. 
Uma proposta de estimação da matriz $O D$ a partir dos fluxos de tráfego observados nas interseções da rede de transportes

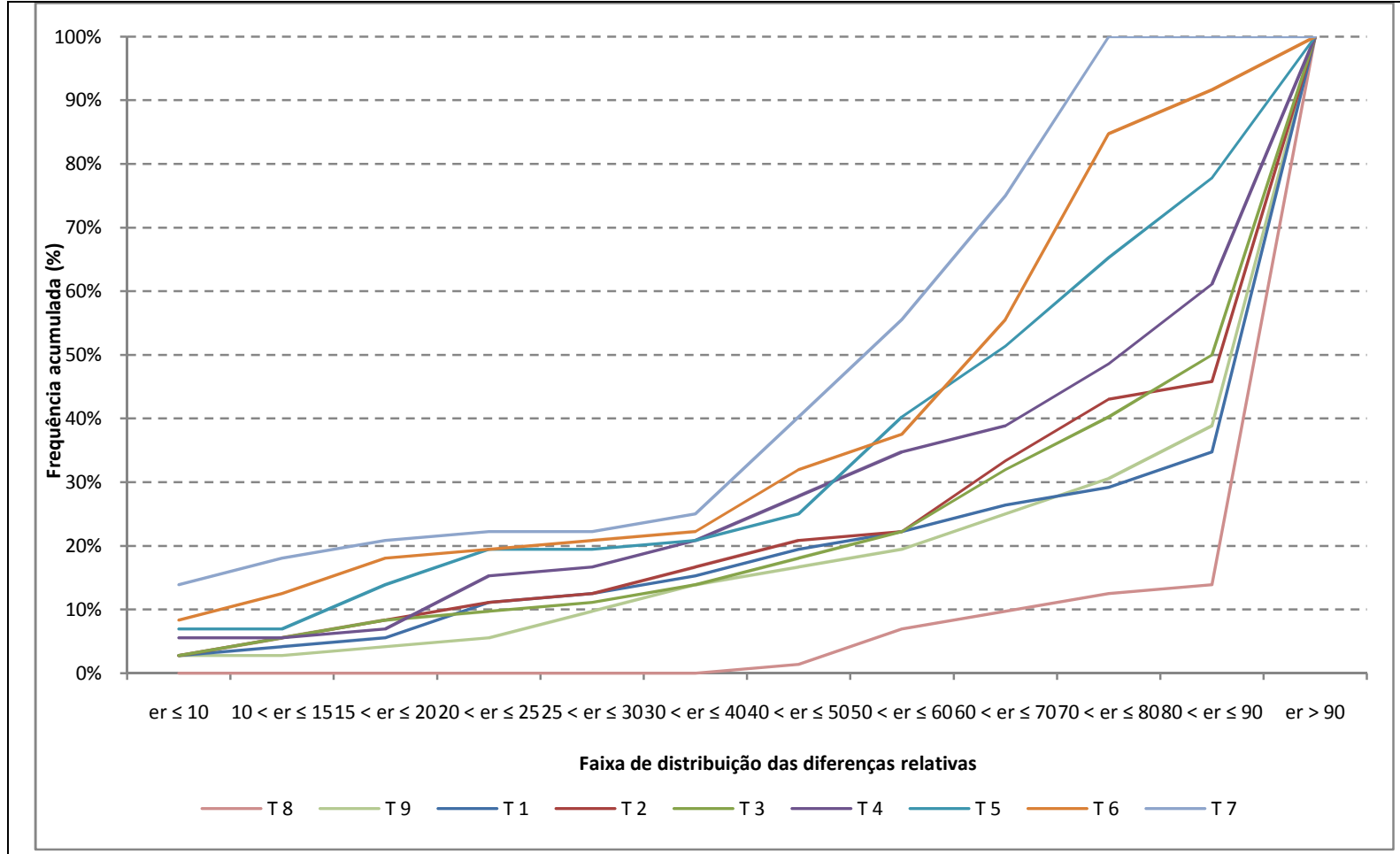

(a)

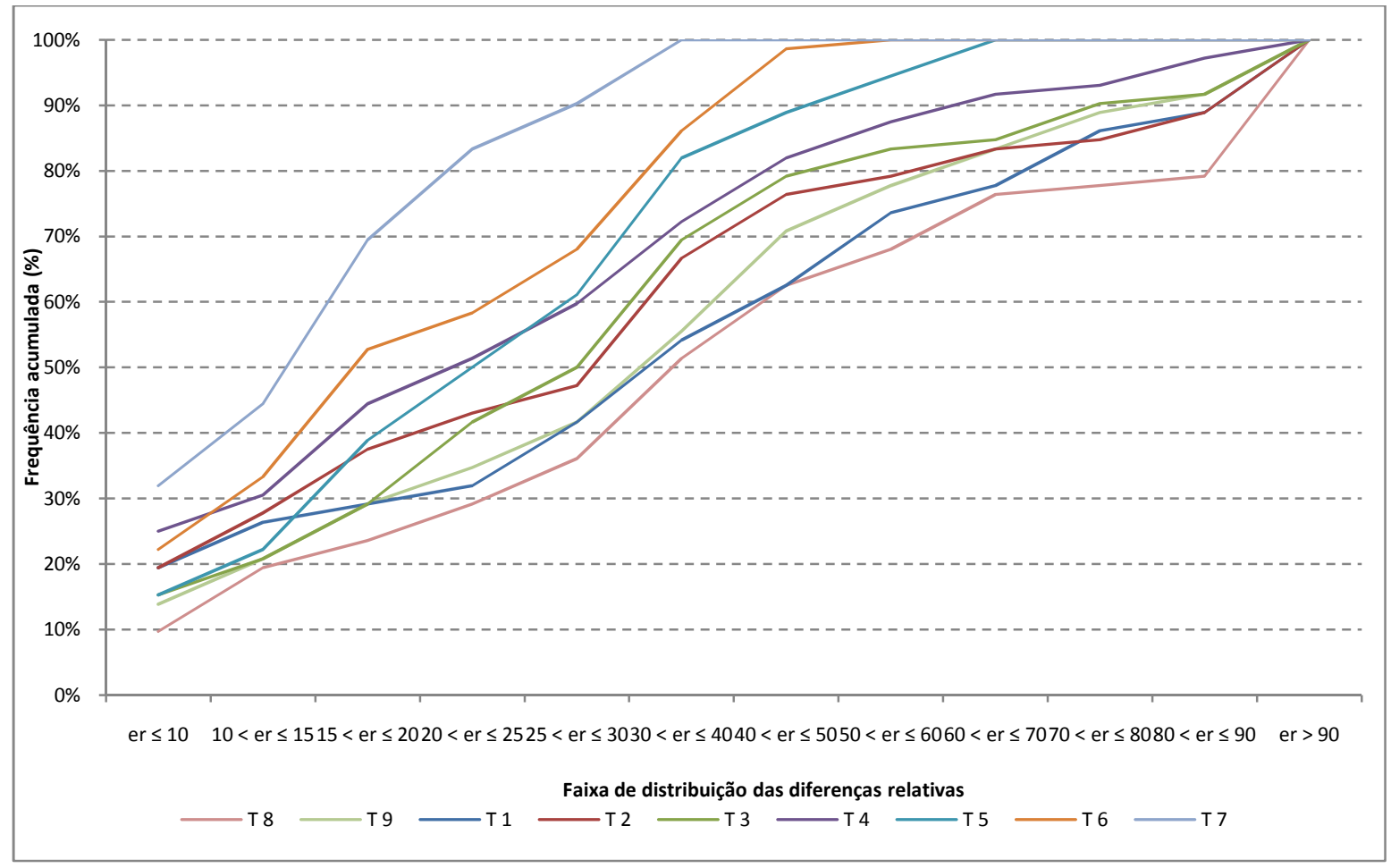

(b) 


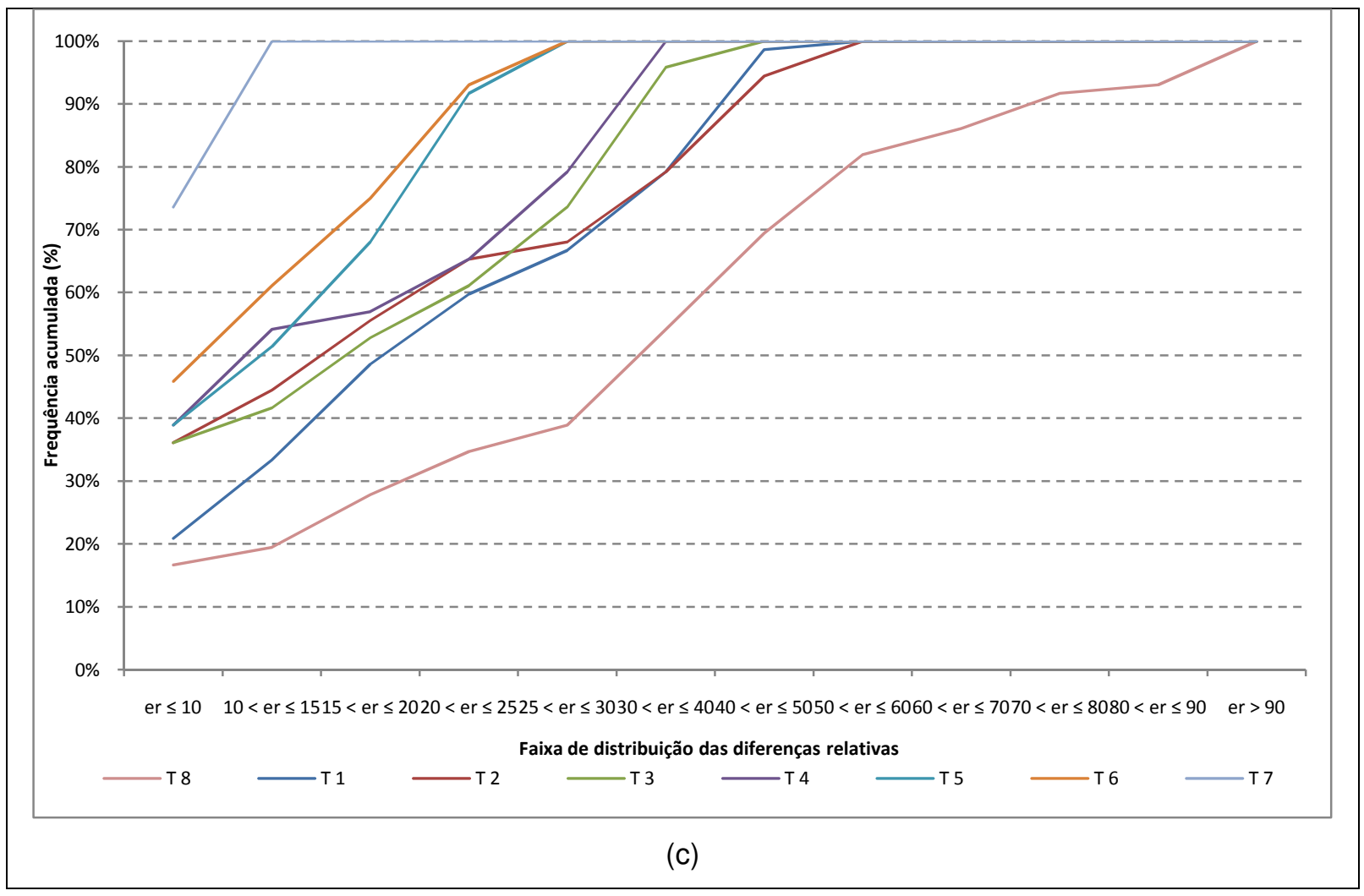

Figura 5. 11: Histograma da distribuição acumulada das diferenças relativa entre viagens: (a) QUEENSOD - matriz semente unitária; (b) TransCAD - matriz semente unitária; (c) MEMS

Para os resultados estimados pelo QUEENSOD, apenas o Teste 7 acumulou 100\% das diferenças relativas antes da faixa de distribuição de $80 \%$ e, neste mesmo teste, $40 \%$ das diferenças relativas foram acumuladas até a faixa de $50 \%$. No Teste 8 , em que houve apenas contagem nos arcos, $31 \%$ das diferenças relativas estavam acumuladas na faixa de distribuição entre 40 e $80 \%$. Ao utilizar a opção turning movement (Teste 9), 17\% das diferenças relativas ficaram acumuladas na faixa de distribuição de até $50 \%$.

Ao considerar os resultados estimados pelo TransCAD, o comportamento apresentado foi melhor (comparando com O QOD), pois houve acúmulo maior das diferenças relativas nas faixas de erro menores. Prova disso é que em três testes o acumulo total das diferenças relativas ocorreu até a faixa de $70 \%$. No Teste 7 , por exemplo, até a faixa de erro relativo $40 \%$ ocorreu o acúmulo de $100 \%$ das diferenças relativas. Em todos os testes considerando uso de "arcos virtuais" (Teste 1 ao 7), mais da metade das observações 
apresentaram erro relativo que foram acumulados nesta faixa, indicando que a idéia foi capaz de estimar matriz com menor erro.

Os Testes 8 e 9, que não utilizaram "arcos virtuais", apresentaram desempenho inferior, tanto pelo QOD, quanto pelo TCD, sendo que o acumulo de $100 \%$ das diferenças relativas só ocorreu na faixa de erro superior a 90\%; o Teste 9 apresenta uma ligeira vantagem em relação ao 8, ao considerar o TCD.

Ao analisar o MEMS, cinco, dos sete testes que avaliaram o acréscimo de informação, apresentaram $100 \%$ das diferenças relativas acumuladas até a faixa de distribuição igual a $50 \%$, sendo que até a faixa de erro $60 \%$ todos os testes tiveram $100 \%$ dos valores da diferença relativa acumulados, levando ao melhor desempenho entre os três métodos.

Em relação aos métodos de estimação empregados, o QUEENSOD é o que teve pior aproveitamento; no entanto o comportamento dos índices obtidos a partir da análise de seus resultados, mostram que eles tendem a melhorar com o aumento da quantidade de informação.

O método MEMS foi o que apresentou melhor comportamento - os parâmetros resultantes dos valores estimados são os que possuem melhores índices entre os métodos utilizados. Pelo resultado do Teste 7 , é possível inferir que com mais iterações os valores estimados tendem a melhorar. Com um processo automatizado será possível realizar tantas iterações, quanto necessárias, até que a convergência seja atingida.

Assim, as principais conclusões obtidas das análises realizadas até então são:

$\Rightarrow \mathrm{O}$ aumento da quantidade de informações devido às contagens nos nós possibilitou aos métodos de estimação gerarem matrizes mais próximas às reais; 
$\Rightarrow$ Mesmo realizando contagens em poucos nós, os resultados estimados foram mais próximos aos valores "reais" de viagem. Ao menos para o método MEMS os ganhos foram significativos;

$\Rightarrow \mathrm{O}$ artifício de utilizar "arcos virtuais", para que os programas pudessem fazer estimação considerando os fluxos de conversão, produziu resultado satisfatório. Os programas puderam ser facilmente adaptados à proposta de estimar a matriz OD apresentada por este trabalho;

$\Rightarrow$ Dos métodos de estimação utilizados, o método do QUEENSOD foi o que apresentou pior desempenho. Isso indica que há problemas em sua formulação ou no algoritmo programado;

$\Rightarrow$ Dos três métodos, o QOD foi o único a estimar zero viagem em muitos pares OD;

$\Rightarrow \mathrm{O}$ uso do arquivo turning movement não surtiu efeito nos resultados do QUEENSOD, mas revelou ser melhor para o TCD. Ainda assim, o desempenho foi pior que o obtido ao considerar contagens nos nós, conforme preconiza este trabalho;

$\Rightarrow \mathrm{O}$ método MEMS teve bom desempenho quando comparado com os programas, nas situações em que eles utilizaram matriz semente unitária;

$\Rightarrow$ Os valores para diferença relativa dos resultados estimados pelo MEMS foram os menores, em comparação com os obtidos pelos demais métodos; o acúmulo de $100 \%$ das observações ocorreu nas faixas com menores erros, inclusive quando considerada apenas contagens nos arcos;

$\Rightarrow \mathrm{O}$ aumento do número de iterações do MEMS permitiu estimar resultados mais próximos aos "reais". Para aplicações práticas, o algoritmo do método 
deverá ser programado para permitir que sejam realizadas as iterações necessárias para atingir a convergência.

\subsection{ANÁLISE DOS RESULTADOS QUANTO À QUALIDADE DA MATRIZ SEMENTE}

O uso da matriz OD semente e sua qualidade tendem a interferir diretamente nos resultados estimados, conforme afirmam Yang et al (1992). Além disso, a matriz semente representa para o modelo aumento na quantidade de informação (VAN ZUYLEN; WILLUMSEN, 1980).

No Capítulo 3 foi definido utilizar uma matriz OD semente proporcional a "real", denominada $S_{70}$. As viagens entre cada par OD desta matriz correspondem a $70 \%$ das viagens "reais". Porém, na prática, o planejador de transportes não dispõe de uma matriz semente com tamanha qualidade, além de o crescimento das viagens entre os pares OD ser desigual ao longo do tempo.

A fim de verificar o efeito causado pelo uso de uma matriz semente em que as viagens entre os pares OD não tivessem a mesma taxa de crescimento, foi proposto no Capítulo 3 que nos Testes 7, 8 e 9 seriam utilizadas outras duas matrizes, as quais corresponderiam a variações em torno de $\pm 20 \%$ e $\pm 10 \%$ na matriz semente $S_{70}$, denominadas $\mathrm{Sem}_{20}$ e $\mathrm{Sem}_{10}$, respectivamente. O aumento da qualidade da matriz semente segue a seguinte ordem: unitária, $\operatorname{Sem}_{20}, \operatorname{Sem}_{10}$ e $\mathrm{S}_{70}$.

Usar $S_{70}$ neste trabalho foi importante uma vez que, por se tratar de matriz com elevada qualidade é esperado que os resultados sejam muito próximos ao "real", o que permitirá avaliar o desempenho dos programas. Este item tem por objetivo analisar os resultados obtidos ao utilizar matriz semente da seguinte forma: (i) observando os efeitos ocasionados pelo uso da matriz semente; e (ii) qual comportamento ao considerar à proposta deste trabalho, aliada à matriz semente. Na Tabela 5.4 há um resumo com as principais medidas analisadas. 


\section{$\Rightarrow \quad$ Total de viagens estimadas e estatística da regressão:}

Mesmo com a utilização de matrizes semente proporcionais a "real" (como a $S_{70}$ ), ou com variação em torno de $\pm 10 \%$ e $\pm 20 \%$, não houve um padrão de comportamento para o total de viagens estimado. Na Figura 5. 12 é apresentado o valor da relação entre o total de viagens estimado, pelo total de viagens "real", para cada teste.

De modo geral, o comportamento do método de estimação do QUEENSOD tende a subestimar viagens. A única superestimação ocorreu no Teste 1, quando foi fornecida matriz semente unitária. A amplitude da porcentagem entre o total de viagens estimadas e o total "real" está menor, em comparação com quando foi usada matriz semente unitária. Em relação ao TransCAD, é possível afirmar que os totais de viagem estimados ao aumentar a qualidade da matriz OD semente estão mais próximos aos totais "reais", na faixa entre $-5 \%$ e $5 \%$. Antes, com matriz semente unitária, a faixa de variação estava entre $-10 \%$ e $15 \%$, portanto mais ampla.

Por não ser possível uma análise confiável apenas em função dos totais de viagem, foram realizadas análises observando os totais de viagem estimados entre cada par OD. $\mathrm{Na}$ Figura 5. 13 há um gráfico com os valores obtidos de $R^{2}$ e a Tabela 5.4 traz um resumo dos demais parâmetros da estatística de regressão. 
Uma proposta de estimação da matriz $O D$ a partir dos fluxos de tráfego observados nas interseções da rede de transportes

Tabela 5. 4: Resumo das medidas que serão analisadas ao considerar matriz semente

\begin{tabular}{|c|c|c|c|c|c|c|c|c|c|}
\hline \multirow[b]{2}{*}{ Teste } & \multirow{2}{*}{$\begin{array}{c}\text { Total de } \\
\text { Viagens } \\
\text { Estimadas }\end{array}$} & \multirow{2}{*}{$\begin{array}{c}\text { DAM } \\
(\%)\end{array}$} & \multicolumn{3}{|c|}{ Dif. Relativa (\%) } & \multicolumn{4}{|c|}{ Est. da Regressão } \\
\hline & & & $\begin{array}{l}\text { Mín. } \\
\text { (neg) }\end{array}$ & Máx. & $\begin{array}{c}\text { Máx. } \\
\text { Abs }\end{array}$ & R-mult & $\mathbf{R}^{2}$ & $\mathbf{R}^{2}$ ajust & $\begin{array}{c}\text { Erro } \\
\text { Padrão }\end{array}$ \\
\hline \multirow{2}{*}{$\begin{array}{c}\mathrm{T} 1 \mathrm{c} / \\
\mathrm{S}_{70}\end{array}$} & 22.798 & 102,24 & -369 & 100 & 369 & 0,0342 & 0,0011 & $-0,013$ & 344,49 \\
\hline & 23.020 & 10,21 & -42 & 26 & 42 & 0,9142 & 0,8358 & 0,833 & 44,00 \\
\hline \multirow{2}{*}{$\begin{array}{c}\mathrm{T} 2 \mathrm{c} / \\
\mathrm{S}_{70}\end{array}$} & 15.686 & 81,19 & -310 & 100 & 310 & 0,1136 & 0,0129 & $-0,001$ & 146,73 \\
\hline & 23.034 & 9,97 & -21 & 32 & 32 & 0,9290 & 0,8630 & 0,861 & 36,57 \\
\hline \multirow{2}{*}{$\begin{array}{c}\text { T3 c/ } \\
\mathrm{S}_{70}\end{array}$} & 16.693 & 75,47 & -219 & 100 & 219 & 0,1861 & 0,0346 & 0,020 & 193,72 \\
\hline & 23.070 & 9,85 & -24 & 18 & 24 & 0,9272 & 0,8598 & 0,857 & 38,23 \\
\hline \multirow{2}{*}{$\begin{array}{c}\mathrm{T} 4 \mathrm{c} / \\
\mathrm{S}_{70} \\
\end{array}$} & 17.415 & 65,70 & -152 & 100 & 152 & 0,1080 & 0,0116 & $-0,002$ & 174,21 \\
\hline & 23.208 & 9,05 & -20 & 19 & 20 & 0,9400 & 0,8836 & 0,881 & 35,74 \\
\hline \multirow{2}{*}{$\begin{array}{c}\text { T5 c/ } \\
\mathrm{S}_{70}\end{array}$} & 15.117 & 62,80 & -143 & 97 & 143 & 0,0294 & 0,0008 & $-0,013$ & 165,86 \\
\hline & 22.843 & 8,90 & -22 & 22 & 22 & 0,9422 & 0,8878 & 0,886 & 34,56 \\
\hline \multirow{2}{*}{$\begin{array}{c}\text { T6 c/ } \\
S_{70}\end{array}$} & 15.696 & 58,23 & -95 & 95 & 95 & 0,1645 & 0,0270 & 0,013 & 126,54 \\
\hline & 23.143 & 7,93 & -19 & 18 & 19 & 0,9529 & 0,9081 & 0,906 & 30,15 \\
\hline \multirow{2}{*}{$\begin{array}{l}\text { T7 c/ } \\
\text { Sem }_{20}\end{array}$} & 16.807 & 63,43 & -205 & 99 & 205 & 0,2011 & 0,0404 & 0,026 & 252,39 \\
\hline & 22.401 & 10,89 & -17 & 63 & 63 & 0,9101 & 0,8284 & 0,826 & 44,82 \\
\hline \multirow{2}{*}{$\begin{array}{l}\text { T7 c/ } \\
\text { Sem }_{10}\end{array}$} & 15.377 & 45,91 & -159 & 97 & 159 & 0,1116 & 0,0124 & $-0,001$ & 131,36 \\
\hline & 22.952 & 7,41 & -16 & 16 & 16 & 0,9595 & 0,9207 & 0,919 & 27,59 \\
\hline \multirow{2}{*}{$\begin{array}{c}\text { T7 c/ } \\
S_{70}\end{array}$} & 15.515 & 46,61 & -74 & 76 & 76 & 0,1652 & 0,0273 & 0,013 & 95,09 \\
\hline & 23.390 & 6,88 & -15 & 14 & 15 & 0,9693 & 0,9396 & 0,938 & 25,68 \\
\hline \multirow{2}{*}{$\begin{array}{l}\text { T8 c/ } \\
\text { Sem }_{20}\end{array}$} & 16.144 & 97,15 & -351 & 100 & 351 & 0,0940 & 0,0088 & $-0,005$ & 397,9 \\
\hline & 22.422 & 18,16 & -74 & 51 & 74 & 0,7730 & 0,5976 & 0,591 & 70,05 \\
\hline \multirow{2}{*}{$\begin{array}{l}\text { T8 c/ } \\
\text { Sem }_{10}\end{array}$} & 16.182 & 108,11 & -441 & 100 & 441 & 0,0265 & 0,0007 & $-0,013$ & 352,0 \\
\hline & 22.855 & 17,28 & -74 & 47 & 74 & 0,7821 & 0,6118 & 0,606 & 67,76 \\
\hline \multirow{2}{*}{$\begin{array}{c}\text { T8 c/ } \\
\mathrm{S}_{70}\end{array}$} & 16.093 & 112,63 & -482 & 100 & 482 & 0,0548 & 0,0030 & $-0,011$ & 423,3 \\
\hline & 23.177 & 12,13 & -55 & 31 & 55 & 0,8853 & 0,7837 & 0,780 & 47,9 \\
\hline \multirow{2}{*}{$\begin{array}{l}\text { T9 c/ } \\
\text { Sem }_{20}\end{array}$} & 16.595 & 99,07 & -499 & 100 & 499 & 0,0036 & $1,32 \mathrm{E}-5$ & $-0,014$ & 382,4 \\
\hline & 22.992 & 12,17 & -35 & 42 & 42 & 0,9043 & 0,8177 & 0,815 & 48,6 \\
\hline \multirow{2}{*}{$\begin{array}{l}\text { T9 c/ } \\
\text { Sem }_{10}\end{array}$} & 16.254 & 101,32 & -502 & 100 & 502 & 0,0246 & 0,0006 & $-0,013$ & 385,6 \\
\hline & 23.128 & 9,47 & -36 & 35 & 36 & 0,9346 & 0,8735 & 0,871 & 38,24 \\
\hline \multirow{2}{*}{$\begin{array}{c}\text { T9 c/ } \\
S_{70}\end{array}$} & 17.298 & 110,40 & -509 & 100 & 509 & 0,0142 & 0,0002 & $-0,014$ & 420,3 \\
\hline & 22.969 & 9,11 & -49 & 37 & 49 & 0,9342 & 0,8729 & 0,8710 & 36,1 \\
\hline
\end{tabular}

Obs: A primeira linha de cada teste contém as medidas referentes aos resultados estimados pelo QUEENSOD e a segunda linha refere-se aos resultados estimados pelo TransCAD. Na terceira linha do Teste 7 estão as medidas ao utilizar o QOD considerando Sem $_{10}$, na quarta contém as medidas considerando Sem $_{10}$ com o TransCAD e nas linhas 5 e 6 estão os valores das medidas considerando Sem 20 ao utilizar o QOD e o TransCAD respectivamente. 


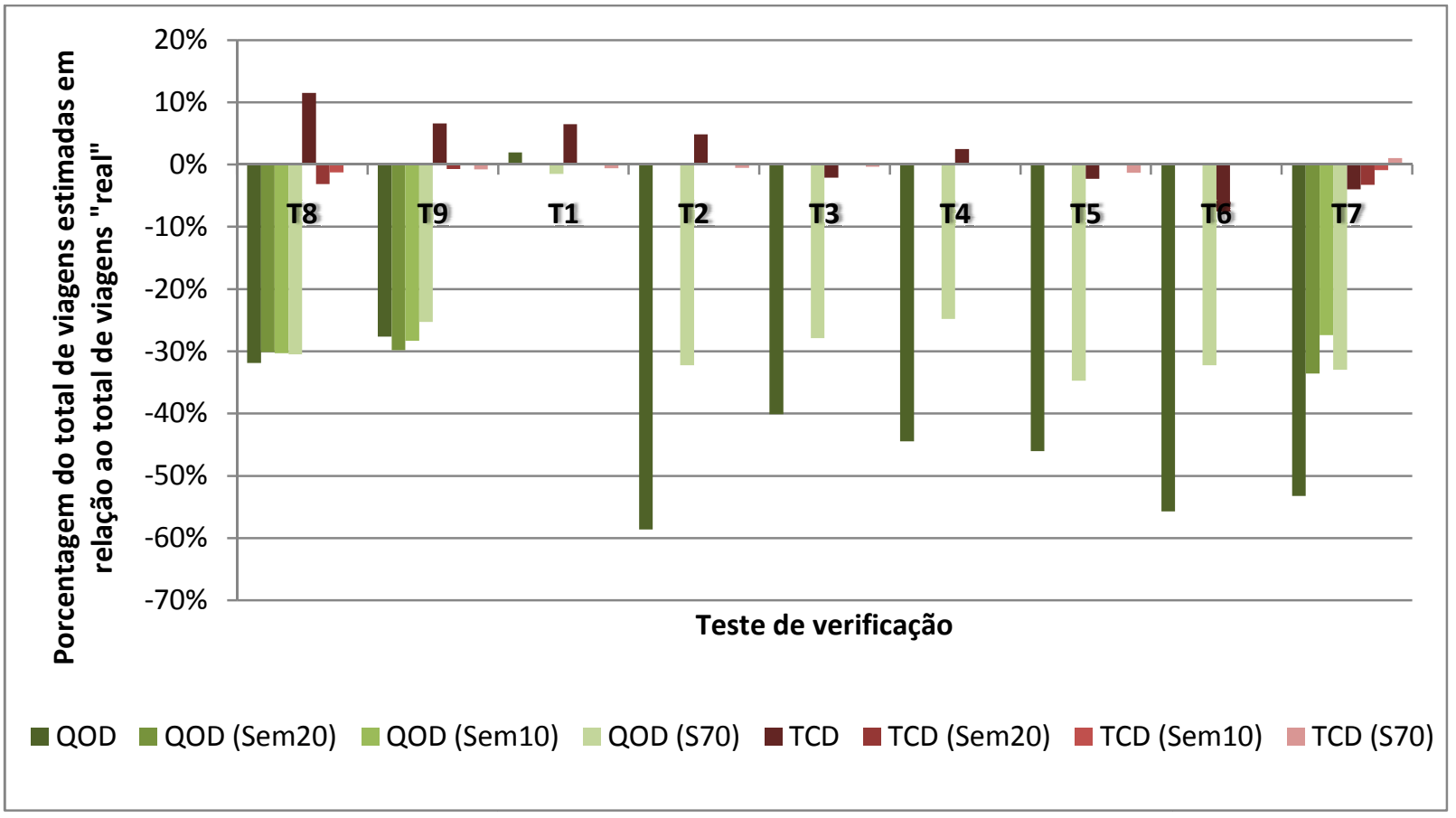

Figura 5. 12: Relação entre o total de viagens estimada pelo total de viagens "real"

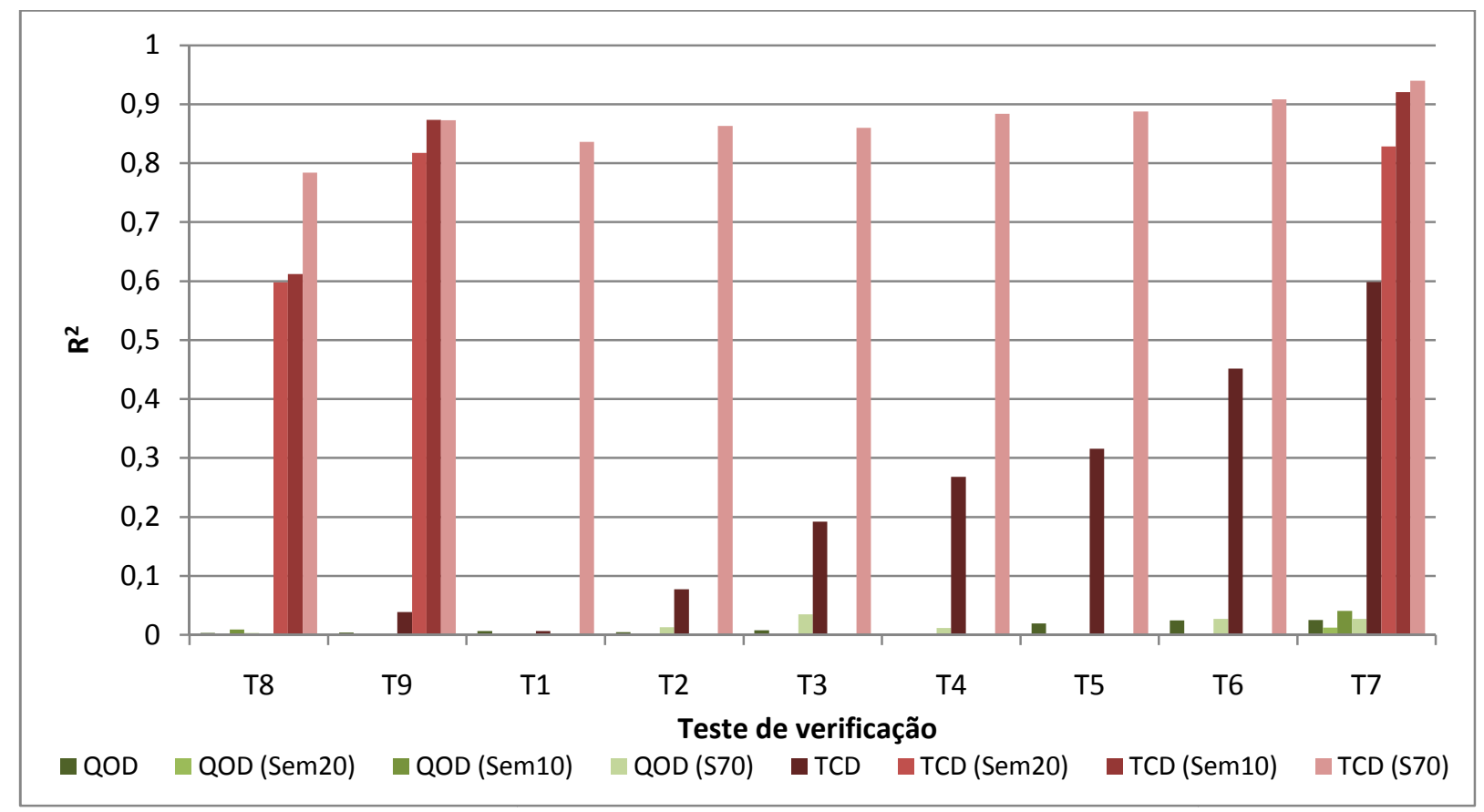

Figura 5. 13: Valor do $R^{2}$ da reta ajustada do diagrama de dispersão

O valor de $\mathrm{R}^{2}$ tende a aumentar à medida que informações adicionais de fluxo são inseridas, conforme já havia sido observado na análise apresentada no item 5.2. A exceção foi o QUEENSOD, cujos resultados estimados para o Teste 4 , ao usar $S_{70}$, causaram redução no valor de $\mathrm{R}^{2}$, muito provavelmente devido a algum problema do programa. Os valores de 
$R^{2}$ para os resultados estimados pelo QOD são irrisórios, mesmo com matriz semente de qualidade.

Os resultados estimados pelo TransCAD estão menos dispersos (em relação aos valores "reais"), do que os estimados pelo QOD. Prova disso é que os valores de $R^{2}$ são superiores quando é considerada a estimação feita pelo TransCAD.

Quanto à matriz semente, quando comparadas as três matrizes com maior qualidade $\left(S_{20}, S_{10}\right.$ e $\left.S_{70}\right)$ é possível observar que na estimativa feita pelo TransCAD, a matriz OD semente Sem $_{20}$ gerou resultados que levaram a um valor de $\mathrm{R}^{2}$ menor que os obtidos ao utilizar Sem $_{10}$ e $S_{70}$. Considerando o QUEENSOD ao usar Sem 10 no Teste 7, o QOD estimou uma matriz, que gerou $\mathrm{R}^{2}$ maior que ao utilizar $\mathrm{S}_{70}$ (matriz proporcional à "real"), conforme pode ser observado na Figura 5. 14.

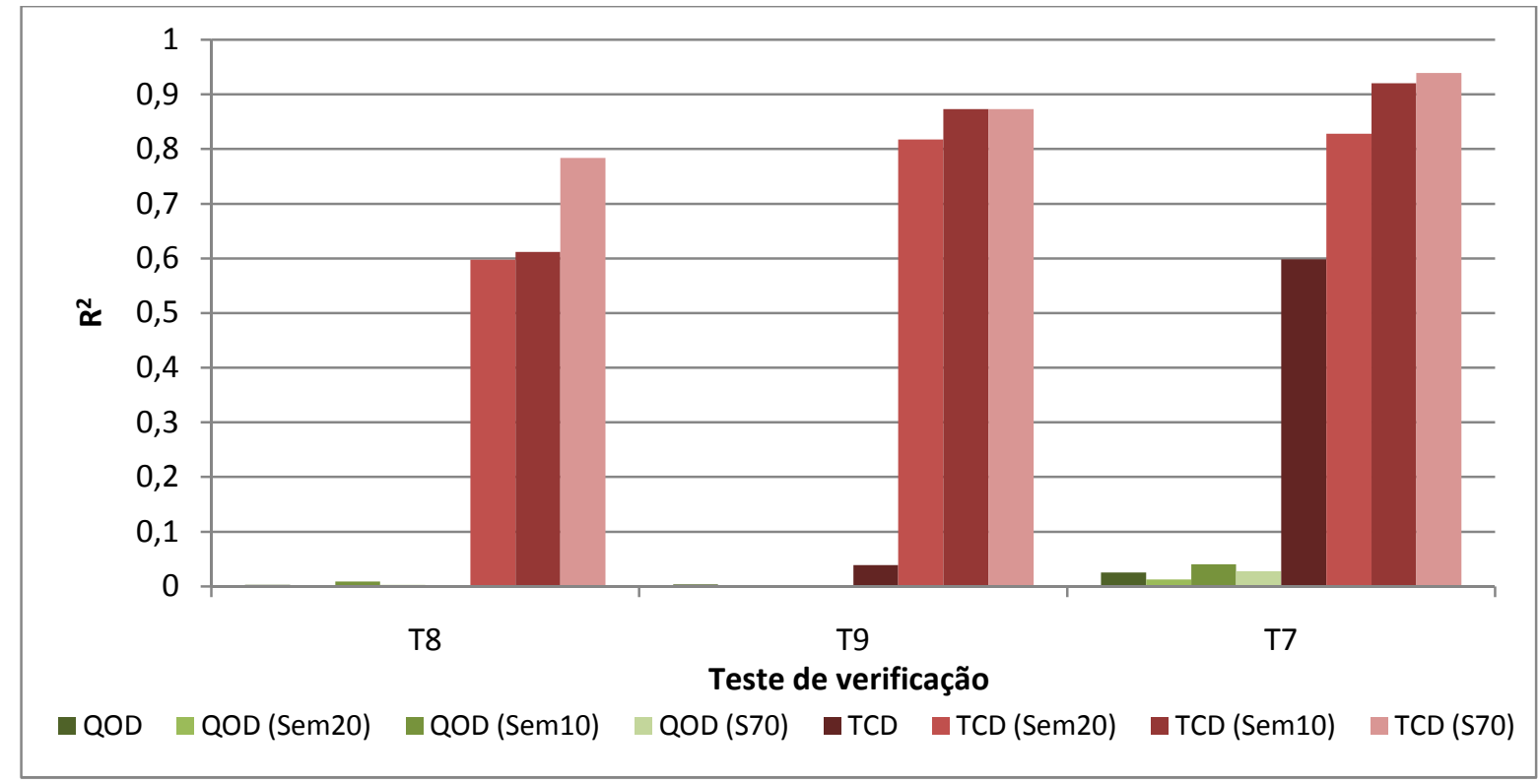

Figura 5. 14: Valor do $R^{2}$ da reta ajustada do gráfico de viagem "real" x viagem estimada, Testes 7 ao 9

Os gráficos de dispersão entre os valores estimados e os valores "reais" para os testes que representam situações extremas, com contagem apenas nos arcos e com contagem em todos os nós (Testes 8 e 7) estão apresentados nas Figura 5.15 e Figura 5. 16, respectivamente. As constatações são: com aumento da informação, a dispersão diminui; os resultados estimados pelo TransCAD estão mais próximos aos "reais"; e que 
apenas para o TransCAD, a qualidade da matriz semente contribuiu para melhoria do resultado, o que indica haver problema com o método do QOD.

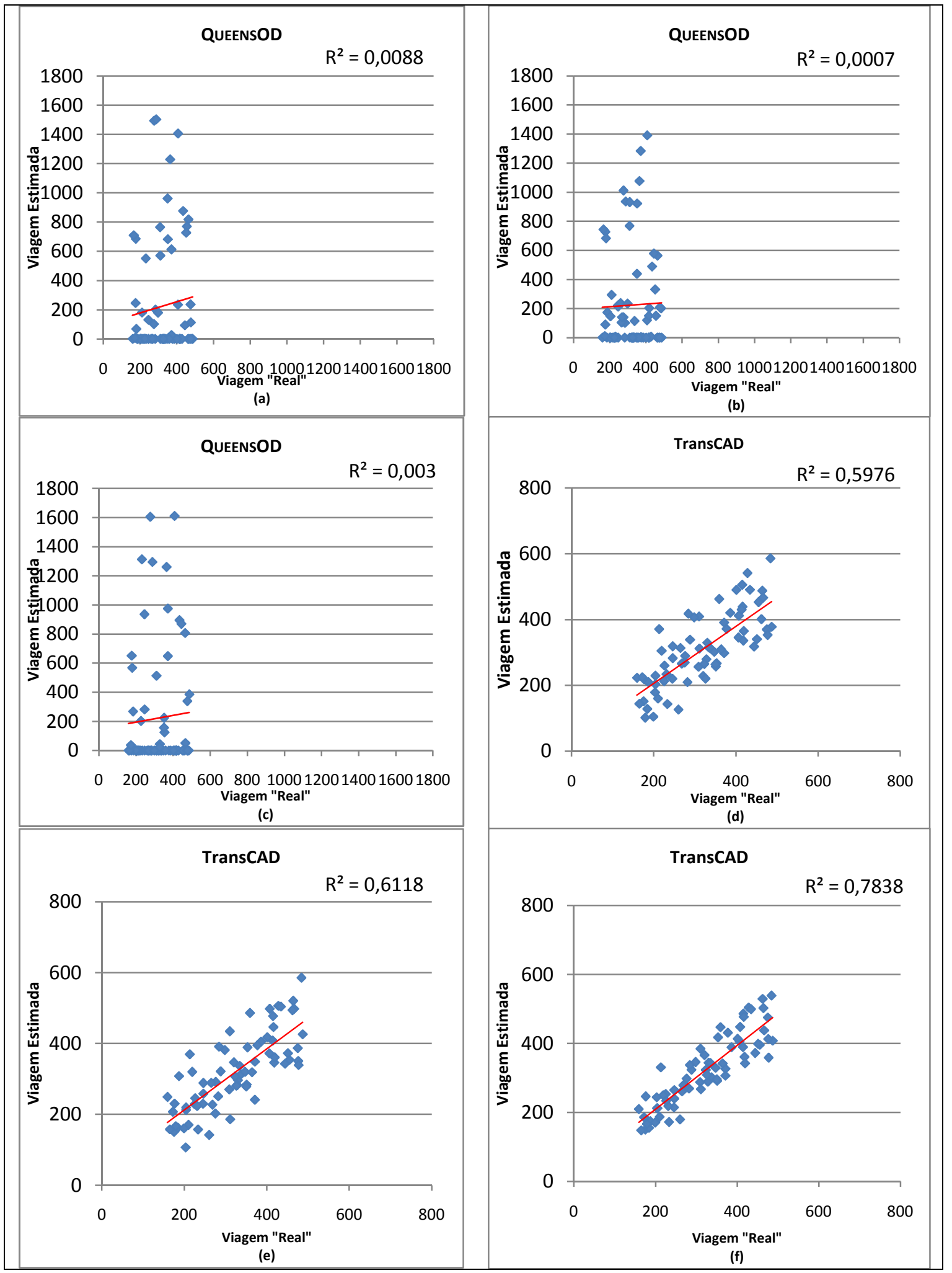

Figura 5. 15: Curvas de dispersão e regressão entre viagens - Teste 8: (a) QOD com Sem ${ }_{20}$; (b) QOD com Sem 10 ; (c) QOD com $\mathrm{S}_{70}$; (d) TCD com Sem 20 ; (e) TCD com Sem 10 ; (f) TCD com $\mathrm{S}_{70}$ 
Uma proposta de estimação da matriz OD a partir dos fluxos de tráfego observados nas interseções da rede de transportes

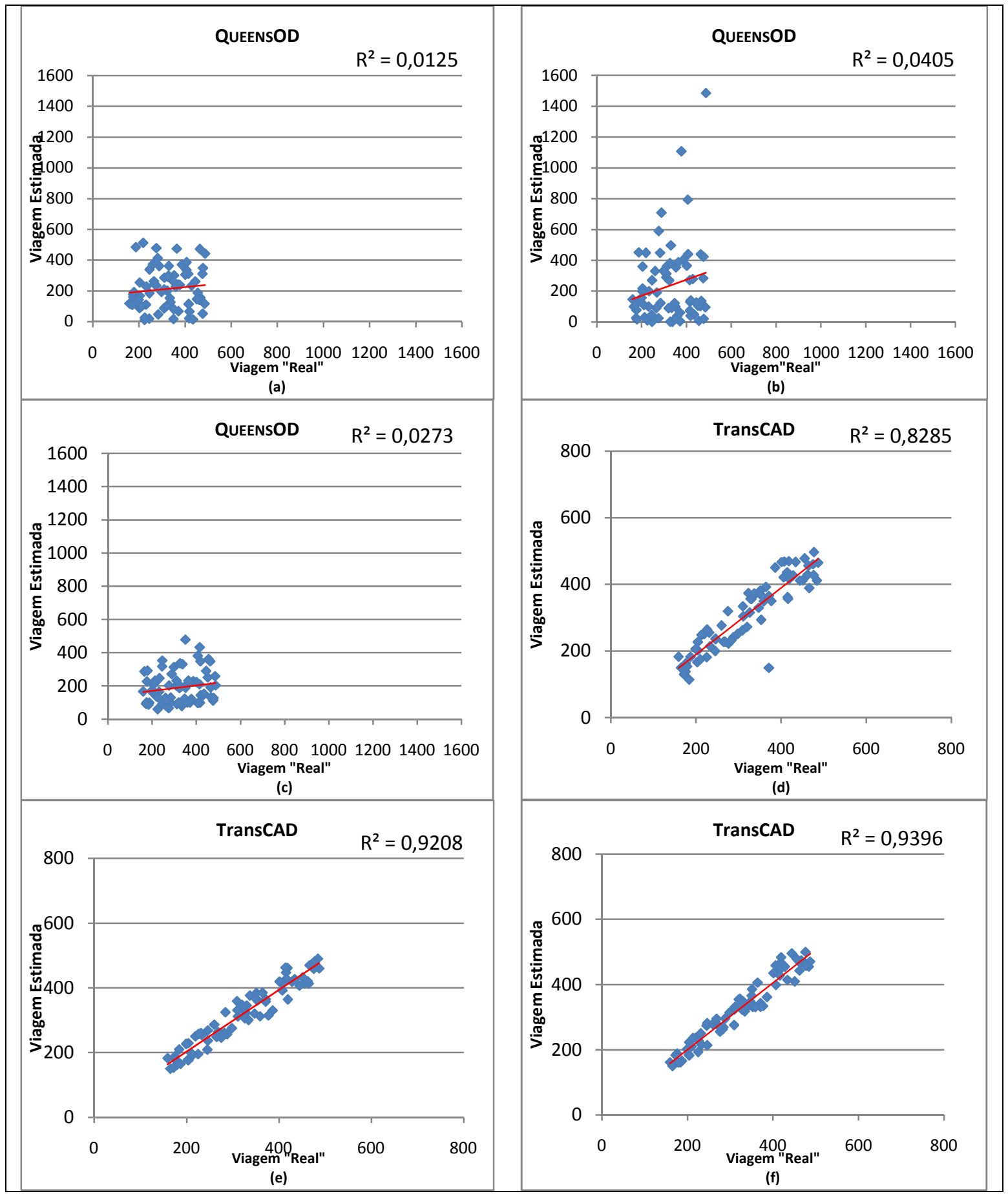

Figura 5. 16: Curvas de dispersão e regressão entre viagens- Teste 7: (a) QOD com Sem 20 ; (b) QOD com Sem 10 ; (c) QOD com S 70 ; (d) TCD com Sem 20 ; (e) TCD com Sem 10 ; (f) TCD com $\mathrm{S}_{70}$

$\Rightarrow \quad$ Diferença Absoluta Média (DAM):

Pela Figura 5. 17 é possível notar que à medida que o número de informações e sua distribuição na rede aumentam, o valor da razão entre o somatório total das diferenças absolutas pelo número total de viagens "real" diminui. A redução do valor da diferença 
absoluta média, à medida que o número de informações adicionais aumenta, é mais significativa no QUEENSOD, do que no TransCAD.

Para analisar os efeitos causados quando impõe variação na matriz OD semente, a proposta foi destacar os Testes 7, 8 e 9, pois neles houve estimação, considerando quatro tipos de matriz semente (unitária, $\operatorname{Sem}_{20}, \operatorname{Sem}_{10}$ e $\mathrm{S}_{70}$ ) conforme gráfico da Figura 5. 18.

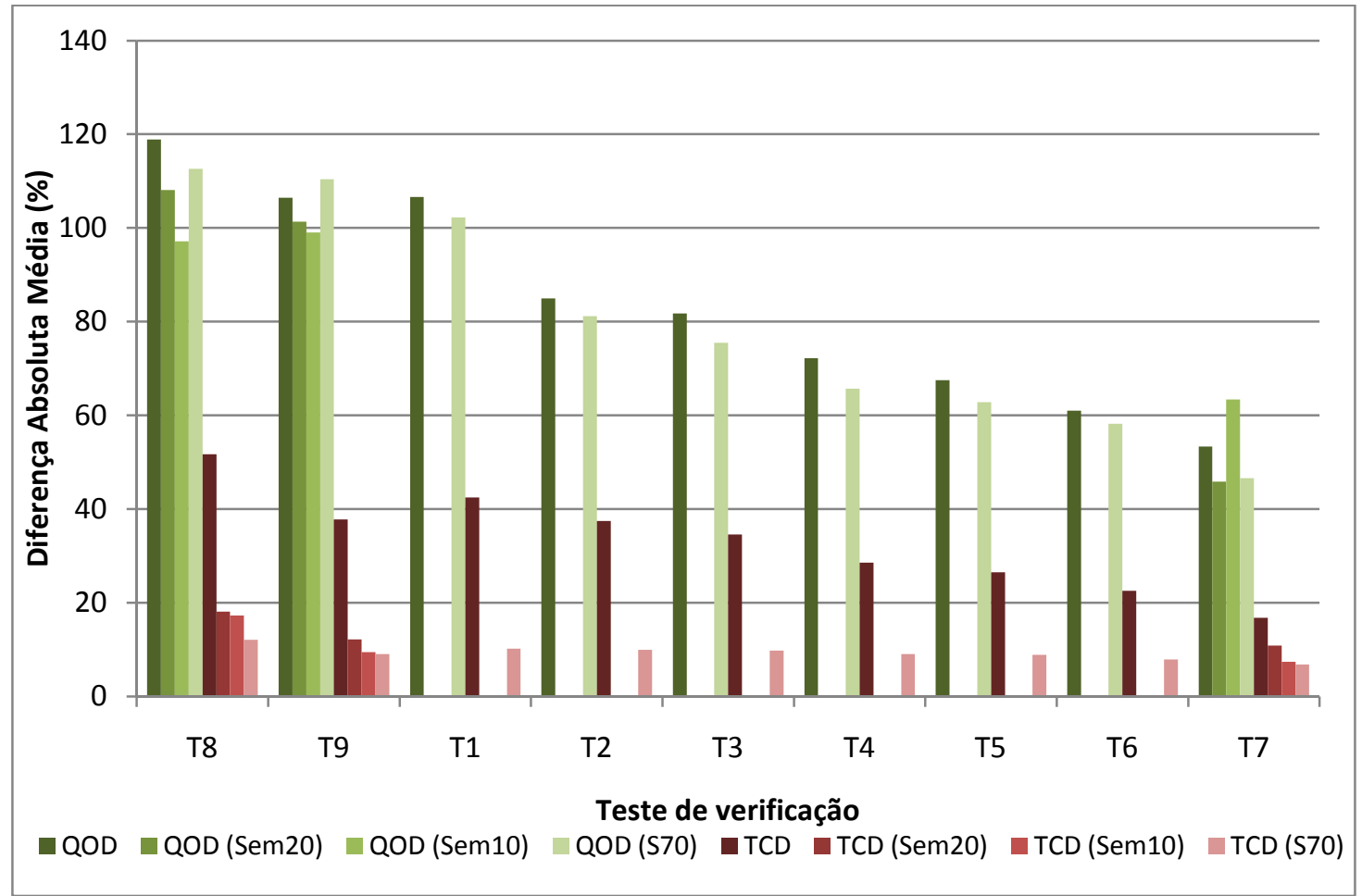

Figura 5. 17: Diferença absoluta média

Pelos dois métodos (QOD e TCD), os maiores valores para a razão foram obtidos quando utilizou matriz semente unitária. Para o Teste 8, considerando estimação pelo QOD, o menor valor foi gerado quando utilizou Sem $_{10}$ como semente; o mesmo ocorreu para o Teste 9 , já no Teste 7 o menor valor foi obtido ao fornecer Sem$_{20}$, como semente. O uso de uma matriz semente proporcional a "real", como o caso de $S_{70}$, resultou em valor da razão menor apenas do que quando utiliza matriz semente unitária, sendo que no Teste 9 isso não ocorreu. 


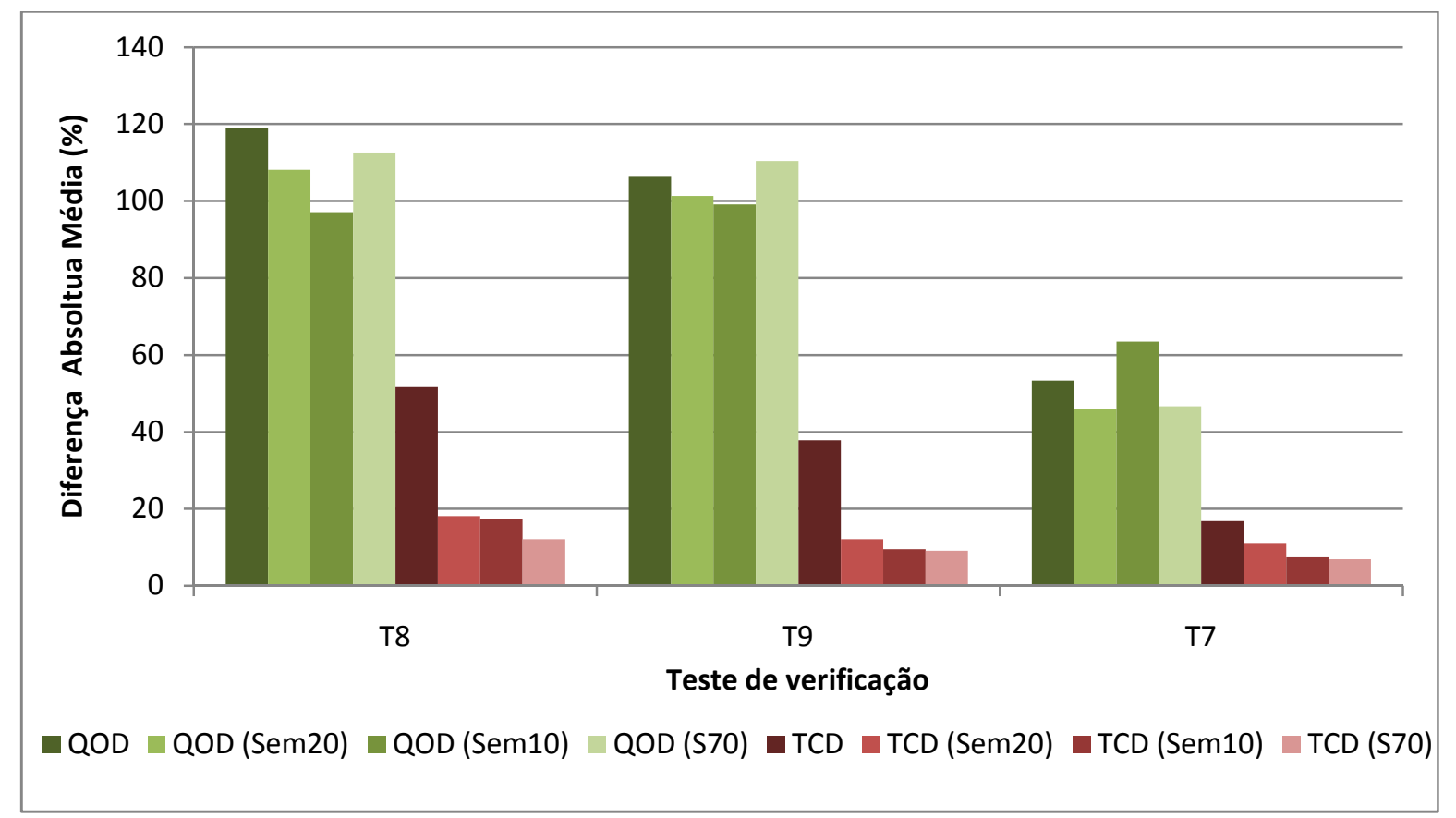

Figura 5. 18: Razão entre a somatória das diferenças absolutas pelo número total de viagens "real", Testes 7, 8 e 9

Os resultados estimados pelo TransCAD apresentaram comportamento diferente dos gerados pelo QOD. Quando foi utilizada matriz semente unitária ocorreram os maiores valores, quando utilizada $\mathrm{Sem}_{20}$ como semente a razão apresentou valor menor que quando utilizada a semente unitária, esse valor foi reduzido quando usado Sem $_{10}$ como semente e atingiu o menor índice quando usado $S_{70}$, indicando haver padrão de comportamento relacionado à qualidade da semente.

Outra questão a ser observada, no caso do TCD, é que acrescentar contagens nas interseções, usando matriz semente unitária, teria efeito equivalente a considerar contagem apenas nos arcos e uma matriz semente idealizada, como $S_{70}$. A explicação é que a proporcionalidade da semente $S_{70}$ com a matriz OD "real" e com os fluxos observados representam situação equivalente, ou até melhor, que a observada quando são realizadas contagens em todas as interseções e utiliza matriz semente unitária. Isto por ser uma situação em que a distribuição de viagens da matriz semente é proporcional à da matriz OD "real". Essa questão pode ser comprovada com a análise dos resultados estimados no Teste 
8, utilizando $\mathrm{S}_{70}$, com os estimados no Teste 7 , usando matriz unitária. Os valores das DAM apresentados na Figura 5. 18 validam essa afirmação.

O uso da matriz semente $S_{70}$ no Teste 8 pelo TCD, resultou valores estimados mais próximos aos "reais", do que os estimados no Teste 7 ao considerar o TransCAD com matriz semente unitária. Esse comportamento não é observado para os valores estimados pelo QOD.

Como na prática não será possível ter à disposição matriz semente proporcional a "real", como a $S_{70}$ - porque, o crescimento das viagens entre os pares OD ao longo do tempo é desigual - o aumento da informação obtido com os volumes de tráfego contados nas interseções consiste na melhor alternativa para estimação de matrizes com qualidade, inclusive nas situações em que foi utilizada matriz semente unitária.

\section{$\Rightarrow \quad$ Diferenças relativas:}

A Figura 5. 19 traz os maiores valores (em módulo) para diferença relativa.

Pode ser inferido que os maiores valores de diferença relativa referem os resultados estimados pelo QUEENSOD, mesmo com a utilização de $S_{70}$. Quando utilizada a matriz OD semente $\mathrm{Sem}_{20}$, o maior valor da diferença relativa, no Teste 8 , foi $351 \%$, observado no par OD 6-7, devido à superestimação das viagens. Com essa matriz semente o número de pares OD que tiveram zero viagem estimada passou a ser 32 (quando utilizada matriz semente unitária o número de OD’s com zero viagem foi 43 ). O uso de Sem $_{10}$ estimou resultados cujo valor máximo da diferença relativa foi igual a $441 \%$, o qual ocorreu no par OD 1-7, devido a superestimação. O número de pares OD que tiveram zero viagem estimada foi 40 . Ao utilizar uma matriz OD semente proporcional a "real" $\left(\mathrm{S}_{70}\right)$, a diferença relativa máxima (em módulo) foi $482 \%$, no par OD 1-7. Nesta situação, 45 pares OD não 
tiveram viagens estimadas. A utilização de $\operatorname{Sem}_{20}$ e $\operatorname{Sem}_{10}$ resultou diferenças relativas maiores que as obtidas com matriz semente unitária.

O desempenho apresentado pelo QOD no Teste 8 foi muito ruim; mesmo na situação em que foi fornecida matriz OD semente proporcional à "real", a quantidade de pares OD com zero viagem estimada foi elevado. O Teste 7 apresenta menor valor para diferença relativa, ao considerar $\mathrm{S}_{70}$, igual a $76 \%$, devido a subestimação de viagens no par OD 8-5 e neste teste entre todos os pares OD houve estimação de viagens. A redução do erro relativo entre o Teste 8 e o Teste 7 foi igual a $84 \%$, ao empregar $S_{70}$.

Os resultados estimados pelo TransCAD ao utilizar $S_{70}$ mantiveram o comportamento de redução do erro à medida que a quantidade de informações aumenta, porém com menor inclinação, em comparação com o QOD.

O desempenho apresentado pelo TransCAD foi melhor que o do QOD, inclusive o valor máximo da diferença relativa apresentado pelo TCD quando fornecida matriz semente unitária, foi menor que o apresentado pelo QOD ao usar $S_{70}$. Além disso, pelo TCD viagens foram estimadas entre todos os pares OD, o mesmo não ocorreu com o QOD.

Considerando os valores estimados para o Teste 8, ao utilizar Sem 20 como semente, o valor máximo da diferença relativa passou a ser $74 \%$ e ocorreu no par OD 4-8, devido a superestimação. Utilizando a matriz semente $\operatorname{Sem}_{10}$, o valor máximo da diferença relativa foi 74\%, no par OD 4-8. A matriz semente $S_{70}$ resultou na estimação da matriz OD, cuja diferença relativa máxima foi igual a 55\%, observada no par OD 4-8; isso é uma redução igual a $86 \%$ em relação à diferença relativa máxima obtida quando não foi fornecida matriz semente. Para o Teste 7 o comportamento foi melhor, o maior valor do erro relativo ao usar $\mathrm{Sem}_{20}$ foi $16 \%$, com $\mathrm{Sem}_{10}$ a diferença máxima apresentou valor igual a $63 \%$ e com $\mathrm{S}_{70}$ foi igual a $15 \%$, indicando que a proposta deste trabalho possibilitou melhorias aos resultados. 


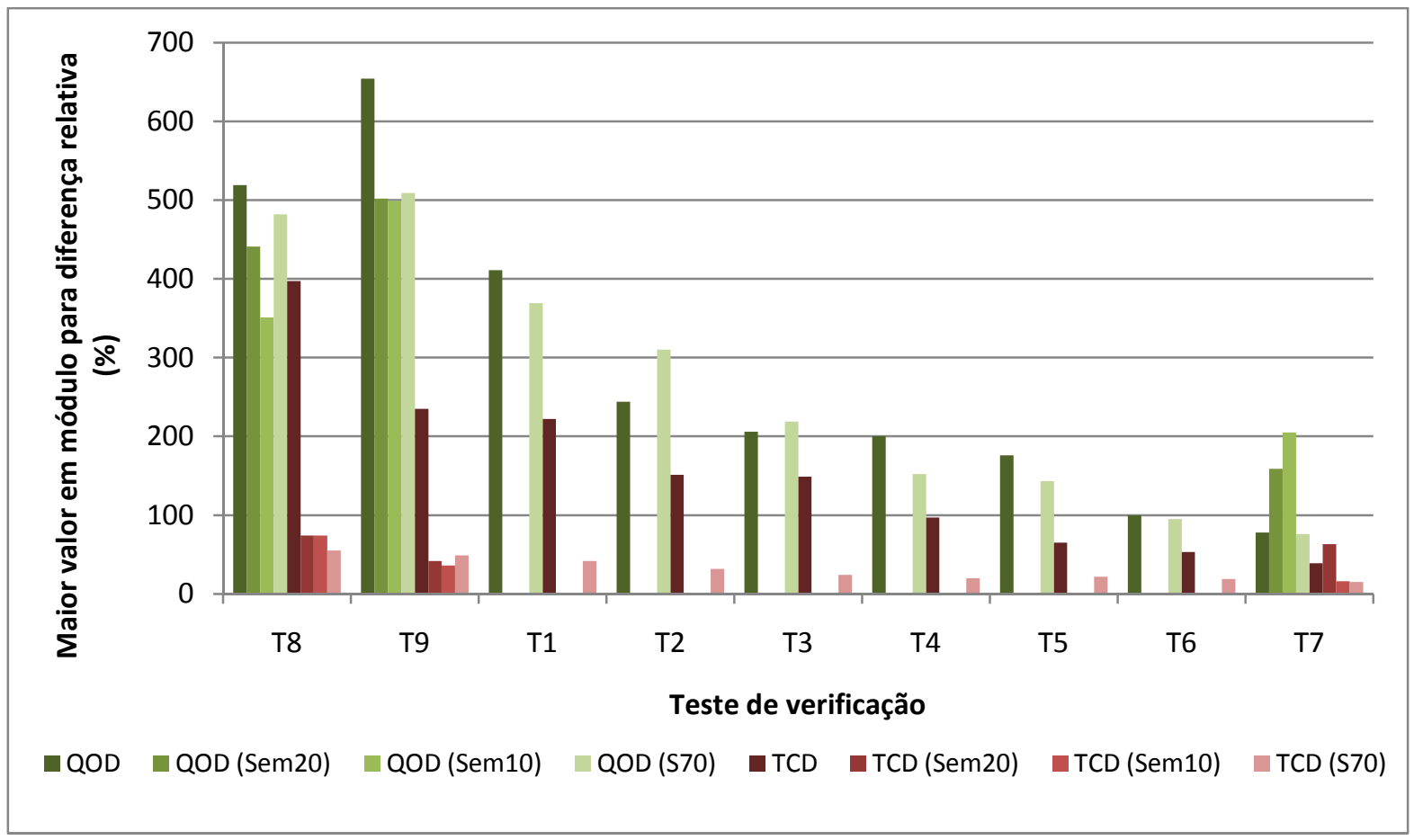

Figura 5. 19: Diferença relativa máxima

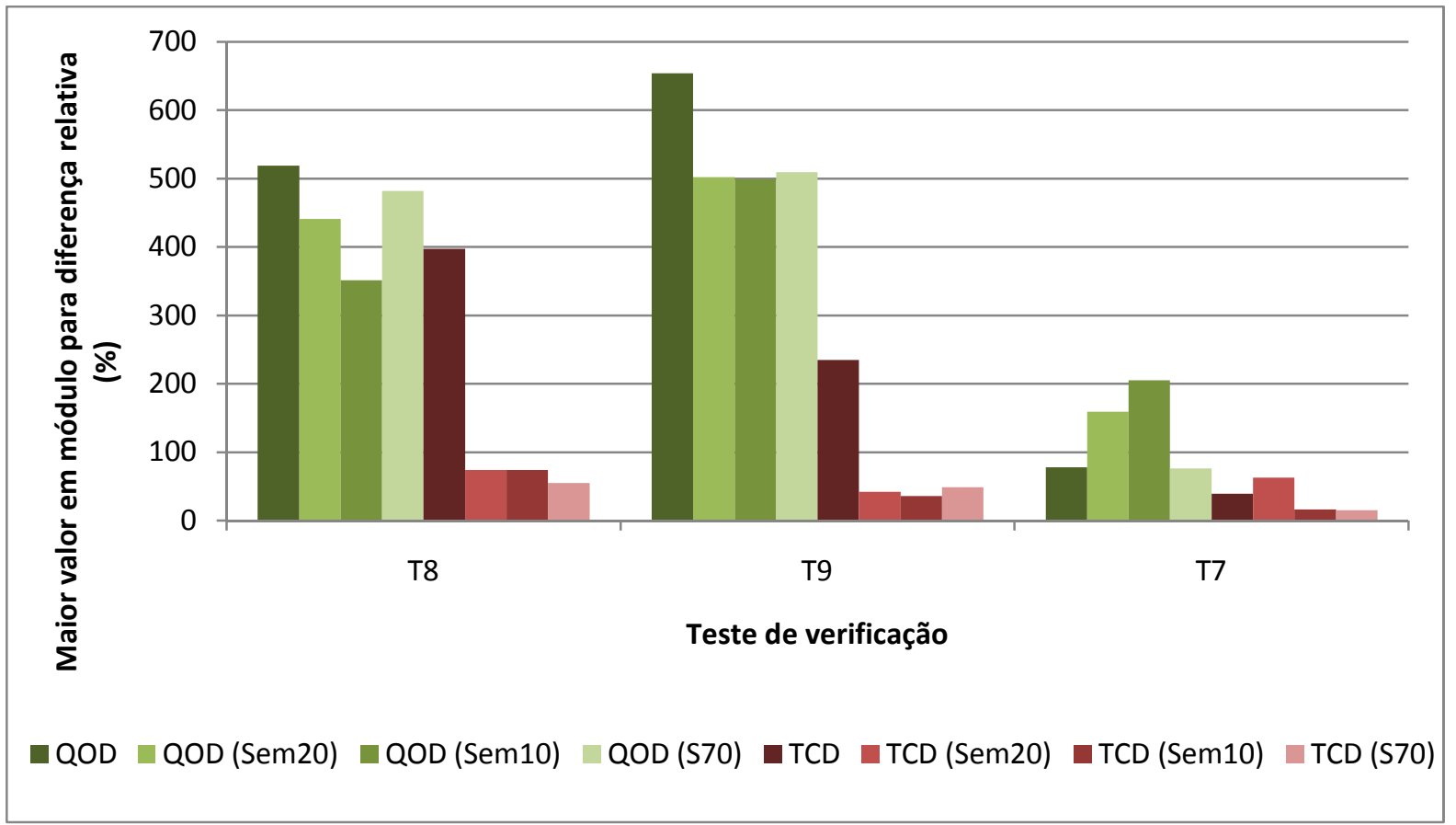

Figura 5. 20: Maior valor (em módulo) da diferença absoluta para o Teste 7, 8 e 9

A Figura 5. 21 apresenta o histograma das freqüências absolutas da distribuição das diferenças relativas dos valores estimados por QOD e TCD considerando o uso das matrizes semente. 
O histograma com os resultados do QUEENSOD apresenta pico para os valores acima de $90 \%$, já os resultados estimados pelo TransCAD possuem comportamento inverso, pois a grande concentração foi encontrada com valores abaixo de $10 \%$.

No Teste 7, 11 viagens apresentaram diferença relativa inferior a 10\%, já no Teste 8 nenhuma viagem apresentou diferença relativa inferior a 10\%, considerando a estimação pelo método do QUEENSOD. Foram 41 viagens com erro relativo inferior a $50 \%$, considerando o Teste 7 e apenas 6 considerando o Teste 8. Já o Teste 9 apresentou 10 viagens com erro inferior a $50 \%$.

Em relação à variação da matriz semente, o comportamento foi parecido nas três situações, ao considerar a estimação feita pelo QOD. Os demais testes que consideram aumento da informação apresentaram quantidade maior de viagens na faixa entre 50 e $80 \%$.

Analisando os resultados do TransCAD é possível dizer que o seu desempenho foi melhor, comparado ao do QOD. Todos os testes apresentaram grande quantidade de observações com erro máximo de 10\%. No Teste 7, por exemplo, foram 52 observações com erro inferior a $10 \%$ e nenhuma observação apresentou erro superior a $20 \%$, inclusive quando considerado o uso de $\operatorname{Sem}_{10}$. 


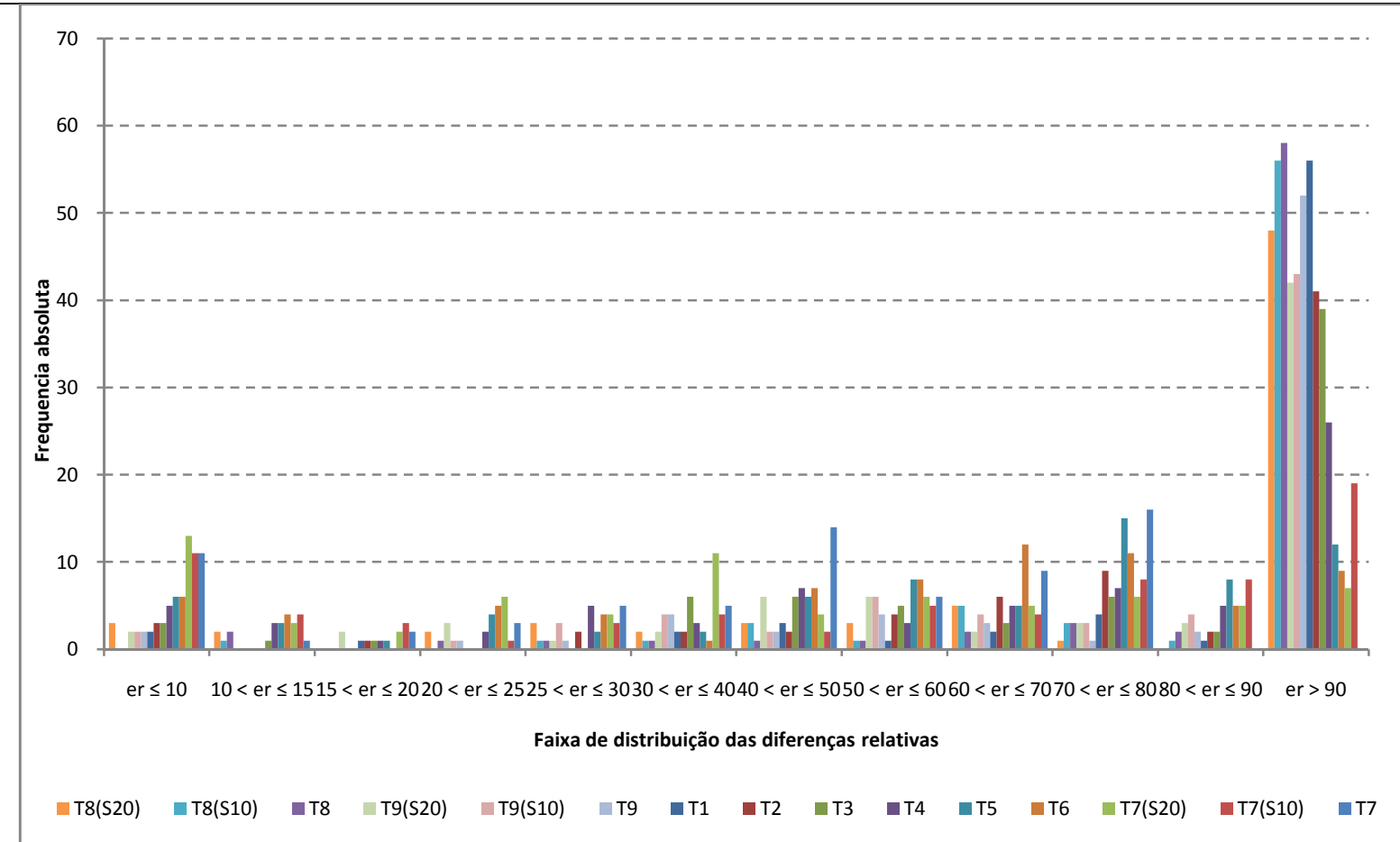

(a)

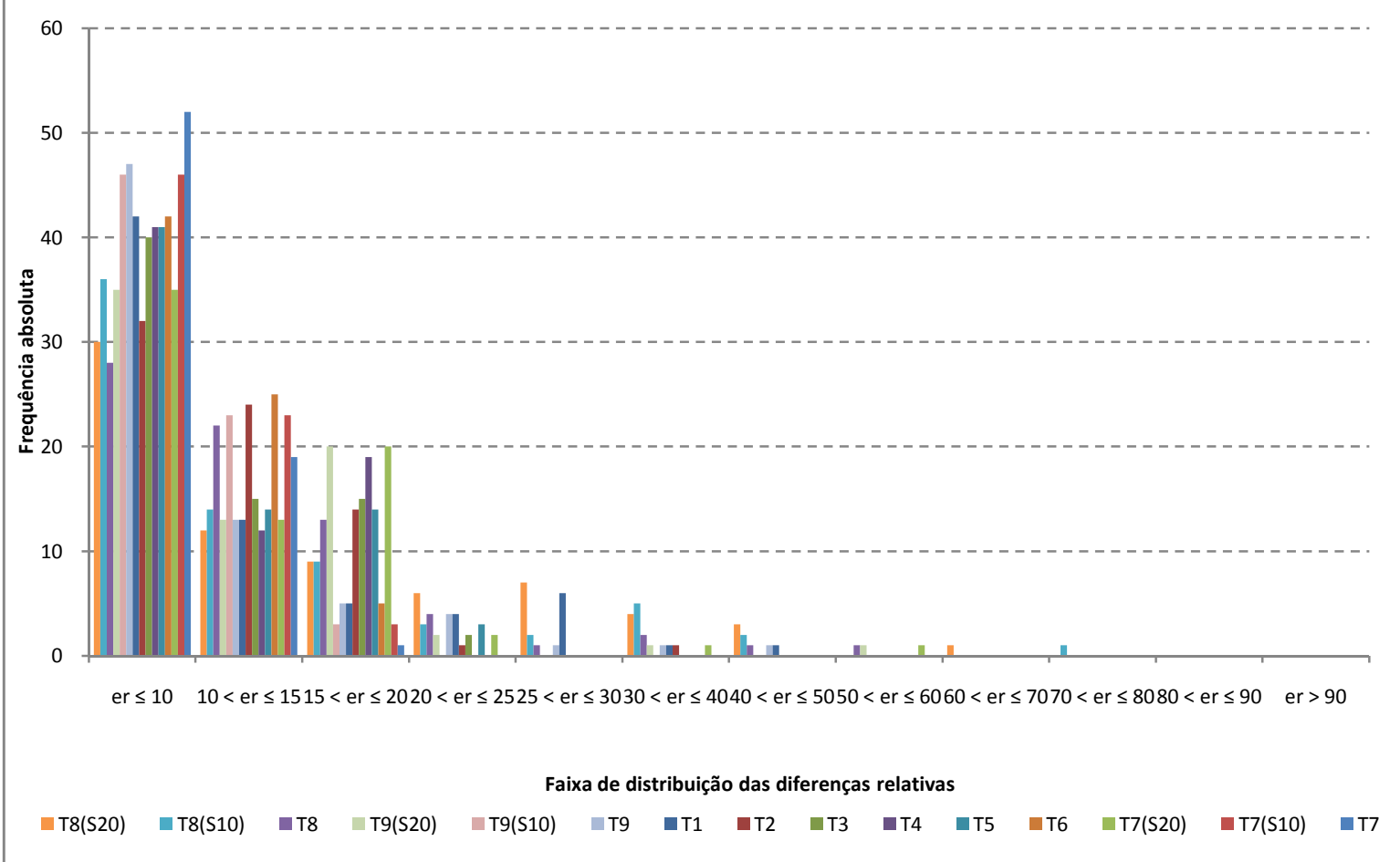

(b)

Figura 5. 21: Histograma da distribuição absoluta das diferenças relativa entre viagens: (a) QUEENSOD; (b) TransCAD

Já o Teste 8 , realizado com TCD, apresentou 28 viagens com erro inferior a $10 \%$ e nenhuma viagem apresentou erro superior a $60 \%$; comportamento parecido ocorreu ao 
fornecer Sem $_{10}$ e Sem 20 . Os valores estimados para o Teste 9 apresentaram 47 viagens com erro inferior a $10 \%$ e o erro relativo máximo foi $50 \%$. Ao utilizar $\operatorname{Sem}_{10}$ e $\operatorname{Sem}_{20}$, o desempenho foi similar.

Os Testes de 1 a 6 apresentaram bom desempenho - em nenhum deles houve erro superior a $50 \%$ e todos apresentaram a grande maioria das viagens com erro inferior a $10 \%$.

Na Figura 5. 22 são apresentados os gráficos com as freqüências acumuladas. Observe que o comportamento apresentado pelo QUEENSOD é o inverso do apresentado pelo TransCAD, pois o maior acúmulo ocorre em faixas de erro elevadas.

Analisando os valores estimados pelo QUEENSOD, apenas o Teste 7 apresentou todos os valores acumulados até a faixa de erro $80 \%$, os demais testes somente acumulam na faixa superior a $90 \%$. Os Testes 1 a 7 foram os que apresentaram maior acumulo até a faixa $50 \%$, seguidos pelo Teste 9 e, por fim, o Teste 8 .

Já a análise do TransCAD indicou um comportamento melhor em todos os Testes, em especial naqueles que consideraram aumento da informação. O Teste 7, por exemplo, na faixa de erro até $20 \%$ tem todos seus valores acumulados. Do Teste 1 ao Teste 7 , todos apresentaram erro inferior a 50\%. O Teste 9, que utilizou a opção turning movement, também apresentou erros inferiores a 50\%. Já o Teste 8 apresentou erro até a faixa de 60\%.

No Teste 7,72\% das viagens estão acumuladas na faixa de erro inferior a 10\%, já para o Teste 8 esse número é 39\% e no Teste 9 é 65\%. As variações na matriz semente $\left(S m_{10}\right.$ e $\left.S_{20}\right)$ permitiram estimar resultados que geraram desempenho próximo ao obtido utilizando $S_{70}$. Por exemplo, no Teste 7 considerando $\operatorname{Sem}_{10}$ a quantidade de viagens com erro inferior a $10 \%$ foi $64 \%$ e no Teste 8 utilizando Sem $_{20}$ foi $42 \%$. 


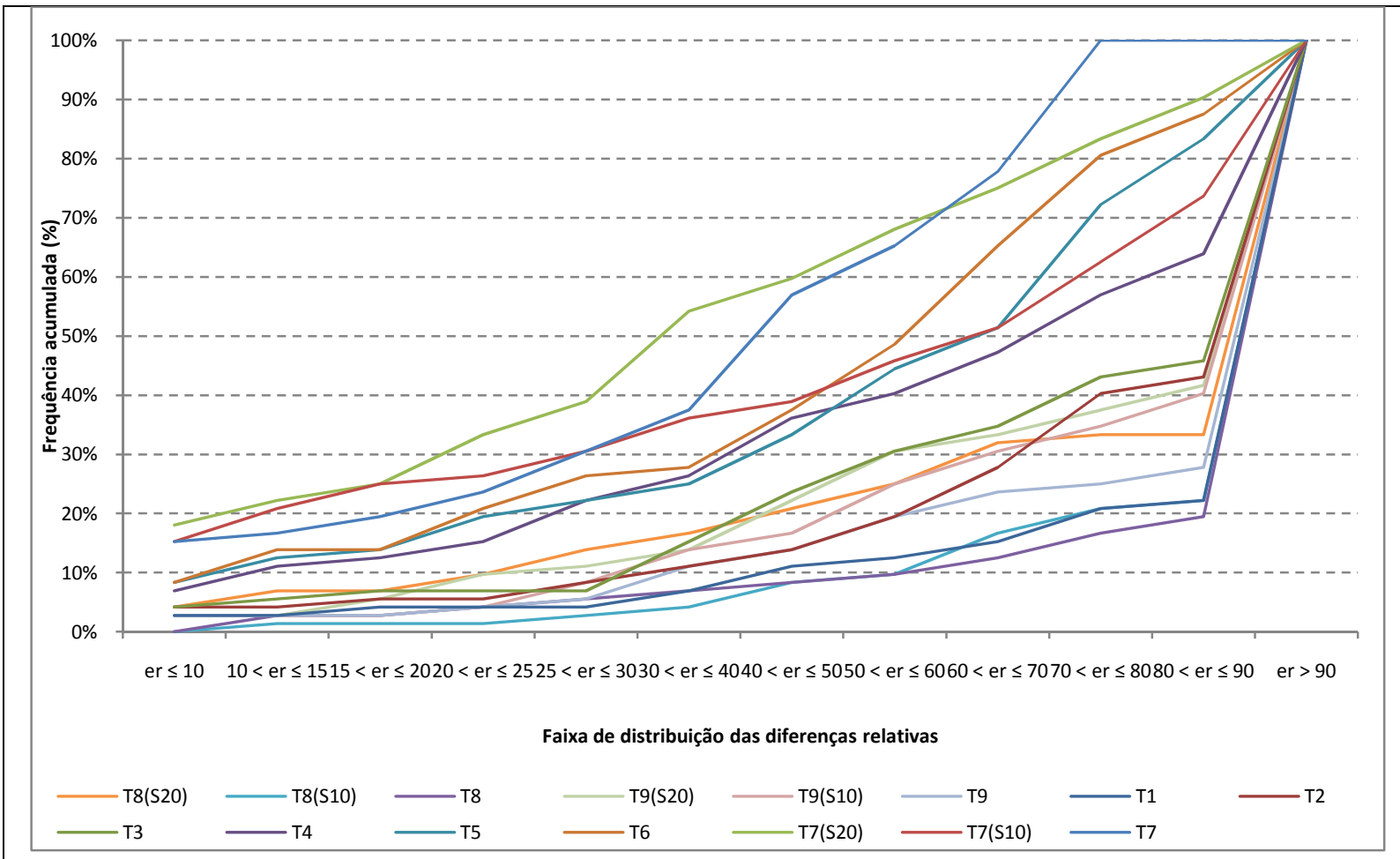

(a)

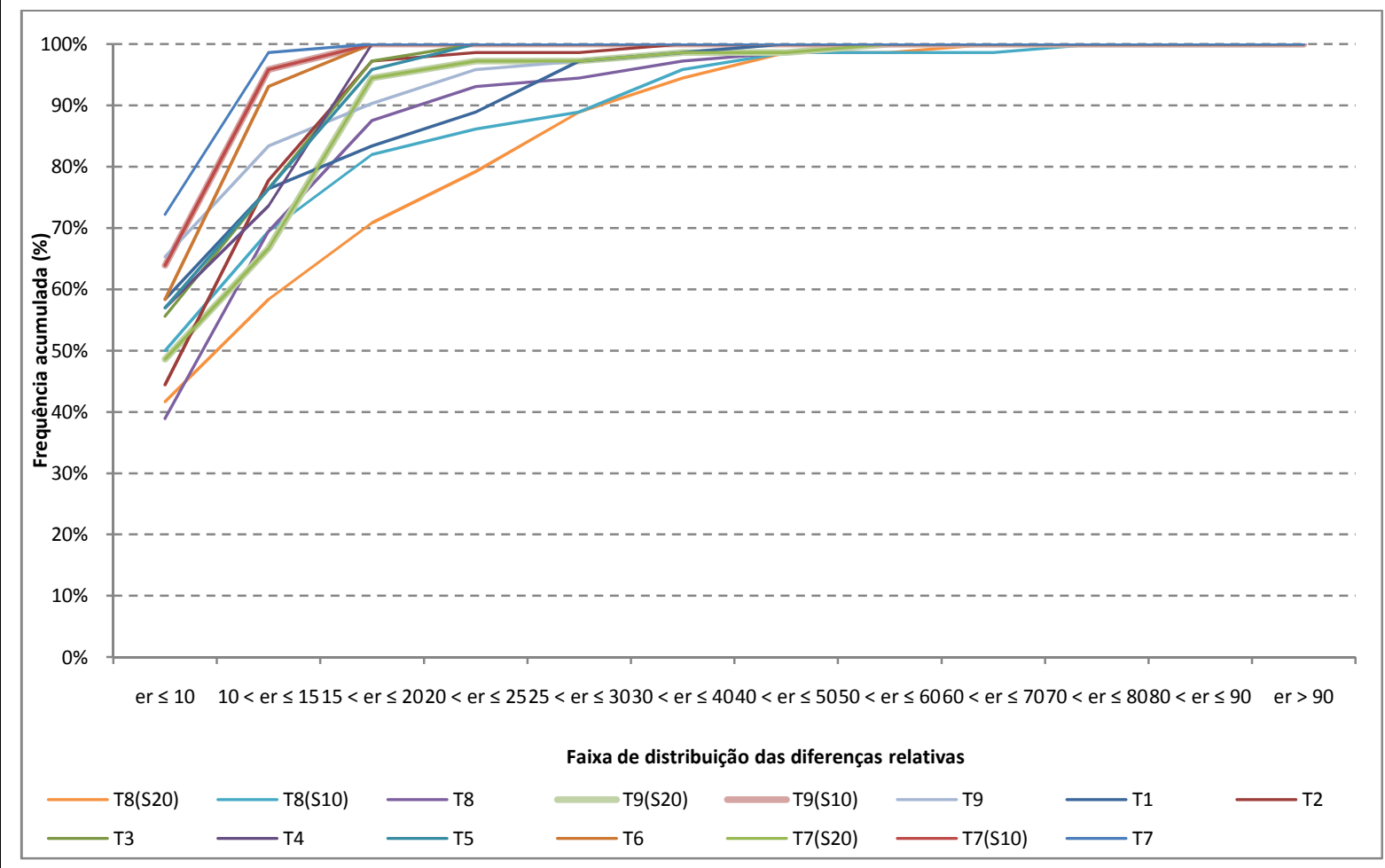

(b)

Figura 5. 22: Histograma da distribuição acumulada das diferenças relativa entre viagens: (a) QUEENSOD; (b) TransCAD 
Com isso estão encerradas as análises sobre a influência causada pelo uso da matriz OD semente. As principais conclusões sobre este tema são:

$\Rightarrow$ À medida que aumenta a quantidade de informações, devido às contagens nas interseções, os valores das medidas de desempenho dos resultados estimados pelos métodos estudados melhoram - conforme já havia sido observado ao utilizar matriz semente unitária;

$\Rightarrow$ À medida que a matriz semente fica proporcional à matriz "real" os resultados tendem a se aproximar do "real", ao menos para o TCD isso foi observado, sendo que para esse método o uso da matriz semente foi mais significativo, do que para o QOD;

$\Rightarrow$ O QUEENSOD, mesmo utilizando matriz semente de qualidade, apresenta resultados ruins, um comportamento que não corresponde com o modelo matemático embutido no programa;

$\Rightarrow$ A situação que considerou contagem em todas as interseções e matriz semente unitária foi capaz de gerar resultados parecidos aos obtidos quando consideradas contagens nos arcos e matriz semente idealizada $\left(\mathrm{S}_{70}\right)$, ao usar o TCD;

$\Rightarrow \mathrm{O}$ TransCAD teve comportamento satisfatório, mas apresentou elevados valores de erro. À medida que foi aumentada a qualidade da matriz OD semente, os índices referentes aos valores estimados apresentaram ganho;

$\Rightarrow$ Os dois métodos de estimação (QOD e TCD) são dependentes da matriz OD semente, sendo que no TCD o efeito é mais significativo.

A seguir, serão apresentadas as discussões dos resultados obtidos neste trabalho. 


\subsection{DISCUSSÕES DOS RESULTADOS}

Os resultados obtidos indicam que as matrizes OD estimadas não foram capazes de recuperar a matriz OD "real". Porém, ao fornecer informações adicionais, provenientes das contagens nos nós, os resultados se aproximaram do "real". À medida que foi aumentada a quantidade de informações, os parâmetros de desempenho analisados apresentaram melhoria em seus índices.

Foi possível constatar que não apenas o aumento da quantidade de informação contribui para melhor estimação, mas também a distribuição dessa informação na rede. Por exemplo, nos Testes 2 e 3 e Testes 4 e 5, o aumento na quantidade de informação foi o mesmo, porém, nos Testes 3 e 5 ela estava distribuída ao longo da rede, o que contribuiu para a melhoria dos resultados.

Quanto à utilização de "arcos virtuais", é possível afirmar que esse artifício possibilitou aos programas QOD e TCD estimarem a matriz OD considerando contagens nas interseções. Os dois programas foram capazes de estimar a matriz OD através deste princípio e em ambos ficou evidente a melhoria na matriz OD estimada.

Contudo, as matrizes estimadas pelo QUEENSOD não apresentaram bom desempenho em comparação com os valores das viagens "reais". Pelo que foi observado nestes testes, o programa não é eficiente pois, entre outros fatores, tem-se que: (i) muitos pares OD não tiveram viagens estimadas; (ii) estimação de viagens concentradas em alguns pares OD; (iii) ao fornecer matriz semente proporcional a "real" os resultados não apresentaram melhoria significativa; e (iv) erros relativos elevados. Em virtude dessas constatações, foi formulada a hipótese que o fato de a rede viária estar bastante carregada, acarretaria na estimação de matrizes com resultados ruins. Foi então proposto novo teste, no qual seria dado alívio de $50 \%$ nas viagens da matriz OD "real". Tal experimento está descrito no Apêndice $\mathrm{C}$ e dele foi possível concluir que os mesmos problemas encontrados 
quando a rede está saturada, foram encontrados quando a rede não está saturada. Isso mostra haver problemas no método de estimação do QUEENSOD, e estes podem ser devidos: ao algoritmo; a sua programação computacional; ou a algum outro fator. Entretanto, por ser um programa fechado, não há como precisar onde está exatamente o problema.

Sobre o TransCAD, pode-se dizer que o desempenho do seu método pôde ser considerado satisfatório. A matriz estimada - à medida que aumentou a informação de fluxo, proveniente das contagens nos nós - mostrou-se mais próxima a "real".

Em relação ao MEMS é possível inferir que este método apresentou melhor desempenho, quando comparado às situações em que foi fornecida apenas matriz unitária para os programas. O método MEMS, aliado à consideração de fluxos observados nos nós, apresentou a melhor performance e não requer uso de matriz semente. No mínimo, o método proposto é mais eficiente, pois alcançou melhores resultados com menor número de iterações e não dependeu do uso de matriz semente para fazer estimação das viagens. A vantagem do método MEMS é que, a cada etapa, as matrizes são estimadas em função dos caminhos mínimos corrigidos pelo carregamento da etapa anterior, o que possibilita evitar carregamentos excessivos e equivocados em algumas rotas.

No entanto, uma aplicação prática dessa idéia demandará que o método seja programado de forma a realizar o número de iterações necessário para que o resultado seja atingido. A programação proposta (utilizando Excel) é válida, porque este trabalho trata de uma verificação de idéia.

Em relação à influência da matriz semente, é possível afirmar que seu uso trouxe melhorias aos resultados estimados pelos programas, por tratar do fornecimento de informações adicionais. Neste trabalho foram considerados quatro tipos de matriz semente (unitária, $\operatorname{Sem}_{20}, \operatorname{Sem}_{10}$ e $\mathrm{S}_{70}$ ). A influência da matriz semente no processo de estimação foi maior no método do TransCAD, pois quanto melhor a qualidade, melhor o resultado estimado. Pode-se observar que os resultados estimados pelo TCD considerando matriz 
semente $S_{70}$ e contagens nos arcos (Teste 8), produziu resultados equivalentes aos obtidos pelo programa, ao usar semente unitária e contagens de tráfego em todos os nós (Teste 7).

Para O QUEENSOD esse comportamento não foi observado, indicando haver problemas com o programa, pois de acordo com o método de estimação implementado isso não poderia ocorrer, pois a matriz estimada deve apresentar distribuição proporcional a da semente utilizada e ao fornecer $S_{70}$ os resultados estimados foram, em alguns testes, piores.

Não houve comparação entre os resultados estimados pelo MEMS e os estimados por QOD e TCD, quando estes utilizam matriz semente diferente da unitária, por tratar-se de análise desigual. A explicação é que matriz semente constitui informação adicional e comparar a eficiência do MEMS que não usa matriz OD semente com a do QOD e TCD usando matriz semente como $\operatorname{Sem}_{20}, \operatorname{Sem}_{10}$ e $\mathrm{S}_{70}$, acarretaria desproporcionalidade.

Então, por que foi feita comparação entre o MEMS com os resultados estimados por QOD e TCD utilizando matriz semente unitária? Porque esse tipo de semente, por ser uniforme, faz com que todas as demandas tenham mesma probabilidade de ocorrer, o que seria equivalente a situação em que a matriz semente não é fornecida (SOUZA, 2007).

Quanto ao uso do arquivo turning movement, a melhoria proporcionada aos resultados não compensa o esforço para criação desse arquivo, conforme os resultados estimados pelo Teste 9. Isso pode explicar o fato de ele ser opcional nos dois programas. Além disso, os testes que consideraram contagens nas interseções tiveram melhor desempenho.

Em função das análises é possível afirmar que a hipótese formulada para esta pesquisa é válida e não pôde ser refutada. Entretanto, não foi possível reconstruir a matriz OD "real", por ser de um problema em que o número de incógnitas é maior que o de informações. Mas, o expediente da maximização da entropia, aliado à proposta desta pesquisa, contribuiu para a estimação da matriz OD mais próxima a matriz de viagens "real". 


\section{CAPITULO 6 CONSIDERAÇÕES FINAIS}

Neste capítulo é descrita a última etapa do método proposto, a qual consiste nas conclusões a respeito do trabalho. As indagações, que motivaram a realização da pesquisa, apresentadas no primeiro capítulo, serão aqui respondidas. Para tanto, o presente capítulo está dividido em três seções: (6.1) Breve exposição do trabalho; (6.2) Principais conclusões; (6.3) Sugestões para trabalhos futuros.

\subsection{BREVE EXPOSIÇÃO DO TRABALHO}

O presente trabalho integra a linha de pesquisa desenvolvida no Departamento de Engenharia de Transportes da EESC/USP sob orientação do Professor Titular Eiji Kawamoto. Esta linha aspira compreender e propor melhorias ao método de estimação da matriz de viagens a partir das contagens de fluxo, também denominado modelo sintético.

A meta deste trabalho foi propor e verificar a hipótese que a contagem de tráfego nas interseções, ao invés de contagem de tráfego nos arcos, faz com que a matriz OD estimada seja mais precisa. Além disto, há cinco objetivos que integram o método, e foram importantes para que a meta fosse atingida: 
(i) Verificar a eficiência da proposta através de experimentos, considerando uma rede viária e uma matriz OD hipotéticas que reflitam uma situação de congestionamento;

(ii) Utilizar os programas de estimação da matriz OD (QUEENSOD e TransCAD) ambos licenciados para uso em pesquisas do Departamento de Engenharia de Transportes da EESC/USP;

(iii) Verificar a sensibilidade dos métodos implementados nos dois programas utilizados quanto ao uso de matriz semente;

(iv) Propor um método para estimação da matriz OD, baseado no conceito de média sucessiva;

(v) Comparar os resultados gerados pelos programas (QUEENSOD e TransCAD) com os obtidos pelo método proposto, através de análises entre a matriz OD estimada e a matriz OD "real".

A partir das próximas subseções serão apresentadas as conclusões para cada uma das etapas que constituem o método.

\subsubsection{Revisão teórica}

\begin{tabular}{|l|c|c|c|c|}
\hline Revisão Teórica & $\begin{array}{c}\text { Detalhamento da } \\
\text { proposta }\end{array}$ & Experimento & $\begin{array}{c}\text { Análises dos } \\
\text { Resultados }\end{array}$ & Conclusões \\
\hline
\end{tabular}

Através da leitura dos artigos foi possível perceber que nas últimas décadas o avanço do modelo sintético não foi significativo, quando comparado aos avanços apresentados por pesquisas de outras áreas. A maioria dos trabalhos publicados derivam das mesmas questões (ABRAHAMSON, 1998).

Quanto aos trabalhos voltados à estimação considerando fluxos de conversão, procuram utilizar esses fluxos como uma forma de garantir o equilíbrio nos nós e auxiliar no processo de escolha da rota. 


\subsubsection{Detalhamento da proposta}

\begin{tabular}{|c|c|c|c|c|}
\hline Revisão Teórica & $\begin{array}{c}\text { Detalhamento da } \\
\text { proposta }\end{array}$ & Experimento & $\begin{array}{c}\text { Análises dos } \\
\text { Resultados }\end{array}$ & Conclusões \\
\hline
\end{tabular}

6.1.2.1 Formulação matemática da proposta de considerar os fluxos de tráfego observados nas interseções

As vantagens da proposta são: o aumento da quantidade de informações de fluxo, proporcionado pela consideração dos movimentos de conversão, o que permite estimação de matrizes OD com erros menores; a idéia proposta pôde ser adequada a programas comerciais, no caso desta tese foram dois programas (QUEENSOD e TransCAD).

\subsubsection{Formulação matemática do método de estimação por médias sucessivas (MEMS)}

Por este método os fluxos resultantes da matriz OD final refletem as condições de equilíbrio do usuário na rede. Não foi necessário procedimento complexo para estimação da matriz, como ocorre com os softwares atualmente em uso; bastou definir a cada iteração os caminhos de custo mínimo entre cada par OD e, então, estimar a matriz de viagens através da maximização da entropia. Além disso, não é necessário o conhecimento de uma matriz OD semente.

6.1.2.3 Detalhamento do experimento elaborado para verificação da proposta

A descrição detalhada de cada uma das etapas permite ao leitor saber, passo a passo, o que foi feito para verificar os objetivos da tese.

Em relação ao fato de o experimento considerar uma situação hipotética, no estado da arte atual em que se encontra o modelo sintético - com modelos apresentando resultados ruins mesmo quando confrontados com casos idealizados - seria inócuo compará-la com uma situação real. 


\subsubsection{Experimento e Análises dos resultados}

\begin{tabular}{|c|c|c|c|c|}
\hline Revisão Teórica & $\begin{array}{c}\text { Detalhamento da } \\
\text { proposta }\end{array}$ & Experimento & $\begin{array}{c}\text { Análises dos } \\
\text { Resultados }\end{array}$ & Conclusões \\
\hline
\end{tabular}

6.1.3.1 Estimação utilizando o QUEENSOD

Os resultados estimados pelo QUEENSOD foram os que apresentaram pior desempenho. O QUEENSOD deixa de estimar viagens entre alguns pares OD e superestima viagens nos demais.

No decorrer do trabalho houve a idéia que o fato de a rede viária estar muito congestionada teria levado à obtenção de resultados ruins pelo QUEENSOD. Então foi proposto reduzir o carregamento em $50 \%$ e refazer os testes, conforme descrito no Apêndice C. Entretanto, os erros continuaram elevados e a estimação de zero viagem entre alguns pares OD persistiu.

Com isto, acredita-se que o QUEENSOD apresenta problemas na codificação de seu algoritmo, a começar por ter como critério de parada a minimização da diferença entre fluxo observado e estimado. Watson e Prevedouros (2006) afirmaram que métodos baseados nesse tipo de critério são passíveis de erros.

Em relação à consideração de contagens de tráfego nas interseções, houve melhoria nos resultados em direção ao aumento da quantidade de informações adicionadas. Para obter resultados melhores, foi necessário apenas observar os fluxos de acordo com o movimento de conversão e supor que tais fluxos seriam observados nos "arcos virtuais". A inserção desses "arcos" ao utilizar o QOD não foi tarefa complexa e não implicou em dificuldades adicionais ao processo de estimação da matriz OD.

- Utilização da matriz semente:

Quanto ao uso da matriz semente, houve sim melhora no resultado estimado, comparado com a situação em que foi fornecida matriz unitária. Por exemplo, as diferenças 
relativas foram menores, indicando ter havido uma melhor distribuição das viagens. $O$ modelo matemático embutido no programa depende da matriz semente, de acordo com ele a matriz estimada terá distribuição proporcional a da semente, mas isso não foi observado no experimento. Além disso, à medida que aumentou a qualidade da matriz semente, os resultados não refletiram essa tendência.

O desconhecimento de uma matriz OD semente, e conseqüente utilização da matriz unitária levaram a resultados com baixa qualidade. Tal constatação serve de alerta para o planejador que desejar utilizar tal ferramenta e não tiver disponível uma matriz semente confiável.

O fato de estimar as viagens considerando os fluxos observados nas interseções, fornecendo matriz semente unitária, trouxe mais benefícios aos resultados de o que a situação em que foi considerado fluxo observado nos arcos e com matriz semente.

\subsubsection{Estimação utilizando o TransCAD}

Os resultados estimados pelo TransCAD apresentaram melhor desempenho que os do QUEENSOD. O TCD aparenta ser um programa mais elaborado que o $Q O D$, fato que pode ser notado nas diferenças entre as matrizes estimadas e a matriz OD "real". Os resultados obtidos podem ser classificados como satisfatórios.

O programa foi capaz de estimar a matriz OD considerando as contagens de fluxo nas interseções, inclusive à medida que aumentou essa informação os resultados apresentaram melhoria.

O método do TransCAD é mais conservador do que o do QOD, o processo como é feita a escolha da rota pode ser escolhido pelo planejador, é possível inserir as informações que forem necessárias para definir os caminhos. O método é mais dependente da matriz OD semente, sem esta informação não é possível estimar matriz de viagens. 
As criticas que se faz ao TransCAD são: (i) se a rede for grande e não houver uma base de dados o processo torna-se moroso, pois a codificação dos dados não é tarefa simples; (ii) o método de estimação depende obrigatoriamente do fornecimento de uma matriz semente; e (iii) não apresenta rápida convergência.

- Utilização da matriz semente:

À medida que aumentou a qualidade da matriz OD semente, os resultados foram mais próximos aos "reais". Os resultados obtidos com matriz unitária só foram bons quando adicionada a idéia principal do trabalho, pois os valores obtidos considerando apenas contagens nos arcos e matriz deste tipo foram ruins.

Pode-se afirmar que o efeito causado pelo uso da matriz semente foi mais significativo no TransCAD que no QUEENSOD. A variação da matriz semente não acarretou em alterações muito grandes nos valores estimados, conforme tinha sido observado com o QOD e houve um padrão de comportamento, em função do tipo de matriz semente, bem definido.

\subsubsection{Estimação utilizando o método MEMS}

Em relação aos resultados estimados pelo MEMS, é possível afirmar que este apresentou o melhor desempenho entre os três métodos analisados. Aliás, essa comparação é um dos objetivos específicos desta pesquisa.

Pode-se dizer que o MEMS é, ao menos, mais eficiente que o método de estimação do TransCAD, pois com uma quantidade bem menor de iterações ele chega a um resultado melhor que o obtido pelo software, que fez uso de matriz semente favorável.

A vantagem do método proposto (MEMS) é não depender de processo complexo, basta que a cada etapa seja definido o caminho de custo mínimo para cada viagem, para, 
então, estimar a matriz OD. Ele prescinde do uso da matriz semente, o que é vantajoso, principalmente para situações em que tal matriz não seja conhecida.

O método MEMS foi implementado em planilha Microsoft Excel. Por se tratar de um processo de verificação, tal procedimento atendeu à expectativa. Porém, será necessário implementar o método em alguma outra linguagem de programação que, inclusive, permita que seja feita estimação de matriz OD em redes com mais pares OD. O Excel é limitado quanto ao tamanho da rede. Ademais, a implementação permitirá que seja realizado um número ilimitado de iterações, até que a convergência da matriz estimada seja atingida.

Outra questão que futuramente deverá ser verificada é quanto aos custos percebidos para utilização dos arcos, no caso desta pesquisa foi considerado que o tempo de viagem expresso conforme BPR (1964) seria o único custo percebido. É possível que maior detalhamento seja necessário em aplicações práticas do método.

\subsubsection{Conclusões}

\begin{tabular}{|c|c|c|c|c|}
\hline Revisão Teórica & $\begin{array}{c}\text { Detalhamento da } \\
\text { proposta }\end{array}$ & Experimento & $\begin{array}{c}\text { Análises dos } \\
\text { Resultados }\end{array}$ & Conclusões \\
\hline
\end{tabular}

De maneira geral, a idéia do trabalho mostrou-se viável, prática e não demanda mais recursos que os atualmente requeridos. O uso do conceito de "arcos virtuais" nos cruzamentos traz melhoria significativa nos três métodos de estimação analisados neste trabalho.

Foi constatado, nos referidos trabalhos, que os fluxos de conversão são usados para compatibilizar o equilíbrio nos nós, ou seja, o total de fluxo que chega no nó, deve ser igual ao que dele sai, desde que não constitua par OD. Com isto é possível afirmar que a idéia defendida nesta tese difere dos trabalhos que consideram os fluxos de conversão. 
À medida que a quantidade de informação aumentou, o grau de indeterminação diminuiu e a matriz estimada se acercou da real. Todavia, é preciso ter atenção quanto ao número de pontos de contagem.

Idealmente seria interessante fazer contagens em todos os nós da rede em estudo. Caso isso não seja possível, a opção poderia ser contar principalmente nos pontos que possivelmente abriguem maior indeterminação, ou nos que sejam comuns a várias rotas de viagens (como o nó 5). Se, ainda assim, não for possível saber qual (ais) é (são) esta (s) interseção (ões), as contagens poderiam ser feitas de forma a ser obtida a maior quantidade de informação possível e que estas estejam bem distribuídas na rede.

Ainda no caso das contagens em interseções, a adoção dos "arcos virtuais" permitiu que essa técnica fosse aplicada nos métodos de estimação do TransCAD e do QUEENSOD. Assim, é possível generalizar afirmando que tal idéia permitirá o uso da técnica por outros programas de estimação, uma vez que todos eles usam os fluxos nos arcos como dados de entrada e a idéia básica deste trabalho é converter as contagens nos nós em contagens nos "arcos virtuais".

Além disso, a consideração dos fluxos de conversão (proposta na presente pesquisa), bem como o MEMS poderão ser aplicados a qualquer tipo de rede: congestionada ou não; e com muitos pares OD ou não. A técnica, por enquanto, poderá ser utilizada apenas nos processos estáticos de estimação, uma adaptação para situação dinâmica faz-se necessária.

Não foi possível provar que a matriz OD estimada pelo método MEMS converge para matriz OD "real", pois trata-se de um problema em que o número de incógnitas é superior ao de informações. Entretanto ficou evidente que à medida que a quantidade de iterações do método aumenta, bem como a quantidade de informações, o resultado tende a apresentar menos erro. 


\subsection{PRINCIPAIS CONCLUSÕES}

O texto apresentado descreve o trabalho realizado, cujo caráter é investigativo e exploratório.

Os objetivos do trabalho foram atingidos e a hipótese formulada não pôde ser refutada, ou seja, o aumento das informações, proporcionado pelos fluxos observados nas interseções, reduziu a indeterminação e assegurou melhorias aos resultados.

Para concluir o texto, as questões sugeridas no capítulo introdutório e que motivaram a realização deste trabalho, são agora respondidas:

a) Aumento da quantidade e melhor distribuição da informação de fluxo traz benefícios significativos à qualidade da matriz OD estimada?

Sim. Foi possível constatar que, à medida que a quantidade de informações de fluxo aumenta, a matriz OD estimada se aproxima da "real". Foram 7 testes de verificação elaborados para analisar esta questão e o comportamento esperado na hipótese do trabalho se manifestou. Pelos três métodos de estimação utilizados a consideração dos fluxos nas interseções trouxe benefícios à matriz OD estimada.

Os resultados estimados ao utilizar os fluxos observados nas interseções foram melhores que os estimados considerando as contagens apenas nos arcos. Ao considerar os resultados estimados pelos três métodos analisados foi possível constatar que os fluxos foram observados em todas as interseções (Teste 7), a razão entre a somatória das diferenças absolutas pelo número total de viagens "real" obtida foi $50 \%$ menor que a razão resultante do Teste 8, que considera contagens apenas nos arcos.

Vale lembrar que aumentar a quantidade de informação não, necessariamente, requer aumentar os pontos de coleta. Os Testes 2 e 3 e Testes 4 e 5, mostram que não apenas o aumento da informação, mas sua distribuição na rede é importante. 
b) Qual influência o uso da matriz semente exerce na qualidade dos resultados estimados?

A influência exercida pelo fornecimento da matriz semente, tanto no QUEENSOD, quanto no TransCAD é evidente, principalmente se a matriz semente for "parecida" ou "proporcional" à matriz "real". Para o TCD à medida que aumenta a qualidade da semente, melhora o resultado.

Porém, é importante salientar que dificilmente os planejadores de transporte, principalmente no Brasil, terão em mãos uma matriz elaborada no passado e muito menos uma matriz semente proporcional à "real", como no caso deste estudo. Considerando que $\mathrm{S}_{70}$ representa uma situação bastante favorável, eram esperados resultados muito melhores que os obtidos até então.

c) Qual a eficiência das implementações computacionais do modelo sintético?

Os programas computacionais utilizados possuem formulação matemática coerente com o problema. Ambos fazem uso de informação adicional proveniente de uma matriz OD semente e fazem a estimação considerando como restrição as contagens de tráfego.

Os resultados obtidos com aplicação desses programas foram ruins, abaixo do esperado, principalmente 0 QOD. Mesmo fornecendo matriz semente de qualidade 0 desempenho alcançado foi baixo, com dispersão elevada da matriz estimada em relação a "real". O TransCAD teve um desempenho mais satisfatório, porém apenas quando fornecida matriz semente de qualidade, o desempenho considerando matriz unitária deixou a desejar.

d) Qual da diferença conceitual na formulação do problema e nos algoritmos de solução dos programas de estimação disponíveis no Departamento de Engenharia de Transportes da Escola de Engenharia de São Carlos da Universidade de São Paulo (EESC/USP)? 
O algoritmo do TransCAD é mais conservador, procura representar melhor a questão do equilíbrio da rede e é mais dependente da matriz semente, o que faz com que a resposta tenha relação direta com a qualidade da semente.

Em relação ao QOD, apesar de ter em sua formulação matemática o método de Van Zuylen e Willumsen (1980), tem como restrição a minimização entre as diferenças quadráticas de volume observado e estimado. Originalmente o QOD foi desenvolvido para estimação da matriz OD em rodovias ou corredores, depois seu uso foi ampliado para redes (RAKHA ET AL, 1998), com o trabalho feito para Salt Lake City - EUA. Acredita-se o problema de estimação em rede de transportes não está sendo devidamente implementado no QOD, por exemplo, ele considera apenas 5 possibilidades de caminho entre os pares OD. Isso pode explicar os resultados ruins obtidos na presente tese com aplicação do QOD.

e) Qual efeito ocasionado ao resultado desses programas devido ao aumento da quantidade de informação? E quanto à qualidade da matriz OD semente?

O aumento da quantidade de informação trouxe melhoria aos resultados, quando essa informação está vinculada ao conhecimento de uma matriz OD semente de qualidade, o desempenho é melhor.

f) Os programas de estimação disponíveis terão capacidade de considerar dados das interseções?

A idéia inicial do trabalho era que tal proposta pudesse ser utilizada por programas de estimação. Por esse motivo foi utilizado o artifício de inserir "arcos virtuais", que tem como função alocar o fluxo observado nas interseções conforme o movimento. Além de ter capacidade de considerar dados das interseções, é possível afirmar que essas informações trouxeram melhorias aos resultados estimados pelos programas.

g) Um novo algoritmo de estimação da matriz OD baseado na maximização da entropia que não necessite de matriz OD semente trará contribuição? 
O algoritmo proposto trouxe contribuição, foi capaz de gerar melhores resultados que os obtidos pelos programas. A vantagem é que leva em consideração uma idéia simples e não faz uso de matriz semente.

h) A idéia da maximização da entropia é uma boa simplificação para estimar a matriz de viagens?

Willumsen (1978) propôs, fazendo analogia ao estudo de Wilson (1970), um método de estimação da matriz OD sintética a partir do conceito de maximização da entropia.

Tal conceito consiste em um expediente utilizado para resolver um problema em que o número de incógnitas é superior ao de informações. Porém, parte do princípio que as viagens, assim como os gases, tendem ao espalhamento, sendo que este será moldado à medida que inserir restrições, pois de acordo com Wilson (1970) o objetivo é encontrar a distribuição, mais provável, capaz de resultar no maior número de microestados dados as restrições.

Não há garantias que a matriz estimada recupere a original pois, ainda assim, tratase de um problema com mais incógnitas que informações. Os fluxos observados servem como pontos de referência que moldam a resposta. Quanto mais pontos de referência maiores são as chances de o resultado estimado se acercar do real. Por isso a idéia de considerar os fluxos observados nas interseções possibilita a estimação de matrizes com menor quantidade de erros.

i) De que forma este estudo pode trazer benefícios para o meio acadêmico e futuramente contribuir para aplicações práticas?

Cabe ressaltar que o estudo apresentado nesta tese constitui apenas um estudo de caso. Para generalizar qualquer conclusão serão necessárias mais verificações. Pode-se apenas afirmar que no estado da arte em que se encontra o modelo sintético, os resultados obtidos tanto pela consideração das contagens nas interseções, quanto pelo MEMS, são bastante satisfatórios e animadores. 
Acredita-se que a idéia defendida neste trabalho poderá, futuramente, vir a contribuir para o processo de estimação da matriz OD sintética. No entanto, há um longo caminho de estudos e análises até possíveis aplicações práticas.

\subsection{SUGESTÕES PARA TRABALHOS FUTUROS}

O modelo sintético é um campo de pesquisa que ainda permite muitos estudos. A abordagem apresentada neste trabalho verificou apenas uma parte, porém há muito a ser estudado. Desta forma, serão listados alguns pontos que podem servir de base para pesquisas futuras:

- Desenvolver uma rotina computacional para o método MEMS, que permita a estimação em redes de transportes com grande quantidade de pares OD;

- Adaptar a proposta de contagem nas interseções e o método de estimação MEMS para estimativa de matrizes OD dinâmicas;

- Propor um estudo mais detalhado sobre os expedientes atualmente utilizados para estimação da matriz OD, em particular o de maximização da entropia;

- Propor um estudo confrontando as técnicas reconstrução x estimação (lógicas frequentistas e baysianas);

- Verificar as possibilidade para unificar os modelos de estimação, com escolha da rota e microssimulação;

- Verificar os impactos dos sistemas ITS nessa linha;

- Considerando que quanto melhor representada pelo modelo estiver a relação entre tempo de percurso em um arco e a relação $(\mathrm{V} / \mathrm{C})$ mais precisa será a matriz $\mathrm{OD}$ resultante, sugere-se que a relação tempo $\times(\mathrm{V} / \mathrm{C})$ seja melhor estudada, bem como o processo de escolha da rota. 


\section{REFERÊNCIAS BIBLIOGRÁFICAS}

ABBAGNANO, N. (1970) Dicionário de filosofia. Mestre Jou, São Paulo.

ABRAHAMSSOM, T. (1998) Estimation of origin-destination matrices using traffic counts - $A$ literature survey. International Institute for Applied Systems Analysis, Interim Report IR- 98021, Austria,1988.

ALIBABAI, H.; MAHMASSANI, H.S. (2008). Dynamic origin-destination demand estimation using turning movement counts. Transportation Research Record: Journal of the Transportation Research Board, n 2085. Transportation Research Board of the National Academies, Washington, DC, p 39-48, 2008.

BAR-GERA, H.; MIRCHANDANI, P.B.; WU, F.(2005) Evaluating the Assumption of Independent Turning Probabilities. Transportation Research B, n.40, p.903-916, 2005.

BELL, M. G. H. (1983) The estimation of an origin-destination matrix from traffic counts. Transportation Science, n. 1, p. 198-217, 1983.

BELL, M. G. H. (1984) The estimation of junction turning volumes. Traffic Engineering and Control, v. 25, n.5., p. 279-281, 1984.

BELL M. G. H. (1991) The estimation of origin-destination matrices by constrained generalized least squares. Transportation Research Part B, n. 25, p. 13-22, 1991. 
BELL, M. G. H.; LAM, W. H. K.; PLOSS, G.; INAUDI, D. (1993) Transportation Traffic Theory, p. 427-439.

BERTONCINI, B. V. (2007) Uma proposta de carregamento incremental de fluxos veiculares para a estimação de matriz OD sintética. Dissertação de mestrado. EESC/USP. 137 p.

BERTONCINI, B. V.; KAWAMOTO, E. (2006) Uma proposta de carregamento incremental de contagens volumétricas para a estimação de matrizes OD sintéticas em redes viárias congestionadas. In: XX Congresso de Pesquisa e Ensino em Transportes, Brasília - DF. Anais do XX ANPET - Panorama Nacional da Pesquisa em Transportes 2006. Rio de Janeiro, RJ: Lagoa, 2006. v.1, p. 493-504.

BERTONCINI, B. V.; KAWAMOTO, E. (2008a) Uma proposta de carregamento incremental de contagens de tráfego para a estimação de matrizes OD sintéticas. Panamerican Conference Transport \& Traffica Engeneering. Cartagena de Indias. PANAN 2008.

BERTONCINI, B. V.; KAWAMOTO, E. (2008b) Obtenção da matriz OD sintética representando a escolha do indivíduo através do modelo logit. In: XXII Congresso de Pesquisa e Ensino em Transportes, 2008, Fortaleza-CE. Panorama Nacional da Pesquisa em Transportes 2008.

BIERLAIRE, M.; TOINT, P.L. (1994) MEUSE: an origin-destination matrix estimator that exploits structure. Transportation Research B, n 29, p.47-60, 1994.

BRILLOUIN, L. (1956) Science and information theory. Academic Press, New York.

BUREAU OF PUBLIC ROADS - BPR (1964) Traffic assignment manual, Washington, DC, USA.

CALIPER (1996) Travel demand modeling with TransCAD 3.0. Caliper Corporation, Newton, USA. 
CAREY, M.; HENDRICKSON, C.; SIDDHARTHAN, K. (1981) A method for direct estimation of origin/destination trip matrices. Transportation Science, n. 15, p. 32-49, 1981.

CAREY, M.; REVELLI, R. (1986) Constrained estimation of direct demand functions and trip matrices. Transportation Science, n. 3, p. 143-152, 1986.

CASCETTA, E. (1984) Estimation of trip matrices from traffic counts and survey data: a generalized least squares estimator. Transportation Research Part B, v. 16, n. 4-5, p. 289299, 1984.

CASCETTA, E.; NGUYEN, S. (1988) A unified framework for estimating or updating origin/destination matrices from traffic counts. Transportation Research Part B, v. 18, n. 6, p. 437-455, 1988.

CHEN, Y. (1994) Bilevel programming problems: analysis, algorithms and applications. Tese de doutorado, CRT-984, Centré de recherché sur les transports, Universté de Montréal, Montréal, Québec, Canada.

CREMER, M.; KELLER, H. (1981) Dynamic identification of flows from traffic counts at complex intersections. Transportation and Traffic Theory, Toronto University, 1981.

CREMER, M.; KELLER, H. (1987) A new class of dynamic methods for the identification of origin-destination flows. Transportation Research B, v. 21, n. 2., pp. 117-132, 1987.

DEMARCHI, S. H.; BERTONCINI, B. V.; LIMA, E. P. (2004) Estimativa de uma matriz O-D sintética para a região central de Maringá utilizando o QUEENSOD. In: XVIII CONGRESSO DE PESQUISA E ENSINO EM TRANSPORTES, Florianópolis, SC. Anais do XVIII ANPET. Rio de Janeiro, RJ: Lagoa, 2004. v. 2, p. 844-855.

DNIT (2006) Manual de estudos de tráfego. Departamento Nacional de Infra-estrutura de Transportes. Instituto de Pesquisas Rodoviárias. Rio de Janeiro. 
DONALD, A. M. (1976) Statistical mechanics. Harper Collins, New York.

EMME/2 (1990) Transportation planning software, INRO Consultants Inc., Users' manual, Centré de recherché sur les transports, Universté de Montréal, Montréal, Québec, Canada.

FISK, C. S. (1988) On combining maximum entropy trip matrix estimation with user optimal assignmenr. Transportation Research Part B, n.22 p. 66-79, 1988.

FLORIAN, M.; CHEN, Y. (1993) A coordinate descent method for the bilevel OD matrix adjustment problem. Presented at the IFORS Conference in Lisbon, Portugal.

GLOVER, F.; HULTZ, J.; KLINGMAN, D.(1977) Improved computer-based planning techniques. Relatório número CCS 283, Center for Cybernetic Studies, The University of Texas, Austin, Texas.

GUR Y.J.; TURNQUIST, M.; SCHNEIDER, M; LEBLANC, L.; KURTH, D. (1980) Estimation of an origin- destination trip table based on observed link volumes and turning movements. Technical Report RD-801034, FHWA, U.S. Department of Transportation, Washington, DC.

GUR, Y. et al. (1978). Determining an origin-destination trip table based on observed volumes. ORSA-TIMS Annual Meeting, New York, May 1978.

HAZELTON, M. L. (2001) Inference for origin-destination matrices: estimation, prediction and reconstruction. Transportation Research B, n.35, p.667-676, 2001.

HAZELTON, M. L. (2008) Statistical inference for time varying origin-destination matrices. Transportation Research B, n.42, p.542-552, 2008.

HELLINGA, B.R. (1994) Estimating dynamic origin - destination demands from link and probe counts. Ph.D. Dissertation, Department of Civil Engineering, Queen's University, Kingston, Ontario, Canada. 
HOGBERG, P. (1976). Estimation of parameters in models for traffic prediction: a non-linear approach. Transportation Research Part B, n. 10, p. 263-265, 1976.

HOLM, J. et al. (1976). Calibrating traffic models on traffic census results only. Traffic Engineering and Control, n. 17, p. 137-140, 1976.

JAYNES, E.T. (1957) Information theory and statistical mechanics. Physics Review, n. 106, p. $620-630,1957$.

JEFFREYS, M.; NORMAN, M. (1977) On finding realistic turning flows at road junctions. Traffic Engineering and Control, v. 18., p. 19-25, 1977.

LEBLANC, L. J.; FARHANGIAN, K. (1982). Selection of a trip table which reproduces observed link flows. Transportation Research Part B, n 16, p 83-88, 1982.

LOW, D. (1972). A new approach to transportation systems modelling. Traffic Quart., n 26, p. 391-404, 1972.

MAHER, M. J. (1983) Inferences on trip matrices from observations on link volumes: A bayesian statistical approach. Transportation Research Part B, n. 17, p. 435-447, 1983.

MARTIN, P.T.; BELL, M.C. (1992) Network programming to derive turning movements from link flows. Transportation Research Record, n 1365, p. 147-154, 1992.

MCNEIL, S.; HENDRICKSON, C. (1985) A regression formulation on matrix estimation problem. Transportation Science, n 19, p. 278-292, 1985.

NGUYEN S. (1977) Estimating an OD matrix from network data: A network equilibrium approach. Publication 87. Centre de Recherche sur les Transports, Université de Montreal.

NIELSEN, O. A.(1993) A new method for estimating trip matrices from traffic counts. Institute of Roads, Traffic, and Town Planning. The Technical University of Denmark, Paper 1993-3. 
NIELSEN, O. A.(1998) Two new methods for estimating trip matrices from traffic counts. Travel Behaviour Research: Updating the State of Play. Ed. Elsevier.

NOBLE, B. (1969) Applied linear algebra. Prentice-Hall, Englewoodd Cliffs, New Jersey.

NORMAN, M.; HOFFMANN, N.; HARDING, F. (1979) Non-iterative methods for generating a realistic turning flow matrix for a junction. Traffic Engineering and Control v. 20, p. 587-589, 1979.

O'NEIL, W.A. (1987) Origin-destination trip table estimation using traffic counts. Ph.D. dissertation, University of New York at Buffalo, NY.

ORTÚZAR, J. D.; WILLUMSEN, L. G. (1994) Modelling transport. John Wiley \& Sons, Chichester.

PARAMAHAMSAN, H. (1999) Fundamental properties of synthetic $O-D$ generation formulations and solutions. Dissertação - Mestrado, Departmento de Engenharia Civil e Ambiental, Virginia Polytechnic Institute and State University, Blacksburg, VA. 133 p.

RAKHA, H.; PARAMAHAMSAN, H.; VAN AERDE, M. (200X). Comparison of static maximum likelihood Origin-Destination formulations.

RAKHA, H.; VAN AERDE, M.; BLOOMBERG, L.; HUANG, X. (1998) Construction and calibration of a large-scale microsimulation model of the Salt Lake Area. Transportation Research Record, n. 1644, p. 93-102, 1998.

ROBILLARD, P. (1975) Estimating the O-D matrix from observed link volumes Transportation Research Part B, n. 9, p. 123-128, 1975.

SCHNEIDER, M. (1959) Gravity models and trip distribution theory. Papers and Proceedings of the Regional Science Association, v.5, p.51-56, 1959. 
SHEFFI, Y. (1985). Urban transportation networks: Equilibrium Analysis with Mathematical Programming Methods. Prentice Hall, Englewood Cliffs, NJ, p. 367-374.

SHERALI, H. D.; NARAYANAN, A.; SIVANANDAN, R. (2003) Estimation of origin-destination trip-tables based on a partial set of traffic link volumes. Transportation Research $B, \mathrm{n} 37, \mathrm{p}$. 815-836, 2003.

SOUZA, D. D. M. R. E (2007) Estimação sintética de matrizes Origem/Destino a partir de contagens volumétricas em áreas com controle do tráfego em tempo real com o auxílio do QUEENSOD. Dissertação (Mestrado em Engenharia de Transportes), Programa de Mestrado em Engenharia de Transportes, Centro de Tecnologia, Universidade Federal do Ceará, Fortaleza, CE. 120 p.

SPIESS, H. (1987) A maximum likelihood model for estimating Origin-Destination matrices. Transportation Research Part B, n. 2I, p 395-412, 1987.

SPIESS, H. (1990) A descent based approach for the OD matrix adjustment problem. Centré de recherchésur les transports, n. 693, Université de Montréal, Montréal, Canada.

SYMONS, J. et al. (1976). A model of inter-city motor travel estimated by link volumes. ARRB Proc.8, p. 53-65.

TEBALDI, C.; WEST, M. (1998) Bayesian inference on network traffic using link count data (with discussion). Journal of the American Statistical Association, n. 93., pp. 557-576, 1998.

TESEKERIS, T.; STATHOPOULOS, A. (2008) Treating uncertain demand information in Origin-Destination matrix estimation with traffic counts. Journal of Transportation Engineering, v.134, n.8, August, p. 327-337, 2008.

TIMMS, P. (2001) A philosophical context for methods to estimate origin-destination trip matrices using link counts. Transport Reviews, v. 21, n. 3, p. 269-301, 2001. 
TURNIQUIST, M.; GUR, Y (1979) Estimation of trip tables from observed link flows. Transportation Research Record, n.730, p.1-6, 1979.

VAN AERDE, M. (1998) QUEENSOD - Release 2.10 - User's Guide: estimating origin destination traffic demands from link flow counts. Michel Van Aerde \& Associates, Ltd, Blacksburg, VA, USA.

VAN AERDE, M.; RAKHA, H.; PARAMAHAMSAN, H. (2003) Estimation of O-D matrices: the relationship between practical and theoretical considerations. Transportation Research Record, 1831, p. 122-130, 2003.

VAN VLIET, D.; HALL, M. D. (1998) SATURN 9.4 User Guide (Epsom: W.S.Atkins)

VAN ZUYLEN, H. (1978). The information minimizing method: validity and applicability to transport planning. In. New Developments in Modeling Travel Demand and Urban Systems. Edited by G. R. M. Jansen et al. Saxon, Farnborough.

VAN ZUYLEN, H. J.; BRANSTON, D. M. (1982) Consistent Link Flow Estimation From Counts. Transportation Research, n 148, pp 28 I-293, 1982.

VAN ZUYLEN, H. J.; WILLUMSEN, L. G. (1980) The most likely trip matrix estimated from traffic counts. Transportation Research Part B, n. 14, p. 281-293, 1980.

VARDI, Y. (1996) Network tomography: estimating source-destination traffic intensities from link data. Journal of the American Statistical Association, n. 91, pp. 365-377, 1996.

WARDROP, J. G. (1952) Some Theoretical Aspects of road Traffic Research. Proc. Inst, Civil Engineers, Part 2, p. 325-378.

WATSON, J. R.; PREVEDOUROS, P. D. (2006) Derivation of origin-destination distributions from traffic counts. Transportation Research Record n. 1964, p. 260-269, 2006. 
WILLUMSEN, L. (1978a) Estimation of an O-D matrix from traffic counts: a review. Institute for Transport Studies. Working paper 99, Leeds University.

WILLUMSEN, L. (1978b) O-D matrices from network data: a comparasion of alternative methods for their estimation. Proc. of PTRC Summer Annual Meeting 1978 Seminar in Transport Models, PTRC Education Research Services Ltd., London.

WILLUMSEN, L.G. (1981) Simplified transport models based on traffic counts. Transportation, n. 10, p. 257-278, 1981.

WILLUMSEN, L. G. (1984) Estimating time-dependent trip matrices from traffic counts. Proceedings of the $9^{\text {th }}$ International Symposium on Transportation and Traffic Theory, The Netherlands, Delft University, July, p. 397-41 I, 1984.

WILSON, A. G. (1967) A statistical theory of spatial distribution models. Transportation Research, v.1, p.253-269, 1967.

WILSON, A. G.(1970) Entropy in urban and regional modeling. Pion, London.

YANG, H.; IIDA, Y.; SASAKI, T. (1994). The equilibrium-based Origin-Destination matrix estimation problem. Transportation Research Part B, n 28, p. 23-33, 1994.

YANG, H.; SASAKI, T.; IIDA, Y.; ASAKURA, Y. (1992). Estimation of Origin-Destination matrices from link traffic counts on congested networks. Transportation Research B, n. 26, p. 417-434, 1992. 


\section{APÊNDICE}

\section{A.1 GRÁFICO "VIAGEM "REAL” X VIAGEM ESTIMADA"}

Os gráficos contendo os valores das viagens "reais" entre cada par OD versus os valores das viagens estimadas entre cada par OD são apresentados neste Apêndice. Estão agrupados por Teste, sendo que em cada um há a divisão de acordo com o método de estimação. 


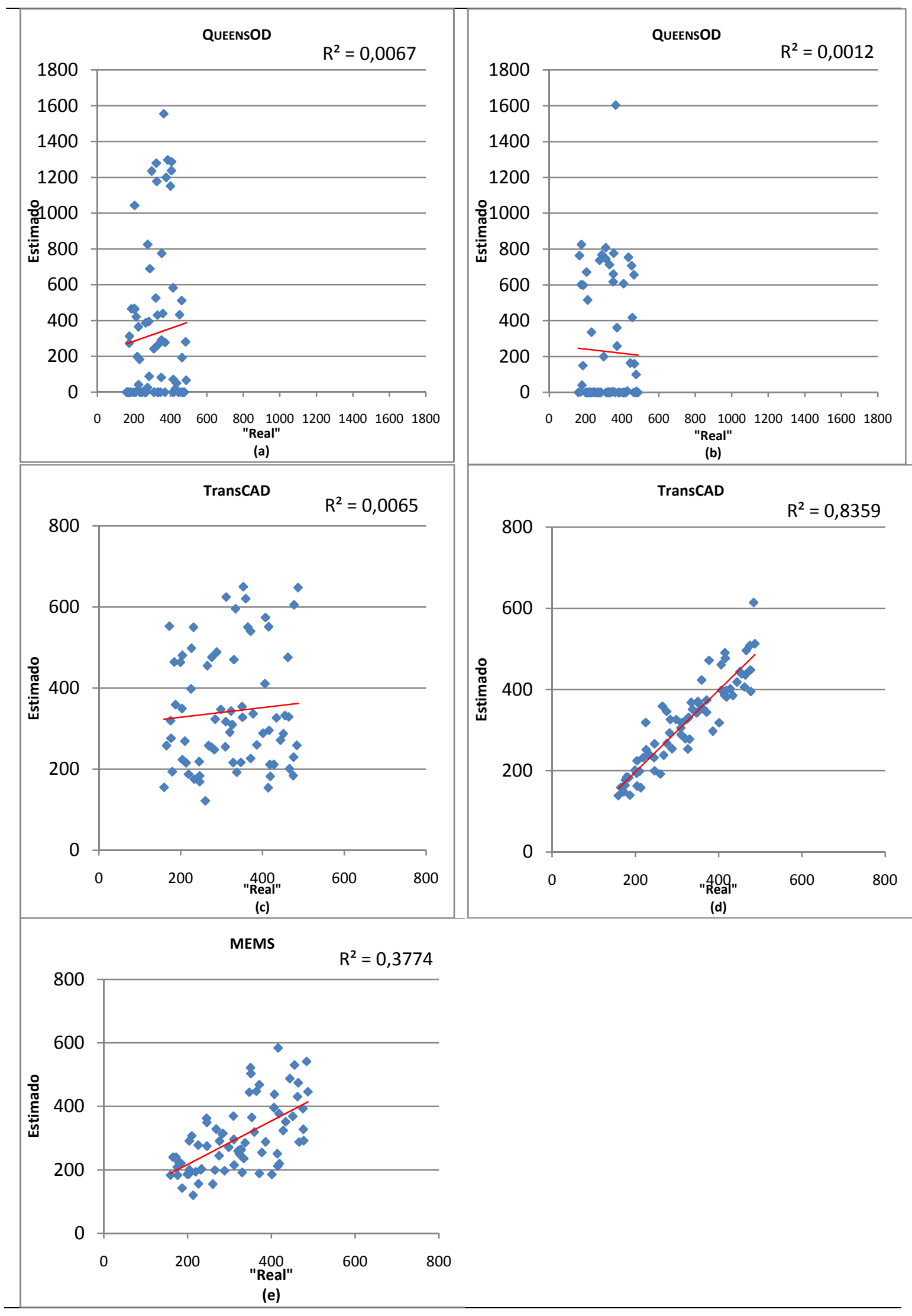

Figura A.1: Viagens "reais" x Viagens Estimadas - Teste 1: (a) QOD; (b) QOD com S 70 ; (c) TCD; (d) TCD com S 70 ; (e) MEMS 

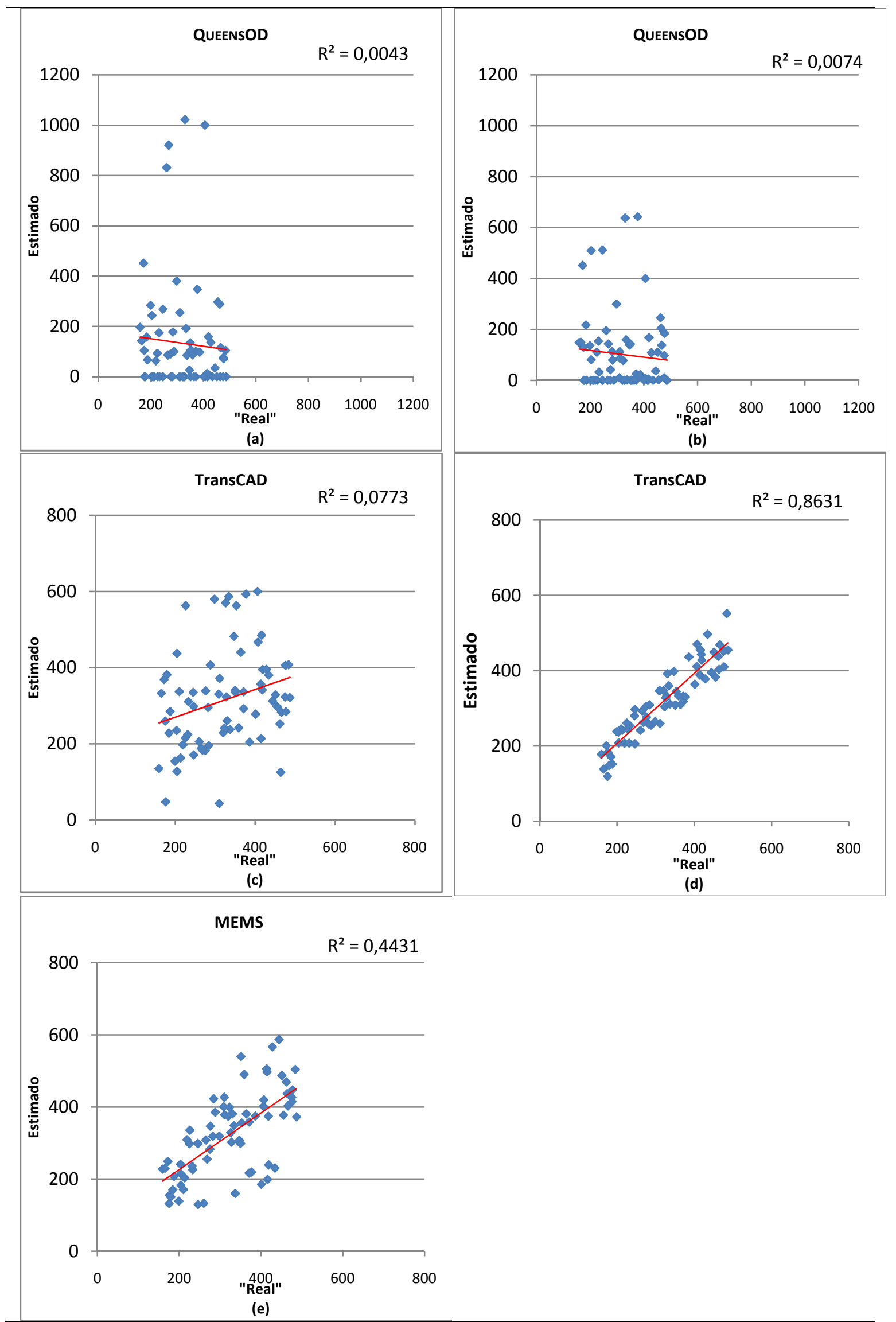

Figura A.2: Viagens "reais" x Viagens Estimadas - Teste 2: (a) QOD; (b) QOD com S70; (c) TCD; (d) TCD com $S_{70}$; (e) MEMS 

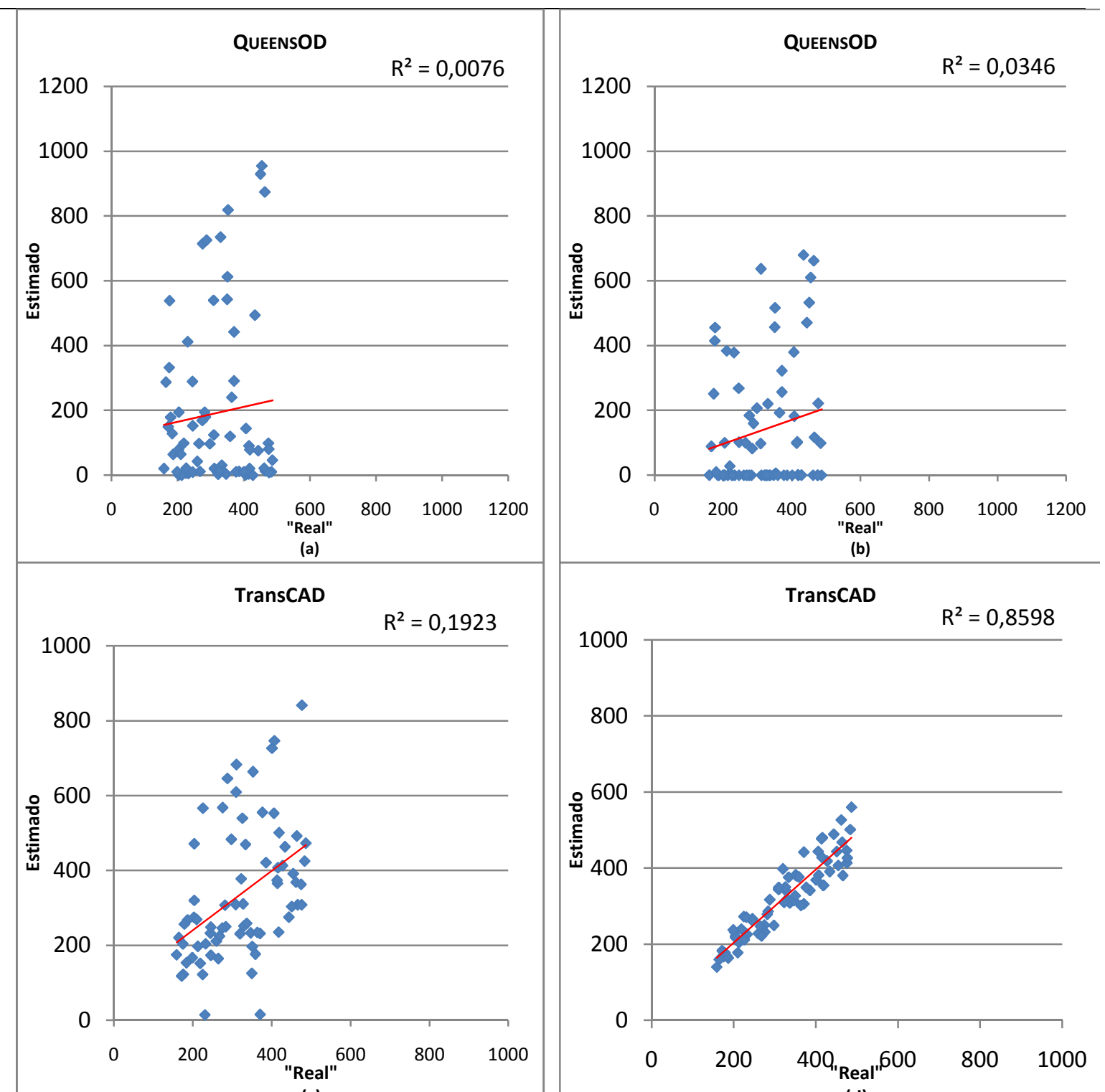

(c)

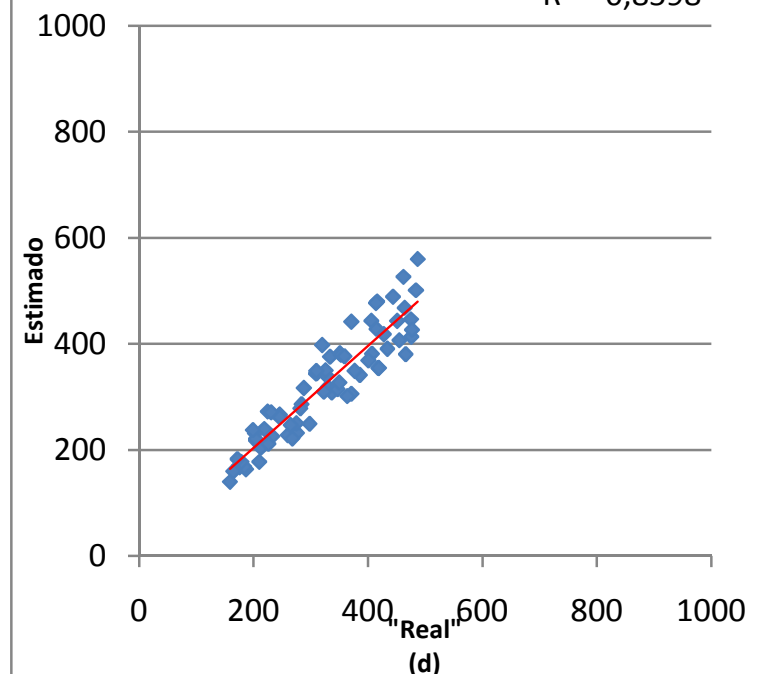

(d)

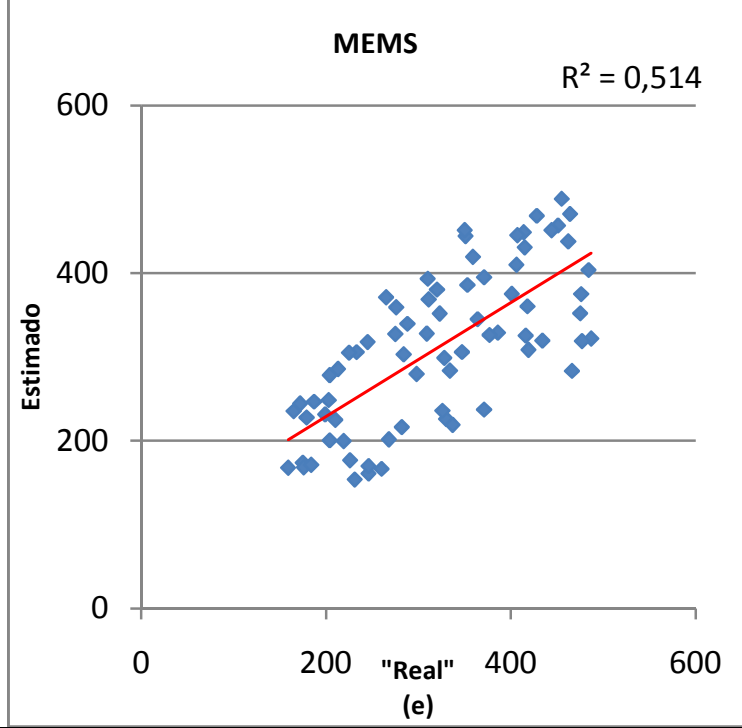

Figura A.3: Viagens "reais" x Viagens Estimadas - Teste 3: (a) QOD; (b) QOD com S70; (c) TCD; (d) TCD com S 70 ; (e) MEMS 


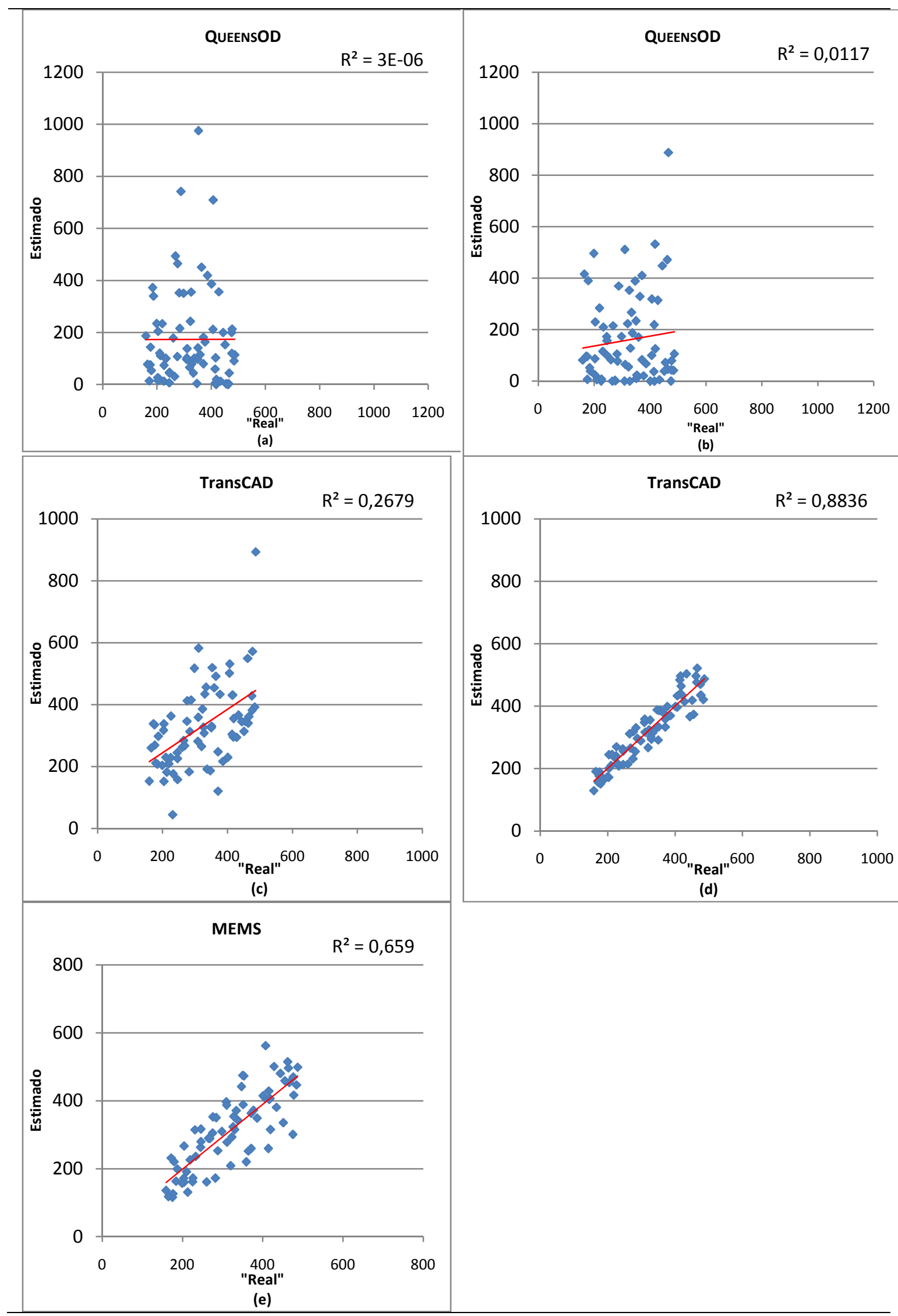

Figura A.4: Viagens "reais" x Viagens Estimadas - Teste 4: (a) QOD; (b) QOD com $\mathrm{S}_{70}$; (c) TCD; (d) TCD com $S_{70}$; (e) MEMS 

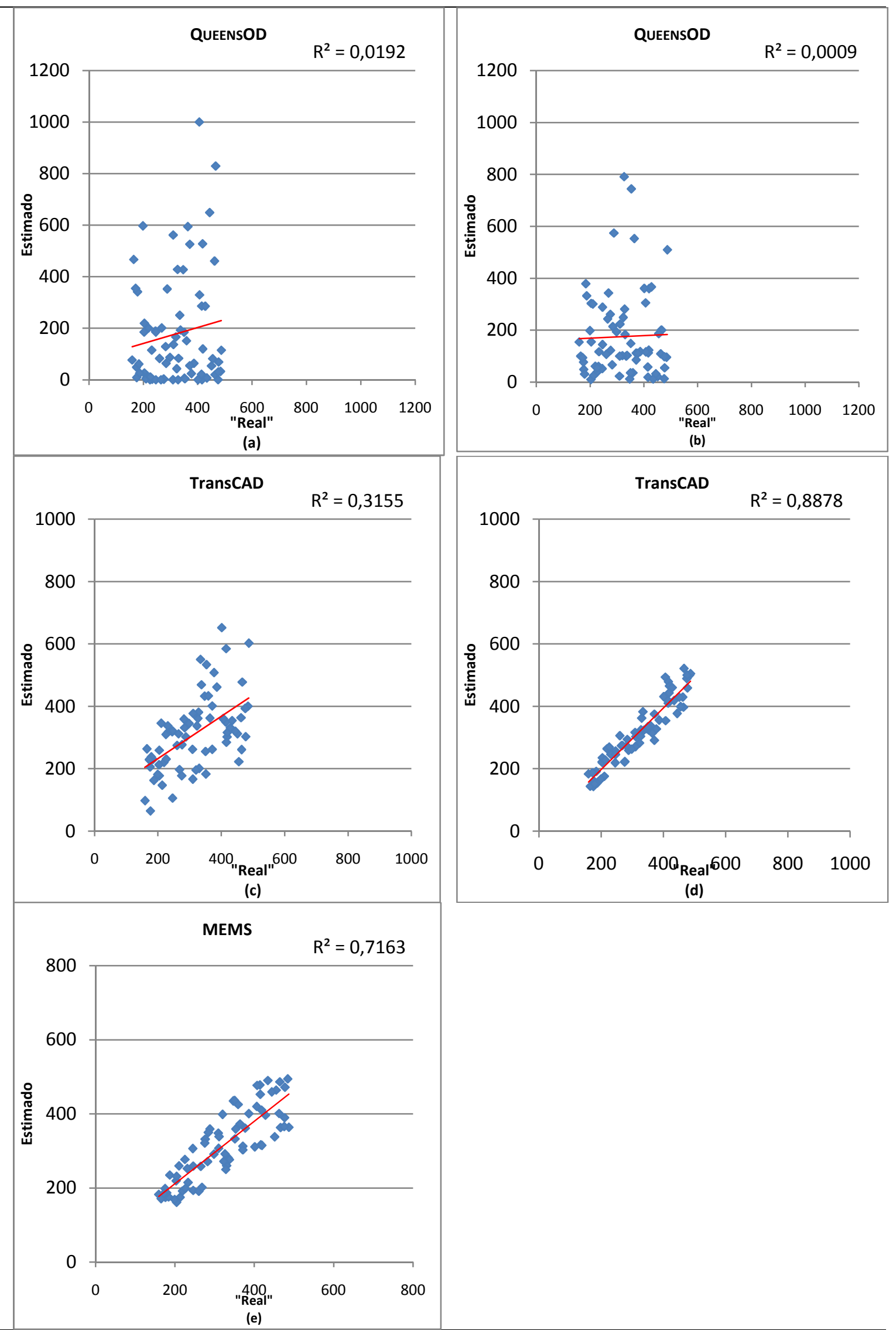

Figura A.5: Viagens "reais" x Viagens Estimadas - Teste 5: (a) QOD; (b) QOD com S ${ }_{70}$; (c) TCD; (d) TCD com $\mathrm{S}_{70}$; (e) MEMS 

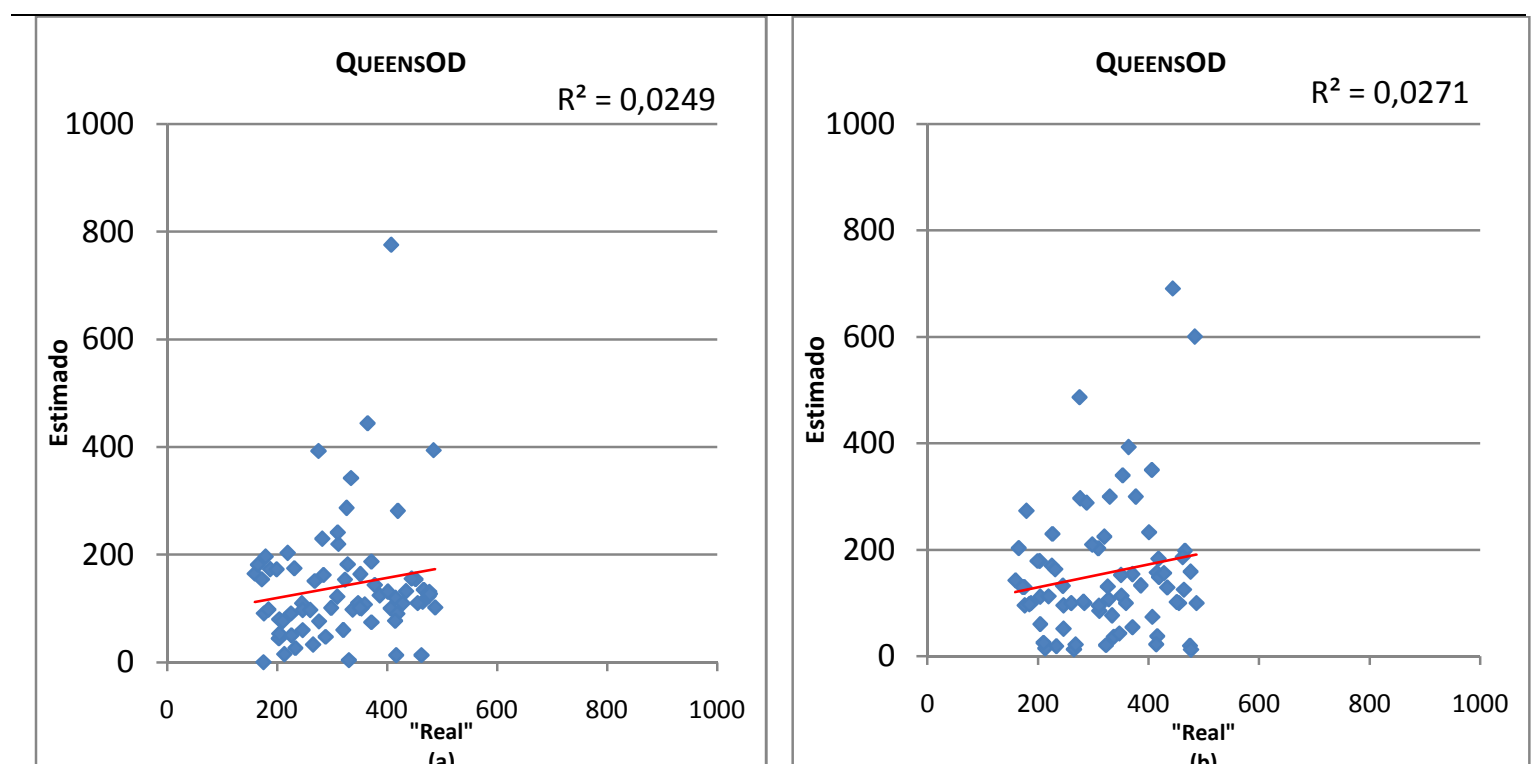

(a)

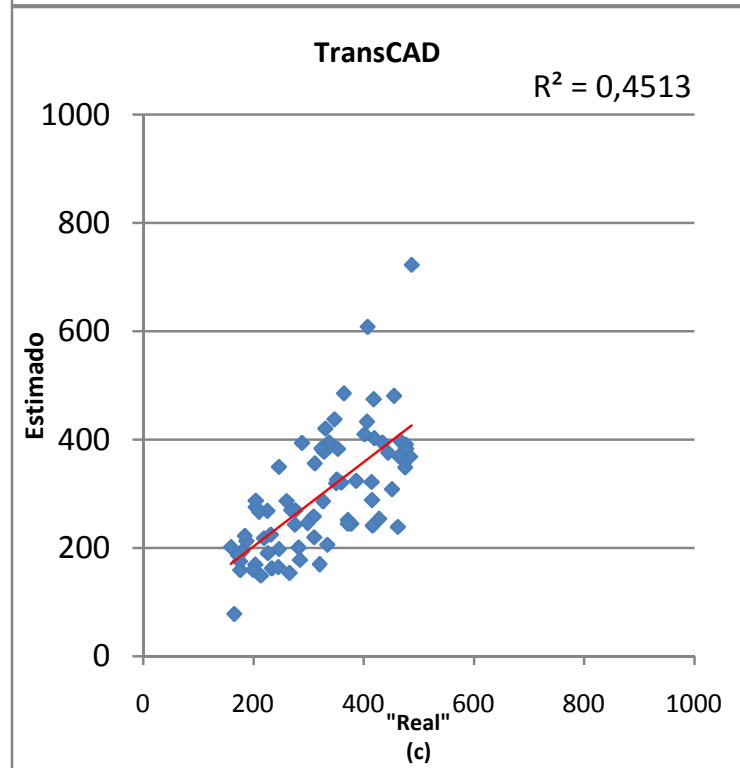

(b)
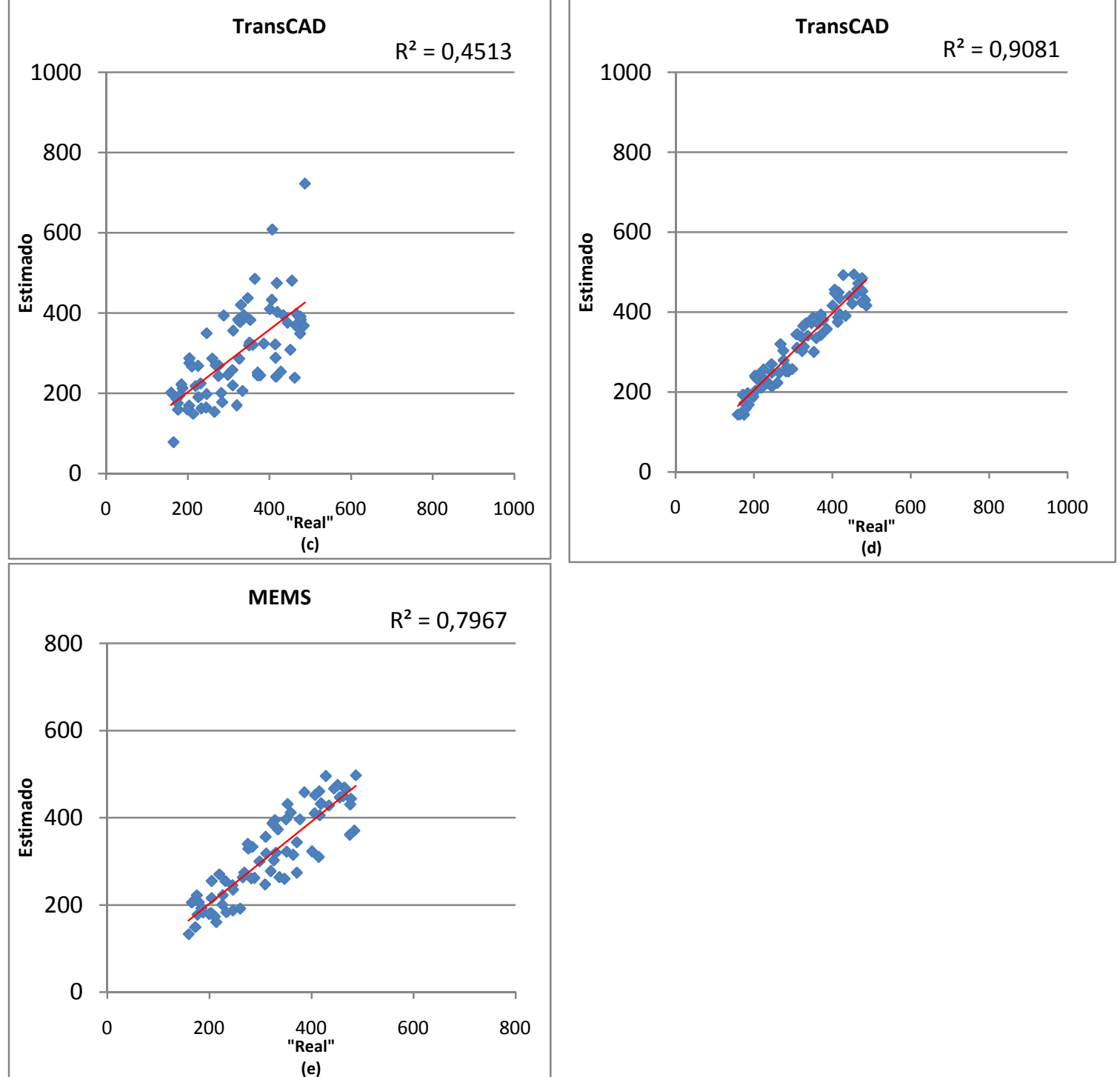

Figura A.6: Viagens "reais" x Viagens Estimadas - Teste 6: (a) QOD; (b) QOD com $\mathrm{S}_{70}$; (c) TCD; (d) TCD com $S_{70}$; (e) MEMS 


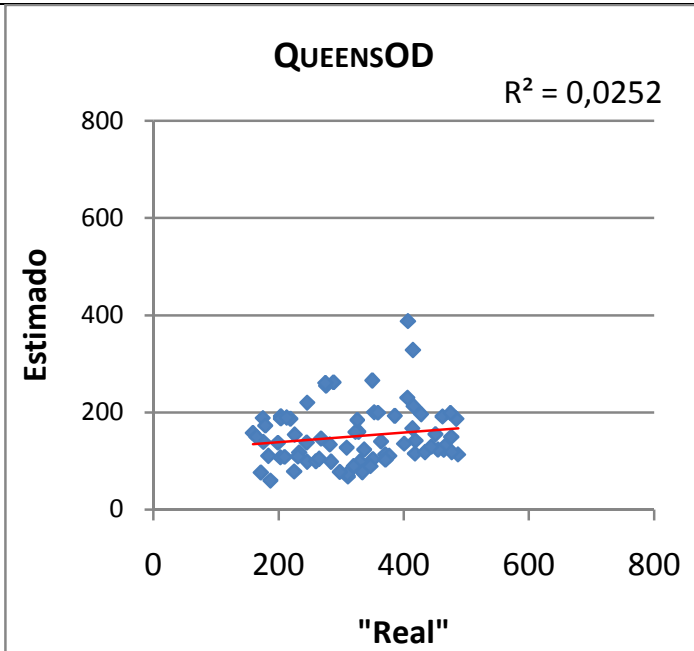

(a)

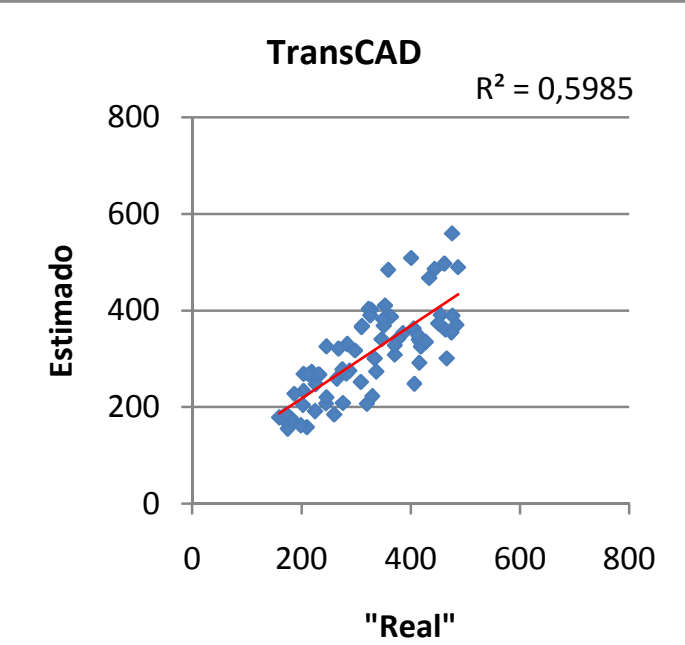

(b)

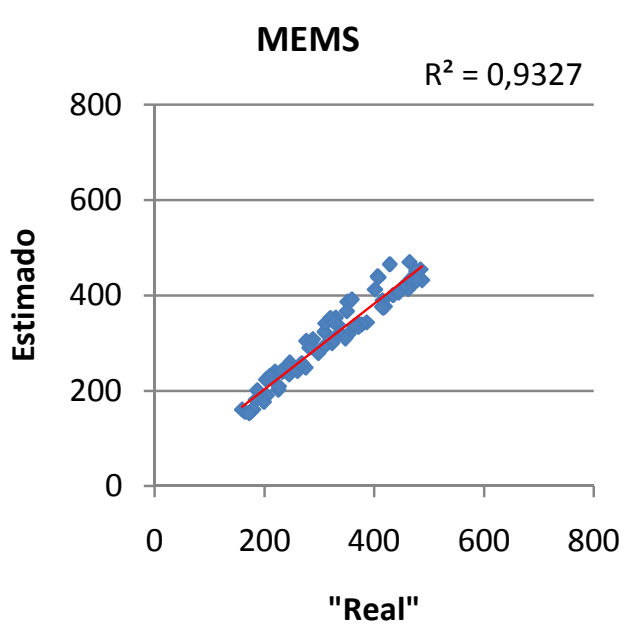

(c)

Figura A.7: Viagens "reais" x Viagens Estimadas - Teste 7: (a) QUEENSOD; (b) TransCAD; (c) MEMS 


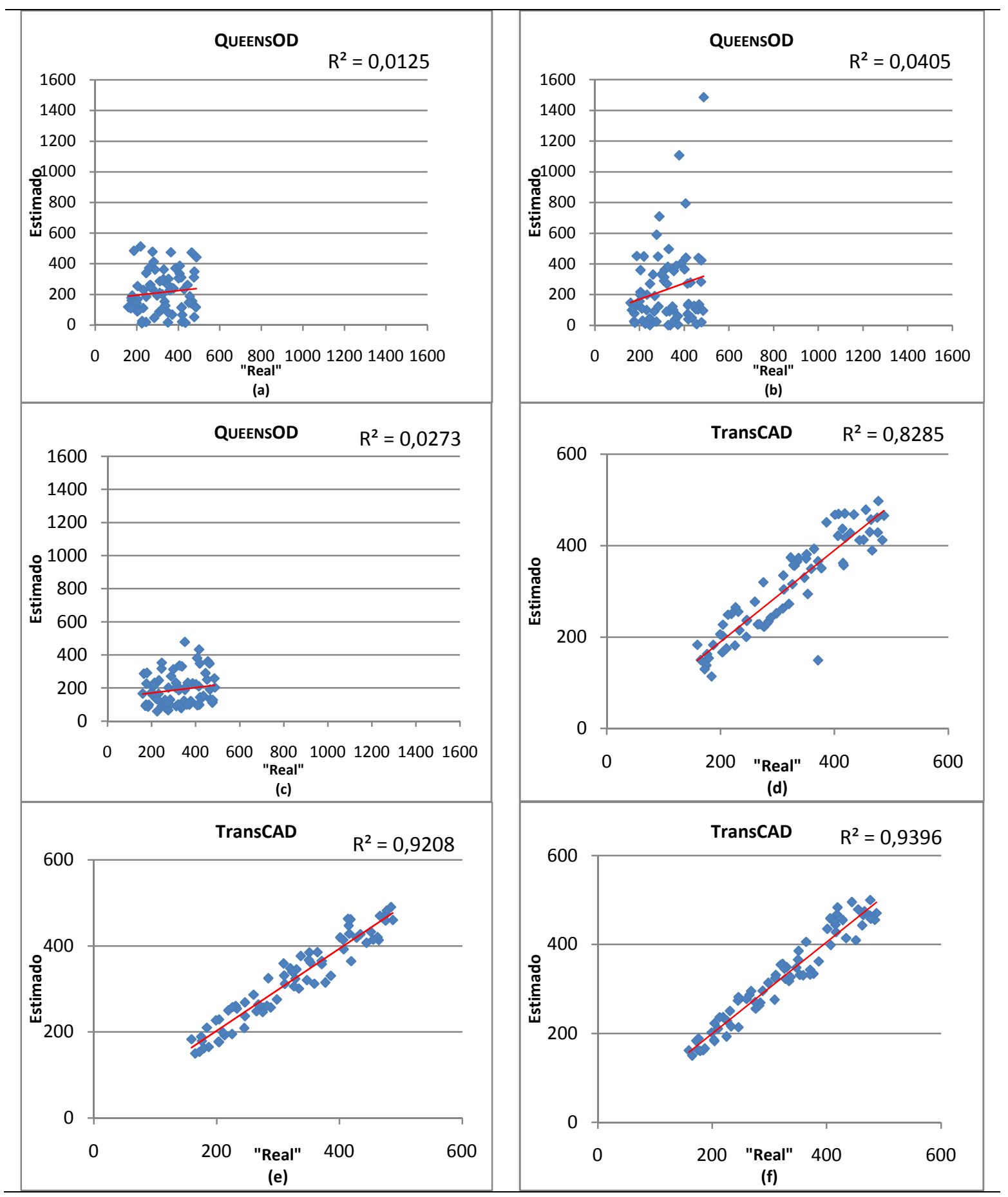

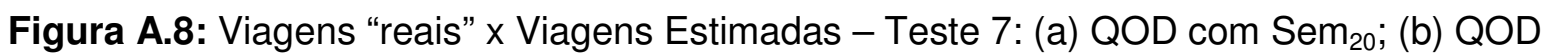
com Sem 10 ; (c) QOD com S70; (d) TCD com Sem 20 ; (e) TCD com Sem 10 ; (f) TCD com S 70 


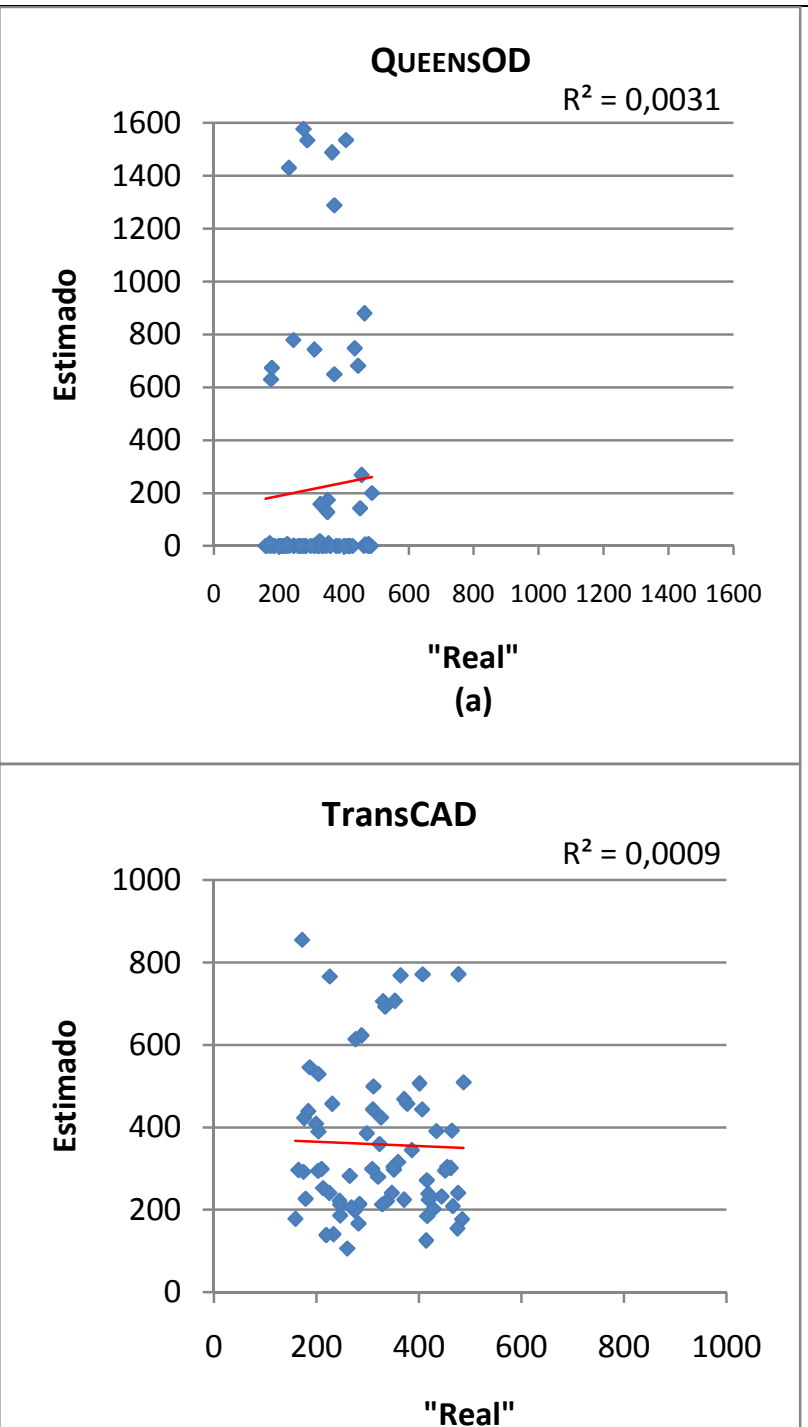

(b)

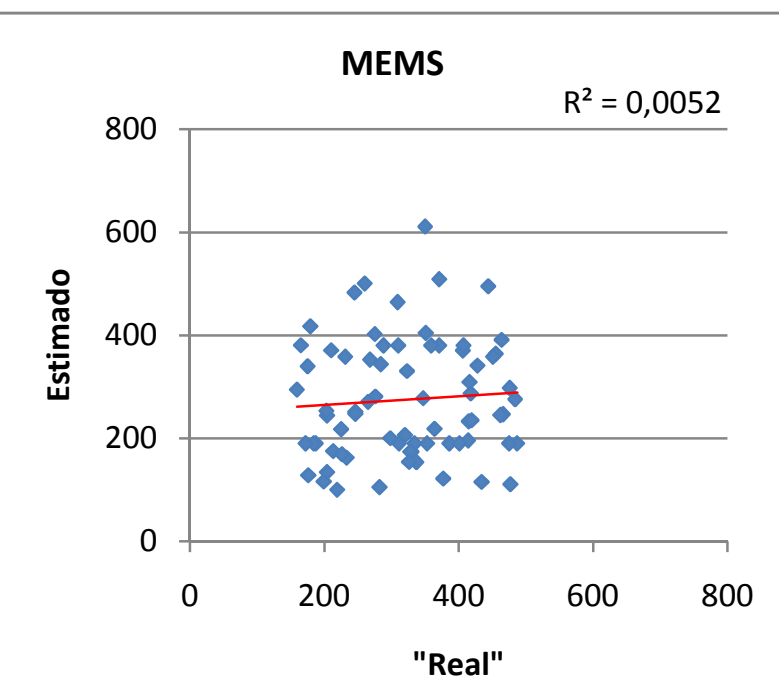

(c)

Figura A.9: Viagens "reais" x Viagens Estimadas - Teste 8: (a) QUEENSOD; (b) TransCAD; (c) MEMS 


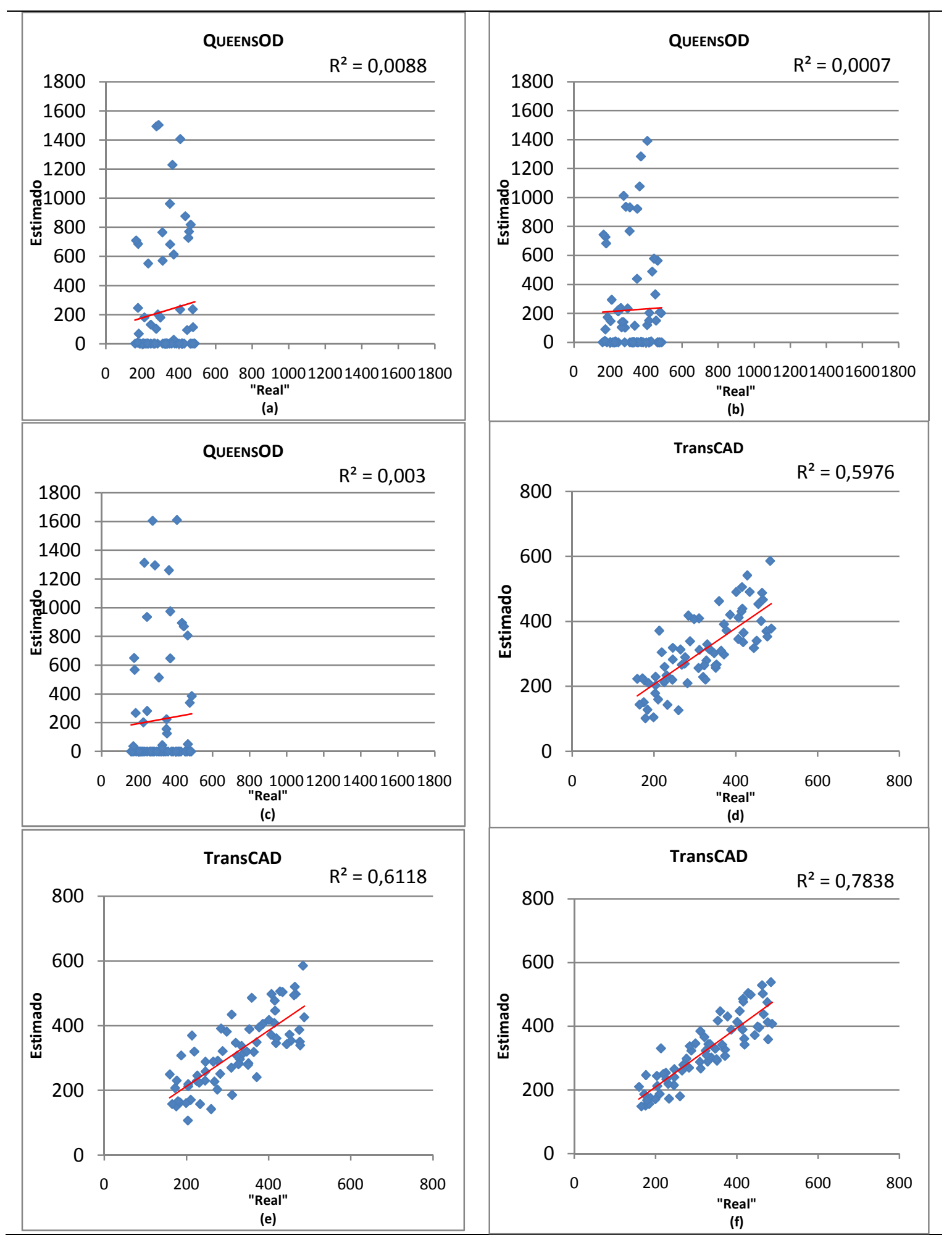

Figura A.10: Viagens "reais" x Viagens Estimadas - Teste 8: (a) QOD com Sem 20 ; (b) QOD com Sem 10 ; (c) QOD com S 70 ; (d) TCD com Sem 20 ; (e) TCD com Sem 10 ; (f) TCD com S 70 


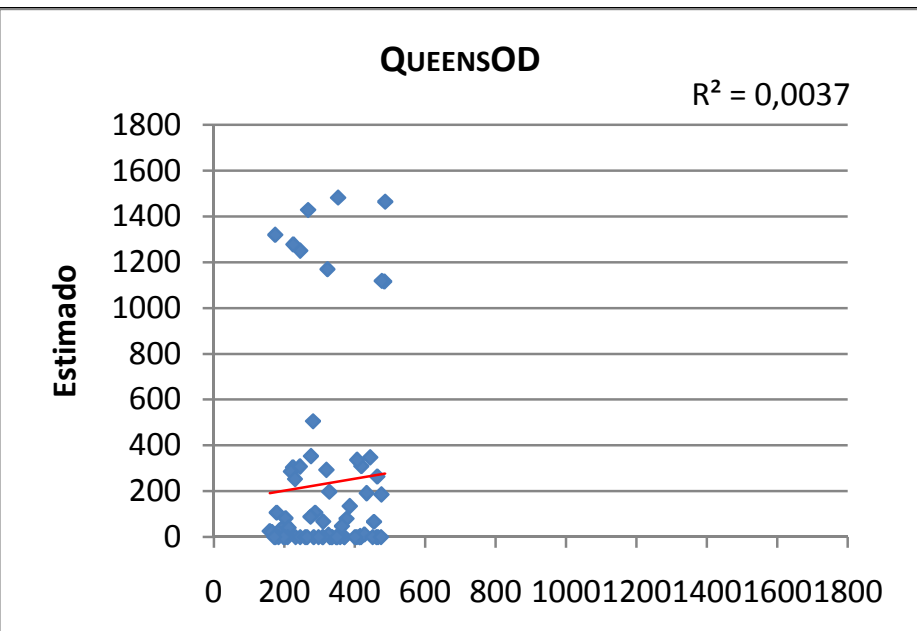

"Real"

(a)

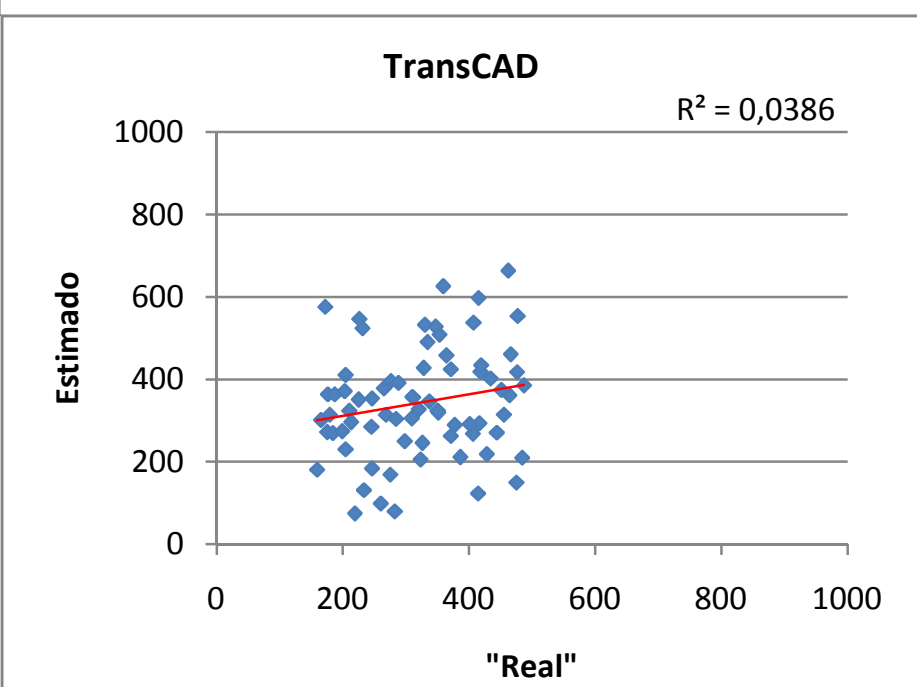

(b)

Figura A.11: Viagens "reais" x Viagens Estimadas - Teste 9: (a) QUEENSOD; (b) TransCAD 


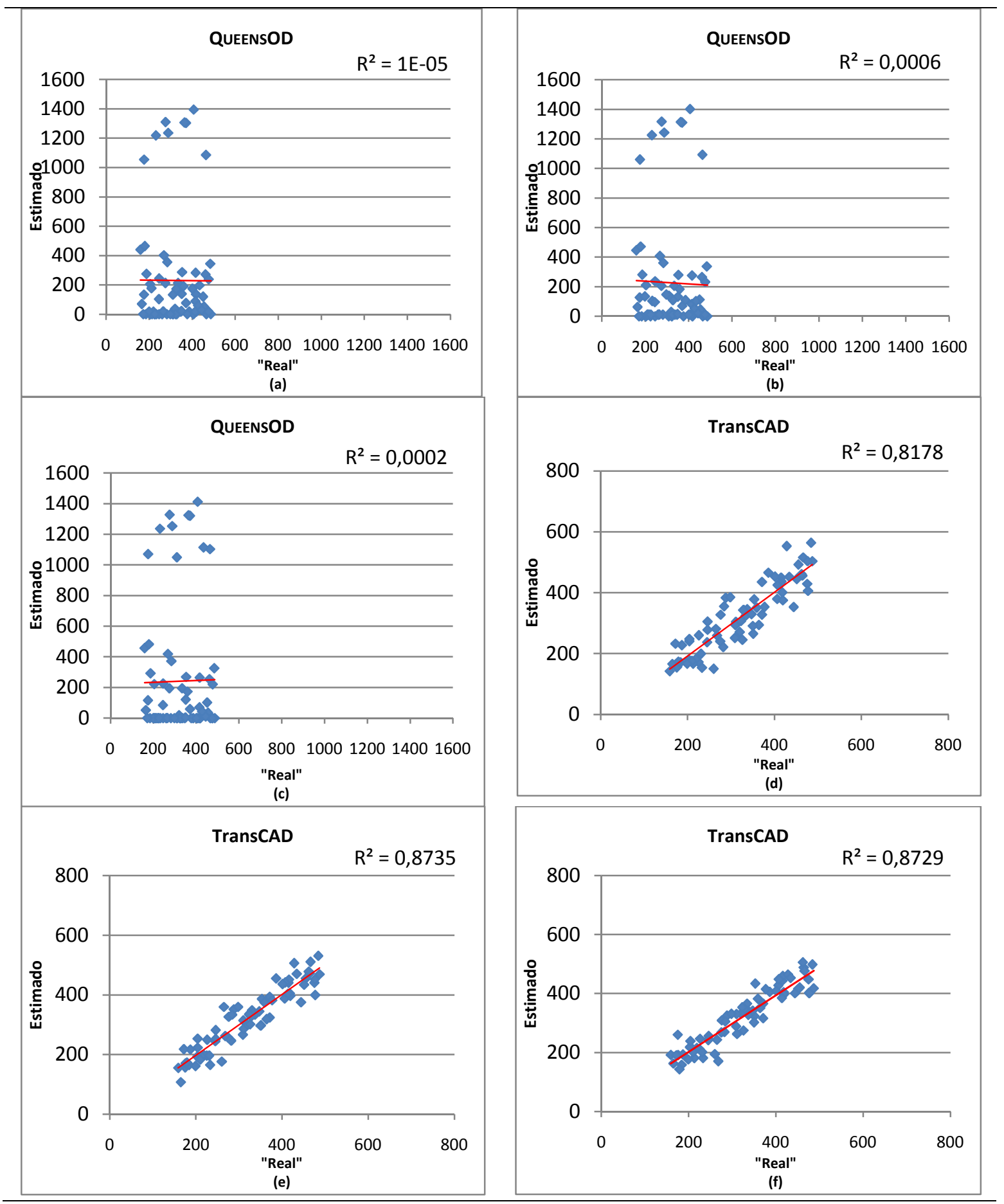

Figura A.12: Viagens "reais" x Viagens Estimadas - Teste 9: (a) QOD com Sem 20 ; (b) QOD com Sem 10 ; (c) QOD com S 70 ; (d) TCD com Sem 20 ; (e) TCD com Sem 10 ; (f) TCD com $S_{70}$ 


\section{APENNDICE}

$\mathbf{B}$

\section{B.1 TABELAS COM AS DIFERENÇAS RELATIVAS ENTRE AS VIAGENS "REAIS” E AS ESTIMADAS NOS PARES OD}

Tabela B.1: Diferença relativa entre viagem "real" e estimada - Teste 1

\begin{tabular}{|c|c|c|c|c|c|c|c|c|c|c|}
\hline O\D & 1 & 2 & 3 & 4 & 5 & 6 & 7 & 8 & 9 & $\Sigma$ \\
\hline \multirow{3}{*}{1} & - & 204,68 & 58,41 & 30,30 & 100,00 & 56,57 & 198,91 & 100,00 & 100,00 & 13,85 \\
\hline & - & 1,23 & 29,09 & 42,42 & 49,52 & 82,86 & 72,46 & 2,52 & 39,08 & 0,04 \\
\hline & - & 2,46 & 2,16 & 41,82 & 9,57 & 19,43 & 5,43 & 15,72 & 26,15 & 0,23 \\
\hline \multirow{3}{*}{2} & 411,27 & - & 236,01 & 40,48 & 100,00 & 62,22 & 82,93 & 9,59 & 41,94 & 48,64 \\
\hline & 9,31 & - & 32,64 & 32,77 & 24,89 & 76,89 & 28,85 & 14,61 & 46,49 & 9,02 \\
\hline & 1,47 & - & 25,39 & 48,67 & 12,88 & 23,56 & 40,38 & 11,42 & 11,98 & 3,06 \\
\hline \multirow{3}{*}{3} & 77,84 & 218,30 & - & 16,81 & 100,00 & 148,66 & 100,00 & 100,00 & 139,58 & 29,27 \\
\hline & 56,82 & 10,61 & - & 6,55 & 56,56 & 91,98 & 11,02 & 31,30 & 69,79 & 3,01 \\
\hline & 4,55 & 32,36 & - & 43,30 & 47,49 & 23,53 & 48,16 & 42,28 & 31,60 & 3,23 \\
\hline \multirow{3}{*}{4} & 20,06 & 130,54 & 100,00 & - & 86,45 & 20,35 & 126,96 & 97,65 & 100,00 & 14,70 \\
\hline & 78,44 & 71,92 & 17,48 & - & 33,06 & 138,10 & 135,78 & 1,41 & 28,10 & 53,54 \\
\hline & 29,34 & 7,39 & 19,74 & - & 8,42 & 13,42 & 43,14 & 43,19 & 46,67 & 1,46 \\
\hline \multirow{3}{*}{5} & 100,00 & 100,00 & 100,00 & 100,00 & - & 100,00 & 100,00 & 100,00 & 100,00 & 100,00 \\
\hline & 43,03 & 62,80 & 25,20 & 152,17 & - & 133,17 & 56,87 & 53,08 & 34,15 & 17,95 \\
\hline & 15,43 & 39,37 & 11,79 & 20,11 & - & 6,53 & 38,20 & 40,00 & 19,51 & 20,87 \\
\hline \multirow{3}{*}{6} & 100,00 & 10,82 & 81,42 & 25,07 & 100,00 & - & 99,39 & 64,38 & 119,83 & 19,86 \\
\hline & 27,03 & 3,03 & 120,35 & 45,55 & 100,96 & - & 56,36 & 9,06 & 84,14 & 37,81 \\
\hline & 16,70 & 6,71 & 30,97 & 49,06 & 30,87 & - & 45,45 & 18,75 & 3,68 & 10,33 \\
\hline \multirow{3}{*}{7} & 216,22 & 95,33 & 100,00 & 100,00 & 100,00 & 4,21 & - & 295,98 & 88,25 & 11,97 \\
\hline & 41,03 & 50,70 & 8,38 & 221,51 & 37,46 & 36,36 & - & 6,19 & 24,65 & 1,28 \\
\hline & 7,62 & 24,30 & 25,14 & 39,53 & 28,24 & 18,18 & - & 22,29 & 18,89 & 3,58 \\
\hline \multirow{3}{*}{8} & 68,66 & 40,07 & 90,55 & 22,28 & 100,00 & 46,04 & 187,03 & - & 261,04 & 37,42 \\
\hline & 13,73 & 12,06 & 7,64 & 72,98 & 61,26 & 71,70 & 28,18 & - & 4,91 & 0,60 \\
\hline & 10,92 & 10,99 & 10,91 & 10,86 & 17,26 & 24,53 & 53,62 & - & 19,02 & 16,16 \\
\hline \multirow{3}{*}{9} & 100,00 & 100,00 & 327,20 & 76,57 & 100,00 & 100,00 & 21,94 & 314,77 & - & 4,29 \\
\hline & 38,96 & 3,73 & 51,10 & 1,14 & 51,89 & 26,83 & 2,26 & 16,44 & - & 1,87 \\
\hline & 9,91 & 22,76 & 23,08 & 49,14 & 31,09 & 38,78 & 4,52 & 8,72 & - & 0,44 \\
\hline \multirow{3}{*}{$\Sigma$} & 13,56 & 34,93 & 27,11 & 16,90 & 97,88 & 4,62 & 10,91 & 79,59 & 6,44 & 1,97 \\
\hline & 5,53 & 13,94 & 3,06 & 53,28 & 21,95 & 55,57 & 2,09 & 10,21 & 1,72 & 6,49 \\
\hline & 1,36 & 12,43 & 1,27 & 5,21 & 16,99 & 15,02 & 2,30 & 12,37 & 1,22 & 6,55 \\
\hline
\end{tabular}

Obs: A primeira linha de cada origem contém as diferenças relativas resultantes dos resultados estimados pelo QUEENSOD, na segunda linha estão as diferenças dos resultados estimados pelo TransCAD e na terceira linha estão as obtidas considerando os resultados estimados pelo MEMS. Célula em destaque indica que o valor estimado é maior que o "real". 
Tabela B.2: Diferença relativa entre viagem "real" e estimada - Teste 2

\begin{tabular}{|c|c|c|c|c|c|c|c|c|c|c|}
\hline O\D & 1 & 2 & 3 & 4 & 5 & 6 & 7 & 8 & 9 & $\Sigma$ \\
\hline \multirow{3}{*}{1} & - & 146,31 & 100,00 & 209,70 & 97,61 & 40,57 & 100,00 & 23,27 & 73,05 & 6,43 \\
\hline & - & 36,21 & 6,03 & 23,64 & 43,78 & 16,57 & 105,80 & 10,06 & 37,47 & 4,31 \\
\hline & - & 1,23 & 5,82 & 15,45 & 10,53 & 24,57 & 25,72 & 43,40 & 3,50 & 2,27 \\
\hline \multirow{3}{*}{2} & 19,12 & - & 74,87 & 100,00 & 100,00 & 58,67 & 100,00 & 71,23 & 78,51 & 76,76 \\
\hline & 131,37 & - & 9,07 & 11,81 & 12,45 & 45,78 & 1,92 & 30,59 & 12,19 & 0,46 \\
\hline & 10,29 & - & 2,85 & 19,76 & 3,00 & 32,44 & 52,16 & 41,10 & 4,13 & 0,31 \\
\hline \multirow{3}{*}{3} & 100,00 & 7,96 & - & 100,00 & 62,05 & 64,17 & 100,00 & 8,94 & 65,28 & 58,89 \\
\hline & 30,11 & 47,21 & - & 43,87 & 19,57 & 43,32 & 4,90 & 29,67 & 124,31 & 17,78 \\
\hline & 11,93 & 41,91 & - & 53,85 & 42,96 & 10,70 & 22,04 & 47,15 & 33,68 & 4,98 \\
\hline \multirow{3}{*}{4} & 42,51 & 100,00 & 100,00 & - & 100,00 & 24,68 & 100,00 & 100,00 & 100,00 & 83,30 \\
\hline & 40,72 & 35,47 & 0,00 & - & 2,87 & 93,94 & 56,86 & 7,51 & 28,10 & 6,21 \\
\hline & 4,49 & 18,72 & 29,45 & - & 23,41 & 2,16 & 5,39 & 4,69 & 18,57 & 0,18 \\
\hline \multirow{3}{*}{5} & 74,78 & 96,86 & 100,00 & 14,13 & - & 42,71 & 75,32 & 219,62 & 100,00 & 38,95 \\
\hline & 23,15 & 9,66 & 0,81 & 16,30 & - & 16,08 & 33,69 & 18,85 & 5,18 & 16,47 \\
\hline & 52,52 & 21,98 & 21,14 & 7,61 & - & 30,15 & 13,52 & 48,85 & 7,93 & 13,27 \\
\hline \multirow{3}{*}{6} & 34,73 & 37,66 & 100,00 & 100,00 & 100,00 & - & 13,33 & 100,00 & 69,97 & 68,68 \\
\hline & 13,85 & 20,13 & 150,88 & 95,96 & 119,61 & - & 33,94 & 27,81 & 88,10 & 17,99 \\
\hline & 17,14 & 1,52 & 48,67 & 41,51 & 21,54 & - & 39,39 & 16,88 & 0,85 & 2,74 \\
\hline \multirow{3}{*}{7} & 100,00 & 67,99 & 100,00 & 162,21 & 92,51 & 100,00 & - & 100,00 & 100,00 & 77,60 \\
\hline & 83,54 & 3,50 & 43,58 & 31,40 & 32,85 & 32,59 & - & 17,03 & 6,91 & 6,31 \\
\hline & 3,19 & 32,24 & 16,20 & 44,77 & 11,24 & 7,98 & - & 23,53 & 46,77 & 2,52 \\
\hline \multirow{3}{*}{8} & 37,32 & 100,00 & 67,27 & 75,77 & 100,00 & 67,55 & 100,00 & - & 100,00 & 83,46 \\
\hline & 11,97 & 8,87 & 10,55 & 50,70 & 23,58 & 37,74 & 81,30 & - & 65,64 & 4,05 \\
\hline & 48,94 & 13,12 & 2,91 & 36,49 & 10,11 & 16,23 & 53,87 & - & 0,92 & 3,64 \\
\hline \multirow{3}{*}{9} & 92,12 & 243,66 & 100,00 & 61,43 & 84,24 & 85,12 & 17,74 & 27,52 & - & 37,36 \\
\hline & 38,06 & 16,04 & 35,71 & 64,29 & 35,29 & 76,52 & 96,77 & 62,08 & - & 3,85 \\
\hline & 32,21 & 4,85 & 4,67 & 14,57 & 12,82 & 6,29 & 37,74 & 7,05 & - & 4,75 \\
\hline \multirow{3}{*}{$\Sigma$} & 61,04 & 4,72 & 92,36 & 26,86 & 91,47 & 60,18 & 79,34 & 14,72 & 85,33 & 58,60 \\
\hline & 13,14 & 8,13 & 13,27 & 44,55 & 5,24 & 5,61 & 36,77 & 1,86 & 27,09 & 4,82 \\
\hline & 0,45 & 4,82 & 8,57 & 12,24 & 13,46 & 2,04 & 7,21 & 2,80 & 5,65 & 0,03 \\
\hline
\end{tabular}

Obs: A primeira linha de cada origem contém as diferenças relativas dos resultados estimados pelo QUEENSOD, na segunda linha estão as diferenças relativas dos resultados estimados pelo TransCAD e na terceira linha estão as diferenças relativas dos resultados estimados pelo MEMS.

Célula em destaque indica que o valor estimado é maior que o "real". 
Tabela B.3: Diferença relativa entre viagem "real" e estimada - Teste 3

\begin{tabular}{|c|c|c|c|c|c|c|c|c|c|c|}
\hline$O \backslash D$ & 1 & 2 & 3 & 4 & 5 & 6 & 7 & 8 & 9 & $\Sigma$ \\
\hline \multirow{3}{*}{1} & - & 99,51 & 88,58 & 122,73 & 94,98 & 90,29 & 159,06 & 86,79 & 21,56 & 15,12 \\
\hline & - & 47,78 & 73,06 & 20,91 & 18,42 & 48,57 & 22,83 & 15,09 & 9,16 & 7,73 \\
\hline & - & 0,99 & 1,51 & 31,52 & 13,88 & 0,57 & 30,07 & 5,66 & 6,47 & 1,39 \\
\hline \multirow{3}{*}{2} & 99,51 & - & 96,89 & 99,04 & 97,42 & 96,89 & 78,13 & 54,79 & 97,73 & 91,05 \\
\hline & 37,25 & - & 47,15 & 48,43 & 33,48 & 4,44 & 16,59 & 10,05 & 15,70 & 16,27 \\
\hline & 1,96 & - & 14,77 & 3,86 & 31,33 & 35,56 & 21,88 & 8,68 & 16,53 & 3,18 \\
\hline \multirow{3}{*}{3} & 206,25 & 97,08 & - & 74,64 & 81,15 & 65,24 & 18,37 & 95,93 & 152,08 & 1,88 \\
\hline & 72,73 & 57,29 & - & 4,56 & 5,73 & 52,41 & 36,73 & 30,49 & 41,32 & 12,23 \\
\hline & 4,55 & 13,53 & - & 26,50 & 26,25 & 32,09 & 29,80 & 34,55 & 18,06 & 1,00 \\
\hline \multirow{3}{*}{4} & 90,72 & 61,08 & 74,76 & - & 90,35 & 78,35 & 4,41 & 99,53 & 69,05 & 37,52 \\
\hline & 75,75 & 15,76 & 7,12 & - & 34,09 & 2,60 & 114,22 & 23,47 & 60,48 & 20,31 \\
\hline & 14,97 & 22,17 & 6,15 & - & 33,88 & 33,33 & 36,27 & 34,27 & 7,14 & 3,06 \\
\hline \multirow{3}{*}{5} & 96,14 & 97,10 & 37,80 & 29,89 & - & 94,47 & 97,21 & 83,46 & 96,65 & 84,18 \\
\hline & 29,38 & 13,77 & 21,14 & 23,91 & - & 22,11 & 39,27 & 20,77 & 1,52 & 14,22 \\
\hline & 35,01 & 8,45 & 30,89 & 7,07 & - & 16,08 & 39,27 & 36,15 & 8,84 & 18,28 \\
\hline \multirow{3}{*}{6} & 109,89 & 95,24 & 90,27 & 19,41 & 93,25 & - & 74,55 & 96,56 & 132,01 & 3,08 \\
\hline & 34,51 & 45,24 & 149,12 & 21,29 & 19,61 & - & 101,82 & 28,44 & 59,21 & 8,97 \\
\hline & 7,47 & 5,19 & 21,68 & 36,12 & 18,65 & - & 42,42 & 18,75 & 9,35 & 1,80 \\
\hline \multirow{3}{*}{7} & 64,37 & 100,00 & 0,00 & 12,79 & 98,85 & 106,21 & - & 98,76 & 13,82 & 30,46 \\
\hline & 14,74 & 7,71 & 112,85 & 114,53 & 38,90 & 27,27 & - & 25,39 & 12,44 & 11,02 \\
\hline & 9,58 & 9,58 & 27,37 & 41,86 & 11,82 & 1,33 & - & 8,98 & 26,27 & 2,88 \\
\hline \multirow{3}{*}{8} & 36,62 & 30,85 & 38,55 & 66,57 & 79,16 & 63,02 & 97,26 & - & 96,01 & 66,82 \\
\hline & 31,34 & 4,61 & 33,45 & 32,59 & 32,00 & 29,06 & 30,67 & - & 74,85 & 14,74 \\
\hline & 6,69 & 23,40 & 18,91 & 16,71 & 25,89 & 40,00 & 6,48 & - & 27,61 & 2,47 \\
\hline \multirow{3}{*}{9} & 82,88 & 95,52 & 33,79 & 55,14 & 82,98 & 98,32 & 59,68 & 67,45 & - & 60,40 \\
\hline & 29,73 & 31,34 & 20,88 & 2,86 & 14,71 & 40,46 & 85,81 & 94,30 & - & 13,32 \\
\hline & 1,58 & 25,00 & 5,22 & 28,86 & 21,22 & 33,12 & 26,77 & 6,04 & - & 5,69 \\
\hline \multirow{3}{*}{$\Sigma$} & 26,54 & 88,27 & 10,53 & 8,10 & 88,69 & 15,66 & 30,45 & 86,02 & 13,03 & 40,12 \\
\hline & 13,93 & 2,54 & 3,10 & 9,91 & 6,79 & 12,22 & 2,05 & 5,74 & 18,97 & 2,12 \\
\hline & 3,07 & 2,89 & 3,06 & 3,63 & 14,75 & 2,17 & 3,42 & 2,26 & 6,80 & 3,09 \\
\hline
\end{tabular}

Obs: A primeira linha de cada origem contém as diferenças relativas dos resultados estimados pelo QUEENSOD, na segunda linha estão as diferenças relativas dos resultados estimados pelo TransCAD e na terceira linha estão as diferenças relativas dos resultados estimados pelo MEMS.

Célula em destaque indica que o valor estimado é maior que o "real". 
Tabela B.4: Diferença relativa entre viagem "real" e estimada - Teste 4

\begin{tabular}{|c|c|c|c|c|c|c|c|c|c|c|}
\hline O\D & 1 & 2 & 3 & 4 & 5 & 6 & 7 & 8 & 9 & $\Sigma$ \\
\hline \multirow{3}{*}{1} & - & 146,31 & 95,69 & 74,85 & 26,08 & 72,00 & 99,28 & 51,57 & 41,78 & 12,16 \\
\hline & - & 23,40 & 26,72 & 31,52 & 29,43 & 91,43 & 49,28 & 3,77 & 33,15 & 4,58 \\
\hline & - & 0,49 & 7,11 & 4,55 & 2,63 & 33,71 & 27,90 & 14,47 & 2,16 & 0,19 \\
\hline \multirow{3}{*}{2} & 87,25 & - & 83,42 & 31,08 & 99,14 & 100,00 & 100,00 & 8,22 & 93,18 & 76,30 \\
\hline & 25,49 & - & 43,78 & 3,61 & 24,46 & 1,78 & 3,85 & 4,57 & 19,01 & 13,36 \\
\hline & 21,57 & - & 9,59 & 3,37 & 1,29 & 28,00 & 2,88 & 3,20 & 7,64 & 6,55 \\
\hline \multirow{3}{*}{3} & 94,89 & 93,63 & - & 98,29 & 71,36 & 86,63 & 22,86 & 24,80 & 22,22 & 60,20 \\
\hline & 52,84 & 14,85 & - & 5,98 & 15,27 & 59,36 & 0,00 & 35,77 & 44,10 & 9,35 \\
\hline & 28,41 & 1,33 & - & 10,83 & 24,82 & 6,42 & 7,35 & 13,82 & 12,15 & 3,98 \\
\hline \multirow{3}{*}{4} & 24,85 & 8,87 & 100,00 & - & 76,39 & 50,22 & 7,35 & 95,31 & 98,10 & 58,97 \\
\hline & 36,83 & 56,65 & 9,06 & - & 83,37 & 80,95 & 65,69 & 14,55 & 9,52 & 25,19 \\
\hline & 11,08 & 15,27 & 28,48 & - & 2,46 & 35,93 & 30,88 & 38,50 & 9,05 & 6,89 \\
\hline \multirow{3}{*}{5} & 42,73 & 94,93 & 100,00 & 66,85 & - & 200,00 & 77,90 & 68,08 & 100,00 & 26,71 \\
\hline & 43,03 & 26,57 & 8,13 & 13,04 & - & 2,51 & 22,32 & 0,77 & 6,10 & 15,12 \\
\hline & 2,08 & 37,20 & 28,86 & 11,41 & - & 21,11 & 2,58 & 38,08 & 7,93 & 9,24 \\
\hline \multirow{3}{*}{6} & 81,98 & 0,22 & 95,13 & 85,18 & 55,95 & - & 183,03 & 48,13 & 98,87 & 48,10 \\
\hline & 23,96 & 18,83 & 60,62 & 67,65 & 87,46 & - & 57,58 & 17,19 & 47,03 & 12,84 \\
\hline & 0,88 & 11,47 & 23,89 & 29,92 & 10,61 & - & 28,48 & 34,69 & 33,99 & 6,72 \\
\hline \multirow{3}{*}{7} & 19,16 & 33,18 & 91,06 & 105,81 & 23,05 & 88,03 & - & 86,69 & 98,39 & 32,80 \\
\hline & 30,71 & 31,31 & 17,88 & 96,51 & 46,11 & 30,38 & - & 19,50 & 15,67 & 4,12 \\
\hline & 38,08 & 17,06 & 23,46 & 34,30 & 27,38 & 25,50 & - & 9,29 & 12,21 & 8,25 \\
\hline \multirow{3}{*}{8} & 77,46 & 54,26 & 98,91 & 57,94 & 100,00 & 100,00 & 100,00 & - & 31,29 & 70,94 \\
\hline & 10,21 & 35,11 & 25,82 & 26,46 & 9,89 & 7,17 & 42,64 & - & 0,31 & 3,82 \\
\hline & 23,59 & 39,01 & 10,91 & 38,72 & 36,63 & 9,43 & 3,49 & - & 0,92 & 10,87 \\
\hline \multirow{3}{*}{9} & 46,17 & 25,00 & 63,19 & 47,14 & 93,70 & 85,53 & 81,29 & 70,81 & - & 20,46 \\
\hline & 22,30 & 0,37 & 35,16 & 7,14 & 19,75 & 19,92 & 15,81 & 73,49 & - & 9,11 \\
\hline & 8,33 & 7,84 & 30,77 & 35,71 & 1,26 & 12,58 & 25,16 & 4,03 & - & 3,11 \\
\hline \multirow{3}{*}{$\Sigma$} & 39,34 & 18,77 & 57,78 & 53,36 & 57,08 & 58,87 & 8,66 & 58,24 & 51,57 & 44,44 \\
\hline & 1,33 & 0,32 & 1,10 & 4,23 & 4,20 & 3,17 & 6,24 & 4,61 & 0,39 & 2,47 \\
\hline & 8,07 & 5,32 & 2,49 & 1,97 & 6,89 & 9,95 & 7,17 & 14,38 & 0,32 & 2,11 \\
\hline
\end{tabular}

Obs: A primeira linha de cada origem contém as diferenças relativas dos resultados estimados pelo QUEENSOD, na segunda linha estão as diferenças relativas dos resultados estimados pelo TransCAD e na terceira linha estão as diferenças relativas dos resultados estimados pelo MEMS.

Célula em destaque indica que o valor estimado é maior que o "real". 
Tabela B.5: Diferença relativa entre viagem "real" e estimada - Teste 5

\begin{tabular}{|c|c|c|c|c|c|c|c|c|c|c|}
\hline$O \backslash D$ & 1 & 2 & 3 & 4 & 5 & 6 & 7 & 8 & 9 & $\Sigma$ \\
\hline \multirow{3}{*}{1} & - & 47,78 & 99,14 & 72,73 & 100,00 & 56,57 & 68,48 & 17,61 & 78,44 & 57,14 \\
\hline & - & 11,08 & 43,75 & 39,09 & 27,75 & 17,71 & 0,36 & 38,99 & 29,38 & 24,32 \\
\hline & - & 3,45 & 4,96 & 20,91 & 1,67 & 13,14 & 20,29 & 15,09 & 15,63 & 0,19 \\
\hline \multirow{3}{*}{2} & 0,00 & - & 8,81 & 98,55 & 56,65 & 94,22 & 75,24 & 6,85 & 81,20 & 54,61 \\
\hline & 26,96 & - & 19,69 & 40,96 & 36,91 & 37,78 & 31,73 & 0,46 & 17,36 & 9,95 \\
\hline & 21,08 & - & 3,89 & 9,16 & 7,73 & 23,11 & 23,80 & 12,33 & 2,27 & 2,75 \\
\hline \multirow{3}{*}{3} & 18,18 & 56,50 & - & 59,83 & 95,23 & 81,82 & 97,14 & 80,89 & 157,64 & 29,88 \\
\hline & 63,64 & 34,75 & - & 47,86 & 24,58 & 13,37 & 29,80 & 57,32 & 4,86 & 14,46 \\
\hline & 0,57 & 3,98 & - & 5,13 & 24,82 & 25,67 & 25,31 & 5,28 & 24,65 & 2,40 \\
\hline \multirow{3}{*}{4} & 86,83 & 86,70 & 68,61 & - & 76,59 & 56,28 & 92,65 & 47,89 & 42,38 & 71,20 \\
\hline & 64,67 & 4,93 & 15,21 & - & 23,61 & 45,89 & 13,24 & 30,99 & 64,76 & 20,22 \\
\hline & 15,57 & 7,88 & 12,62 & - & 25,26 & 9,09 & 13,73 & 17,84 & 23,81 & 2,69 \\
\hline \multirow{3}{*}{5} & 70,03 & 85,51 & 82,11 & 102,72 & - & 18,09 & 90,56 & 31,15 & 75,91 & 54,23 \\
\hline & 39,17 & 15,70 & 30,49 & 25,00 & - & 9,05 & 2,58 & 5,38 & 16,16 & 10,23 \\
\hline & 17,80 & 15,46 & 21,14 & 4,35 & - & 15,08 & 21,89 & 26,54 & 23,78 & 13,80 \\
\hline \multirow{3}{*}{6} & 99,34 & 100,00 & 67,26 & 50,94 & 55,63 & - & 52,73 & 79,38 & 176,49 & 43,03 \\
\hline & 51,21 & 21,43 & 2,21 & 8,09 & 21,22 & - & 59,39 & 38,75 & 51,27 & 2,85 \\
\hline & 1,98 & 13,20 & 11,95 & 18,33 & 9,00 & - & 3,64 & 24,69 & 1,70 & 1,01 \\
\hline \multirow{3}{*}{7} & 74,45 & 16,82 & 69,83 & 91,86 & 98,85 & 66,08 & - & 24,77 & 97,00 & 43,56 \\
\hline & 11,79 & 22,66 & 32,96 & 33,14 & 24,50 & 30,82 & - & 4,33 & 18,43 & 5,44 \\
\hline & 17,20 & 7,24 & 4,47 & 7,56 & 25,36 & 25,06 & - & 15,79 & 12,90 & 1,50 \\
\hline \multirow{3}{*}{8} & 23,94 & 25,18 & 60,73 & 67,97 & 57,89 & 88,30 & 3,49 & - & 9,20 & 33,86 \\
\hline & 16,55 & 27,30 & 35,64 & 20,61 & 17,05 & 17,74 & 62,59 & - & 10,74 & 13,20 \\
\hline & 23,24 & 3,90 & 16,73 & 18,66 & 22,95 & 2,64 & 22,44 & - & 10,43 & 2,66 \\
\hline \multirow{3}{*}{9} & 54,95 & 84,33 & 23,90 & 72,29 & 74,79 & 55,35 & 67,10 & 17,79 & - & 32,11 \\
\hline & 27,93 & 26,49 & 0,55 & 27,14 & 17,44 & 36,48 & 46,45 & 15,77 & - & 21,63 \\
\hline & 3,60 & 24,63 & 2,47 & 24,86 & 18,07 & 1,05 & 0,97 & 2,01 & - & 1,84 \\
\hline \multirow{3}{*}{$\Sigma$} & 38,58 & 41,34 & 48,92 & 59,79 & 77,95 & 47,42 & 51,63 & 30,42 & 12,06 & 46,05 \\
\hline & 2,54 & 5,60 & 5,51 & 0,59 & 0,98 & 3,94 & 5,32 & 15,55 & 5,23 & 2,30 \\
\hline & 0,15 & 3,13 & 2,49 & 1,62 & 10,45 & 0,41 & 5,76 & 3,73 & 0,89 & 2,23 \\
\hline
\end{tabular}

Obs: A primeira linha de cada origem contém as diferenças relativas dos resultados estimados pelo QUEENSOD, na segunda linha estão as diferenças relativas dos resultados estimados pelo TransCAD e na terceira linha estão as diferenças relativas dos resultados estimados pelo MEMS.

Célula em destaque indica que o valor estimado é maior que o "real". 
Tabela B.6: Diferença relativa entre viagem "real" e estimada - Teste 6

\begin{tabular}{|c|c|c|c|c|c|c|c|c|c|c|}
\hline O\D & 1 & 2 & 3 & 4 & 5 & 6 & 7 & 8 & 9 & $\Sigma$ \\
\hline \multirow{3}{*}{1} & - & 75,37 & 75,86 & 98,79 & 78,47 & 100,00 & 72,46 & 3,77 & 49,60 & 71,76 \\
\hline & - & 6,65 & 20,47 & 27,58 & 13,64 & 0,00 & 2,17 & 27,04 & 32,08 & 0,08 \\
\hline & - & 0,99 & 1,08 & 3,03 & 3,35 & 26,86 & 19,20 & 16,35 & 7,28 & 2,35 \\
\hline \multirow{3}{*}{2} & 60,78 & - & 67,88 & 71,08 & 88,84 & 59,56 & 96,88 & 7,31 & 18,60 & 59,30 \\
\hline & 34,80 & - & 16,06 & 30,60 & 30,04 & 19,56 & 42,07 & 0,46 & 23,97 & 16,89 \\
\hline & 5,88 & - & 18,91 & 11,08 & 21,46 & 10,67 & 2,40 & 23,29 & 23,35 & 0,62 \\
\hline \multirow{3}{*}{3} & 48,30 & 61,80 & - & 53,28 & 32,94 & 7,49 & 55,10 & 60,57 & 83,68 & 51,64 \\
\hline & 9,66 & 35,01 & - & 7,12 & 3,82 & 13,90 & 32,65 & 19,51 & 36,81 & 8,13 \\
\hline & 1,14 & 5,04 & - & 8,26 & 3,34 & 2,14 & 0,00 & 4,47 & 9,03 & 1,53 \\
\hline \multirow{3}{*}{4} & 2,40 & 78,33 & 60,52 & - & 79,06 & 24,68 & 74,02 & 92,96 & 63,81 & 57,60 \\
\hline & 38,32 & 16,75 & 16,50 & - & 48,46 & 3,03 & 40,69 & 30,05 & 27,14 & 4,20 \\
\hline & 11,68 & 10,34 & 20,06 & - & 2,26 & 10,39 & 25,00 & 24,41 & 17,14 & 2,19 \\
\hline \multirow{3}{*}{5} & 70,92 & 81,40 & 75,61 & 46,74 & - & 13,07 & 71,03 & 62,69 & 44,51 & 62,24 \\
\hline & 17,21 & 22,22 & 42,28 & 20,65 & - & 19,60 & 14,59 & 10,38 & 14,94 & 3,16 \\
\hline & 21,66 & 25,12 & 23,58 & 4,89 & - & 10,05 & 0,43 & 26,15 & 20,12 & 10,15 \\
\hline \multirow{3}{*}{6} & 75,82 & 97,19 & 77,88 & 80,05 & 29,26 & - & 9,70 & 81,25 & 71,67 & 69,66 \\
\hline & 5,71 & 48,27 & 15,49 & 34,23 & 14,47 & - & 52,73 & 46,88 & 8,50 & 19,56 \\
\hline & 1,76 & 2,60 & 1,77 & 26,15 & 2,25 & - & 24,85 & 13,13 & 22,38 & 1,35 \\
\hline \multirow{3}{*}{7} & 90,66 & 74,30 & 9,50 & 10,47 & 68,30 & 65,85 & - & 52,63 & 69,59 & 34,88 \\
\hline & 49,39 & 40,65 & 8,38 & 8,14 & 26,22 & 31,71 & - & 18,58 & 8,99 & 0,91 \\
\hline & 11,06 & 15,89 & 15,08 & 13,37 & 25,07 & 5,54 & - & 20,12 & 1,38 & 4,16 \\
\hline \multirow{3}{*}{8} & 42,96 & 18,44 & 42,91 & 69,92 & 74,11 & 87,55 & 67,33 & - & 11,96 & 45,03 \\
\hline & 37,32 & 28,72 & 11,64 & 10,86 & 26,53 & 41,89 & 2,24 & - & 12,27 & 19,72 \\
\hline & 17,25 & 7,45 & 23,64 & 14,76 & 24,00 & 0,75 & 19,45 & - & 7,36 & 2,62 \\
\hline \multirow{3}{*}{9} & 64,86 & 43,66 & 21,98 & 71,14 & 72,48 & 73,38 & 22,26 & 66,11 & - & 51,39 \\
\hline & 15,32 & 0,75 & 33,24 & 8,57 & 17,86 & 19,71 & 29,03 & 17,45 & - & 9,91 \\
\hline & 5,18 & 2,24 & 13,46 & 13,43 & 9,45 & 6,92 & 15,16 & 0,67 & - & 0,10 \\
\hline \multirow{3}{*}{$\Sigma$} & 31,31 & 69,44 & 38,71 & 67,54 & 65,76 & 58,14 & 62,14 & 56,23 & 49,71 & 55,73 \\
\hline & 1,40 & 24,89 & 1,43 & 8,10 & 4,17 & 14,66 & 16,67 & 9,08 & 2,58 & 7,66 \\
\hline & 3,37 & 2,11 & 0,08 & 0,20 & 7,90 & 0,54 & 4,23 & 4,02 & 3,11 & 1,21 \\
\hline
\end{tabular}

Obs: A primeira linha de cada origem contém as diferenças relativas dos resultados estimados pelo QUEENSOD, na segunda linha estão as diferenças relativas dos resultados estimados pelo TransCAD e na terceira linha estão as diferenças relativas dos resultados estimados pelo MEMS.

Célula em destaque indica que o valor estimado é maior que o "real". 
Tabela B.7: Diferença relativa entre viagem "real" e estimada - Teste 7

\begin{tabular}{|c|c|c|c|c|c|c|c|c|c|c|}
\hline$O \backslash D$ & 1 & 2 & 3 & 4 & 5 & 6 & 7 & 8 & 9 & $\Sigma$ \\
\hline \multirow{4}{*}{1} & - & 43,35 & 73,49 & 70,30 & 72,49 & 7,43 & 7,61 & 1,26 & 69,54 & 50,79 \\
\hline & - & 10,84 & 22,20 & 32,42 & 19,86 & 11,43 & 24,28 & 12,58 & 16,71 & 17,93 \\
\hline & - & 8,37 & 1,29 & 6,97 & 10,05 & 10,86 & 10,14 & 0,63 & 8,09 & 0,04 \\
\hline & - & 5,41 & 4,52 & 6,96 & 2,87 & 0,57 & 2,53 & 6,91 & 9,16 & 2,30 \\
\hline \multirow{4}{*}{2} & 5,88 & - & 50,00 & 20,96 & 49,79 & 65,33 & 49,04 & 14,61 & 61,36 & 42,18 \\
\hline & 14,22 & - & 8,55 & 18,07 & 14,59 & 14,67 & 29,81 & 24,66 & 23,35 & 10,11 \\
\hline & 6,86 & - & 11,14 & 6,02 & 3,00 & 10,22 & 10,10 & 9,13 & 6,20 & 5,81 \\
\hline & 3,43 & - & 4,40 & 3,13 & 6,86 & 9,33 & 2,16 & 9,58 & 5,99 & 0,42 \\
\hline \multirow{4}{*}{3} & 21,02 & 70,82 & - & 70,66 & 66,35 & 68,45 & 44,08 & 10,57 & 9,03 & 48,80 \\
\hline & 1,70 & 9,55 & - & 5,13 & 22,20 & 21,93 & 15,10 & 32,52 & 4,51 & 1,62 \\
\hline & 10,80 & 10,08 & - & 9,97 & 10,02 & 7,49 & 4,49 & 5,28 & 6,94 & 1,27 \\
\hline & 5,11 & 3,18 & - & 4,55 & 4,05 & 8,55 & 5,71 & 0 & 1,38 & 1,22 \\
\hline \multirow{4}{*}{4} & 76,95 & 47,29 & 58,90 & - & 76,80 & 52,81 & 8,33 & 11,27 & 48,57 & 53,58 \\
\hline & 9,88 & 0,49 & 18,45 & - & 0,62 & 16,02 & 31,86 & 25,82 & 24,76 & 0,87 \\
\hline & 0,90 & 9,85 & 4,85 & - & 11,29 & 4,76 & 9,80 & 9,39 & 10,00 & 2,46 \\
\hline & 8,98 & 9,35 & 6,47 & - & 3,49 & 8,65 & 6,37 & 3,75 & 2,85 & 2,14 \\
\hline \multirow{4}{*}{5} & 63,50 & 59,66 & 60,16 & 40,22 & - & 31,16 & 71,89 & 61,92 & 51,22 & 57,89 \\
\hline & 18,69 & 15,70 & 10,57 & 6,52 & - & 18,59 & 35,41 & 28,85 & 22,56 & 15,16 \\
\hline & 4,75 & 9,18 & 1,22 & 2,17 & - & 11,06 & 6,87 & 7,31 & 5,49 & 6,00 \\
\hline & 7,71 & 2,65 & 9,34 & 8,69 & - & 3,51 & 0,85 & 4,23 & 1,52 & 1,60 \\
\hline \multirow{4}{*}{6} & 72,97 & 58,66 & 31,86 & 72,51 & 78,14 & - & 9,70 & 72,19 & 43,34 & 59,59 \\
\hline & 14,07 & 7,58 & 9,73 & 11,59 & 18,33 & - & 7,88 & 35,31 & 16,15 & 1,35 \\
\hline & 7,91 & 10,61 & 7,52 & 10,24 & 9,65 & - & 6,06 & 10,31 & 9,63 & 4,54 \\
\hline & 0,43 & 1,29 & 9,29 & 3,23 & 2,57 & - & 6,66 & 7,81 & 5,94 & 1,23 \\
\hline \multirow{4}{*}{7} & 4,67 & 54,21 & 3,91 & 55,81 & 74,35 & 65,63 & - & 50,77 & 72,81 & 50,60 \\
\hline & 39,07 & 21,73 & 0,56 & 8,14 & 1,73 & 17,29 & - & 24,77 & 7,83 & 7,62 \\
\hline & 7,62 & 8,64 & 10,61 & 11,05 & 10,95 & 7,76 & - & 7,12 & 7,83 & 3,61 \\
\hline & 3,19 & 3,73 & 8,93 & 2,32 & 6,91 & 3,10 & - & 1,85 & 2,07 & 0,25 \\
\hline \multirow{4}{*}{8} & 65,49 & 52,48 & 5,45 & 44,57 & 58,32 & 60,75 & 66,33 & - & 43,56 & 50,77 \\
\hline & 16,55 & 4,26 & 1,09 & 35,10 & 25,26 & 2,26 & 26,93 & - & 19,63 & 7,87 \\
\hline & 5,99 & 2,84 & 9,82 & 8,91 & 7,16 & 4,15 & 2,74 & - & 5,52 & 0,56 \\
\hline & 6,33 & 7,44 & 5,45 & 9,19 & 3,15 & 2,26 & 6,48 & - & 4,90 & 1,79 \\
\hline \multirow{4}{*}{9} & 70,95 & 45,52 & 61,54 & 24,00 & 68,70 & 75,26 & 76,45 & 74,16 & - & 63,27 \\
\hline & 9,46 & 19,78 & 6,32 & 9,14 & 17,65 & 18,45 & 18,06 & 6,38 & - & 7,40 \\
\hline & 8,56 & 4,10 & 7,42 & 4,86 & 5,25 & 9,64 & 5,16 & 6,38 & - & 5,52 \\
\hline & 0,22 & 1,11 & 3,02 & 2,57 & 7,77 & 7,12 & 4,83 & 3,35 & - & 2,14 \\
\hline \multirow{4}{*}{$\Sigma$} & 51,99 & 54,89 & 48,26 & 49,37 & 68,70 & 57,06 & 48,45 & 42,20 & 52,36 & 53,25 \\
\hline & 7,50 & 5,67 & 7,02 & 1,86 & 3,92 & 8,33 & 6,08 & 5,89 & 0,39 & 4,01 \\
\hline & 2,76 & 1,30 & 4,45 & 0,87 & 6,29 & 5,97 & 2,05 & 1,28 & 3,08 & 2,76 \\
\hline & 1,09 & 0,73 & 1,59 & 1,61 & 2,36 & 2,57 & 2,69 & 0,68 & 2,29 & 0,57 \\
\hline
\end{tabular}

Obs: A primeira linha de cada origem contém as diferenças relativas dos resultados estimados pelo QUEENSOD, na segunda linha estão as diferenças relativas dos resultados estimados pelo TransCAD, na terceira linha estão as diferenças relativas dos resultados estimados pelo MEMS considerando 250 iterações e na quarta linha as diferenças relativas dos valores estimados pelo MEMS após 500 iterações.

Célula em destaque indica que o valor estimado é maior que o "real". 
Tabela B.8: Diferença relativa entre viagem "real" e estimada - Teste 8

\begin{tabular}{|c|c|c|c|c|c|c|c|c|c|c|}
\hline$O \backslash D$ & 1 & 2 & 3 & 4 & 5 & 6 & 7 & 8 & 9 & $\Sigma$ \\
\hline \multirow{3}{*}{1} & - & 100,00 & 89,66 & 98,48 & 100,00 & 100,00 & 471,38 & 100,00 & 74,93 & 19,70 \\
\hline & - & 9,36 & 15,52 & 113,94 & 42,82 & 66,86 & 122,46 & 11,95 & 39,35 & 18,89 \\
\hline & - & 8,62 & 15,73 & 47,27 & 31,34 & 94,29 & 1,81 & 85,53 & 37,20 & 1,89 \\
\hline \multirow{3}{*}{2} & 100,00 & - & 100,00 & 100,00 & 100,00 & 100,00 & 100,00 & 100,00 & 100,00 & 100,00 \\
\hline & 91,18 & - & 10,62 & 34,46 & 39,48 & 7,11 & 55,53 & 36,53 & 63,43 & 26,80 \\
\hline & 19,61 & - & 50,78 & 43,86 & 30,04 & 3,11 & 25,48 & 54,34 & 42,98 & 32,84 \\
\hline \multirow{3}{*}{3} & 257,95 & 100,00 & - & 50,43 & 100,00 & 100,00 & 217,96 & 100,00 & 432,64 & 36,13 \\
\hline & 140,34 & 21,22 & - & 15,10 & 46,54 & 191,98 & 9,39 & 24,39 & 116,32 & 30,14 \\
\hline & 27,27 & 67,64 & - & 15,38 & 43,91 & 1,60 & 97,14 & 2,44 & 31,94 & 4,06 \\
\hline \multirow{3}{*}{4} & 100,00 & 100,00 & 99,68 & - & 58,93 & 519,05 & 100,00 & 100,00 & 100,00 & 25,60 \\
\hline & 107,49 & 45,32 & 3,24 & - & 4,72 & 98,27 & 159,80 & 18,78 & 42,38 & 52,30 \\
\hline & 43,11 & 24,63 & 50,16 & - & 60,99 & 54,98 & 34,31 & 17,84 & 76,67 & 2,46 \\
\hline \multirow{3}{*}{5} & 100,00 & 100,00 & 99,19 & 100,00 & - & 100,00 & 98,71 & 100,00 & 51,83 & 93,22 \\
\hline & 34,42 & 69,57 & 13,41 & 138,59 & - & 105,53 & 55,15 & 59,23 & 35,06 & 20,46 \\
\hline & 54,30 & 52,66 & 0,81 & 3,26 & - & 41,71 & 47,00 & 92,69 & 46,95 & 24,98 \\
\hline \multirow{3}{*}{6} & 40,88 & 100,00 & 96,46 & 247,17 & 100,00 & - & 100,00 & 100,00 & 97,17 & 40,86 \\
\hline & 33,19 & 34,63 & 238,94 & 26,42 & 60,45 & - & 80,00 & 12,50 & 100,28 & 36,09 \\
\hline & 20,00 & 46,97 & 25,22 & 2,43 & 38,91 & - & 130,91 & 35,31 & 46,18 & 20,13 \\
\hline \multirow{3}{*}{7} & 277,15 & 100,00 & 275,98 & 93,60 & 100,00 & 68,51 & - & 100,00 & 72,12 & 13,39 \\
\hline & 89,68 & 52,80 & 26,82 & 397,09 & 30,55 & 34,59 & - & 11,46 & 9,91 & 21,96 \\
\hline & 6,63 & 20,33 & 132,96 & 10,47 & 19,88 & 20,40 & - & 2,48 & 73,50 & 12,00 \\
\hline \multirow{3}{*}{8} & 100,00 & 100,00 & 100,00 & 100,00 & 100,00 & 100,00 & 100,00 & - & 94,17 & 99,29 \\
\hline & 24,65 & 40,78 & 27,64 & 11,98 & 67,37 & 6,42 & 26,43 & - & 30,06 & 15,11 \\
\hline & 21,13 & 62,77 & 46,55 & 5,85 & 60,00 & 2,26 & 52,62 & - & 52,76 & 23,58 \\
\hline \multirow{3}{*}{9} & 53,60 & 100,00 & 308,79 & 63,43 & 98,32 & 100,00 & 139,68 & 100,00 & - & 2,04 \\
\hline & 47,75 & 23,13 & 111,26 & 12,86 & 49,37 & 61,84 & 43,23 & 29,53 & - & 12,32 \\
\hline & 11,49 & 31,72 & 39,84 & 74,57 & 37,39 & 76,73 & 22,58 & 32,89 & - & 10,71 \\
\hline \multirow{3}{*}{$\Sigma$} & 17,95 & 100,00 & 24,58 & 36,57 & 93,43 & 28,87 & 25,01 & 100,00 & 11,56 & 31,87 \\
\hline & 23,02 & 22,57 & 31,07 & 44,55 & 28,93 & 49,10 & 21,14 & 7,36 & 9,48 & 11,51 \\
\hline & 12,87 & 30,04 & 2,16 & 1,26 & 42,17 & 11,13 & 3,10 & 1,08 & 22,33 & 14,55 \\
\hline
\end{tabular}

Obs: A primeira linha de cada origem contém as diferenças relativas dos resultados estimados pelo QUEENSOD, na segunda linha estão as diferenças relativas dos resultados estimados pelo TransCAD e na terceira linha estão as diferenças relativas dos resultados estimados pelo MEMS.

Célula em destaque indica que o valor estimado é maior que o "real". 
Tabela B.9: Diferença relativa entre viagem "real" e estimada - Teste 9

\begin{tabular}{|c|c|c|c|c|c|c|c|c|c|c|}
\hline O\D & 1 & 2 & 3 & 4 & 5 & 6 & 7 & 8 & 9 & $\Sigma$ \\
\hline \multirow{2}{*}{1} & - & 100,0 & 42,89 & 100,0 & 100,0 & 654,29 & 28,26 & 83,65 & 100,00 & 24,39 \\
\hline & - & 33,99 & 21,98 & 61,52 & 0,24 & 55,43 & 43,48 & 13,84 & 29,11 & 3,66 \\
\hline \multirow{2}{*}{2} & 100,0 & - & 65,03 & 100,0 & 100,0 & 35,56 & 99,04 & 31,05 & 130,79 & 28,43 \\
\hline & 12,75 & - & 45,34 & 44,10 & 43,78 & 56,00 & 29,33 & 65,75 & 56,61 & 18,67 \\
\hline \multirow{2}{*}{3} & 100,0 & 78,78 & - & 100,0 & 26,01 & 84,49 & 25,71 & 408,54 & 62,85 & 8,91 \\
\hline & 106,82 & 23,08 & - & 8,83 & 3,82 & 94,65 & 16,33 & 25,20 & 36,11 & 15,07 \\
\hline \multirow{2}{*}{4} & 100,0 & 74,38 & 100,00 & - & 200,8 & 9,96 & 59,31 & 80,75 & 100,00 & 13,51 \\
\hline & 47,01 & 83,25 & 0,97 & - & 20,94 & 126,84 & 101,4 & 39,44 & 54,29 & 41,94 \\
\hline \multirow{2}{*}{5} & 100,0 & 100,0 & 100,00 & 100,0 & - & 100,00 & 100,0 & 100,0 & 39,63 & 91,87 \\
\hline & 2,97 & 70,29 & 43,90 & 46,74 & - & 37,69 & 1,07 & 61,92 & 30,49 & 3,20 \\
\hline \multirow{2}{*}{6} & 85,27 & 100,0 & 465,49 & 100,0 & 78,14 & - & 86,67 & 8,13 & 320,11 & 20,62 \\
\hline & 30,99 & 43,72 & 142,04 & 14,56 & 14,47 & - & 83,03 & 2,50 & 44,19 & 29,37 \\
\hline \multirow{2}{*}{7} & 17,20 & 97,20 & 40,22 & 100,0 & 100,0 & 100,00 & - & 262,23 & 55,76 & 33,67 \\
\hline & 32,19 & 48,83 & 75,42 & 234,88 & 52,16 & 16,85 & - & 36,22 & 7,37 & 15,21 \\
\hline \multirow{2}{*}{8} & 100,0 & 79,43 & 67,64 & 100,0 & 100,0 & 100,00 & 100,0 & - & 96,93 & 77,32 \\
\hline & 7,04 & 71,63 & 38,55 & 74,37 & 68,63 & 42,64 & 27,18 & - & 24,54 & 15,86 \\
\hline \multirow{2}{*}{9} & 21,62 & 433,2 & 86,81 & 100,0 & 60,92 & 134,59 & 100,0 & 100,0 & - & 4,79 \\
\hline & 38,96 & 17,16 & 25,82 & 7,43 & 12,18 & 16,14 & 15,48 & 16,11 & - & 1,34 \\
\hline \multirow{2}{*}{$\Sigma$} & 71,53 & 26,80 & 21,52 & 100,0 & 35,91 & 36,97 & 68,95 & 50,59 & 11,20 & 27,63 \\
\hline & 8,25 & 17,96 & 11,11 & 45,02 & 10,90 & 39,91 & 12,73 & 20,51 & 0,72 & 6,63 \\
\hline
\end{tabular}

Obs: A primeira linha de cada origem contém as diferenças relativas dos resultados estimados pelo QUEENSOD e na segunda linha estão as diferenças relativas dos resultados estimados pelo TransCAD.

Célula em destaque indica que o valor estimado é maior que o "real".

Tabela B.10: Diferença relativa entre viagem "real" e estimada - Teste 1 usando $S_{70}$

\begin{tabular}{|c|c|c|c|c|c|c|c|c|c|c|}
\hline O\D & 1 & 2 & 3 & 4 & 5 & 6 & 7 & 8 & 9 & $\Sigma$ \\
\hline \multirow{2}{*}{1} & - & 100,00 & 41,59 & 116,06 & 94,02 & 244,00 & 167,03 & 100,00 & 30,19 & 45,36 \\
\hline & - & 13,55 & 6,03 & 15,76 & 5,02 & 6,29 & 2,90 & 12,58 & 7,28 & 4,31 \\
\hline \multirow{2}{*}{2} & 100,00 & - & 100,00 & 119,28 & 100,00 & 252,44 & 100,00 & 100,00 & 25,41 & 10,53 \\
\hline & 20,59 & - & 22,80 & 18,31 & 3,00 & 41,78 & 14,66 & 5,94 & 26,86 & 9,76 \\
\hline \multirow{2}{*}{3} & 369,32 & 100,00 & - & 88,32 & 100,00 & 220,32 & 98,78 & 100,00 & 166,67 & 24,81 \\
\hline & 0,57 & 25,20 & - & 1,42 & 8,83 & 25,13 & 5,31 & 18,70 & 11,81 & 3,80 \\
\hline \multirow{2}{*}{4} & 99,70 & 100,00 & 161,49 & - & 100,00 & 45,45 & 229,41 & 91,55 & 146,19 & 25,19 \\
\hline & 10,18 & 4,43 & 1,29 & - & 5,34 & 3,46 & 10,29 & 25,82 & 5,24 & 0,41 \\
\hline \multirow{2}{*}{5} & 100,00 & 32,61 & 100,00 & 18,48 & - & 100,00 & 65,67 & 100,00 & 100,00 & 64,71 \\
\hline & 4,15 & 6,76 & 8,13 & 0,54 & - & 1,01 & 6,44 & 26,15 & 0,91 & 1,11 \\
\hline \multirow{2}{*}{6} & 8,13 & 100,00 & 100,00 & 2,43 & 100,00 & - & 363,03 & 100,00 & 120,11 & 12,84 \\
\hline & 3,52 & 12,12 & 11,50 & 0,81 & 2,25 & - & 3,64 & 12,81 & 3,12 & 2,70 \\
\hline \multirow{2}{*}{7} & 49,39 & 98,3 & 77,65 & 97,67 & 98,56 & 56,98 & - & 6,19 & 73,73 & 9,96 \\
\hline & 2,21 & 6,07 & 2,79 & 13,37 & 1,15 & 1,55 & - & 1,24 & 11,29 & 4,01 \\
\hline \multirow{2}{*}{8} & 183,45 & 6,38 & 100,00 & 71,59 & 100,00 & 123,02 & 100,00 & - & 62,27 & 27,97 \\
\hline & 14,79 & 3,90 & 25,82 & 18,11 & 7,16 & 35,47 & 20,70 & - & 22,39 & 6,07 \\
\hline \multirow{2}{*}{9} & 62,84 & 61,5 & 340,66 & 76,57 & 78,99 & 98,74 & 140,97 & 32,89 & - & 18,58 \\
\hline & 5,86 & 11,19 & 3,30 & 6,00 & 5,88 & 17,19 & 6,77 & 9,40 & - & 5,02 \\
\hline \multirow{2}{*}{$\Sigma$} & 6,89 & 66,23 & 26,95 & 38,94 & 71,07 & 64,48 & 24,16 & 53,34 & 36,18 & 1,53 \\
\hline & 0,00 & 0,42 & 0,37 & 3,24 & 0,51 & 2,31 & 0,81 & 9,08 & 1,72 & 0,57 \\
\hline
\end{tabular}

Obs: A primeira linha de cada origem contém as diferenças relativas dos resultados estimados pelo QUEENSOD e na segunda linha estão as diferenças relativas dos resultados estimados pelo TransCAD. Célula em destaque indica que o valor estimado é maior que o "real". 
Tabela B.11: Diferença relativa entre viagem "real" e estimada - Teste 2 usando $S_{70}$

\begin{tabular}{|c|c|c|c|c|c|c|c|c|c|c|}
\hline O\D & 1 & 2 & 3 & 4 & 5 & 6 & 7 & 8 & 9 & $\Sigma$ \\
\hline \multirow{2}{*}{1} & - & 1,48 & 56,03 & 93,03 & 10,29 & 25,71 & 84,78 & 6,92 & 93,26 & 21,24 \\
\hline & - & 1,23 & 13,15 & 18,79 & 5,98 & 32,00 & 0,36 & 11,95 & 10,51 & 1,65 \\
\hline \multirow{2}{*}{2} & 149,51 & - & 16,58 & 100,00 & 38,63 & 51,11 & 98,80 & 309,59 & 100,00 & 16,11 \\
\hline & 1,96 & - & 13,21 & 9,88 & 9,01 & 16,00 & 9,62 & 5,02 & 14,05 & 9,68 \\
\hline \multirow{2}{*}{3} & 100,00 & 70,29 & - & 99,43 & 60,14 & 167,91 & 185,71 & 108,13 & 100,00 & 40,80 \\
\hline & 3,98 & 12,47 & - & 11,97 & 2,15 & 18,72 & 14,29 & 16,26 & 11,46 & 6,33 \\
\hline \multirow{2}{*}{4} & 52,40 & 100,00 & 96,76 & - & 100,00 & 33,33 & 60,29 & 100,00 & 100,00 & 81,56 \\
\hline & 7,78 & 16,75 & 12,30 & - & 6,57 & 9,96 & 17,65 & 13,62 & 16,67 & 6,48 \\
\hline \multirow{2}{*}{5} & 60,24 & 100,00 & 100,00 & 17,93 & - & 31,66 & 70,39 & 25,00 & 100,00 & 66,35 \\
\hline & 7,42 & 6,04 & 20,73 & 6,52 & - & 19,60 & 0,64 & 6,92 & 1,22 & 0,66 \\
\hline \multirow{2}{*}{6} & 8,35 & 46,75 & 100,00 & 100,00 & 72,03 & - & 9,70 & 100,00 & 15,01 & 54,98 \\
\hline & 15,82 & 5,19 & 8,85 & 14,29 & 16,40 & - & 15,76 & 8,44 & 2,27 & 7,06 \\
\hline \multirow{2}{*}{7} & 98,53 & 74,77 & 100,00 & 162,21 & 60,23 & 75,61 & - & 75,85 & 100,00 & 67,49 \\
\hline & 15,72 & 11,68 & 17,32 & 16,86 & 14,70 & 0,22 & - & 5,88 & 14,52 & 3,83 \\
\hline \multirow{2}{*}{8} & 72,18 & 60,28 & 190,18 & 174,93 & 15,79 & 21,51 & 157,86 & - & 6,13 & 47,13 \\
\hline & 8,80 & 8,16 & 10,91 & 6,96 & 4,21 & 10,57 & 9,23 & - & 0,31 & 0,75 \\
\hline \multirow{2}{*}{9} & 91,67 & 46,64 & 100,00 & 59,43 & 79,62 & 61,43 & 63,87 & 0,67 & - & 66,05 \\
\hline & 11,04 & 1,87 & 14,84 & 11,71 & 5,04 & 14,05 & 11,94 & 11,07 & "'-"'-' & 7,90 \\
\hline \multirow{2}{*}{$\Sigma$} & 49,22 & 41,87 & 45,53 & 23,78 & 47,13 & 30,63 & 9,02 & 4,47 & 77,42 & 32,25 \\
\hline & 0,76 & 4,75 & 1,80 & 1,66 & 0,63 & 3,57 & 3,54 & 2,36 & 3,33 & 0,51 \\
\hline
\end{tabular}

Obs: A primeira linha de cada origem contém as diferenças relativas dos resultados estimados pelo QUEENSOD e na segunda linha estão as diferenças relativas dos resultados estimados pelo TransCAD.

Célula em destaque indica que o valor estimado é maior que o "real".

Tabela B.12: Diferença relativa entre viagem "real" e estimada - Teste 3 usando $S_{70}$

\begin{tabular}{|c|c|c|c|c|c|c|c|c|c|c|}
\hline$O \backslash D$ & 1 & 2 & 3 & 4 & 5 & 6 & 7 & 8 & 9 & $\Sigma$ \\
\hline \multirow{2}{*}{1} & - & 6,40 & 42,6 & 33,33 & 99,76 & 137,14 & 33,33 & 100,00 & 12,94 & 15,89 \\
\hline & - & 9,36 & 0,86 & 3,33 & 15,07 & 2,29 & 15,94 & 11,95 & 17,52 & 6,35 \\
\hline \multirow{2}{*}{2} & 50,98 & - & 100,00 & 75,66 & 100,00 & 140,44 & 75,24 & 87,21 & 79,55 & 62,35 \\
\hline & 6,86 & - & 11,66 & 3,13 & 3,00 & 21,33 & 15,38 & 9,59 & 3,51 & 4,84 \\
\hline \multirow{2}{*}{3} & 159,09 & 100,00 & - & 47,29 & 100,00 & 100,00 & 9,80 & 100,00 & 44,44 & 38,79 \\
\hline & 4,55 & 7,43 & - & 8,83 & 15,27 & 12,30 & 8,16 & 8,54 & 10,07 & 0,96 \\
\hline \multirow{2}{*}{4} & 19,76 & 48,28 & 68,28 & - & 100,00 & 64,07 & 100,00 & 218,78 & 82,86 & 2,24 \\
\hline & 12,57 & 13,79 & 11,33 & - & 14,99 & 17,32 & 8,33 & 4,23 & 15,24 & 8,90 \\
\hline \multirow{2}{*}{5} & 68,25 & 76,09 & 58,54 & 100,00 & - & 100,00 & 74,89 & 100,00 & 63,72 & 41,58 \\
\hline & 8,61 & 15,22 & 6,50 & 8,15 & - & 19,60 & 18,24 & 12,31 & 3,66 & 1,31 \\
\hline \multirow{2}{*}{6} & 34,07 & 100,00 & 100,00 & 30,73 & 100,00 & - & 46,06 & 100,00 & 2,55 & 50,51 \\
\hline & 10,55 & 14,07 & 6,19 & 19,14 & 10,93 & - & 3,03 & 24,38 & 7,37 & 7,77 \\
\hline \multirow{2}{*}{7} & 55,28 & 40,65 & 94,41 & 46,51 & 100,00 & 18,18 & - & 100,00 & 56,68 & 17,58 \\
\hline & 6,14 & 2,10 & 0,56 & 6,40 & 9,51 & 1,77 & - & 4,02 & 9,91 & 4,41 \\
\hline \multirow{2}{*}{8} & 71,13 & 100,00 & 110,55 & 100,00 & 54,74 & 62,26 & 51,87 & - & 100,00 & 21,07 \\
\hline & 0,70 & 1,06 & 9,09 & 5,01 & 6,11 & 6,79 & 7,98 & - & 7,36 & 2,32 \\
\hline \multirow{2}{*}{9} & 6,08 & 100,00 & 46,98 & 30,57 & 26,68 & 53,46 & 105,48 & 30,54 & - & 6,63 \\
\hline & 10,14 & 17,16 & 17,03 & 6,57 & 13,03 & 10,48 & 12,58 & 16,11 & - & 6,96 \\
\hline \multirow{2}{*}{$\Sigma$} & 8,60 & 51,34 & 32,87 & 28,75 & 57,71 & 0,95 & 19,13 & 55,15 & 8,91 & 27,90 \\
\hline & 0,27 & 3,77 & 3,76 & 3,75 & 4,77 & 1,09 & 1,05 & 0,05 & 1,15 & 0,36 \\
\hline
\end{tabular}

Obs: A primeira linha de cada origem contém as diferenças relativas dos resultados estimados pelo QUEENSOD e na segunda linha estão as diferenças relativas dos resultados estimados pelo TransCAD. Célula em destaque indica que o valor estimado é maior que o "real". 
Tabela B.13: Diferença relativa entre viagem "real" e estimada - Teste 4 usando $S_{70}$

\begin{tabular}{|c|c|c|c|c|c|c|c|c|c|c|}
\hline$O \backslash D$ & 1 & 2 & 3 & 4 & 5 & 6 & 7 & 8 & 9 & $\Sigma$ \\
\hline \multirow{2}{*}{1} & - & 75,37 & 90,09 & 61,21 & 27,27 & 45,14 & 11,59 & 48,43 & 10,78 & 34,47 \\
\hline & - & 2,22 & 2,80 & 10,91 & 11,24 & 1,14 & 15,22 & 18,87 & 10,24 & 0,31 \\
\hline \multirow{2}{*}{2} & 88,73 & - & 82,38 & 47,23 & 9,87 & 91,56 & 103,61 & 30,14 & 91,32 & 17,70 \\
\hline & 20,10 & - & 4,15 & 6,02 & 10,30 & 7,11 & 19,47 & 8,68 & 13,02 & 3,02 \\
\hline \multirow{2}{*}{3} & 96,02 & 94,43 & - & 96,87 & 69,93 & 79,14 & 29,39 & 36,18 & 28,47 & 60,59 \\
\hline & 7,39 & 5,84 & - & 4,84 & 4,53 & 12,83 & 7,76 & 13,41 & 3,13 & 0,35 \\
\hline \multirow{2}{*}{4} & 20,06 & 57,14 & 30,74 & - & 78,23 & 49,78 & 12,75 & 95,31 & 97,14 & 44,04 \\
\hline & 5,39 & 14,78 & 12,62 & "3"- & 0,21 & 6,93 & 1,47 & 15,49 & 0,00 & 0,23 \\
\hline \multirow{2}{*}{5} & 44,51 & 91,06 & 59,35 & 71,74 & - & 149,25 & 90,56 & 68,08 & 100,00 & 24,24 \\
\hline & 4,15 & 16,91 & 4,07 & 7,07 & - & 13,07 & 12,02 & 17,31 & 7,93 & 0,53 \\
\hline \multirow{2}{*}{6} & 84,18 & 2,16 & 96,46 & 77,63 & 79,10 & - & 152,12 & 30,31 & 76,77 & 26,25 \\
\hline & 17,80 & 7,58 & 19,47 & 3,23 & 1,93 & - & 15,76 & 16,56 & 9,35 & 0,08 \\
\hline \multirow{2}{*}{7} & 21,62 & 26,64 & 117,88 & 44,19 & 12,10 & 91,35 & - & 82,66 & 78,80 & 13,21 \\
\hline & 6,39 & 3,04 & 15,64 & 9,30 & 11,82 & 7,10 & - & 0,62 & 16,13 & 1,86 \\
\hline \multirow{2}{*}{8} & 72,54 & 62,77 & 106,91 & 52,37 & 68,63 & 72,45 & 75,31 & - & 8,28 & 21,37 \\
\hline & 16,55 & 9,57 & 15,64 & 7,24 & 1,05 & 17,74 & 0,50 & - & 9,20 & 2,74 \\
\hline \multirow{2}{*}{9} & 1,13 & 19,78 & 9,62 & 33,14 & 90,76 & 83,23 & 65,16 & 41,61 & - & 31,84 \\
\hline & 17,34 & 0,75 & 4,67 & 16,57 & 8,61 & 8,60 & 15,81 & 3,02 & - & 5,42 \\
\hline \multirow{2}{*}{$\Sigma$} & 46,88 & 52,43 & 21,85 & 60,70 & 28,24 & 20,68 & 64,20 & 47,50 & 7,66 & 24,78 \\
\hline & 2,39 & 1,62 & 1,51 & 3,99 & 1,36 & 3,35 & 10,79 & 5,69 & 0,57 & 0,24 \\
\hline
\end{tabular}

Obs: A primeira linha de cada origem contém as diferenças relativas dos resultados estimados pelo QUEENSOD e na segunda linha estão as diferenças relativas dos resultados estimados pelo TransCAD.

Célula em destaque indica que o valor estimado é maior que o "real".

Tabela B.14: Diferença relativa entre viagem "real" e estimada - Teste 5 usando $S_{70}$

\begin{tabular}{|c|c|c|c|c|c|c|c|c|c|c|}
\hline O\D & 1 & 2 & 3 & 4 & 5 & 6 & 7 & 8 & 9 & $\Sigma$ \\
\hline \multirow{2}{*}{1} & - & 24,88 & 56,90 & 44,55 & 70,57 & 58,29 & 55,43 & 2,52 & 69,81 & 43,13 \\
\hline & - & 21,67 & 14,44 & 9,70 & 5,98 & 18,29 & 19,20 & 15,09 & 21,56 & 2,42 \\
\hline \multirow{2}{*}{2} & 48,53 & - & 69,69 & 95,42 & 49,79 & 83,11 & 72,84 & 72,15 & 80,17 & 66,54 \\
\hline & 7,35 & - & 7,77 & 1,20 & 6,44 & 16,89 & 15,14 & 20,55 & 3,31 & 6,12 \\
\hline \multirow{2}{*}{3} & 72,16 & 70,56 & - & 57,55 & 14,08 & 77,54 & 78,78 & 17,48 & 99,31 & 16,30 \\
\hline & 8,52 & 13,26 & - & 4,56 & 10,98 & 17,65 & 10,61 & 4,07 & 10,07 & 4,94 \\
\hline \multirow{2}{*}{4} & 70,06 & 52,71 & 36,89 & - & 4,72 & 73,59 & 24,02 & 88,26 & 43,33 & 14,01 \\
\hline & 14,67 & 9,36 & 2,27 & - & 3,70 & 6,49 & 15,20 & 7,04 & 16,19 & 5,48 \\
\hline \multirow{2}{*}{5} & 69,44 & 85,99 & 41,06 & 105,98 & - & 0,00 & 57,08 & 58,85 & 14,33 & 39,52 \\
\hline & 4,15 & 1,21 & 0,41 & 3,80 & - & 16,08 & 12,02 & 17,69 & 0,91 & 2,63 \\
\hline \multirow{2}{*}{6} & 58,90 & 76,41 & 75,66 & 76,82 & 28,30 & - & 39,39 & 68,13 & 110,76 & 39,73 \\
\hline & 12,31 & 6,93 & 19,03 & 1,08 & 2,57 & - & 13,33 & 2,50 & 8,22 & 4,06 \\
\hline \multirow{2}{*}{7} & 71,25 & 14,25 & 82,68 & 45,35 & 96,54 & 95,34 & - & 22,91 & 97,24 & 67,06 \\
\hline & 13,02 & 7,48 & 15,64 & 8,72 & 5,48 & 4,88 & - & 12,69 & 3,46 & 4,74 \\
\hline \multirow{2}{*}{8} & 24,65 & 76,24 & 5,09 & 89,97 & 97,26 & 8,30 & 9,98 & - & 142,64 & 25,53 \\
\hline & 3,52 & 3,19 & 19,64 & 6,13 & 2,95 & 3,40 & 7,48 & - & 6,75 & 1,65 \\
\hline \multirow{2}{*}{9} & 25,23 & 27,99 & 51,92 & 24,57 & 4,62 & 16,35 & 67,74 & 35,23 & - & 0,77 \\
\hline & 15,09 & 2,61 & 13,74 & 4,57 & 5,04 & 3,77 & 12,58 & 11,74 & - & 6,49 \\
\hline \multirow{2}{*}{$\Sigma$} & 46,84 & 41,23 & 27,11 & 45,42 & 41,38 & 21,90 & 51,55 & 42,05 & 4,19 & 34,71 \\
\hline & 4,96 & 2,11 & 7,27 & 0,00 & 3,66 & 3,39 & 1,57 & 2,75 & 7,05 & 1,34 \\
\hline
\end{tabular}

Obs: A primeira linha de cada origem contém as diferenças relativas dos resultados estimados pelo QUEENSOD e na segunda linha estão as diferenças relativas dos resultados estimados pelo TransCAD. Célula em destaque indica que o valor estimado é maior que o "real". 
Tabela B.15: Diferença relativa entre viagem "real" e estimada - Teste 6 usando $S_{70}$

\begin{tabular}{|c|c|c|c|c|c|c|c|c|c|c|}
\hline$O \backslash D$ & 1 & 2 & 3 & 4 & 5 & 6 & 7 & 8 & 9 & $\Sigma$ \\
\hline \multirow{2}{*}{1} & - & 13,79 & 73,06 & 9,09 & 56,22 & 25,71 & 7,61 & 10,06 & 58,22 & 35,24 \\
\hline & - & 12,32 & 1,51 & 11,82 & 4,07 & 18,29 & 1,45 & 9,43 & 6,20 & 2,96 \\
\hline \multirow{2}{*}{2} & 45,10 & - & 65,54 & 62,17 & 79,83 & 24,44 & 18,75 & 48,40 & 24,17 & 20,88 \\
\hline & 16,18 & - & 7,51 & 6,75 & 4,72 & 13,78 & 7,93 & 4,11 & 11,16 & 1,28 \\
\hline \multirow{2}{*}{3} & 45,45 & 20,42 & - & 67,52 & 64,44 & 46,52 & 46,12 & 78,86 & 0,35 & 46,18 \\
\hline & 2,27 & 0,80 & - & 9,97 & 5,97 & 10,16 & 10,20 & 1,22 & 12,85 & 0,83 \\
\hline \multirow{2}{*}{4} & 12,87 & 11,82 & 34,30 & - & 79,47 & 29,00 & 70,10 & 94,84 & 87,62 & 30,44 \\
\hline & 11,38 & 18,72 & 11,33 & - & 14,58 & 0,87 & 0,49 & 14,55 & 10,00 & 4,06 \\
\hline \multirow{2}{*}{5} & 89,02 & 94,44 & 60,98 & 61,96 & - & 10,05 & 57,30 & 61,54 & 67,38 & 57,35 \\
\hline & 1,19 & 9,42 & 13,01 & 7,07 & - & 5,03 & 1,29 & 14,23 & 4,57 & 4,56 \\
\hline \multirow{2}{*}{6} & 78,02 & 59,52 & 1,77 & 85,18 & 72,35 & - & 23,03 & 29,69 & 3,68 & 46,49 \\
\hline & 8,57 & 3,46 & 2,21 & 7,55 & 10,61 & - & 12,73 & 5,63 & 15,01 & 0,79 \\
\hline \multirow{2}{*}{7} & 16,46 & 63,32 & 53,07 & 24,42 & 27,67 & 77,38 & - & 30,34 & 70,28 & 22,33 \\
\hline & 9,83 & 15,19 & 11,73 & 12,21 & 7,49 & 6,65 & - & 6,19 & 9,91 & 1,31 \\
\hline \multirow{2}{*}{8} & 64,79 & 63,48 & 77,09 & 72,14 & 11,58 & 95,09 & 41,90 & - & 59,82 & 40,49 \\
\hline & 7,75 & 10,64 & 10,55 & 6,69 & 10,74 & 6,42 & 3,74 & - & 11,96 & 2,29 \\
\hline \multirow{2}{*}{9} & 55,63 & 94,78 & 7,97 & 56,29 & 66,60 & 13,42 & 59,68 & 29,53 & - & 1,61 \\
\hline & 1,13 & 19,40 & 1,92 & 9,43 & 1,89 & 5,03 & 0,32 & 13,76 & - & 1,07 \\
\hline \multirow{2}{*}{$\Sigma$} & 24,76 & 35,92 & 20,74 & 48,38 & 38,12 & 42,53 & 21,14 & 17,66 & 36,40 & 32,21 \\
\hline & 4,66 & 4,33 & 0,53 & 2,37 & 2,27 & 4,71 & 2,50 & 3,39 & 4,26 & 0,04 \\
\hline
\end{tabular}

Obs: A primeira linha de cada origem contém as diferenças relativas dos resultados estimados pelo QUEENSOD e na segunda linha estão as diferenças relativas dos resultados estimados pelo TransCAD.

Célula em destaque indica que o valor estimado é maior que o "real".

Tabela B.16: Diferença relativa entre viagem "real" e estimada - Teste 7 usando Sem 20

\begin{tabular}{|c|c|c|c|c|c|c|c|c|c|c|}
\hline$O \backslash D$ & 1 & 2 & 3 & 4 & 5 & 6 & 7 & 8 & 9 & $\Sigma$ \\
\hline \multirow{2}{*}{1} & - & 17,00 & 1,94 & 10,00 & 94,74 & 1,71 & 73,55 & 25,16 & 81,67 & 21,59 \\
\hline & - & 3,69 & 1,51 & 7,88 & 12,44 & 21,14 & 19,57 & 15,09 & 59,84 & 7,77 \\
\hline \multirow{2}{*}{2} & 17,16 & - & 3,89 & 72,29 & 1,72 & 94,67 & 72,12 & 134,25 & 75,83 & 36,41 \\
\hline & 0,98 & - & 16,84 & 12,77 & 7,73 & 19,11 & 14,18 & 14,61 & 14,88 & 5,85 \\
\hline \multirow{2}{*}{3} & 7,95 & 36,60 & - & 76,64 & 84,01 & 159,36 & 91,84 & 24,80 & 26,04 & 30,01 \\
\hline & 7,39 & 7,16 & - & 8,55 & 0,48 & 2,14 & 18,37 & 4,07 & 15,97 & 5,11 \\
\hline \multirow{2}{*}{4} & 53,89 & 55,67 & 71,52 & - & 9,24 & 51,52 & 25,00 & 52,58 & 51,90 & 38,75 \\
\hline & 9,28 & 17,73 & 15,21 & - & 4,52 & 10,82 & 11,27 & 16,90 & 16,67 & 1,14 \\
\hline \multirow{2}{*}{5} & 62,31 & 24,88 & 38,21 & 24,46 & - & 27,64 & 66,31 & 43,08 & 8,54 & 22,39 \\
\hline & 10,68 & 5,56 & 3,66 & 38,04 & - & 3,52 & 16,52 & 6,54 & 8,84 & 1,81 \\
\hline \multirow{2}{*}{6} & 58,68 & 69,26 & 88,50 & 34,77 & 8,04 & - & 30,30 & 68,13 & 14,45 & 47,28 \\
\hline & 5,05 & 7,14 & 17,26 & 1,35 & 2,25 & - & 9,09 & 14,69 & 16,71 & 3,91 \\
\hline \multirow{2}{*}{7} & 4,91 & 45,09 & 7,82 & 36,05 & 23,34 & 67,18 & - & 37,46 & 96,54 & 43,27 \\
\hline & 15,23 & 0,23 & 13,97 & 24,42 & 4,90 & 8,43 & - & 15,79 & 7,83 & 0,84 \\
\hline \multirow{2}{*}{8} & 83,45 & 46,45 & 14,55 & 36,77 & 34,53 & 0,38 & 23,44 & - & 10,43 & 21,41 \\
\hline & 17,61 & 18,09 & 16,36 & 2,79 & 2,95 & 13,96 & 16,46 & - & 3,07 & 2,29 \\
\hline \multirow{2}{*}{9} & 40,99 & 7,84 & 30,49 & 94,86 & 89,08 & 26,83 & 31,94 & 34,56 & - & 39,44 \\
\hline & 7,21 & 14,93 & 7,97 & 6,29 & 10,08 & 4,19 & 8,06 & 15,44 & - & 2,38 \\
\hline \multirow{2}{*}{$\Sigma$} & 43,39 & 29,12 & 10,09 & 48,82 & 47,06 & 23,53 & 33,23 & 12,22 & 44,24 & 33,59 \\
\hline & 2,08 & 5,28 & 3,63 & 4,07 & 2,37 & 4,89 & 5,44 & 2,75 & 13,64 & 3,25 \\
\hline
\end{tabular}

Obs: A primeira linha de cada origem contém as diferenças relativas dos resultados estimados pelo QUEENSOD e na segunda linha estão as diferenças relativas dos resultados estimados pelo TransCAD. Célula em destaque indica que o valor estimado é maior que o "real". 
Tabela B.17: Diferença relativa entre viagem "real" e estimada - Teste 7 usando Sem $_{10}$

\begin{tabular}{|c|c|c|c|c|c|c|c|c|c|c|}
\hline$O \backslash D$ & 1 & 2 & 3 & 4 & 5 & 6 & 7 & 8 & 9 & $\Sigma$ \\
\hline \multirow{2}{*}{1} & - & 95,57 & 5,17 & 50,61 & 90,43 & 85,14 & 114,13 & 7,55 & 83,56 & 0,12 \\
\hline & - & 1,97 & 10,78 & 4,85 & 10,53 & 8,00 & 7,25 & 15,09 & 3,50 & 0,85 \\
\hline \multirow{2}{*}{2} & 6,86 & - & 4,66 & 81,93 & 14,16 & 94,22 & 68,51 & 105,02 & 79,96 & 38,54 \\
\hline & 13,73 & - & 14,25 & 7,71 & 9,01 & 13,33 & 2,88 & 14,16 & 1,45 & 0,35 \\
\hline \multirow{2}{*}{3} & 55,68 & 193,90 & - & 71,51 & 66,35 & 141,71 & 81,63 & 10,16 & 146,53 & 26,91 \\
\hline & 1,70 & 16,45 & - & 9,69 & 12,89 & 11,76 & 14,69 & 3,66 & 10,76 & 7,73 \\
\hline \multirow{2}{*}{4} & 72,16 & 1,48 & 6,15 & - & 205,13 & 56,28 & 76,47 & 85,92 & 47,62 & 21,86 \\
\hline & 9,88 & 12,81 & 16,18 & - & 5,54 & 12,99 & 12,25 & 9,86 & 5,24 & 0,55 \\
\hline \multirow{2}{*}{5} & 99,41 & 34,30 & 99,19 & 25,00 & - & 20,60 & 70,60 & 27,31 & 99,39 & 57,19 \\
\hline & 11,87 & 11,84 & 9,35 & 14,13 & - & 14,07 & 0,86 & 10,38 & 1,22 & 7,89 \\
\hline \multirow{2}{*}{6} & 98,24 & 77,27 & 94,69 & 98,38 & 15,76 & - & 39,39 & 71,88 & 0,57 & 61,10 \\
\hline & 8,79 & 8,87 & 14,16 & 1,62 & 0,32 & - & 9,09 & 8,75 & 2,27 & 1,28 \\
\hline \multirow{2}{*}{7} & 8,35 & 34,81 & 90,50 & 36,05 & 64,55 & 76,27 & - & 16,41 & 88,48 & 49,07 \\
\hline & 3,69 & 2,10 & 9,50 & 10,47 & 7,49 & 3,99 & - & 5,26 & 1,61 & 3,39 \\
\hline \multirow{2}{*}{8} & 56,34 & 59,22 & 90,91 & 89,14 & 40,21 & 65,66 & 8,73 & - & 16,87 & 34,05 \\
\hline & 14,44 & 7,45 & 10,55 & 13,09 & 3,37 & 6,42 & 4,74 & - & 6,13 & 3,37 \\
\hline \multirow{2}{*}{9} & 71,62 & 28,36 & 6,59 & 94,29 & 10,92 & 95,60 & 1,29 & 11,41 & - & 39,17 \\
\hline & 8,33 & 1,49 & 5,77 & 4,86 & 0,42 & 1,05 & 6,77 & 7,38 & - & 0,00 \\
\hline \multirow{2}{*}{$\Sigma$} & 58,73 & 19,68 & 35,57 & 61,14 & 3,41 & 56,20 & 17,72 & 5,69 & 36,79 & 27,41 \\
\hline & 2,61 & 3,73 & 1,02 & 2,13 & 1,86 & 0,45 & 0,44 & 3,68 & 2,58 & 0,87 \\
\hline
\end{tabular}

Obs: A primeira linha de cada origem contém as diferenças relativas dos resultados estimados pelo QUEENSOD e na segunda linha estão as diferenças relativas dos resultados estimados pelo TransCAD.

Célula em destaque indica que o valor estimado é maior que o "real".

Tabela B.18: Diferença relativa entre viagem "real" e estimada - Teste 7 usando $S_{70}$

\begin{tabular}{|c|c|c|c|c|c|c|c|c|c|c|}
\hline O\D & 1 & 2 & 3 & 4 & 5 & 6 & 7 & 8 & 9 & $\Sigma$ \\
\hline \multirow{2}{*}{1} & - & 6,40 & 58,84 & 41,21 & 16,99 & \multirow{2}{*}{$\begin{array}{c}42,86 \\
6,86\end{array}$} & 26,81 & 5,03 & 73,05 & 35,36 \\
\hline & - & 13,05 & 0,43 & 5,76 & 11,72 & & 7,25 & 1,89 & 7,55 & 2,50 \\
\hline \multirow{2}{*}{2} & 22,55 & - & 40,93 & 4,10 & 5,58 & 73,78 & 76,20 & 37,44 & 46,69 & 37,41 \\
\hline & 10,29 & - & 6,22 & 6,99 & 7,30 & 14,22 & 2,88 & 8,22 & 5,99 & 2,48 \\
\hline \multirow{2}{*}{3} & 28,41 & 67,90 & - & 46,15 & 65,87 & 47,59 & 29,39 & 43,09 & 5,90 & 24,99 \\
\hline & 6,82 & 11,41 & - & 9,97 & 15,51 & 11,23 & 11,84 & 13,01 & 2,78 & 2,27 \\
\hline \multirow{2}{*}{4} & 16,47 & 16,26 & 34,95 & - & 58,32 & 28,57 & 2,45 & 8,45 & 1,43 & 23,73 \\
\hline & 4,79 & 8,87 & 10,68 & - & 3,49 & 8,23 & 9,31 & 10,80 & 0,48 & 1,00 \\
\hline \multirow{2}{*}{5} & 2,08 & 49,28 & 63,41 & 55,98 & - & 13,57 & 71,89 & 50,77 & 71,95 & 40,88 \\
\hline & 2,97 & 8,94 & 14,63 & 11,96 & - & 1,51 & 1,72 & 6,54 & 1,52 & 2,63 \\
\hline \multirow{2}{*}{6} & 20,66 & 24,89 & 42,04 & 70,62 & 6,75 & - & 73,94 & 68,75 & 42,49 & 31,36 \\
\hline & 5,27 & 4,11 & 0,88 & 10,51 & 6,43 & - & 9,09 & 10,94 & 5,95 & 0,49 \\
\hline \multirow{2}{*}{7} & 2,70 & 67,06 & 62,57 & 46,51 & 64,55 & 44,57 & - & 42,11 & 64,98 & 40,50 \\
\hline & 1,97 & 6,31 & 10,06 & 6,40 & 0,29 & 9,31 & - & 10,22 & 4,61 & 0,58 \\
\hline \multirow{2}{*}{8} & 54,58 & 41,13 & 33,09 & 11,42 & 76,42 & 71,32 & 44,64 & - & 2,76 & 23,58 \\
\hline & 5,28 & 6,74 & 1,82 & 7,80 & 1,89 & 8,30 & 8,48 & - & 6,13 & 0,04 \\
\hline \multirow{2}{*}{9} & 34,68 & 58,96 & 36,54 & 36,57 & 75,84 & 73,17 & 25,48 & 4,70 & - & 36,59 \\
\hline & 11,49 & 10,07 & 11,54 & 4,57 & 5,04 & 3,98 & 4,52 & 5,37 & - & 5,72 \\
\hline \multirow{2}{*}{$\Sigma$} & 17,91 & 33,94 & 29,40 & 13,94 & 50,09 & 52,58 & 31,66 & 20,80 & 41,91 & 32,99 \\
\hline & 0,64 & 1,58 & 0,08 & 0,83 & 3,66 & 3,71 & 3,26 & 5,50 & 2,68 & 1,02 \\
\hline
\end{tabular}

Obs: A primeira linha de cada origem contém as diferenças relativas dos resultados estimados pelo QUEENSOD e na segunda linha estão as diferenças relativas dos resultados estimados pelo TransCAD. Célula em destaque indica que o valor estimado é maior que o "real". 
Tabela B.19: Diferença relativa entre viagem "real" e estimada - Teste 8 usando $S_{20}$

\begin{tabular}{|c|c|c|c|c|c|c|c|c|c|c|}
\hline O\D & 1 & 2 & 3 & 4 & 5 & 6 & 7 & 8 & 9 & $\Sigma$ \\
\hline \multirow{2}{*}{1} & - & 70,69 & 21,55 & 100,00 & 51,44 & 48,57 & 266,67 & 100,00 & 245,82 & 25,82 \\
\hline & - & 14,89 & 5,13 & 0,12 & 19,62 & 13,57 & 4,91 & 40,35 & 5,39 & 1,73 \\
\hline \multirow{2}{*}{2} & 100,00 & - & 100,00 & 100,00 & 100,00 & 100,00 & 63,94 & 100,00 & 58,47 & 86,41 \\
\hline & 12,44 & - & 8,97 & 21,89 & 38,52 & 5,36 & 5,58 & 39,28 & 21,17 & 10,10 \\
\hline \multirow{2}{*}{3} & 313,64 & 99,73 & - & 162,68 & 100,00 & 7,49 & 9,80 & 100,00 & 225,00 & 30,23 \\
\hline & 24,48 & 1,34 & - & 26,70 & 12,86 & 12,18 & 10,11 & 29,61 & 17,71 & 0,54 \\
\hline \multirow{2}{*}{4} & 100,00 & 100,00 & 148,87 & - & 100,00 & 96,97 & 27,94 & 100,00 & 39,52 & 44,50 \\
\hline & 5,56 & 12,00 & 17,03 & - & 22,33 & 1,28 & 0,43 & 74,26 & 23,88 & 4,30 \\
\hline \multirow{2}{*}{5} & 66,17 & 100,00 & 13,41 & 100,00 & - & 100,00 & 100,00 & 8,85 & 100,00 & 76,83 \\
\hline & 7,05 & 4,00 & 14,99 & 30,34 & - & 47,43 & 0,18 & 51,44 & 14,84 & 12,41 \\
\hline \multirow{2}{*}{6} & 67,03 & 100,00 & 100,00 & 99,46 & 100,00 & - & 350,91 & 100,00 & 100,00 & 66,35 \\
\hline & 0,33 & 13,15 & 15,11 & 19,67 & 0,40 & - & 12,77 & 28,53 & 24,33 & 11,20 \\
\hline \multirow{2}{*}{7} & 241,77 & 98,36 & 281,56 & 93,60 & 100,00 & 26,61 & - & 100,00 & 12,67 & 6,24 \\
\hline & 1,22 & 26,56 & 43,22 & 30,57 & 13,00 & 24,51 & - & 17,84 & 13,09 & 2,29 \\
\hline \multirow{2}{*}{8} & 64,44 & 100,00 & 49,09 & 100,00 & 100,00 & 60,75 & 100,00 & - & 100,00 & 87,06 \\
\hline & 47,26 & 25,58 & 1,98 & 28,87 & 22,13 & 18,35 & 22,33 & - & 32,28 & 3,30 \\
\hline \multirow{2}{*}{9} & 30,18 & 47,76 & 195,88 & 25,43 & 100,00 & 56,39 & 200,65 & 21,48 & - & 20,82 \\
\hline & 28,40 & 0,64 & 14,91 & 24,53 & 22,46 & 25,91 & $-32,11$ & $-36,58$ & - & 9,71 \\
\hline \multirow{2}{*}{$\Sigma$} & 15,98 & 90,63 & 40,67 & 45,73 & 93,59 & 58,64 & 29,12 & 76,89 & 14,64 & 30,27 \\
\hline & 1,43 & 3,32 & 2,46 & 2,44 & 18,64 & 13,12 & 7,25 & 10,18 & 2,14 & 3,16 \\
\hline
\end{tabular}

Obs: A primeira linha de cada origem contém as diferenças relativas dos resultados estimados pelo QUEENSOD e na segunda linha estão as diferenças relativas dos resultados estimados pelo TransCAD.

Célula em destaque indica que o valor estimado é maior que o "real".

Tabela B.20: Diferença relativa entre viagem "real" e estimada - Teste 8 usando Sem Se $_{10}$

\begin{tabular}{|c|c|c|c|c|c|c|c|c|c|c|}
\hline O\D & 1 & 2 & 3 & 4 & 5 & 6 & 7 & 8 & 9 & $\Sigma$ \\
\hline \multirow{2}{*}{1} & - & 42,36 & 76,29 & 100,00 & 100,00 & 40,00 & 441,30 & 100,00 & 65,23 & 31,01 \\
\hline & - & 8,32 & 12,16 & 10,17 & 17,18 & 13,76 & 5,63 & 56,89 & 5,99 & 0,89 \\
\hline \multirow{2}{*}{2} & 100,00 & - & 100,00 & 100,00 & 100,00 & 100,00 & 100,00 & 100,00 & 99,79 & 99,96 \\
\hline & 4,23 & - & 4,99 & 15,03 & 32,31 & 1,59 & 7,30 & 46,11 & 20,97 & 9,74 \\
\hline \multirow{2}{*}{3} & 289,77 & 100,00 & - & 94,30 & 100,00 & 100,00 & 46,53 & 100,00 & 421,88 & 31,15 \\
\hline & 30,90 & 4,77 & - & 19,07 & 13,86 & 64,67 & 6,09 & 17,32 & 11,61 & 5,65 \\
\hline \multirow{2}{*}{4} & 100,00 & 100,00 & 147,57 & - & 100,00 & 138,10 & 100,00 & 100,00 & 14,29 & 31,72 \\
\hline & 0,94 & 47,28 & 12,52 & - & 12,52 & 3,11 & 7,56 & 73,58 & 18,68 & 3,05 \\
\hline \multirow{2}{*}{5} & 100,00 & 100,00 & 100,00 & 100,00 & - & 100,00 & 100,00 & 100,00 & 100,00 & 100,00 \\
\hline & 7,12 & 1,39 & 5,09 & 11,70 & - & 19,20 & 6,84 & 45,25 & 13,70 & 8,53 \\
\hline \multirow{2}{*}{6} & 69,23 & 100,00 & 99,56 & 92,72 & 100,00 & - & 329,70 & 100,00 & 98,87 & 43,26 \\
\hline & 22,22 & 6,99 & 8,79 & 35,00 & 40,12 & - & 4,32 & 8,46 & 10,24 & 9,29 \\
\hline \multirow{2}{*}{7} & 245,45 & 100,00 & 62,01 & 95,93 & 100,00 & 61,20 & - & 100,00 & 101,84 & 12,51 \\
\hline & 22,27 & 18,27 & 6,94 & 20,58 & 7,78 & 17,39 & - & 4,94 & 16,14 & 5,12 \\
\hline \multirow{2}{*}{8} & 29,23 & 100,00 & 63,27 & 100,00 & 50,32 & 100,00 & 100,00 & - & 100,00 & 79,83 \\
\hline & 37,75 & 10,98 & 26,36 & 35,43 & 18,51 & 9,06 & 4,20 & - & 13,83 & 1,45 \\
\hline \multirow[t]{2}{*}{0} & 79,05 & 100,00 & 237,64 & 174,57 & 100,00 & 76,31 & 83,87 & 39,93 & - & 5,29 \\
\hline & 22,77 & 15,19 & 12,35 & 20,32 & 26,38 & 28,89 & 40,15 & 28,02 & - & 10,49 \\
\hline & 19,50 & 91,76 & 21,80 & 33,73 & 92,55 & 25,97 & 17,00 & 91,22 & 13,67 & 30,11 \\
\hline & 1,43 & 2,77 & 2,47 & 3,87 & 19,94 & 6,21 & 8,56 & 18,04 & 3,21 & 1,29 \\
\hline
\end{tabular}

Obs: A primeira linha de cada origem contém as diferenças relativas dos resultados estimados pelo QUEENSOD e na segunda linha estão as diferenças relativas dos resultados estimados pelo TransCAD. Célula em destaque indica que o valor estimado é maior que o "real". 
Tabela B.21: Diferença relativa entre viagem "real" e estimada - Teste 8 usando $S_{70}$

\begin{tabular}{|c|c|c|c|c|c|c|c|c|c|c|}
\hline O\D & 1 & 2 & 3 & 4 & 5 & 6 & 7 & 8 & 9 & $\Sigma$ \\
\hline \multirow{2}{*}{1} & - & 100,00 & 73,92 & 98,18 & 100,00 & 100,00 & 481,52 & 100,00 & 74,66 & 17,97 \\
\hline & - & 0,00 & 8,41 & 4,24 & 13,64 & 13,71 & 8,33 & 32,08 & 11,86 & 0,00 \\
\hline \multirow{2}{*}{2} & 100,00 & - & 100,00 & 100,00 & 100,00 & 100,00 & 100,00 & 100,00 & 100,00 & 100,00 \\
\hline & 3,92 & - & 0,78 & 17,11 & 25,75 & 12,89 & 14,66 & 14,16 & 11,36 & 7,67 \\
\hline \multirow{2}{*}{3} & 269,89 & 100,00 & - & 36,18 & 100,00 & 100,00 & 282,04 & 100,00 & 349,65 & 35,69 \\
\hline & 40,34 & 14,32 & - & 16,81 & 18,38 & 6,42 & 12,24 & 7,72 & 12,50 & 0,09 \\
\hline \multirow{2}{*}{4} & 100,00 & 100,00 & 100,00 & - & 20,74 & 468,40 & 100,00 & 100,00 & 100,00 & 22,46 \\
\hline & 2,99 & 20,20 & 6,80 & - & 16,22 & 5,19 & 4,41 & 55,40 & 10,48 & 1,96 \\
\hline \multirow{2}{*}{5} & 100,00 & 100,00 & 14,63 & 45,65 & - & 100,00 & 89,06 & 100,00 & 86,59 & 73,50 \\
\hline & 10,39 & 5,80 & 2,44 & 15,22 & - & 14,07 & 6,01 & 30,77 & 11,89 & 11,01 \\
\hline \multirow{2}{*}{6} & 100,00 & 100,00 & 10,18 & 162,80 & 100,00 & - & 100,00 & 100,00 & 64,59 & 51,07 \\
\hline & 12,97 & 14,50 & 3,54 & 17,25 & 13,83 & - & 10,30 & 14,38 & 18,41 & 0,11 \\
\hline \multirow{2}{*}{7} & 295,82 & 100,00 & 217,32 & 78,49 & 100,00 & 100,00 & - & 100,00 & 106,22 & 13,50 \\
\hline & 10,07 & 17,76 & 6,70 & 8,72 & 5,19 & 11,53 & - & 0,00 & 14,98 & 4,23 \\
\hline \multirow{2}{*}{8} & 100,00 & 100,00 & 100,00 & 100,00 & 100,00 & 100,00 & 100,00 & - & 93,25 & 99,18 \\
\hline & 19,01 & 4,26 & 0,73 & 24,51 & 0,00 & 1,51 & 3,24 & - & 5,21 & 4,61 \\
\hline \multirow{2}{*}{9} & 95,95 & 100,00 & 246,43 & 55,14 & 28,78 & 100,00 & 65,81 & 100,00 & - & 5,16 \\
\hline & 16,22 & 4,10 & 6,04 & 15,14 & 13,24 & 24,74 & 24,19 & 16,11 & - & 6,49 \\
\hline \multirow{2}{*}{$\Sigma$} & 18,59 & 100,00 & 27,44 & 34,16 & 77,10 & 40,59 & 25,09 & 100,00 & 8,41 & 30,49 \\
\hline & 0,68 & 7,50 & 0,37 & 0,67 & 12,54 & 10,00 & 4,23 & 11,48 & 3,51 & 0,10 \\
\hline
\end{tabular}

Obs: A primeira linha de cada origem contém as diferenças relativas dos resultados estimados pelo QUEENSOD e na segunda linha estão as diferenças relativas dos resultados estimados pelo TransCAD.

Célula em destaque indica que o valor estimado é maior que o "real".

Tabela B.22: Diferença relativa entre viagem "real" e estimada - Teste 9 usando Sem $_{20}$

\begin{tabular}{|c|c|c|c|c|c|c|c|c|c|c|}
\hline 이D & 1 & 2 & 3 & 4 & 5 & 6 & 7 & 8 & 9 & $\Sigma$ \\
\hline \multirow{2}{*}{1} & - & 100,00 & 134,05 & 94,24 & 67,46 & 24,00 & 374,64 & 176,73 & 79,51 & 23,12 \\
\hline & - & 6,65 & 1,72 & 3,94 & 4,07 & 11,43 & 18,48 & 10,69 & 17,25 & 1,50 \\
\hline \multirow{2}{*}{2} & 100,00 & - & 95,60 & 78,80 & 100,00 & 100,00 & 32,21 & 92,24 & 29,13 & 70,99 \\
\hline & 17,65 & - & 20,73 & 8,43 & 34,33 & 23,56 & 5,05 & 16,89 & 16,53 & 3,18 \\
\hline \multirow{2}{*}{3} & 498,86 & 100,00 & - & 60,68 & 95,94 & 47,06 & 58,37 & 1,22 & 329,17 & 33,90 \\
\hline & 10,80 & 6,10 & - & 24,50 & 10,50 & 21,93 & 3,27 & 23,98 & 32,99 & 0,66 \\
\hline \multirow{2}{*}{4} & 36,53 & 100,00 & 100,00 & - & 100,00 & 427,71 & 0,49 & 100,00 & 15,71 & 17,30 \\
\hline & 2,69 & 11,33 & 18,77 & - & 3,29 & 13,85 & 21,57 & 21,60 & 16,67 & 6,48 \\
\hline \multirow{2}{*}{5} & 47,48 & 95,89 & 100,00 & 100,00 & - & 90,95 & 100,00 & 100,00 & 100,00 & 91,29 \\
\hline & 2,37 & 3,62 & 13,01 & 7,07 & - & 16,08 & 10,73 & 42,31 & 4,57 & 1,44 \\
\hline \multirow{2}{*}{6} & 88,57 & 41,34 & 100,00 & 251,48 & 100,00 & - & 58,18 & 88,75 & 18,98 & 24,18 \\
\hline & 8,13 & 0,22 & 15,04 & 11,59 & 2,25 & - & 0,61 & 15,31 & 7,08 & 0,11 \\
\hline \multirow{2}{*}{7} & 242,75 & 86,21 & 159,78 & 100,00 & 95,10 & 73,61 & - & 100,00 & 54,61 & 17,84 \\
\hline & 4,42 & 29,21 & 2,79 & 34,88 & 4,90 & 1,33 & - & 4,95 & 4,15 & 6,46 \\
\hline \multirow{2}{*}{8} & 25,00 & 100,00 & 22,91 & 47,08 & 96,42 & 93,21 & 56,61 & - & 47,24 & 57,29 \\
\hline & 25,00 & 21,28 & 12,73 & 2,23 & 9,68 & 6,04 & 12,97 & - & 24,85 & 3,45 \\
\hline \multirow{2}{*}{9} & 93,92 & 50,00 & 259,07 & 94,00 & 96,43 & 50,10 & 57,10 & 100,00 & - & 28,19 \\
\hline & 20,50 & 3,36 & 19,23 & 16,86 & 5,88 & 14,88 & 5,16 & 29,19 & & 6,76 \\
\hline \multirow{2}{*}{$\Sigma$} & 23,89 & 73,59 & 26,05 & 30,45 & 93,49 & 8,55 & 8,38 & 63,84 & 10,99 & 28,32 \\
\hline & 1,97 & 0,11 & 1,22 & 4,03 & 5,27 & 7,15 & 7,85 & 6,33 & 6,51 & 0,70 \\
\hline
\end{tabular}

Obs: A primeira linha de cada origem contém as diferenças relativas dos resultados estimados pelo QUEENSOD e na segunda linha estão as diferenças relativas dos resultados estimados pelo TransCAD. Célula em destaque indica que o valor estimado é maior que o "real". 
Tabela B.23: Diferença relativa entre viagem "real" e estimada - Teste 9 usando Sem ${ }_{10}$

\begin{tabular}{|c|c|c|c|c|c|c|c|c|c|c|}
\hline$O \backslash D$ & 1 & 2 & 3 & 4 & 5 & 6 & 7 & 8 & 9 & $\Sigma$ \\
\hline \multirow{2}{*}{1} & - & 97,29 & 135,34 & 96,06 & 100,00 & 27,43 & 376,81 & 180,50 & 81,13 & 18,31 \\
\hline & - & 4,43 & 1,72 & 5,76 & 3,11 & 10,29 & 18,48 & 2,52 & 6,20 & 1,85 \\
\hline \multirow{2}{*}{2} & 100,00 & - & 71,76 & 80,24 & 55,79 & 100,00 & 33,65 & 94,98 & 30,37 & 64,41 \\
\hline & 9,31 & - & 17,88 & 6,27 & 29,18 & 12,44 & 8,41 & 9,59 & 9,71 & 3,10 \\
\hline \multirow{2}{*}{3} & 502,27 & 100,00 & - & 62,39 & 97,37 & 50,27 & 60,82 & 3,66 & 331,25 & 33,64 \\
\hline & 2,84 & 1,33 & - & 15,10 & 5,25 & 16,04 & 0,00 & 14,63 & 22,22 & 2,40 \\
\hline \multirow{2}{*}{4} & 38,32 & 100,00 & 100,00 & - & 100,00 & 430,30 & 3,43 & 94,84 & 94,76 & 24,05 \\
\hline & 2,10 & 4,43 & 13,59 & - & 3,70 & 14,72 & 24,02 & 8,92 & 12,86 & 4,24 \\
\hline \multirow{2}{*}{5} & 96,74 & 97,34 & 100,00 & 100,00 & - & 32,66 & 100,00 & 95,77 & 66,46 & 88,62 \\
\hline & 0,89 & 2,17 & 2,85 & 9,78 & - & 18,59 & 9,66 & 31,92 & 0,00 & 4,15 \\
\hline \multirow{2}{*}{6} & 89,89 & 42,64 & 95,13 & 253,10 & 96,46 & - & 61,82 & 90,63 & 20,68 & 24,30 \\
\hline & 0,00 & 3,46 & 10,62 & 12,67 & 7,72 & - & 34,55 & 6,25 & 9,63 & 2,78 \\
\hline \multirow{2}{*}{7} & 244,23 & 87,62 & 163,13 & 100,00 & 96,83 & 74,94 & - & 100,00 & 76,27 & 21,49 \\
\hline & 8,60 & 18,46 & 2,79 & 26,74 & 0,58 & 3,77 & - & 3,72 & 8,29 & 6,71 \\
\hline \multirow{2}{*}{8} & 27,11 & 96,10 & 25,09 & 48,75 & 97,68 & 95,47 & 97,26 & - & 96,63 & 69,74 \\
\hline & 17,61 & 12,41 & 6,55 & 4,46 & 7,16 & 35,85 & 8,98 & - & 7,36 & 3,15 \\
\hline \multirow{2}{*}{9} & 95,27 & 52,24 & 260,71 & 95,71 & 97,69 & 51,36 & 55,16 & 50,67 & - & 23,47 \\
\hline & 15,54 & 2,24 & 12,36 & 15,14 & 5,04 & 16,14 & 1,29 & 20,81 & - & 6,93 \\
\hline \multirow{2}{*}{$\Sigma$} & 17,61 & 73,27 & 30,75 & 31,44 & 95,01 & 3,89 & 14,94 & 56,18 & 22,55 & 29,80 \\
\hline & 1,25 & 0,77 & 0,08 & 2,53 & 6,44 & 3,94 & 6,56 & 1,82 & 5,44 & 0,11 \\
\hline
\end{tabular}

Obs: A primeira linha de cada origem contém as diferenças relativas dos resultados estimados pelo QUEENSOD e na segunda linha estão as diferenças relativas dos resultados estimados pelo TransCAD.

Célula em destaque indica que o valor estimado é maior que o "real".

Tabela B.24: Diferença relativa entre viagem "real" e estimada - Teste 9 usando $S_{70}$

\begin{tabular}{|c|c|c|c|c|c|c|c|c|c|c|}
\hline$O \backslash D$ & 1 & 2 & 3 & 4 & 5 & 6 & 7 & 8 & 9 & $\Sigma$ \\
\hline \multirow{2}{*}{1} & - & 100,00 & 137,72 & 99,39 & 100,00 & 33,71 & 380,80 & 187,42 & 84,10 & 17,89 \\
\hline & - & 5,17 & 5,17 & 6,36 & 3,35 & 48,57 & 11,96 & 20,75 & 1,35 & 7,62 \\
\hline \multirow{2}{*}{2} & 100,00 & - & 100,00 & 82,89 & 100,00 & 100,00 & 36,30 & 100,00 & 32,64 & 74,36 \\
\hline & 7,35 & - & 5,18 & 6,99 & 22,32 & 6,22 & 10,34 & 1,83 & 2,89 & 1,98 \\
\hline \multirow{2}{*}{3} & 508,52 & 100,00 & - & 65,53 & 100,00 & 56,15 & 65,31 & 8,13 & 335,07 & 33,16 \\
\hline & 8,52 & 10,08 & - & 7,98 & 5,01 & 3,21 & 1,22 & 4,07 & 12,85 & 2,32 \\
\hline \multirow{2}{*}{4} & 41,62 & 100,00 & 100,00 & - & 100,00 & 435,06 & 8,82 & 100,00 & 100,00 & 24,55 \\
\hline & 9,58 & 7,39 & 6,47 & - & 14,37 & 12,99 & 16,67 & 15,02 & 4,29 & 3,65 \\
\hline \multirow{2}{*}{5} & 100,00 & 100,00 & 100,00 & 100,00 & - & 100,00 & 100,00 & 100,00 & 100,00 & 100,00 \\
\hline & 2,67 & 7,00 & 0,41 & 14,13 & - & 11,56 & 2,36 & 25,38 & 6,10 & 5,09 \\
\hline \multirow{2}{*}{6} & 92,31 & 45,02 & 100,00 & 256,06 & 100,00 & - & 68,48 & 94,06 & 23,80 & 26,77 \\
\hline & 7,69 & 9,52 & 8,85 & 14,82 & 15,43 & - & 1,21 & 3,75 & 22,95 & 0,60 \\
\hline \multirow{2}{*}{7} & 246,93 & 90,19 & 169,27 & 100,00 & 100,00 & 77,38 & - & 100,00 & 156,68 & 14,99 \\
\hline & 10,07 & 8,41 & 20,11 & 11,05 & 1,44 & 7,98 & - & 9,29 & 4,38 & 2,52 \\
\hline \multirow{2}{*}{8} & 30,99 & 100,00 & 29,09 & 51,81 & 100,00 & 99,62 & 100,00 & - & 100,00 & 72,22 \\
\hline & 7,39 & 4,61 & 2,55 & 6,41 & 5,68 & 8,30 & 2,00 & - & 15,64 & 2,55 \\
\hline \multirow[t]{2}{*}{9} & 97,75 & 56,34 & 263,74 & 98,86 & 100,00 & 53,67 & 238,71 & 100,00 & - & 1,37 \\
\hline & 9,68 & 36,57 & 3,57 & 13,71 & 15,55 & 15,93 & 6,45 & 11,07 & - & 10,01 \\
\hline \multirow{2}{*}{$\Sigma$} & 17,19 & 74,82 & 26,75 & 33,18 & 100,00 & 10,95 & 20,86 & 65,55 & 8,12 & 25,29 \\
\hline & 1,40 & 0,53 & 0,57 & 2,57 & 9,82 & 4,93 & 5,80 & 0,79 & 3,76 & 0,79 \\
\hline
\end{tabular}

Obs: A primeira linha de cada origem contém as diferenças dos resultados estimados pelo QUEENSOD e na segunda linha estão as diferenças relativas dos resultados estimados pelo TransCAD. Célula em destaque indica que o valor estimado é maior que o "real". 


\section{APENNDICE}

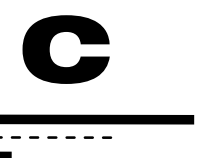

C.1 ESTIMAÇÃO DA MATRIZ OD PELO QUEENSOD, CONSIDERANDO A REDE DE TRÁFEGO ALIVIADA EM 50\%

Tabela C.1: Matriz OD "real" aliviada em 50\%

\begin{tabular}{c|ccccccccc|c}
\hline O\D & $\mathbf{1}$ & $\mathbf{2}$ & $\mathbf{3}$ & $\mathbf{4}$ & $\mathbf{5}$ & $\mathbf{6}$ & $\mathbf{7}$ & $\mathbf{8}$ & $\mathbf{9}$ & $\boldsymbol{\Sigma}$ \\
\hline $\mathbf{1}$ & - & 203 & 232 & 165 & 209 & 88 & 138 & 80 & 186 & $\mathbf{1 . 3 0 0}$ \\
$\mathbf{2}$ & 102 & - & 193 & 208 & 117 & 113 & 208 & 110 & 242 & $\mathbf{1 . 2 9 1}$ \\
$\mathbf{3}$ & 88 & 189 & - & 176 & 210 & 94 & 123 & 123 & 144 & $\mathbf{1 . 1 4 5}$ \\
$\mathbf{4}$ & 167 & 102 & 155 & - & 244 & 116 & 102 & 107 & 105 & $\mathbf{1 . 0 9 6}$ \\
$\mathbf{5}$ & 169 & 207 & 123 & 92 & - & 100 & 233 & 130 & 164 & $\mathbf{1 . 2 1 7}$ \\
$\mathbf{6}$ & 228 & 231 & 113 & 186 & 156 & - & 83 & 160 & 177 & $\mathbf{1 . 3 3 2}$ \\
$\mathbf{7}$ & 204 & 214 & 90 & 86 & 174 & 226 & - & 162 & 217 & $\mathbf{1 . 3 7 1}$ \\
$\mathbf{8}$ & 142 & 141 & 138 & 180 & 238 & 133 & 201 & - & 163 & $\mathbf{1 . 3 3 4}$ \\
$\mathbf{9}$ & 222 & 134 & 182 & 175 & 238 & 239 & 155 & 149 & - & $\mathbf{1 . 4 9 4}$ \\
\hline $\boldsymbol{\Sigma}$ & $\mathbf{1 . 3 2 1}$ & $\mathbf{1 . 4 2 0}$ & $\mathbf{1 . 2 2 5}$ & $\mathbf{1 . 2 6 6}$ & $\mathbf{1 . 5 8 3}$ & $\mathbf{1 . 1 0 5}$ & $\mathbf{1 . 2 4 2}$ & $\mathbf{1 . 0 1 9}$ & $\mathbf{1 . 3 9 7}$ & $\mathbf{1 1 . 5 7 7}$ \\
\hline
\end{tabular}


Tabela C.2: Matriz estimada para rede apenas 50\% carregada

\begin{tabular}{|c|c|c|c|c|c|c|c|c|c|c|}
\hline OO\D & 1 & 2 & 3 & 4 & 5 & 6 & 7 & 8 & 9 & $\Sigma$ \\
\hline \multirow{4}{*}{1} & - & 203 & 232 & 165 & 209 & 88 & 138 & 80 & 186 & 1.300 \\
\hline & - & 200 & 237 & 102 & 100 & 50 & 201 & 36 & 42 & 968 \\
\hline & - & 3 & 0 & 358 & 0 & 212 & 250 & 0 & 59 & 881 \\
\hline & - & 432 & 0 & 63 & 21 & 1 & 381 & 259 & 165 & 1.323 \\
\hline \multirow{4}{*}{2} & 102 & - & 193 & 208 & 117 & 113 & 208 & 110 & 242 & 1.291 \\
\hline & 29 & - & 293 & 50 & 101 & 90 & 93 & 126 & 68 & 851 \\
\hline & 0 & - & 0 & 0 & 0 & 0 & 2 & 0 & 3 & 5 \\
\hline & 211 & - & 460 & 280 & 0 & 155 & 173 & 152 & 154 & 1.586 \\
\hline \multirow{4}{*}{3} & 88 & 189 & - & 176 & 210 & 94 & 123 & 123 & 144 & 1.145 \\
\hline & 79 & 110 & - & 283 & 124 & 103 & 101 & 152 & 243 & 1.195 \\
\hline & 0 & 32 & - & 70 & 0 & 171 & 79 & 1 & 271 & 623 \\
\hline & 94 & 281 & - & 8 & 0 & 82 & 218 & 312 & 160 & 1.154 \\
\hline \multirow{4}{*}{4} & 167 & 102 & 155 & - & 244 & 116 & 102 & 107 & 105 & 1.096 \\
\hline & 135 & 31 & 100 & - & 100 & 98 & 100 & 100 & 101 & 765 \\
\hline & 228 & 0 & 65 & - & 90 & 63 & 152 & 0 & 44 & 641 \\
\hline & 320 & 0 & 0 & - & 446 & 0 & 13 & 0 & 0 & 778 \\
\hline \multirow{4}{*}{5} & 169 & 207 & 123 & 92 & - & 100 & 233 & 130 & 164 & 1.217 \\
\hline & 201 & 97 & 87 & 44 & - & 106 & 81 & 176 & 50 & 843 \\
\hline & 0 & 0 & 0 & 0 & - & 257 & 0 & 0 & 0 & 257 \\
\hline & 0 & 0 & 0 & 281 & - & 223 & 25 & 8 & 20 & 557 \\
\hline \multirow{4}{*}{6} & 228 & 231 & 113 & 186 & 156 & - & 83 & 160 & 177 & 1.332 \\
\hline & 220 & 47 & 155 & 38 & 69 & - & 30 & 59 & 55 & 672 \\
\hline & 87 & 1 & 296 & 132 & 0 & - & 145 & 0 & 340 & 1.001 \\
\hline & 93 & 107 & 0 & 104 & 75 & - & 12 & 21 & 309 & 720 \\
\hline \multirow{4}{*}{7} & 204 & 214 & 90 & 86 & 174 & 226 & - & 162 & 217 & 1.371 \\
\hline & 172 & 173 & 63 & 78 & 126 & 50 & - & 80 & 340 & 1.082 \\
\hline & 43 & 25 & 256 & 23 & 0 & 152 & - & 0 & 8 & 508 \\
\hline & 198 & 79 & 104 & 123 & 0 & 1 & - & 314 & 0 & 818 \\
\hline \multirow{4}{*}{8} & 142 & 141 & 138 & 180 & 238 & 133 & 201 & - & 163 & 1.334 \\
\hline & 100 & 52 & 71 & 43 & 61 & 120 & 95 & - & 47 & 588 \\
\hline & 1 & 0 & 10 & 0 & 0 & 0 & 69 & - & 108 & 188 \\
\hline & 72 & 51 & 12 & 122 & 12 & 261 & 403 & - & 439 & 1.373 \\
\hline \multirow{4}{*}{9} & 222 & 134 & 182 & 175 & 238 & 239 & 155 & 149 & - & 1.494 \\
\hline & 46 & 44 & 193 & 76 & 52 & 50 & 167 & 80 & - & 707 \\
\hline & 66 & 53 & 271 & 78 & 0 & 378 & 35 & 0 & - & 880 \\
\hline & 204 & 209 & 69 & 138 & 181 & 6 & 0 & 244 & - & 1.051 \\
\hline \multirow{4}{*}{$\Sigma$} & 1.321 & 1.420 & 1.225 & 1.266 & 1.583 & 1.105 & 1.242 & 1.019 & 1.397 & 11.577 \\
\hline & 981 & 754 & 1.199 & 713 & 733 & 666 & 869 & 809 & 945 & 7.669 \\
\hline & 425 & 113 & 897 & 660 & 90 & 1.233 & 730 & 1 & 834 & 4.983 \\
\hline & 1.192 & 1.159 & 645 & 1.118 & 735 & 729 & 1.224 & 1.310 & 1.247 & 9.360 \\
\hline \multicolumn{11}{|c|}{$\begin{array}{l}\text { Obs: Os valores da primeira linha de cada origem são referentes aos valores das viagens "reais"; } \\
\text { na segunda linha são apresentados os valores estimado considerando o Teste } 7 \text {; na terceira linha } \\
\text { constam os valores estimados para o Teste } 8 \text {; na quarta linha estão apresentados os valores } \\
\text { estimados ao considerar o Teste } 9\end{array}$} \\
\hline
\end{tabular}


Tabela C.3: Matriz estimada para rede apenas $50 \%$ carregada e semente $\mathrm{S}_{70}$

\begin{tabular}{|c|c|c|c|c|c|c|c|c|c|c|}
\hline O\D & 1 & 2 & 3 & 4 & 5 & 6 & 7 & 8 & 9 & $\Sigma$ \\
\hline \multirow{4}{*}{1} & - & 203 & 232 & 165 & 209 & 88 & 138 & 80 & 186 & 1.300 \\
\hline & - & 100 & 417 & 99 & 153 & 39 & 97 & 24 & 79 & 1.009 \\
\hline & - & 8 & 0 & 64 & 110 & 95 & 243 & 0 & 82 & 603 \\
\hline & - & 294 & 108 & 144 & 90 & 20 & 78 & 27 & 96 & 858 \\
\hline \multirow{4}{*}{2} & 102 & - & 193 & 208 & 117 & 113 & 208 & 110 & 242 & 1.291 \\
\hline & 97 & - & 221 & 185 & 89 & 97 & 67 & 98 & 120 & 974 \\
\hline & 108 & "'-" & 49 & 37 & 81 & 99 & 1 & 78 & 1 & 453 \\
\hline & 35 & - & 60 & 297 & 101 & 136 & 175 & 104 & 133 & 1.041 \\
\hline \multirow{4}{*}{3} & 88 & 189 & - & 176 & 210 & 94 & 123 & 123 & 144 & 1.145 \\
\hline & 63 & 175 & - & 288 & 44 & 38 & 79 & 190 & 195 & 1.072 \\
\hline & 0 & 35 & - & 130 & 77 & 184 & 70 & 100 & 258 & 854 \\
\hline & 13 & 71 & - & 12 & 99 & 82 & 209 & 87 & 175 & 748 \\
\hline \multirow{4}{*}{4} & 167 & 102 & 155 & - & 244 & 116 & 102 & 107 & 105 & 1.096 \\
\hline & 146 & 133 & 99 & - & 67 & 88 & 101 & 62 & 103 & 799 \\
\hline & 317 & 109 & 68 & - & 79 & 96 & 158 & 100 & 75 & 1.000 \\
\hline & 268 & 68 & 99 & - & 45 & 77 & 109 & 98 & 87 & 851 \\
\hline \multirow{4}{*}{5} & 169 & 207 & 123 & 92 & - & 100 & 233 & 130 & 164 & 1.217 \\
\hline & 99 & 48 & 99 & 76 & - & 72 & 83 & 74 & 33 & 584 \\
\hline & 101 & 79 & 78 & 33 & - & 50 & 77 & 30 & 100 & 548 \\
\hline & 33 & 23 & 77 & 92 & - & 72 & 36 & 10 & 12 & 355 \\
\hline \multirow{4}{*}{6} & 228 & 231 & 113 & 186 & 156 & - & 83 & 160 & 177 & 1.332 \\
\hline & 99 & 73 & 90 & 120 & 43 & - & 66 & 89 & 76 & 655 \\
\hline & 126 & 107 & 314 & 167 & 108 & - & 167 & 100 & 353 & 1.442 \\
\hline & 126 & 146 & 2 & 89 & 7 & - & 6 & 26 & 294 & 696 \\
\hline \multirow{4}{*}{7} & 204 & 214 & 90 & 86 & 174 & 226 & - & 162 & 217 & 1.371 \\
\hline & 107 & 232 & 99 & 86 & 55 & 257 & - & 76 & 306 & 1.219 \\
\hline & 343 & 23 & 477 & 372 & 77 & 102 & - & 0 & 10 & 1.404 \\
\hline & 250 & 72 & 44 & 81 & 0 & 7 & - & 317 & 99 & 869 \\
\hline \multirow{4}{*}{8} & 142 & 141 & 138 & 180 & 238 & 133 & 201 & - & 163 & 1.334 \\
\hline & 100 & 57 & 83 & 282 & 122 & 29 & 138 & - & 42 & 853 \\
\hline & 92 & 79 & 4 & 77 & 35 & 33 & 61 & - & 163 & 543 \\
\hline & 83 & 61 & 12 & 105 & 8 & 259 & 47 & - & 50 & 626 \\
\hline \multirow{4}{*}{9} & 222 & 134 & 182 & 175 & 238 & 239 & 155 & 149 & - & 1.494 \\
\hline & 109 & 142 & 274 & 81 & 222 & 141 & 126 & 77 & - & 1.172 \\
\hline & 638 & 48 & 353 & 89 & 101 & 396 & 31 & 104 & - & 1.759 \\
\hline & 213 & 127 & 629 & 140 & 188 & 58 & 0 & 244 & - & 1.597 \\
\hline \multirow{4}{*}{$\Sigma$} & 1.321 & 1.420 & 1.225 & 1.266 & 1.583 & 1.105 & 1.242 & 1.019 & 1.397 & 11.577 \\
\hline & 820 & 959 & 1.382 & 1.217 & 795 & 762 & 757 & 691 & 955 & 8.336 \\
\hline & 1.725 & 488 & 1.343 & 968 & 668 & 1.055 & 807 & 512 & 1.042 & 8.606 \\
\hline & 1.021 & 862 & 1.031 & 960 & 538 & 710 & 660 & 913 & 946 & 7.641 \\
\hline
\end{tabular}

Obs: Os valores da primeira linha de cada origem são referentes aos valores das viagens "reais"; na segunda linha são apresentados os valores estimado considerando o Teste 7; na terceira linha constam os valores estimados para o Teste 8; na quarta linha estão apresentados os valores estimados ao considerar o Teste 9 


\section{C.2 ANÁLISE DOS RESULTADOS}

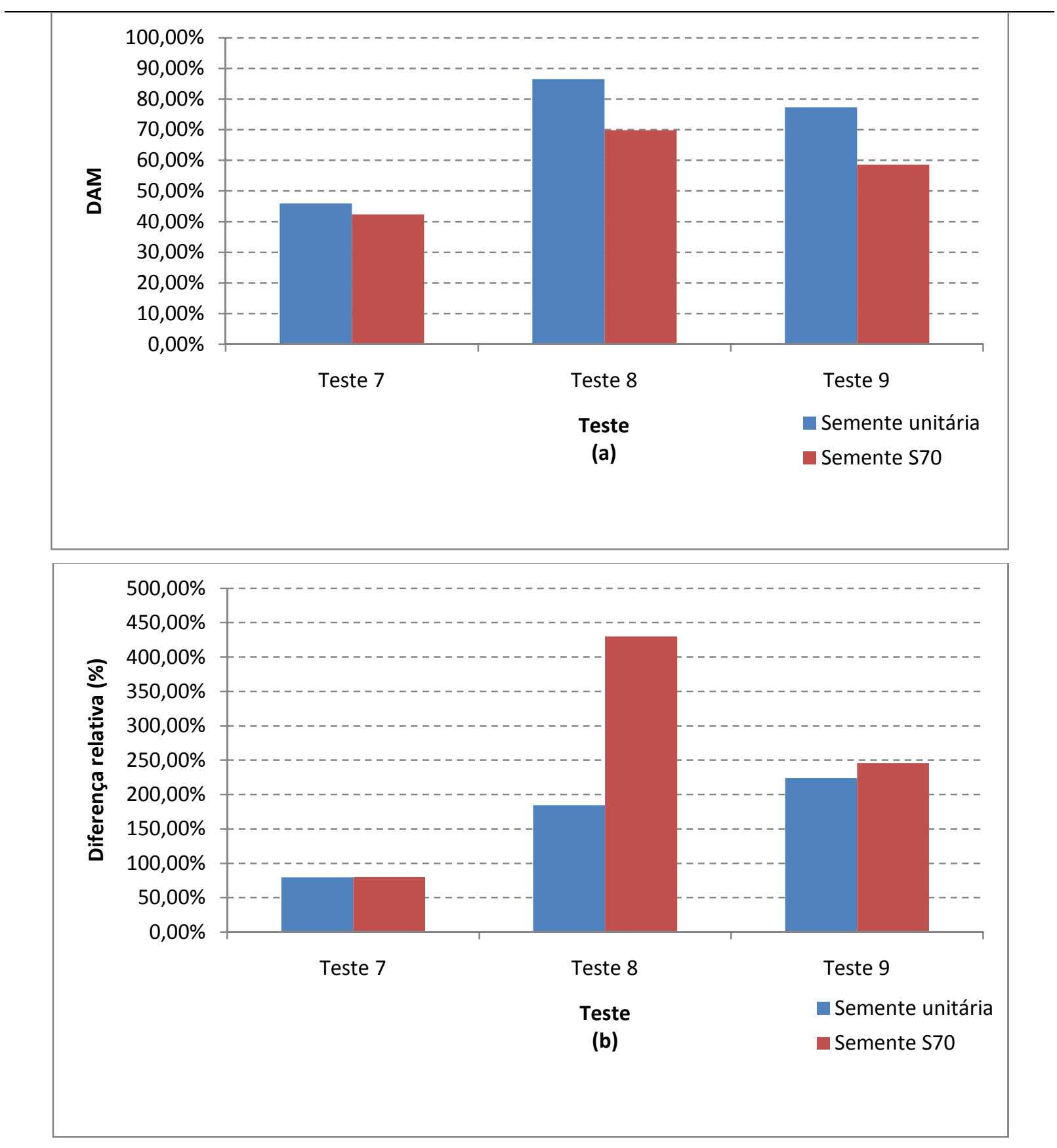

Figura C.1: (a) Diferença absoluta média; (b) Diferença relativa máxima, em termos absolutos 

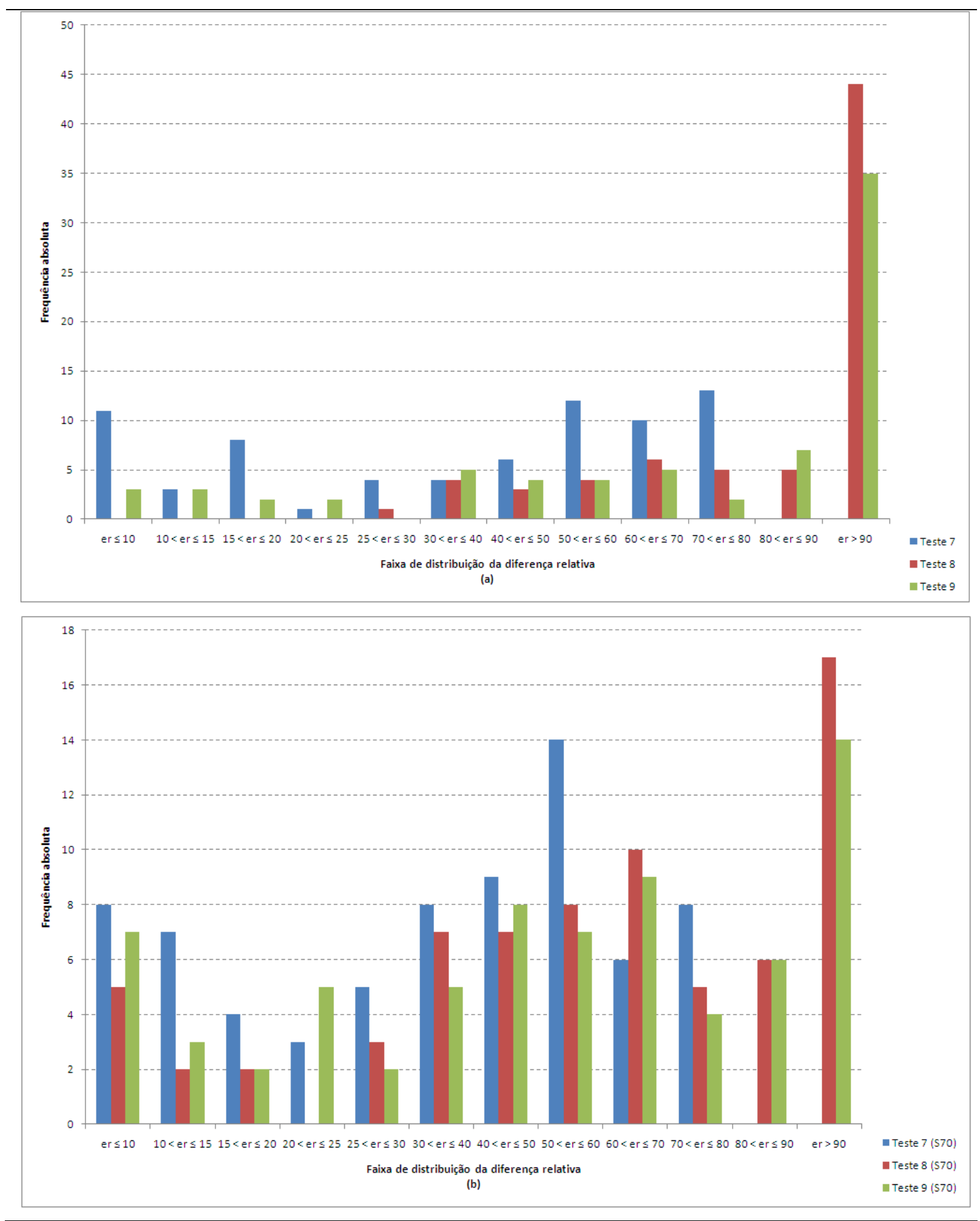

Figura C.2: Histograma da distribuição absoluta das diferenças relativas (a) semente unitária; (b) semente $\mathrm{S}_{70}$ 

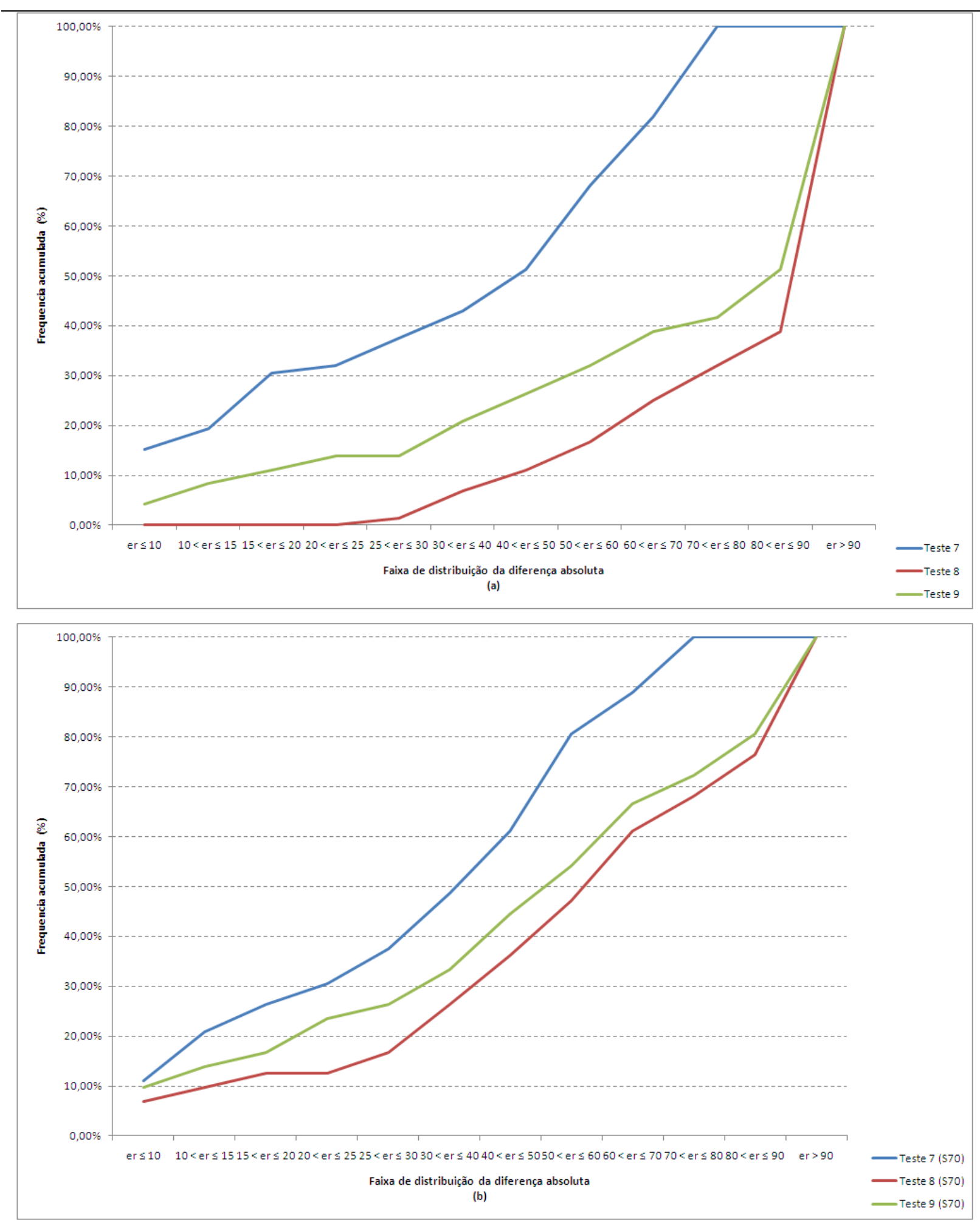

Figura C.3: Histograma da distribuição acumulada das diferenças relativas (a) semente unitária; (b) semente $\mathrm{S}_{70}$ 